UNIVERSIDAD POLITÉCNICA DE CARTAGENA DEPARTAMENTO DE ECONOMÍA DE LA EMPRESA

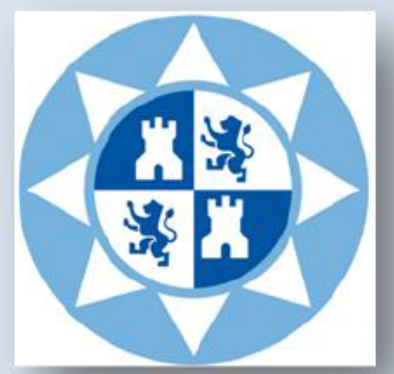

\title{
LAS NUEVAS TECNOLOGÍAS APLICADAS A LA GESTIÓN DEL CONOCIMIENTO EN EL SECTOR SANITARIO
}

\section{TESIS DOCTORAL}

MARCELINA SOLANO LORENTE 

Universidad Politécnica De Cartagena

Departamento de Economía de Empresa

\section{LAS NUEVAS TECNOLOGÍAS APLICADAS}

\section{A LA GESTIÓN DEL CONOCIMIENTO EN}

\section{EL SECTOR SANITARIO}

MARCELINA SOLANO LORENTE

Directores:

DRA. DÑA. EVA MARTINEZ CARO

DR. D. JUAN GABRIEL CEGARRA NAVARRO 


\section{Universidad \\ Politécnica \\ de Cartagena}

\section{CONFORMIDAD DE DEPÓSITO DE TESIS DOCTORAL POR LA COMISIÓN ACADÉMICA DEL PROGRAMA}

D/D ${ }^{a}$. CARMELO REVERTE MAYA, Presidente de la Comisión Académica del

Programa "ADMINISTRACIÓN Y DIRECCIÓN DE EMPRESAS".

\section{INFORMA:}

Que la Tesis Doctoral titulada, "LAS NUEVAS TECNOLOGÍAS APLICADAS A LA GESTIÓN DEL CONOCIMIENTO EN EL SECTOR SANITARIO", ha sido realizada por $\mathrm{D}^{\mathrm{a}}$. MARCELINA SOLANO LORENTE, bajo la dirección y supervisión de la Dra. EVA MARTINEZ CARO y del Dr. JUAN GABRIEL CEGARRA NAVARRO.

En reunión de la Comisión Académica de fecha 27/11/2012, visto que la mencionada tesis doctoral tiene acreditados los indicios de calidad, requeridos para el depósito de tesis doctorales, regulados en el artículo 32 del Reglamento de Estudios Oficiales de Máster y Doctorado de la UPCT, y la autorización del Director de la misma, se acordó dar la conformidad para que a dicha tesis le sea autorizado, por la Comisión de Doctorado, su depósito.

La Rama de conocimiento por la que esta tesis ha sido desarrollada es:

$\square$ Ciencias

- Ciencias Sociales y Jurídicas

口Ingeniería y Arquitectura

En Cartagena, a 27 de NOVIEMBRE de 2012

EL PRESIDENTE DE LA COMISIÓN ACADÉMICA DEL PROGRAMA

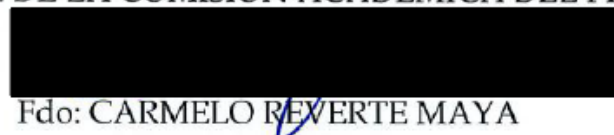

COMISIÓN DE DOCTORADO 


\section{Universidad \\ Politécnica \\ de Cartagena}

DT-16

\section{CONFORMIDAD DE SOLICITUD DEAUTORIZACIÓN DE DEPÓSITO DE TESIS DOCTORAL POR LOS DIRECTORES DE LA TESIS}

$D^{a}$. Eva Martínez Caro y D. Juan Gabriel Cegarra Navarro Directores de la Tesis doctoral Las Nuevas Tecnologías Aplicadas a la Gestión del Conocimiento en el Sector Sanitario.

\section{INFORMA:}

Que la referida Tesis Doctoral, ha sido realizada por $D^{a}$.Marcelina Solano Lorente, dando nuestra conformidad para que sea presentada ante la Comisión de Doctorado, para ser autorizado su depósito.

La rama de conocimiento por la que esta tesis ha sido desarrollada es:

$\square \quad$ Ciencias

$\mathrm{X}$ Ciencias Sociales y Jurídicas

$\square \quad$ Ingeniería y Arquitectura

En Cartagena, a 26 de Noviembre de 2012

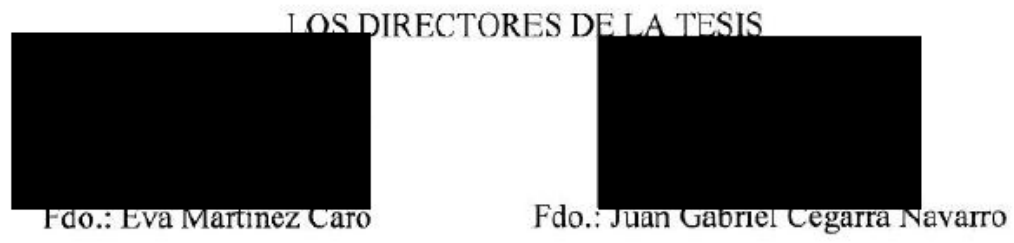

COMISIÓN DE DOCTORADO 


\section{AGRADECIMIENTOS}

Me gustaría expresar mi más sincero agradecimiento a los directores de esta Tesis Doctoral, a la Dra. Dña. Eva Martínez Caro y al Dr. D. Juan Gabriel Cegarra Navarro, por el apoyo, el ánimo y la motivación a lo largo de todo el período de la Suficiencia Investigadora y más tarde, de esta Tesis. Me siento afortunada por haber contado con sus sugerencias y consejos $y$, por haber trabajado con dos excelentes profesionales. Sin sus inestimables colaboraciones no hubiera sido posible realizar este trabajo.

Hago extensivo mi agradecimiento a todas las personas que aceptaron ser entrevistadas para la presente investigación. También a aquellas personas que de una $u$ otra forma colaboraron o participaron en la realización de esta investigación y del mismo modo a aquellos de los que he aprendido algo, me conozcan o no pues por ellos se logró este objetivo.

Finalmente, el agradecimiento a mis padres, a mis hermanos y a mi marido, por haberme apoyado y animado a llegar hasta aquí y sobre todo, por haberme prestado su ayuda en los momentos más importantes de esta etapa. 


\section{RESUMEN}

En el actual entorno económico, las Tecnologías de la Información y la Comunicación (TIC) y la Gestión del Conocimiento cobran importancia al configurarse como claves que aportan a las organizaciones la capacidad de respuesta necesaria para ofrecer con rapidez lo que el entorno está demandando. El uso de TIC dentro de una organización es una herramienta importante para la Gestión de su Conocimiento con el fin de mejorar su rendimiento. A su vez, las decisiones que conciernen a la aceptación de las TIC por parte de los diferentes miembros de una organización requieren de una adecuada Gestión del Conocimiento en dicha organización.

En este estudio se propone un modelo de aceptación de las tecnologías centrado, por un lado, en el análisis de las variables que afectan al valor percibido, por otro lado, de la relación que existe entre el valor percibido y la satisfacción y por último, en la influencia de la variable de satisfacción sobre la e-lealtad hacia el uso de las TIC por los usuarios externos del sector sanitario. El modelo se ha testado en el contexto de los servicios online proporcionados por la sanidad pública a sus pacientes en un intento de mejorar su eficacia y reducir gastos. En concreto se empleó una muestra de 256 usuarios de dichos servicios proporcionados por el Servicio Murciano de Salud.

Los resultados sugieren que la capacidad innovativa, la autoeficacia ante las nuevas tecnologías, así como la accesibilidad a la información y la comunicación y el nivel de seguridad de los servicios sanitarios online tienen efectos positivos sobre 
el valor percibido de los pacientes en el uso de dichos servicios. De igual forma, se confirma tanto la dependencia existente entre la satisfacción y la variable de valor percibido, como la dependencia de la e-lealtad con respecto a la satisfacción. Finalmente, este estudio discute las implicaciones de los resultados, establece las conclusiones del estudio y abre nuevas líneas futuras de investigación basadas en la aceptación de las tecnologías.

Palabras claves: Tecnología de la Información y la Comunicación, Gestión del Conocimiento, Aceptación de Tecnologías, Capacidad Innovativa, Autoeficacia, Accesibilidad, Seguridad, Valor Percibido, Satisfacción y E-lealtad. 


\begin{abstract}
In the current economic environment, Information Technology and Communication (ICT) and Knowledge Management to gain importance as a key configured to organizations that provide the responsiveness needed to quickly deliver what the environment is demanding. The use of ICT within an organization is an important tool for Knowledge Management to improve performance. In turn, decisions concerning to the acceptance of ICT by different members of an organization requires an adequate Knowledge Management in that organization.
\end{abstract}

This study proposes a model of acceptance of the technology focused on the one hand, on the analysis of the variables that affect the perceived value, on the other hand, on the relationship between perceived value and satisfaction and finally, on the influence of the variable of satisfaction on e-loyalty towards the use of ICT use by external users of the health sector. The model has been tested in the context of online services provided by public health to their patients in an attempt to improve efficiency and reduce costs. In particular we used a sample of 256 users of the services provided by the Health Service of Murcia.

The results suggest that the innovative capacity and self-efficacy of new technologies to patients, as well as accessibility to information and communication and level of the safety of online health services have positive effects on the perceived value of the patients in the use of such services. Similarly, it confirms, firstly, the dependence of the variables of satisfaction and perceived value and secondly, the dependence of the e-loyalty to satisfaction. Finally, this study 
discusses the implications of the results and opens new lines of future research based on the acceptance of technologies.

Keywords: Information Technology and Communication, Knowledge Management, Technology Acceptance, Innovative Capacity, Self-Efficacy, Accessibility, Safety, Perceived Value, Satisfaction and E-loyalty 


\section{ÍNDICES}




\section{ÍNDICE GENERAL}

\section{CAPITULO 1. TECNOLOGÍAS DE LA INFORMACIÓN Y GESTIÓN DEL CONOCIMIENTO EN EL SECTOR SANITARIO.}

OBJETIVO.

INTRODUCCIÓN

1. ANTECEDENTES Y ESTADO ACTUAL DE LAS TECNOLOGÍAS DE LA INFORMACIÓN Y LA COMUNICACIÓN EN EL SECTOR SANITARIO.

2. IMPLANTACIÓN DE LAS TIC: BENEFICIOS Y BARRERAS 30

3. GESTIÓN DEL CONOCIMIENTO ................................................ 37

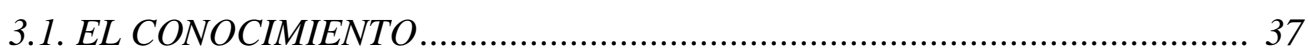

3.2. LA GESTIÓN DEL CONOCIMIENTO ……............................................... 41

3.2.1. La gestión del conocimiento en el sector sanitario................................. 50

3.3. PROCESOS BÁSICOS DE LA GESTIÓN DEL CONOCIMIENTO …............. 55

3.3.1. Creación del conocimiento..................................................................... 55

3.3.2. Distribución del conocimiento ................................................................ 56

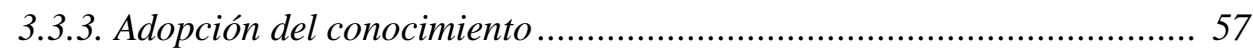

3.3.4. Revisión del conocimiento................................................................ 58

4. RELACIÓN ENTRE TIC Y GESTIÓN DEL CONOCIMIENTO ......................60

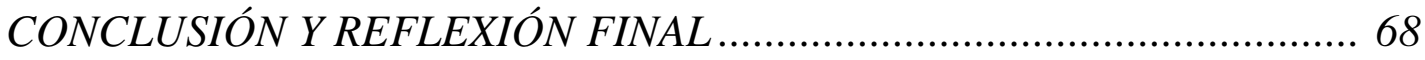




\section{CAPITULO 2. MODELOS DE ACEPTACIÓN DE LA TECNOLOGÍA.}

OBJETIVO

INTRODUCCIÓN 78

1. TEORÍA DE LA ACCIÓN RAZONADA (Theory oF Reasioned Action, TRA) 79

2. MODELO DE ACEPTACIÓN DE LA TECNOLOGÍA (Technology Acceptance Model, TAM)

4. TEORÍA DEL COMPORTAMIENTO PLANIFICADO (Theory of planned behavior, TPB)

5. MODELO DE COMBINACIÓN DEL TAM Y EL TPB (Model Combining TAM and TPB, C-TAM-TPB)

6. MODELO DE UTILIZACIÓN DEL ORDENADOR PERSONAL (Model Personal Computer Utilization, MPCU)

7. TEORÍA DE LA DIFUSIÓN DE LA INNOVACIÓN (Innovation Diffusion Theory, IDT).

8. TEORÍA SOCIAL COGNITIVA (Social Cognitive Theory, SCT). 100

9. TEORÍA UNIFICADA DE ACEPTACIÓN Y USO DE LA TECNOLOGÍA (Unified Theory of Acceptance and Use of Technology, UTAUT)

10. COMPARACIÓN DE MODELOS 106

CONCLUSIÓN Y REFLEXIÓN FINAL 110 
CAPITULO 3. DESARROLLO DE UN MODELO DE ACEPTACIÓN DE TECNOLOGÍAS EN USUARIOS EXTERNOS DEL SECTOR SANITARIO.

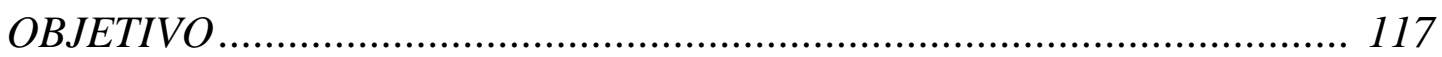

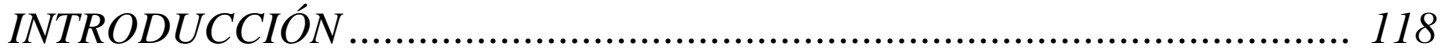

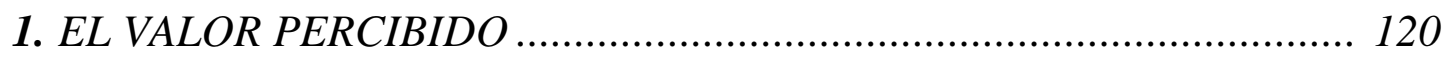

2. FACTORES QUE INFLUYEN EN EL VALOR PERCIBIDO ................. 122

2.1. CAPACIDAD INNOVATIVA................................................................. 124

2.2. AUTOEFICACIA HACIA NUEVAS TECNOLOGÍAS..................................... 128

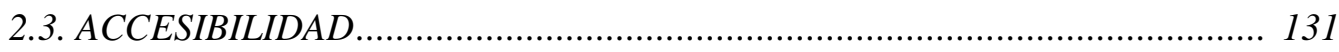

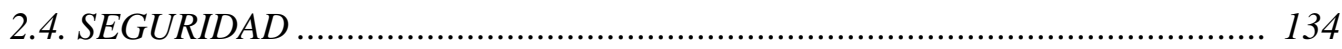

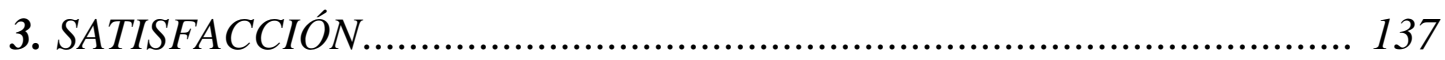

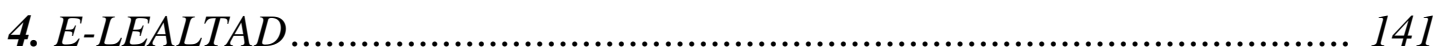

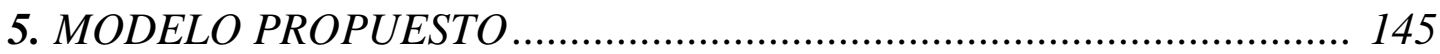

CONCLUSIÓN Y REFLEXIÓN FINAL …………............................... 146

CAPITULO 4. REVISIÓN DE LA LITERATURA EMPÍRICA Y METODOLOGÍA.

OBJETIVO 
1.1. ADQUISICIÓN, TRANSFERENCIA Y UTILIZACIÓN DEL CONOCIMIENTO. ESTUDIOS EMPÍRICOS

1.2. TECNOLOGÍAS ORIENTADAS A LA ADQUISICIÓN, TRANSFERENCIA Y UTILIZACIÓN DE LA INFORMACIÓN. ESTUDIOS EMPÍRICOS

1.2.1. Tecnologías orientadas a la adquisición de información .................... 165

1.2.2. Tecnologías orientadas a la distribución de información..................... 168

1.2.3. Tecnologías orientadas a la utilización de información ....................... 172

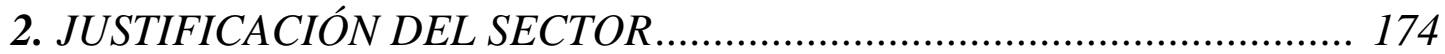

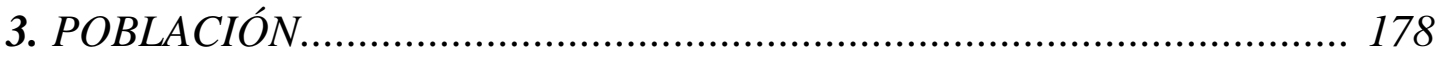

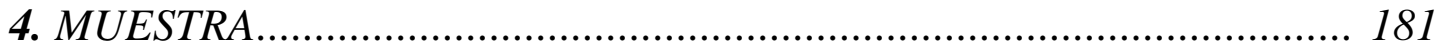

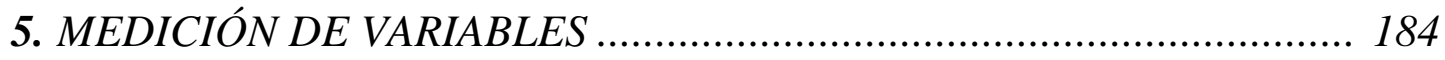

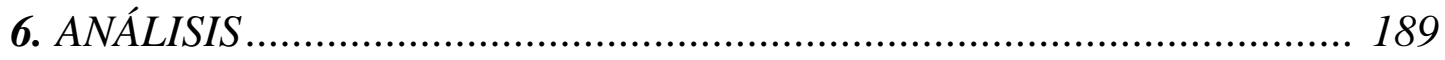

CONCLUSIÓN Y REFLEXIÓN FINAL ……………............................. 193

\section{CAPITULO 5. ANÁLISIS DE LOS RESULTADOS.}

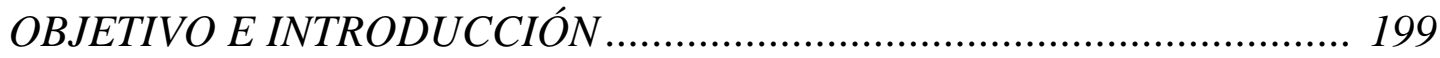

1. FIABILIDAD Y VALIDEZ DE LAS ESCALAS …................................. 199

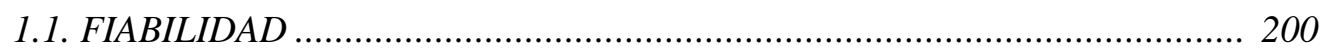

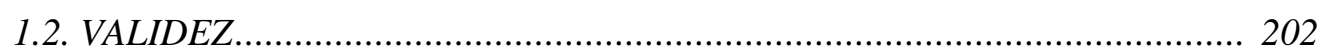

1.2.1. Análisis de KMO y prueba de esfericidad de Barlett.......................... 204

1.2.2. Análisis factorial ........................................................................ 208

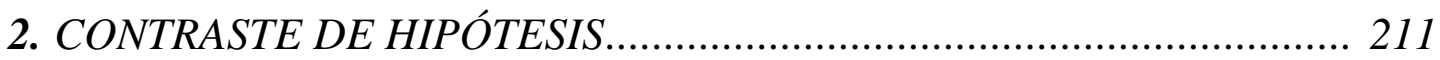

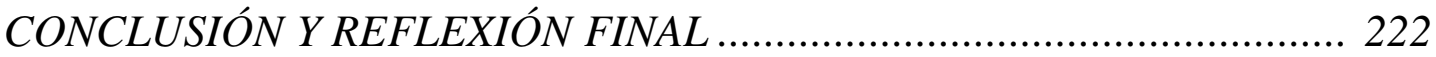


CONCLUSIONES, LIMITACIONES, LÍNEAS FUTURAS DE INVESTIGACIÓN Y APORTACIONES.

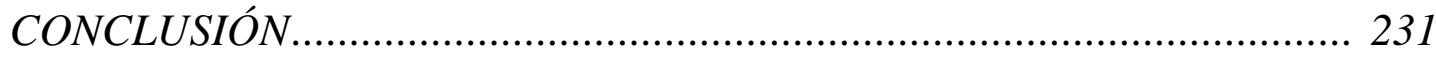

LIMITACIONES Y LÍNEAS FUTURAS DE INVESTIGACIÓN .................... 240

APORTACIONES DE LA INVESTIGACIÓN N.......................................... 243

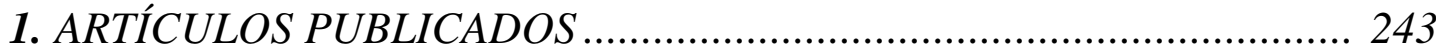

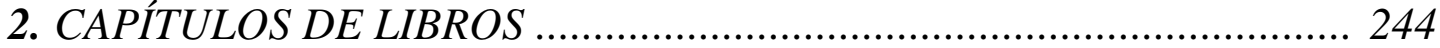

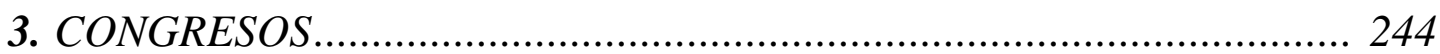

REFERENCIAS BIBLIOGRÁFICAS .................................. 249

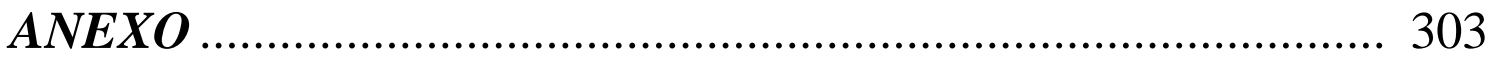




\section{ÍNDICE DE FIGURAS}

\section{CAPITULO 1. TECNOLOGÍAS DE LA INFORMACIÓN Y GESTIÓN DEL CONOCIMIENTO EN EL SECTOR SANITARIO.}

Figura 1. MODELO DE IMPLANTACIÓN DE SERVICIOS SANITARIOS

ONLINE.

Figura 2. MODELO DE RELAICIÓN DE LAS TIC CON EL SECTOR SANITARIO ACTUAL

Figura 3. LA TRIADA CONCEPTUAL (Bueno, 2002).

Figura 4. MODELO DE PROCESOS BÁSICOS DE GESTIÓN DEL CONOCIMIENTO

Figura 5. FACTORES QUE INCIDEN SOBRE EL DESARROLLO Y

MEJORA DE LOS SERVICIOS SANITARIOS ONLINE 72

\section{CAPITULO 2. MODELOS DE ACEPTACIÓN DE LA TECNOLOGÍA.}

Figura 6. MODELO TRA (Ajzen y Fishbein, 1975) ................................. 81

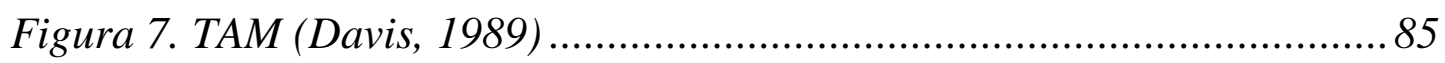

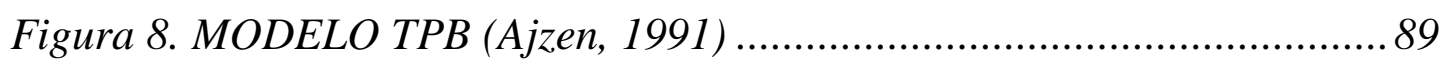

Figura 9. MODELO C-TAM-TPB (Taylor y Todd, 1995) ......................... 93

Figura 10. MODELO TRIANDIS (Adaptado de Triandis) ........................... 95

Figura 11. MODELO MPCU (Thompson et al., 1991) .............................97 
Figura 12. DETERMINISMO RECÍPROCO O RECIPROCIDAD

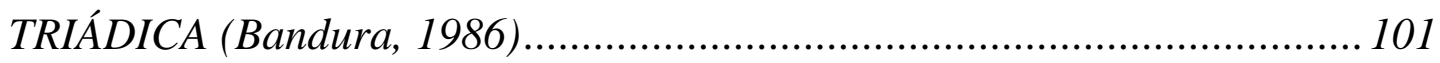

Figura 13. MODELO UTAUT (Venkatesh et al., 2003).............................. 105

CAPITULO 3. DESARROLLO DE UN MODELO DE ACEPTACIÓN DE TECNOLOGÍAS EN USUARIOS EXTERNOS DEL SECTOR SANITARIO.

Figura 14. RELACIÓN ENTRE CAPACIDAD INNOVATIVA Y VALOR PERCIBIDO.

Figura 15. RELACIÓN ENTRE AUTOEFICACIA Y VALOR PERCIBIDO . 130 Figura 16. RELACIÓN ENTRE ACCESIBILIDAD Y VALOR PERCIBIDO.134 Figura 17. RELACIÓN ENTRE SEGURIDAD Y VALOR PERCIBIDO ........ 137 Figura 18. RELACIÓN ENTRE VALOR PERCIBIDO Y SATISFACCIÓN .. 140 Figura 19. RELACIÓN ENTRE SATISFACCIÓN Y E-LEALTAD ................. 145 Figura 20. MODELO TEÓRICO PROPUESTO …………........................... 146

\section{CAPITULO 4. REVISIÓN DE LA LITERATURA EMPÍRICA Y METODOLOGÍA.}

Figura 21. FUNCIONAMIENTO DE TECNOLOGÍAS

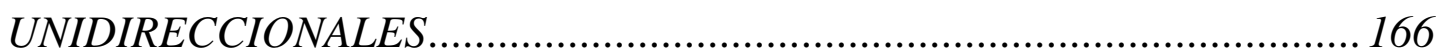

Figura 22. SITIO WEB DEL SERVICIO MURCIANO DE SALUD.............. 168 Figura 23. PÁGINA DE CONTENIDOS DEL SERVICIO MURCIANO DE SALUD 
Figura 24. FUNCIONAMIENTO DE LAS TECNOLOGÍAS ORIENTADAS A LA DISTRIBUCIÓN DE INFORMACIÓN

Figura 25. DIRECCIÓN DE CORREO ELECTRÓNICO DEL SERVICIO MURCIANO SALUD (murciasalud@carm.es).....

Figura 26. EJEMPLO DE ENLACE A LA BASE DE DATOS DE PROQUEST MEDICAL COLLECTION

Figura 27. ENLACE AL SISTEMA DE QUEJAS Y SUGERENCIAS DEL SERVICIO MURCIANO DE SALUD.

Figura 28. SERVICIO DE CITA PREVIA EN SU CENTRO DE ATENCIÓN PRIMARIA

Figura 29. POBLACIÓN DE LA REGIÓN DE MURCIA. USUARIOS DEL SERVICIO MURCIANO DE SALUD DISTRIBUIDOS POR EDADES 182

Figura 30. DISTRIBUCIÓN POR SEXOS DE LOS USUARIOS DEL SERVICIO MURCIANO DE SALUD.

Figura 31. PIRÁMIDE DE EDAD (CREM. Padrón Municipal de Habitantes)

\section{CAPITULO 5. ANÁLISIS DE LOS RESULTADOS.}

\section{CONCLUSIONES, LIMITACIONES, LÍNEAS FUTURAS DE INVESTIGACIÓN Y APORTACIONES.}

Figura 33. ESQUEMA PLANTEADO PARA LÍNEAS FUTURAS DE INVESTIGACIÓN 


\section{ÍNDICE DE TABLAS}

CAPITULO 1. TECNOLOGÍAS DE LA INFORMACIÓN Y GESTIÓN DEL CONOCIMIENTO EN EL SECTOR SANITARIO.

Tabla 1. VENTAJAS E INCONVENIENTES DE LA APARICIÓN DE LAS TIC.

Tabla 2. DEFINICIONES SOBRE GESTIÓN DEL CONOCIMIENTO. 46

CAPITULO 2. MODELOS DE ACEPTACIÓN DE LA TECNOLOGÍA.

Tabla 3. COMPARACIÓN DE LOS MODELOS 106

CAPITULO 3. DESARROLLO DE UN MODELO DE ACEPTACIÓN DE TECNOLOGÍAS EN USUARIOS EXTERNOS DEL SECTOR SANITARIO.

Tabla 4. DIFERENTES ACEPCIONES Y DEFINICIONES DEL VALOR PERCIBIDO.

Tabla 5. VARIABLES ADICIONALES A LOS CONSTRUCTOS PRINCIPALES DE LOS MODELOS DE ACEPTACIÓN DE LA TECNOLOGÍA. 


\section{CAPITULO 4. REVISIÓN DE LA LITERATURA EMPÍRICA Y METODOLOGÍA.}

Tabla 6. HERRAMIENTAS TECNOLÓGICAS ORIENTADAS A LA ADQUISICIÓN DE INFORMACIÓN................................................... 167

Tabla 7. HERRAMIENTAS TECNOLÓGICAS ORIENTADAS A LA DISTRIBUCIÓN DE INFORMACIÓN

Tabla 8. HERRAMIENTAS TECNOLÓGICAS ORIENTADAS A LA UTILIZACIÓN DE INFORMACIÓN

Tabla 9. FICHA TÉCNICA DE INVESTIGACIÓN EMPÍRICA 182

Tabla 10. ÍTEMS QUE REPRESENTAN LA CAPACIDAD INNOVATIVA . 185

Tabla 11. ÍTEMS QUE REPRESENTAN LA AUTOEFICACIA 185

Tabla 12. ÍTEMS QUE REPRESENTAN LA ACCESIBILIDAD. 186

Tabla 13. ÍTEMS QUE REPRESENTAN LA SEGURIDAD 187

Tabla 14. ÍTEMS QUE REPRESENTAN EL VALOR PERCIBIDO 187

Tabla 15. ÍTEMS QUE REPRESENTAN LA SATISFACCIÓN. 188

Tabla 16. ÍTEMS QUE REPRESENTAN LA E-LEALTAD 188

\section{CAPITULO 5. ANÁLISIS DE LOS RESULTADOS.}

Tabla 17. ANÁLISIS DE FIABILIDAD A TRAVÉS DEL ALFA DE CRONBACH Y CORRELACIÓN ÍTEM-TOTAL 201 
Tabla 18. KMO Y PRUEBA DE BARTLETT PARA LA CAPACIDAD

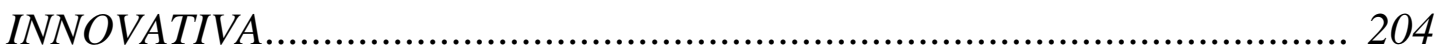

Tabla 19. KMO Y PRUEBA DE BARTLETT PARA LA AUTOEFICACIA ..205

Tabla 20. KMO Y PRUEBA DE BARTLETT PARA LA ACCESIBILIDAD . 205

Tabla 21. KMO Y PRUEBA DE BARTLETT PARA LA SEGURIDAD ........ 206

Tabla 22. KMO Y PRUEBA DE BARTLETT PARA EL VALOR

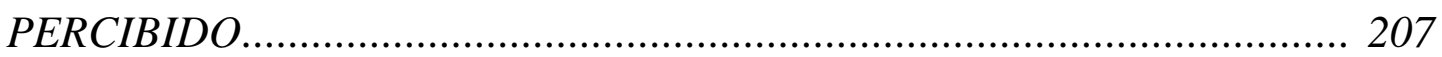

Tabla 23. KMO Y PRUEBA DE BARLETT PARA LA SATISFACCIÓN...... 207

Tabla 24. KMO Y PRUEBA DE BARLETT PARA LA E-LEALTAD............ 208

Tabla 25. ANÁLISIS FACTORIAL PARA LA VARIABLE CAPACIDAD

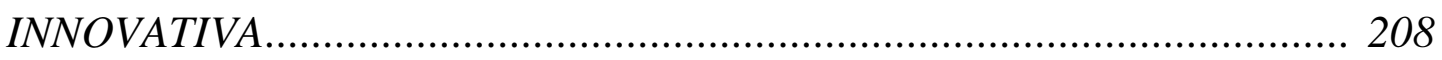

Tabla 26. ANÁLISIS FACTORIAL PARA LA VARIABLE AUTOEFICACIA 209

Tabla 27. ANÁLISIS FACTORIAL PARA LA VARIABLE

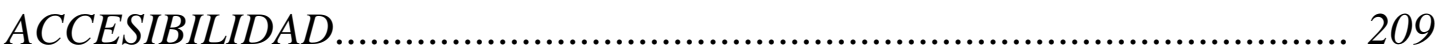

Tabla 28. ANÁLISIS FACTORIAL PARA LA VARIABLE SEGURIDAD..... 209

Tabla 29. ANÁLISIS FACTORIAL PARA LA VARIABLE VALOR

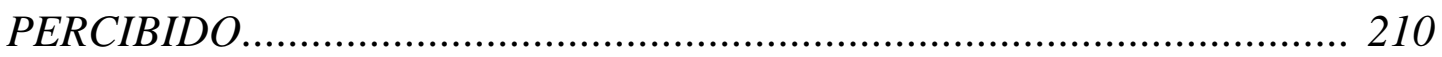

Tabla 30. ANÁLISIS FACTORIAL PARA LA VARIABLE SATISFACCIÓN 210 Tabla 31. ANÁLISIS FACTORIAL PARA LA VARIABLE E-LEALTAD ...... 210 Tabla 32. ESTADÍSTICOS DE COLINEALIDAD ...................................... 214 
Tabla 33. DIAGNÓSTICOS DE COLINEALIDAD DE LAS VARIABLES EXTERNAS CON RESPECTO AL VALOR PERCIBIDO

Tabla 34. ESTADÍSTICOS DE COLINEALIDAD DE VALOR PERCIBIDO A SATISFACCIÓN.

Tabla 35. DIAGNÓSTICOS DE COLINEALIDAD DE VP A SAT 215

Tabla 36. ESTADÍSTICOS DE COLINEALIDAD DE SATISFACCIÓN A E-LEALTAD. 216

Tabla 37. DIAGNÓSTICO DE COLINEALIDAD DE SAT A EL 216

Tabla 38. ANÁLISIS DE REGRESIÓN DE LAS VARIABLES EXTERNAS AL VALOR PERCIBIDO

Tabla 39. ANÁLISIS DE REGRESIÓN DE VP A SAT. 217

Tabla 40. ANÁLISIS DE REGRESIÓN DE SAT A EL 218

Tabla 41. RESULTADOS DEL CONTRASTE DE HIPÓTESIS 222

CONCLUSIONES, LIMITACIONES, LÍNEAS FUTURAS DE INVESTIGACIÓN Y APORTACIONES. 


INTRODUCCIÓN 



\section{INTRODUCCIÓN}

En los últimos años se ha producido un espectacular avance tecnológico, el cual ha alcanzado su punto álgido con las tecnologías de la información. Esto es consecuencia del desarrollo de la microelectrónica que unido a la aparición de nuevos materiales y a la mejora de las telecomunicaciones, han dado lugar a lo que podríamos denominar "revolución tecnológica de las tecnologías de la información". Estas tecnologías han tenido un fuerte impacto en los ámbitos social y económico de los países desarrollados; y se ha convertido en la actualidad en un recurso estratégico de cuya adecuada explotación depende en gran medida no sólo el éxito empresarial sino también su supervivencia.

De ahí que las organizaciones se están viendo obligadas a la continua adaptación de un entorno complejo, dinámico e impredecible, en el que no sólo hay nuevos elementos sino que, además, éstos cambian con gran rapidez, lo que les exige adquirir nuevos conocimientos para poder hacerles frente. Los cambios que se están produciendo son parte de un conjunto de profundas transformaciones que está sufriendo nuestra sociedad desde hace algunos años, como es el paso de la sociedad industrial, basada en la producción y distribución de bienes, a una sociedad post-industrial, basada en el conocimiento y la información. Además, la organización crea un poderoso instrumento social, a través de la coordinación de un gran número de acciones humanas; por todo ello, nos encontramos ante un reto que requiere un replanteamiento sustancial en la 
organización, el cual consiste en formular respuestas innovadoras frente a nuevos entornos.

La incorporación de las tecnologías de la información y la comunicación (TIC) están cambiando la forma de competir de las organizaciones, pues es capaz de modificar la estrutura de un sector creando nuevas ventajas competitivas, lo que nos lleva a considerar las aplicaciones de las TIC como un recurso estratégico. Es más, el uso de TIC requiere el desarrollo de mayores niveles de innovación y de la gestión del conocimiento en las empresas que adoptan estas nuevas tecnologías (Denning, 2000; Gargallo y Pérez, 2009).

Sin embargo, las TIC por sí solas originan grandes barreras físicas y organizacionales entre los departamentos de procesamiento de datos y gestión del conocimiento. Debido a ello, hay un uso limitado de los sistemas, porque las personas sí tienen acceso a la tecnología, pero no en el contexto ni el sector concreto en que desarrolla su actividad. Por tanto, el crecimiento de este nuevo mundo electrónico requiere innovación y la generación de nuevos negocios con desarrollo e influencia de conocimiento, incluyendo nuevas habilidades, nuevas formas de integración, intensivas relaciones con entidades externas, nuevos escenarios de actuación mantenidos por usuarios, canales y suministradores mediante las TIC y, naturalmente, nuevo conocimiento por parte de los usuarios potenciales.

Por tanto, el papel más importante en las nuevas pautas de actuación de las organizaciones, lo juegan la tecnología y el conocimiento. Ambas variables son consideradas como importantes vehículos que permiten la transformación de los procesos empresariales (Agarwal et al., 1997; Gargallo y Pérez, 2009). Es por ello, que 
la rápida aceptación de la integración de ambos conceptos (tecnología y conocimiento) es de una importancia primordial para conseguir ventajas competitivas cualquiera que sea la organización o el sector en que desarrolle su actividad (Ravichandran, 2005).

Por ende, la aceptación de las TIC por parte de los usuarios se ha convertido en una condición indispensable (Al-Gahtani y King, 1999). La aceptación de las TIC se ha llegado a convertir en un aspecto crítico para investigadores y gestores que a lo largo de los años han tratado de definir correctamente qué factores condicionan una decisión tan trascendente para las organizaciones (Taylor y Todd, 1995; Chau y Hu, 2002, AlSomali et al., 2009).

No obstante, el uso y aceptación de las TIC tiene repercusiones en las actuaciones de nuestra vida diaria, afectando a todas las facetas de la misma. En esta investigación nos centramos en el papel que tiene la aceptación de las TIC en el sector sanitario y cómo hoy en día, este sector se está viendo beneficiado por los avances tecnológicos y sus repercusiones en las aplicaciones en comunicaciones y tecnologías de la información.

Como consecuencia de esto, surge un nuevo campo de actuación referido a la intersección entre los servicios sanitarios ofrecidos por las instituciones de salud públicas y la información que se entrega y se mejora a través de Internet y de las tecnologías relacionadas con la prestación de los servicios sanitarios online. En un sentido más amplio, se hace referencia a una nueva forma de actuar, de pensar y de un compromiso por parte de los usuarios del sector sanitario para poder fomentar la mejora de los cuidados de salud mediante el uso de las tecnologías de la información y la comunicación. 
Por ello, las tecnologías de la Información y la Comunicación (TIC) juegan un papel fundamental para la obtención de soluciones en este ámbito y más, teniendo en cuenta las numerosas aplicaciones de las TIC que se desarrollan en este sector.

En concreto, este estudio se refiere específicamente a los servicios sanitarios online que son prestados a las instituciones públicas de salud, tales como, petición de citas, comprobación de las listas de espera, realizar sugerencias o quejas, compartir información con otros pacientes, leer información sobre el personal médico, o especialistas e incluso sobre la infraestructura de los hospitales. También se puede obtener información sobre la salud como noticias o eventos, además de asuntos relacionados con la organización tales como horarios, localización o instrucciones de admisión. Las instituciones sanitarias públicas han hecho un gran esfuerzo por mejorar la eficiencia de sus servicios mediante el desarrollo de servicios online, ya que ahorran tiempo y esfuerzo al paciente, proporcionándole una mayor accesibilidad al sistema sanitario.

Estas nuevas formas de trabajo basadas en el uso de las TIC permiten además ahorro de costes e incrementan la satisfacción del paciente, únicamente si los pacientes utilizan las TIC de forma regular en su vida diaria. Consecuentemente, para justificar la inversión en las TIC sería necesario un uso continuo por parte de los usuarios. De ello deriva la necesidad de dirigir este estudio a una variable de carácter conductual como es la lealtad electrónica, referida a la actitud favorable del paciente a utilizar repetidamente los servicios sanitarios basados en las TIC.

A pesar de la importancia de las TIC en nuestra sociedad, pocas investigaciones se han desarrollado en el sector sanitario respecto al uso de las tecnologías (Aggelidis y 
Chatzoglou, 2009). Es más, los pocos estudios realizados en el sector sanitario han ido enfocados al análisis de la información sanitaria en la páginas web (por ejemplo, Kim y Chang, 2007).

Las investigaciones en el área de aceptación de las tecnologías han resultado en varios modelos teóricos que explican la aceptación de sistemas de información y de tecnología. La mayoría de estos estudios parten de teorías relacionadas con el comportamiento, y desarrollan modelos contrastados empíricamente que explican el conjunto de actuaciones del individuo a partir de sus creencias y/o actitudes.

El presente trabajo se plantea como objetivo desarrollar un modelo de aceptación de las TIC a partir de los modelos previos. En concreto, el objetivo es introducir una serie de variables seleccionadas desde un enfoque de gestión del conocimiento que reflejarán, por tanto, flujos e intercambios de conocimiento entre las organizaciones sanitarias y sus usuarios. Para ello, el trabajo se estructura como sigue:

Capítulo 1: Tecnologías de la Información y Gestión del Conocimiento en el Sector Sanitario.

Este capítulo es fundamental para la comprensión del resto de nuestro trabajo, pues constituye el marco de referencia de los siguientes capítulos. En él se pone de manifiesto la revolución que han provocado las TIC en la sociedad y, en particular, en las organizaciones sanitarias. Además se plantea la necesidad de la gestión del conocimiento en una economía altamente competitiva y cambiante, en la que 
únicamente sobreviven las organizaciones que crean nuevos conocimientos, los difunden e incorporan rápidamente a nuevos procesos, servicios y productos y más aún teniendo en cuenta los rápidos avances tecnológicos y el uso de servicios sanitarios online.

Por otro lado, la gestión del conocimiento es a menudo pasada por alto como un factor clave para el éxito o fracaso inicial de la introducción de algunas nuevas tecnologías en una organización (Hoffman y Klepper, 2000). Además, la gestión del conocimiento y los nuevos sistemas tecnológicos cobran importancia al configurarse como variables claves que aportan a las organizaciones sanitarias la capacidad de respuesta necesaria para ofrecer con rapidez lo que el entorno y, sobre todo, sus usuarios externos, les están demandando y mantener o mejorar, de esta forma, su posición competitiva. De ahí, que la relación entre la gestión del conocimiento y las TIC sea cada vez más importante y más teniendo en cuenta los rápidos cambios que se están produciendo en el ámbito tecnológico.

Por ello, en este capítulo se analiza la relación entre TIC y gestión del conocimiento, partiendo en primer lugar, de un estudio sobre estas tecnologías y sus repercusiones en el sector sanitario; en segundo lugar, se identifican las barreras que impiden la exitosa implantación de las TIC en este sector y los beneficios que estas tecnologías pueden aportar; finalmente, se analiza qué papel juega la gestión del conocimiento en el ámbito sanitario y qué variables influyen en esta gestión. Consecuentemente, la relación entre TIC y gestión del conocimiento hace necesario plantear la necesidad de aceptar las tecnologías por parte de los usuarios externos de 
este sector (tales como, pacientes o cuidadores), para que los servicios sanitarios online se utilicen de forma habitual en nuestra vida diaria.

Capítulo 2: Modelos de Aceptación de la Tecnología.

La aceptación del uso de nuevas tecnologías es descrita con frecuencia como una de las áreas de investigación más madura en la literatura de los sistemas de la información contemporánea. Debido a ello, las investigaciones en esta área han resultado en varios modelos teóricos que explican la aceptación de sistemas de información y de tecnología. A lo largo de este capítulo se analizan los modelos de aceptación de la tecnología más relevantes en la literatura y que han permitido sentar las bases del modelo teórico propuesto en este estudio.

Capítulo 3: Desarrollo de un Modelo de Aceptación de Tecnologías en Usuarios Externos del Sector Sanitario.

En este capítulo se pretende desarrollar un modelo de aceptación de las TIC a partir de los modelos previos. En concreto, el objetivo es centrar el modelo en una de las variables clave como antecedente de la aceptación y uso de las tecnologías recogida en los modelos previos. Partiendo de esa variable, se pretende introducir una serie de variables que influyan en el valor percibido de los usuarios al utilizar las TIC. La 
elección de dichas variables se realizará desde un enfoque de gestión del conocimiento y, por tanto, reflejarán flujos e intercambios de conocimiento entre la organización y el usuario externo del sector sanitario.

Posteriormente se proponen dos nuevas variables que tendrán repercusión sobre el uso de las TIC en el sector sanitario. Por un lado, la satisfacción del usuario, como variable afectiva que viene motivada por el valor percibido de los usuarios externos y, por último, una variable de carácter conductual, considerada como variable final del modelo propuesto y que a su vez viene impulsada por la satisfacción, se trata de la elealtad o lealtad electrónica de los usuarios externos hacia el uso de los servicios sanitarios online.

Capítulo 4: Revisión de la Literatura Empírica y Metodología.

A lo largo de este capítulo se procede a la descripción de la metodología empleada para contrastar el modelo propuesto. En primer lugar, se procede a realizar una revisión empírica de la literatura, y en segundo lugar, se justifica el sector elegido para realizar el estudio empírico, el sector sanitario público. Posteriormente se describen las características de la población y de la muestra, usuarios de los servicios sanitarios online del Servicio Murciano de Salud. Asimismo se detallan las herramientas de medida empleadas y las técnicas empleadas para el análisis de los datos recogidos. 
Capítulo 5: Análisis de los Resultados.

En este capítulo se procede al contraste del modelo propuesto en este estudio. Para ello, en primer lugar, se realizan pruebas previas para asegurar la fiabilidad y validez de las herramientas de medida. Posteriormente, se procede a contrastar las hipótesis planteadas mediante un análisis de regresión. Finalmente, se analizan los resultados obtenidos.

Se finaliza con las conclusiones y las aportaciones más relevantes del trabajo, así como con las limitaciones y la propuesta de líneas de investigación futuras. 

CAPÍTULO 1. TECNOLOGÍAS DE LA INFORMACIÓN Y GESTIÓN DEL CONOCIMIENTO EN EL SECTOR SANITARIO 



\section{OBJETIVO}

El objetivo de este capítulo, es llevar a cabo una revisión literaria sobre los principales conceptos que se derivan de esta investigación, tales como, las tecnologías de la información y la comunicación (TIC), la gestión del conocimiento o el sector sanitario, todo ello bajo el estudio de diversas fuentes documentarias oficiales, que a lo largo de los años, han analizado cada uno de los conceptos anteriormente expuestos.

Para lograr este objetivo, examinaremos en primer lugar el concepto de las TIC, desde su aparición hasta el estado actual de las mimas y su aplicación en el sector sanitario. En segundo lugar, se analizarán las barreras y los beneficios que supone la implantación de las TIC en el sector sanitario. En tercer lugar, se analizarán los términos de conocimiento y gestión del conocimiento para posteriormente, descubrir la repercusión que la gestión del conocimiento tiene en el sector sanitario. Finalmente, se procederá al análisis de la relación existente entre las TIC y la gestión del conocimiento, con la finalidad de determinar que variables pueden incidir en la aceptación de las TIC por parte de los usuarios del sector sanitario y en particular, de los pacientes.

\section{INTRODUCCIÓN}

Nadie duda de la capacidad de las tecnologías de la información y la comunicación (TIC) y de la necesidad de incorporar estas valiosas herramientas a cualquier organización. En la actualidad no basta con tener acceso a una gran cantidad de información. Es necesario, además, poder recoger toda esa información y utilizarla 
de forma que resulte útil a quién accede a ella. Con esa información se genera nuevo conocimiento que conduce a la innovación, al aprendizaje, a la creatividad y a la novedad.

Por ello, el conocimiento se ha convertido, junto con las TIC, en el factor de producción más importante en esta economía de la información. De ahí que la gestión del conocimiento sea algo más que la gestión de información y trate de unir la información disponible con la forma de actuar de las personas proporcionando las bases para un aprendizaje organizacional ${ }^{1}$.

La gestión del conocimiento es un ámbito de rápido crecimiento que atraviesa diversas disciplinas, por ejemplo, la relacionada con los sistemas de información. Además, puede ser vista como un término complejo que envuelve un amplio abanico de temas y puntos de vista. Tradicionalmente, el término de conocimiento organizacional ${ }^{2}$ debe convertirse en un recurso que proporcione beneficios a la hora de compartir información. Por ello es necesario capturar e interpretar la información y transferirla en conocimiento para que continúe al servicio del sector sanitario, independientemente del propósito de los usuarios de este sector al recopilar información.

Numerosos investigadores (McFarlan et al. 1983; Davenport y Short, 1990; Henderson y Venkatraman, 1993; Venkatraman, 1994; Applegate et al., 1999;

\footnotetext{
${ }^{1}$ El aprendizaje organizacional constituye un proceso sistemático e indispensable para el funcionamiento de una organización, ya que posibilita perfeccionar de forma efectiva, el conocimiento esencial que fluye dentro y fuera de los límites de la organización; además posibilita mejorar las capacidades organizacionales. Unas capacidades logradas por medio de la creación de procesos que contribuyen al flujo de conocimiento entre los miembros de la organización, y de éstos con el entorno (Hernández y Martí, 2006).

2 El conocimiento organizativo son todos aquellos conocimientos acumulados por la empresa en relación a sus productos, a sus servicios, a sus clientes y a sus mercados. Es un activo muy difícil de sustituir o reproducir. Este tipo de conocimiento se ve reflejado en la acumulación de capacidades para la empresa y en la internalización de nuevos conocimientos para cada individuo (Vera, 2006).
} 
McNurlin y Sprague, 2004) ponen énfasis en la perspectiva de que las TIC pueden convertirse en la clave para el funcionamiento de una organización. Con el fin de aprovechar al máximo las oportunidades facilitadas por las TIC, en particular cuando se aplica a la gestión el conocimiento, muchas investigaciones han propuesto y probado modelos para la gestión del conocimiento, con o sin el apoyo de las TIC (Dwivedi et al., 2002; Bhatt et al., 2005; Papoutsakis y Vallés, 2006).

Vincular ambas variables con el rendimiento de una organización nunca ha sido una tarea fácil (Papoutsakis y Vallés, 2006). Sin embargo, es una realidad que la mayoría de las organizaciones que incorporan nuevas tecnologías implantan un programa estándar, sin plantearse los problemas y las barreras que van a condicionar la implantación de una u otra tecnología. No obstante, hay que tener en cuenta que el gasto en TIC (incluyendo el estudio de cuándo incorporarlas, cómo afectan éstas a la organización, etc.) supone costes elevados asociados principalmente al apoyo técnico de las organizaciones (Rahimpour et al., 2008).

Benjamin y Levinson (1993) enfatizan que para que el cambio basado en las TIC sea efectivo se debe adaptar a todos y cada uno de los factores a los que afecta. Sin embargo, las organizaciones dedican la mayor parte de sus recursos, esfuerzos y tiempo a la implantación indiscriminada de aplicaciones, sin plantearse dónde reside el conocimiento necesario para implantar las TIC y cómo transformar y usar ese conocimiento en los nuevos sistemas de información.

Sin embargo, el principal problema de esta investigación está en que a pesar de la cantidad de estudios dedicados a examinar los determinantes de la aceptación y éxito de las TIC, muy pocas investigaciones se han dirigido al área del sector sanitario 
(Aggelidis y Chatzoglou, 2009). Por lo tanto, la implantación de servicios sanitarios online $^{3}$ puede ser difícil si no partimos de una adecuada gestión del conocimiento por parte de los usuarios de este sector.

Una posible solución al problema de la implantación de los servicios sanitarios online sería llevar a cabo una buena gestión del conocimiento de los agentes que intervienen en el sector sanitario, en concreto, de los agentes externos (pacientes, cuidadores, etc.). Si la información que reciben es capturada, interpretada y transferida en nuevo conocimiento, y éste, a su vez, se complementa con el conocimiento que los usuarios tenían anteriormente, esto podría derivar en una adecuada gestión del conocimiento que serviría de soporte para la toma de decisiones a todos los niveles de la organización. Si además, son capaces de aceptar y usar las TIC como instrumentos apropiados para facilitar la gestión del conocimiento, se generarían una serie de ventajas competitivas que favorecerían el desarrollo de los servicios sanitarios online. Todo este proceso se representa en la figura 1 que se muestra a continuación.

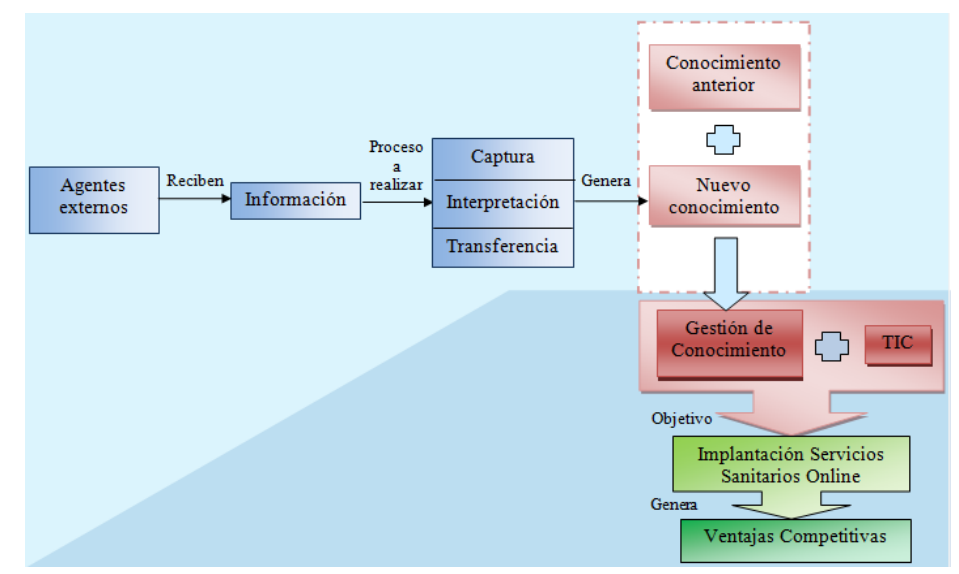

Figura 1. Modelo de implantación de Servicios Sanitarios Online (Elaboración propia).

3 Online significa "en línea". Es un concepto utilizado en el ámbito de la informática para afirmar que algo está conectado o alguien está haciendo uso de una red. Se trata de información disponible a través de Internet. 


\section{ANTECEDENTES Y ESTADO ACTUAL DE LAS TIC EN EL SECTOR SANITARIO}

Desde mediados de la década de los noventa, el cambio tecnológico no sólo continúa acelerándose, sino que se está convirtiendo en una fuente principal de productividad en el sector sanitario que nos conduce a un tipo de sociedad distinta. Han ido apareciendo una serie de nuevos servicios y productos verdaderamente revolucionarios (como Internet, el teléfono móvil, etc.) que están modificando profundamente nuestra forma de vivir y que se han ido aprovechando en el sector sanitario para diversos usos médicos desde el primer momento de su introducción.

Hasta muy recientemente, las implantaciones de servicios de salud online tenían un carácter exploratorio ${ }^{4}$ guiados por las posibilidades tecnológicas y con naturaleza de proyectos de $\mathrm{I}+\mathrm{D}+\mathrm{I}^{5}$ bajo una iniciativa mayoritariamente individual, estando generalmente basados en conexiones bilaterales entre pocos entes sanitarios. En la actualidad se está produciendo una evolución hacia la implantación de sistemas para uso rutinario, guiados por la satisfacción de las necesidades sanitarias de los pacientes bajo iniciativa institucional, donde cobran protagonismo la mejora del acceso y la continuidad de los cuidados junto con los objetivos de eficiencia, mínimo coste y máximo beneficio para los usuarios externos (pacientes, etc.).

En este momento estamos en el umbral de un cambio radical en la propia organización y provisión de los servicios sanitarios propiciado por una nueva

\footnotetext{
$4 \mathrm{Su}$ carácter exploratorio es debido a que el tema analizado es desconocido o poco estudiado, por lo que sus resultados constituyen una visión aproximada, es decir, a un nivel superficial de conocimiento.

5 Las siglas de I+D+I hacen referencia a proyectos centrados en investigación, desarrollo e innovación.
} 
generación de infraestructuras de telecomunicaciones y de conectividad en red (Monteagudo et al., 2005).

De ahí que las TIC sean el punto de referencia y se consideren como una herramienta analítica de utilidad, ya que motivan una serie de cambios en las actuaciones diarias del sector sanitario. No obstante, hay que tener cuidado con su aplicación, pues el estudio de las TIC ha de enmarcarse en un contexto organizacional. En este sentido, cabe cuestionarse qué políticas se han de llevar a cabo como paso previo a la implantación de las TIC, ya que, la presencia de las TIC sin un contexto previo es irrelevante (Ackerman, 2000).

Faramarz (2001) comenta que, debido a este cambio, se crea un nuevo entorno en el cual sólo existen dos opciones: entrar o no entrar y que, para entrar a éste, era necesario adaptarse al mismo, adaptarse a los nuevos valores, las nuevas reglas, pero, sobre todo, adaptarse a la nueva forma de gestionar. Asimismo, Brenix (2003) comenta que, a raíz de las nuevas tecnologías, se crearon y abrieron nuevas oportunidades para las organizaciones, pero al mismo tiempo, surgieron muchos problemas que era necesario enfrentar.

De ahí que una organización no opere en un espacio aislado y, además de encontrar, almacenar y compartir los conocimientos internos, necesite disponer de la información de los agentes tanto externos como internos (doctores, enfermeros, pacientes, etc.). Una manera de obtener información de los agentes externos e internos es mediante la colaboración entre ellos, cuyo propósito, desde el punto de vista de la organización, será conseguir objetivos institucionales tales como la supervivencia y el crecimiento en términos económicos, que posteriormente puedan aplicarse para el 
desarrollo de sus propias actividades y negocios (Harrigan, 1985). Por ende, Moyano et al., (2008) afirman que dichos agentes pueden incidir en la generación y mantenimiento de una ventaja competitiva sólida en la organización.

De cualquier forma, Gargallo y Pérez (2009) corroboran que en un entorno cambiante como el actual, las organizaciones deben, por un lado, potenciar las fortalezas derivadas de su funcionamiento, al tiempo que solventan sus debilidades, y por otro lado, hacer frente a las amenazas provenientes del entorno, aprovechando oportunidades como las ofrecidas por las TIC (tales como incrementar los servicios sanitarios online, la atención y servicio al paciente, la rapidez en la respuesta a sus demandas, etc.) para conseguir efectos positivos (como la fidelización de los usuarios externos - pacientes, cuidadores, etc.-) con la utilización de las TIC en el sector sanitario.

A lo largo de la literatura especializada son abundantes los trabajos que estudian la incidencia de las TIC en el crecimiento económico de los países, así como su aportación a la generación de ventajas competitivas en las organizaciones que las incorporan en sus procesos. A nivel de organización, los estudios relacionados con las TIC han sido muy diversos, difiriendo en las muestras utilizadas, los sectores revisados, las metodologías y las variables empleadas, así como los resultados obtenidos. En la tabla 1 se muestran algunos de esos trabajos diferenciando entre las ventajas e inconvenientes derivadas de los mismos: 
Tabla 1. Ventajas e inconvenientes de la aparición de las TIC.

\begin{tabular}{|c|c|c|c|}
\hline $\boldsymbol{A N} \boldsymbol{O}$ & AUTOR & VENTAJAS & INCONVENIENTES \\
\hline 1997 & $\begin{array}{c}\text { Poon y } \\
\text { Swatman }\end{array}$ & $\begin{array}{l}\text { Las tecnologías de la información } \\
\text { son un medio de comunicación de } \\
\text { bajo coste para interactuar con } \\
\text { clientes, suministradores } \quad \text { y } \\
\text { compañeros de empresa. }\end{array}$ & $\begin{array}{l}\text { Ausencia de infraestructuras, la } \\
\text { percepción de una posible carencia } \\
\text { de confidencialidad, las barreras } \\
\text { culturales y la falta de comprensión } \\
\text { de cómo las TIC pueden afectar en } \\
\text { sus negocios. }\end{array}$ \\
\hline 1998 & Haynes et al. & $\begin{array}{l}\text { Las pequeñas empresas están } \\
\text { adoptando e incorporando las } \\
\text { tecnologías de la información más } \\
\text { rápidamente en sus operaciones que } \\
\text { las medianas y grandes empresas. } \\
\text { Con las TIC las empresas pueden } \\
\text { mejorar el acceso a una gama } \\
\text { amplia de clientes y ser capaces de } \\
\text { analizar su competencia y sus } \\
\text { referentes mundiales como nunca lo } \\
\text { habían podido hacer con } \\
\text { anterioridad. }\end{array}$ & $\begin{array}{l}\text { No percibir las } \\
\text { TIC como una } \\
\text { oportunidad para mejorar sus } \\
\text { operaciones y su no utilización } \\
\text { continúa por parte de las } \\
\text { organizaciones. }\end{array}$ \\
\hline 2001 & Lee y Runge & $\begin{array}{l}\text { La percepción de los propietarios } \\
\text { hacia la adopción de tecnologías de } \\
\text { la información, influye a la hora de } \\
\text { considerarlas como generadoras de } \\
\text { ventajas competitivas. }\end{array}$ & $\begin{array}{l}\text { La implantación de las TIC para } \\
\text { desarrollar programas de } \\
\text { fidelización de clientes depende de } \\
\text { la propensión a innovar de los } \\
\text { propietarios o gestores del negocio } \\
\text { únicamente, sin tener en cuenta una } \\
\text { decisión a nivel de toda la } \\
\text { organización, lo cual puede suponer } \\
\text { inconvenientes de cara a su } \\
\text { aceptación. }\end{array}$ \\
\hline 2001 & Moreno & $\begin{array}{l}\text { Las TIC han impulsado la aparición } \\
\text { del teletrabajo }{ }^{6} \text {, ya que favorecen } \\
\text { la conexión entre empresa y } \\
\text { trabajador a través de nuevos } \\
\text { canales de comunicación, } \\
\text { aumentando la adquisición de } \\
\text { competencias y habilidades } \\
\text { tecnológicas de los trabajadores. }\end{array}$ & $\begin{array}{l}\text { La falta de capacitación y } \\
\text { formación de los trabajadores para } \\
\text { manejar las herramientas } \\
\text { informáticas. La ausencia de un } \\
\text { marco jurídico sobre las } \\
\text { modalidades de contratos y la } \\
\text { problemática laboral de los } \\
\text { trabajadores y la necesidad de una } \\
\text { reforma legislativa que permita } \\
\text { combinar la flexibilidad laboral, } \\
\text { con los deberes y derechos de los } \\
\text { trabajadores. }\end{array}$ \\
\hline 2002 & $\begin{array}{c}\text { Sadowski et } \\
\text { al. }\end{array}$ & $\begin{array}{l}\text { Las tecnologías de la información } \\
\text { suponen un medio económico y } \\
\text { fácil para que se produzca la } \\
\text { comunicación interna y externa. } \\
\text { También promocionan una imagen } \\
\text { de la compañía. }\end{array}$ & $\begin{array}{l}\text { La adopción de las TIC está } \\
\text { condicionada por el tiempo y el } \\
\text { esfuerzo necesario para } \\
\text { incorporarlas en la organización. Es } \\
\text { más, su adopción responde en } \\
\text { muchas ocasiones a un factor de } \\
\text { oportunidad más que a un uso } \\
\text { estratégico de las mismas. }\end{array}$ \\
\hline
\end{tabular}

${ }^{6}$ El teletrabajo corresponde a una modalidad de trabajo remunerado caracterizada específicamente por ser realizado manteniendo una distancia física entre el trabajador y la empresa (así lo entienden, por ejemplo, Gareca et al., 2007 y Salazar, 2007). Se trata de un trabajo a distancia que requiere el uso de las TIC. 


\begin{tabular}{|c|c|c|c|}
\hline 2002 & $\begin{array}{l}\text { Ponsa y } \\
\text { Aranda }\end{array}$ & $\begin{array}{l}\text { Los avances técnicos desarrollados } \\
\text { estos últimos años en el campo de } \\
\text { las tecnologías de la información y } \\
\text { de la comunicación (TIC), han } \\
\text { hecho que la aplicación de estas en } \\
\text { el ámbito educativo se haga cada } \\
\text { vez más extensivo tanto en clases } \\
\text { presenciales y de laboratorio, como } \\
\text { en la elaboración de materiales de } \\
\text { apoyo que faciliten el } \\
\text { autoaprendizaje por parte del } \\
\text { alumno. }\end{array}$ & $\begin{array}{l}\text { Es necesaria la } \begin{array}{l}\text { continua } \\
\text { actualización de contenidos. }\end{array} \\
\text { Además, no todos los alumnos } \\
\text { parecen apreciar de igual grado las } \\
\text { nuevas herramientas educativas que } \\
\text { surgen a través de las TIC. Esto } \\
\text { parece estar relacionado con lo que } \\
\text { los expertos llaman estilos } \\
\text { cognitivos o de aprendizaje. Cada } \\
\text { persona tiene un estilo y si no } \\
\text { somos capaces de adecuar la } \\
\text { presentación de los contenidos a } \\
\text { cada estilo cognitivo, } \\
\text { probablemente no seremos capaces } \\
\text { de generar un aprendizaje efectivo } \\
\text { en un grupo amplio de personas. }\end{array}$ \\
\hline 2002 & Dillon & $\begin{array}{l}\text { Las TIC constituyen un excelente } \\
\text { instrumento auxiliar para el } \\
\text { desarrollo local, tanto por sus } \\
\text { cualidades educativas como por la } \\
\text { eficacia con que permiten reunir } \\
\text { datos y analizar soluciones, dos } \\
\text { premisas indispensables para la } \\
\text { planificación estratégica. }\end{array}$ & $\begin{array}{l}\text { Dificultad para detectar las } \\
\text { necesidades reales de las } \\
\text { comunidades en desarrollo y el no } \\
\text { aprovechamiento total de las TIC. }\end{array}$ \\
\hline 2004 & Amador & $\begin{array}{l}\text { Las TIC son un instrumento de } \\
\text { enormes potencialidades y ayuda en } \\
\text { el campo de la educación, ya que } \\
\text { permiten el uso de unos recursos } \\
\text { con un alto nivel de interacción, } \\
\text { accesibilidad, apertura y } \\
\text { sincronización, además de un alto } \\
\text { nivel de comunicabilidad y } \\
\text { seguimiento de los procesos de } \\
\text { enseñanza y aprendizaje. }\end{array}$ & $\begin{array}{l}\text { Es necesario formación para su } \\
\text { manejo, su mal uso puede conducir } \\
\text { al rechazo de las TIC, es necesario } \\
\text { poseer las infraestructuras } \\
\text { necesarias para el desarrollo de las } \\
\text { TIC, lo cual lleva un coste implícito } \\
\text { que no siempre es posible soportar } \\
\text { por la organización. }\end{array}$ \\
\hline 2005 & Trujillo & $\begin{array}{l}\text { Las TIC ofrecen multitud de } \\
\text { aplicaciones relevantes en el campo } \\
\text { de la psicología clínica: acceso a } \\
\text { recursos e información, } \\
\text { popularización de guías de } \\
\text { autoayuda, servicios psicológicos, } \\
\text { etc. En la actualidad, las TIC e } \\
\text { Internet, más concretamente, son un } \\
\text { instrumento que permite llevar a } \\
\text { cabo sesiones de tratamiento } \\
\text { psicológico a distancia, o consultas } \\
\text { u orientaciones psicológicas, } \\
\text { complementándolas con sesiones } \\
\text { presenciales. }\end{array}$ & $\begin{array}{l}\text { Las TIC, en el ámbito de la } \\
\text { psicología clínica, no se consideran } \\
\text { que puedan reemplazar a la } \\
\text { psicoterapia tradicional, ya que el } \\
\text { tipo de intervención que ofrece no } \\
\text { es la indicada para todo tipo de } \\
\text { casos ni de pacientes. } \\
\text { Más previamente han de primar } \\
\text { aspectos como la ética, la } \\
\text { confidencialidad y la efectividad de } \\
\text { los servicios ofrecidos por las TIC. } \\
\text { En concreto, la efectividad depende } \\
\text { de características personales, de las } \\
\text { actitudes de las personas, del } \\
\text { proceso de implantación y de los } \\
\text { objetivos que se persigan. De ahí } \\
\text { que las tecnologías puedan } \\
\text { considerarse una herramienta } \\
\text { inadecuada para algunos propósitos, } \\
\text { personas o grupos sociales, ya sea } \\
\text { en sus relaciones cotidianas, en las } \\
\text { aulas, en el trabajo o en el centro de } \\
\text { salud. }\end{array}$ \\
\hline
\end{tabular}




\begin{tabular}{|c|c|c|c|}
\hline 2005 & Trujillo & $\begin{array}{l}\text { El proyecto de la comunidad } \\
\text { educativa es utilizar las tecnologías } \\
\text { de la información y la } \\
\text { comunicación como instrumentos } \\
\text { integradores de formación y } \\
\text { desarrollo de capacidades, } \\
\text { atendiendo a las necesidades } \\
\text { específicas e individuales de cada } \\
\text { alumno/a y bajo una perspectiva } \\
\text { interdisciplinar? No obstante, las } \\
\text { TIC se consideran como uno de los } \\
\text { instrumentos más eficaces para la } \\
\text { formación a lo largo de la vida, que } \\
\text { potenciará la adaptabilidad a las } \\
\text { nuevas exigencias de la sociedad, } \\
\text { ya sea desde el ámbito del empleo, } \\
\text { de la industria, del comercio o de la } \\
\text { vida cotidiana. }\end{array}$ & $\begin{array}{l}\text { Todo plan de introducción de las } \\
\text { TIC en el entorno educativo debe } \\
\text { contemplar, de forma simultánea, la } \\
\text { dotación tecnológica de los centros, } \\
\text { la formación del profesorado y el } \\
\text { desarrollo de contenidos, cosa que } \\
\text { no siempre es posible. }\end{array}$ \\
\hline 2006 & $\begin{array}{l}\text { Rueda- } \\
\text { Clausen }\end{array}$ & $\begin{array}{l}\text { El desarrollo de las TIC en paralelo } \\
\text { al de la Historia Clínica } \\
\text { Informatizada }\left(\mathrm{HCI}^{8}\right) \text {, permite } \\
\text { utilizar la información disponible } \\
\text { cumpliendo con las condiciones } \\
\text { ideales para el manejo documental } \\
\text { y asistencial de los expedientes } \\
\text { sanitarios. }\end{array}$ & $\begin{array}{l}\text { Falta de capacitación de los } \\
\text { usuarios del sistema en temas } \\
\text { informáticos generales y } \\
\text { específicos, así como la falta de } \\
\text { coordinación y comunicación entre } \\
\text { los administradores y usuarios del } \\
\text { sistema. Además se genera una } \\
\text { resistencia al cambio por parte de } \\
\text { los usuarios debido al } \\
\text { incumplimiento de sus expectativas. }\end{array}$ \\
\hline 2006 & Gómez & $\begin{array}{l}\text { Las TIC están ayudando a paliar los } \\
\text { costes de todo proceso de } \\
\text { internalización emprendido por } \\
\text { cualquier empresa, es decir, de } \\
\text { costes de comunicación, control y } \\
\text { coordinación, puesto que permiten } \\
\text { dinamizar relaciones comerciales } \\
\text { en mercados en los que antes era } \\
\text { mucho más complicado hacerlo. }\end{array}$ & $\begin{array}{l}\text { La implantación de las TIC puede } \\
\text { ser un problema cuando las } \\
\text { empresas intentan desarrollar tareas } \\
\text { complicadas ofreciendo productos } \\
\text { online. }\end{array}$ \\
\hline 2008 & $\begin{array}{c}\text { Molina y } \\
\text { Cuestas }\end{array}$ & $\begin{array}{l}\text { Las nuevas tecnologías y } \\
\text { principalmente la referida a Internet } \\
\text { están cambiando la forma de hacer } \\
\text { negocios ya que facilitan los } \\
\text { intercambios por parte de las } \\
\text { empresas, un ejemplo es el uso del } \\
\text { comercio electrónico.9 }\end{array}$ & $\begin{array}{l}\text { Para el correcto desarrollo del } \\
\text { marketing electrónico en una } \\
\text { empresa es necesario contar con } \\
\text { expertos en tecnologías de la } \\
\text { información o contratar un servicio } \\
\text { externo. Esto supone una limitación } \\
\text { añadida y un coste asociado a tener } \\
\text { en cuenta. }\end{array}$ \\
\hline
\end{tabular}

7 La perspectiva interdisciplinar integra teorías, métodos, instrumentos, y, en general, fórmulas de acción científica de diferentes disciplinas, a partir de una concepción multidimensional de los fenómenos, y del reconocimiento del carácter relativo de los enfoques científicos por separado.

8 La Historia Clínica Informatizada (HCI) se define como el conjunto global y estructurado de información, relacionado con los procesos de la asistencia médico-sanitaria de los pacientes, soportado en una plataforma informática para cumplir con las expectativas de todos los usuarios

9 El comercio electrónico es un nueva forma «nueva forma comercial que utilizando las TIC permite al cliente efectuar la consulta, selección y adquisición de la oferta de un distribuidor a través de un terminal doméstico, en tiempo real y desde el propio hogar» (Rodríguez, 2002). 


\begin{tabular}{|c|c|c|c|}
\hline 2009 & $\begin{array}{c}\text { Temprano y } \\
\text { Gallego }\end{array}$ & $\begin{array}{l}\text { Las TIC permiten la realización de } \\
\text { actividades basadas en el uso de } \\
\text { Internet. Dentro de estas } \\
\text { actividades destacan las webquest }{ }^{10} \text {. }\end{array}$ & $\begin{array}{l}\text { Se presentan considerables } \\
\text { dificultades de tipo técnico, } \\
\text { incluyendo la necesidad de crear } \\
\text { documentos web, editar imágenes o } \\
\text { manejar servidores remotos en los } \\
\text { que colocar los documentos } \\
\text { creados. Ello requiere por parte de } \\
\text { los profesores un nivel avanzado en } \\
\text { el manejo de las herramientas } \\
\text { informáticas y esto no siempre es } \\
\text { posible. }\end{array}$ \\
\hline 2009 & Gil et al. & $\begin{array}{l}\text { Las TIC ofrecen nuevas } \\
\text { posibilidades para la gestión de la } \\
\text { empresa comercial. De la } \\
\text { aplicación de las TIC se derivan } \\
\text { una serie de beneficios para la } \\
\text { empresa, como ahorro de tiempo, } \\
\text { ahorro de gastos de personal, etc. } \\
\text { Desde el punto de vista del cliente, } \\
\text { las TIC ofrecen mejoras en el } \\
\text { servicio, ya que economizan el } \\
\text { tiempo de compra. } \\
\text { Por todo ello, las TIC influyen } \\
\text { positivamente en el valor de las } \\
\text { relaciones de la empresa comercial } \\
\text { con sus proveedores y clientes e } \\
\text { incrementan la satisfacción del } \\
\text { cliente en el comercio minorista. }\end{array}$ & $\begin{array}{l}\text { Las TIC no contribuyen a } \\
\text { incrementar la satisfacción del } \\
\text { cliente. Esto puede deberse a que } \\
\text { los beneficios del empleo de tal } \\
\text { tecnología no son apreciados por el } \\
\text { consumidor. }\end{array}$ \\
\hline 2010 & $\begin{array}{l}\text { Martínez y } \\
\text { Hermosilla }\end{array}$ & $\begin{array}{l}\text { Uno de los ámbitos de innovación } \\
\text { que exige el proceso de } \\
\text { convergencia para la creación de un } \\
\text { Espacio Europeo de Educación } \\
\text { Superior (EEES), pasa } \\
\text { necesariamente por el empleo } \\
\text { generalizado de las TIC en la } \\
\text { enseñanza. }\end{array}$ & $\begin{array}{l}\text { El rechazo al uso de las TIC por } \\
\text { parte de los usuarios, la ausencia de } \\
\text { conexión doméstica a Internet, no } \\
\text { disponer de ordenador y el escaso } \\
\text { dominio del software a utilizar. }\end{array}$ \\
\hline 2011 & Sainz & $\begin{array}{l}\text { La implantación de las nuevas } \\
\text { tecnologías ha supuesto una mejora } \\
\text { considerable en las comunicaciones } \\
\text { entre pacientes y profesionales, } \\
\text { haciendo la atención cada vez más } \\
\text { especializada y profesional, } \\
\text { facilitando la movilidad de las } \\
\text { personas y evitando } \\
\text { desplazamientos. Con el uso de las } \\
\text { TIC se potencia la calidad de los } \\
\text { servicios y la atención a los } \\
\text { ciudadanos. }\end{array}$ & $\begin{array}{l}\text { El nivel de aceptabilidad no es el } \\
\text { mismo en pacientes que en } \\
\text { profesionales; los pacientes están } \\
\text { más motivados en interactuar con el } \\
\text { profesional haciendo uso de } \\
\text { Internet, que al revés. Desde el } \\
\text { punto de vista de los profesionales, } \\
\text { esta preferencia por comunicarse } \\
\text { mediante el correo electrónico es } \\
\text { menor, ya que creen que en el trato } \\
\text { directo, pueden llegar a mejores } \\
\text { resultados sobre el tratamiento o } \\
\text { proceso a seguir. }\end{array}$ \\
\hline
\end{tabular}

${ }^{10}$ La webquest son actividades educativas que adoptan el formato de aventuras guiadas que tienen como marco Internet, y en las que los profesores que las crean proponen al alumnado la resolución de una serie de tareas. Se usan para apoyar la reflexión del alumno en los niveles de análisis, síntesis y evaluación (Watson, 1999), y desde el punto de vista metodológico constituyen un recurso educativo basado en el paradigma constructivista, en cuanto que el conocimiento es construido por el propio alumno, pasando el profesor a ser un facilitador del proceso de aprendizaje y dejando atrás su tradicional papel directivo y de transmisor único y exclusivo del conocimiento. 


\begin{tabular}{|c|c|c|c|}
\hline 2011 & Sainz et al. & $\begin{array}{l}\text { Las TIC permiten un desarrollo } \\
\text { adecuado de las tecnologías en el } \\
\text { área de la salud (e-Health }{ }^{11} \text { ), } \\
\text { gracias a la cual el paciente se } \\
\text { encuentra más informado y } \\
\text { próximo a su médico por la } \\
\text { posibilidad de concertar citas a } \\
\text { través de Internet, realizar consultas } \\
\text { médicas por e-mail, solicitar } \\
\text { diagnósticos a distancia, etc., } \\
\text { constituyendo una herramienta } \\
\text { eficaz para la mejora de la calidad } \\
\text { en la atención sanitaria. Además, } \\
\text { estas tecnologías son vitales para } \\
\text { abaratar costes, ganar tiempo y } \\
\text { mejorar la vida del paciente. }\end{array}$ & $\begin{array}{l}\text { Carecer de } \\
\text { infraestructuras } \\
\text { necesarias para el uso de las TIC, } \\
\text { tales como, no disponer de } \\
\text { ordenador, ni de conexión a } \\
\text { Internet. }\end{array}$ \\
\hline
\end{tabular}

Fuente: Elaboración propia.

Son múltiples las posibilidades, ventajas y desventajas que ofrece el desarrollo de las TIC al sistema sanitario en su relación con el paciente (Trujillo, 2005; RuedaClausen, 2006; Sainz, 2011; Sainz et al., 2011). La necesidad actual de los centros hospitalarios de dar respuesta al paciente es cada vez más exigente y el desarrollo de las TIC ha hecho posible el acercamiento del mismo a los centros sanitarios a través de los nuevos servicios sanitarios online ofrecidos por este sector.

Sin embargo, no se ha justificado cuál es la relación que existe entre la inversión en tecnologías de la información y los resultados organizativos. La inversión en TIC en el sector sanitario ha sido tradicionalmente escasa, irregular y heterogénea. A este hecho ha contribuido un conjunto de factores que van, desde la información que se maneja hasta el temor a realizar inversiones de fuerte calado que luego no den resultados a corto plazo o incluso fracasen (Durán, 2008).

11 De acuerdo con la Organización Mundial de la Salud (OMS), el e-Health es "el uso, en el sector de la salud, de información digital, transmitida, almacenada u obtenida electrónicamente para el apoyo al cuidado de la salud tanto a nivel local como a distancia", y se sustenta en el uso de las TIC en aspectos que van desde la gestión de las organizaciones, el acceso a información relevante a través de Internet o el seguimiento del paciente. 
En cualquier caso, según Durán (2008), aparece la exigencia de unas tecnologías cada vez más avanzadas (tales como, portales de usuario, mapas de la web ${ }^{12}$, e-mail ${ }^{13}$, etc.) que fácilmente se integran en el ámbito doméstico. Disponer de los datos organizados, con independencia de tiempo y lugar y ejecutar una serie de funciones básicas a través de las TIC, es ventajoso tanto para los usuarios internos (profesionales sanitarios, tales como, médicos, enfermeros, etc.) como para los usuarios externos (pacientes, etc.). Hoy día, sin la tecnología no se tendría capacidad de obtener información específica en el momento y lugar deseado.

Consecuentemente, para que la información adquiera significado es indispensable la intermediación humana (Rivero, 2002). Por ello, el intercambio de información entre los usuarios y el intercambio de información con los suministradores son los objetivos fundamentales de la implantación de TIC en las organizaciones. Así, por ejemplo, los individuos intercambian y combinan información utilizando diferentes recursos de la organización (contactos telefónicos, correos electrónicos, etc.).

Esta nueva forma de trabajar y actuar en el sector sanitario se expresa en forma de Internet o herramientas que facilitan el acceso a los servicios sanitarios online (Baldwin et al., 2002).

En relación a nuestro estudio cabe destacar las nuevas formas de actuar del sector sanitario mediante la incorporación de los servicios sanitarios online que se están desarrollando para el seguimiento y control de los pacientes, tales como, petición de

\footnotetext{
12 El mapa de la web es una herramienta de planificación que ayuda a los usuarios a hallar la información que necesitan. Por ello, resulta muy útil y de gran ayuda, ya que refleja la estructura de información de un sitio web concreto.

13 E- mail (electronic mail) es el correo electrónico utilizado como método de intercambio de mensajes digitales. Este tipo de correo opera a través de Internet u otras redes informáticas.
} 
citas, comprobación de las listas de espera, realizar sugerencias o quejas, compartir información con otros pacientes, leer información sobre el personal médico, o especialistas e incluso sobre la infraestructura de los hospitales. También se puede obtener información sobre la salud como noticias o eventos, además de asuntos relacionados con la organización tales como horarios, localización o instrucciones de admisión.

Este cambio se debe a que desde hace varios años los modelos sanitarios de los países desarrollados se encuentran en revisión continua en un intento de dar respuesta a las exigencias de satisfacer una mayor demanda de servicios de salud, con mejor calidad, haciéndolos más compatibles con las limitaciones existentes de recursos. Este cambio está guiado por principios tales como poner al paciente en el eje de todas las actuaciones, mejorar la continuidad en la asistencia, la equidad en el acceso, la gestión integrada de procesos y la búsqueda de eficiencia operacional ${ }^{14}$ para facilitar la ausencia de errores (Monteagudo et al., 2005).

Los cambios tecnológicos influyen y se complementan con los cambios organizativos y de concepción de los servicios sanitarios. Es evidente que los recursos tecnológicos que exhiben los hospitales de hoy día son muy diferentes a los de apenas una década y con toda seguridad a los de dentro de unos años. Por ello, y ligado a la evolución general de la sociedad, se ha planteado esta nueva forma de actuar en el sector sanitario a través de los nuevos servicios online, haciendo uso intensivo de

\footnotetext{
14 La eficiencia operacional significa costos más bajos y calidad superior. Estas dos palabras están relacionadas, puesto que para tener costos más bajos se requiere trabajar con alta calidad. Su beneficio es doble, por un lado se reducen los costos de producción y por el otro, se desarrollan niveles de calidad superior a favor de los usuarios internos y externos de la organización.
} 
tecnologías de la información y desarrollando el trabajo y la comunicación en red entre el personal sanitario y los pacientes.

Consecuentemente, resulta evidente la potencialidad que Internet, las comunicaciones móviles ${ }^{15}$, dispositivos portátiles $^{16}$ e instrumentación electrónica ${ }^{17}$ están teniendo en el desarrollo de servicios sanitarios online como por ejemplo, la monitorización, seguimiento o control extra-hospitalario de los pacientes (Monteagudo et al., 2004).

Por otra parte, es obvia la existencia de importantes problemas en la difusión y aceptación, a nivel general, de estos servicios debido a que se trata de sistemas y servicios innovadores y a la necesidad de conseguir, en el proceso de cambio, evidencia contrastable sobre la eficiencia, efectividad y coste/beneficio que reportan los nuevos servicios sanitarios online (Monteagudo et al., 2004). Es más, algunos trabajos han señalado barreras y han emitido recomendaciones sobre las posibles actuaciones para favorecer la difusión de las aplicaciones sanitarias online en la sociedad de la información y la comunicación (Loane y Wootton, 2002; Monteagudo et al, 2004; Trujillo, 2005; Rueda-Clausen, 2006; Sainz, 2011; Sainz et al, 2011).

La figura 2 muestra la influencia de las TIC sobre el desarrollo de los nuevos servicios online y el papel que ejercen sobre los sistemas de información actuales.

15 Las comunicaciones móviles son aquellas en las que el emisor y el receptor están en movimiento. Se necesitan cables para realizar la comunicación entre ambos agentes.

16 Los dispositivos móviles, como la computadora de mano, son aparatos de pequeño tamaño, con algunas capacidades de procesamiento, con conexión o no a una red y con memoria limitada.

17 Es la parte de la electrónica que se encarga del manejo de los aparatos electrónicos y el procesamiento de la información proveniente de una serie de variables a partir de las cuales realiza el monitoreo y control de procesos, empleando dispositivos y tecnologías electrónicas. 


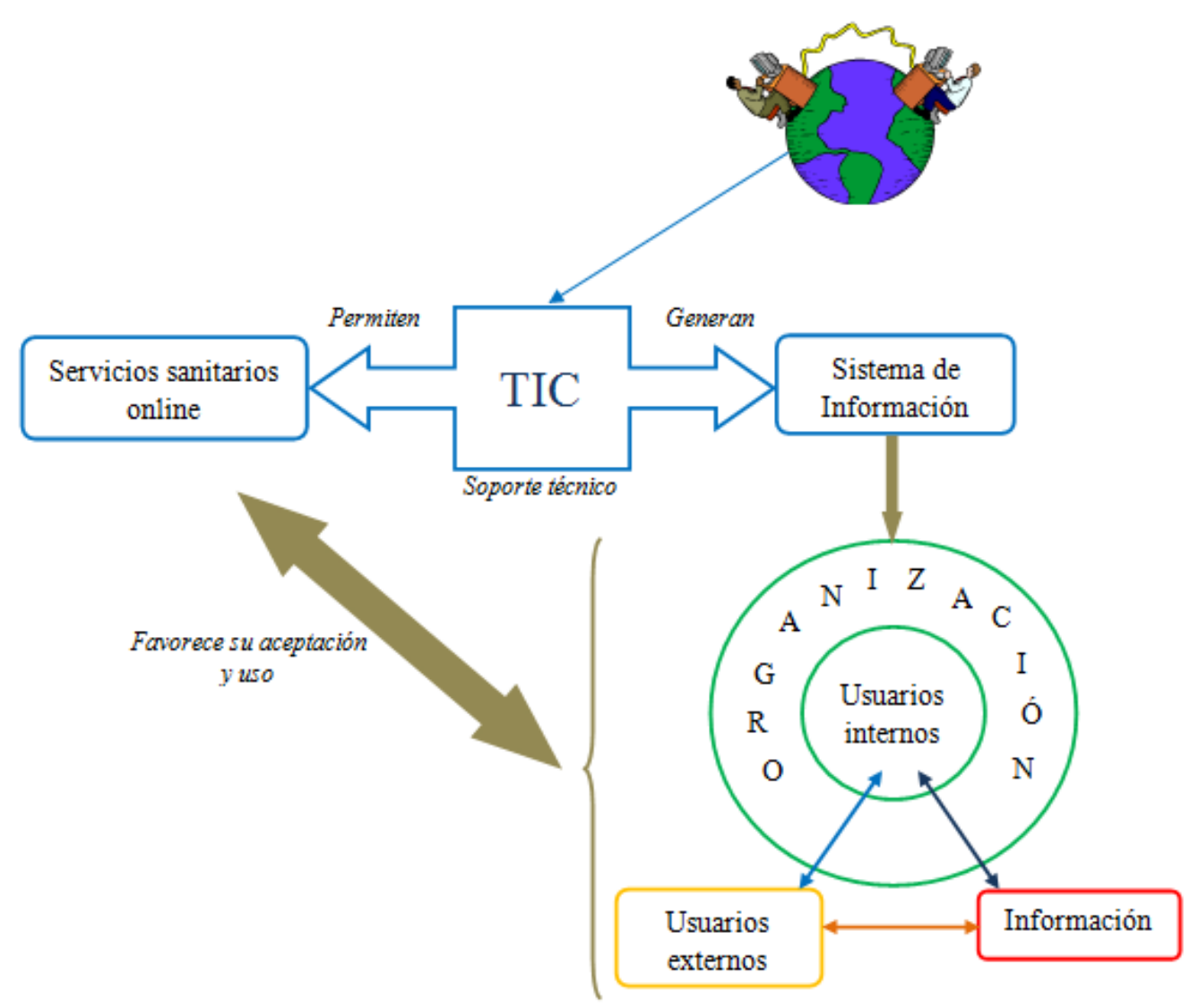

Figura 2. Modelo de relación de las TIC con el sector sanitario actual (Elaboración propia).

\section{IMPLANTACIÓN DE LAS TIC: BENEFICIOS Y BARRERAS}

Las TIC están produciendo un gran cambio en los países avanzados. Es a través de las TIC por lo que podemos hablar de una nueva forma de sociedad, la sociedad de la información y el conocimiento, donde la generación, el procesamiento y la transmisión de información se convierten en las fuentes principales de la productividad debido a las nuevas condiciones tecnológicas que surgen en este período histórico. El uso de TIC en los distintos sectores de actividad, ofrece un gran potencial para mejorar la calidad de 
los servicios y la eficiencia y efectividad del personal sanitario, pero también reducen los gastos organizacionales (Sainz et al., 2011).

Son muy pocos los que dudan de que las TIC ejerzan un considerable impacto sobre el entorno económico actual. De hecho, ya se pueden empezar a observar algunos de los cambios que estas nuevas tecnologías producen sobre el diseño de los procesos en los modelos organizacionales, los tamaños y límites de los mercados o incluso en la dinámica competitiva dentro de un sector como es el sanitario (Porter, 2001).

Es un hecho que las organizaciones sanitarias perciben la inversión en TIC como uno de los ejes estratégicos centrales de los nuevos procesos asistenciales. Las TIC permiten compaginar las actuaciones locales con los niveles de formalidad y objetividad que a menudo se demandan entre comunidades. De ahí, que las organizaciones puedan utilizar múltiples herramientas tecnológicas para almacenar conocimiento y reutilizarlo, sin embargo, de entre todas ellas, son las tecnologías de Internet las más utilizadas (Arjonilla y Medina, 2002). Pero la implantación de estas tecnologías basadas en el uso de Internet depende principalmente de la disponibilidad que tenga la organización o el centro sanitario concreto para conseguir hardware, software, telecomunicaciones e infraestructura (Nahar, 2001).

Respecto a la presencia de Internet, es de destacar que su aparición ha supuesto una ventaja para las organizaciones que la han implantado ya que, ofrece nuevas oportunidades y servicios online y su uso correcto se traduce en una eficiencia tecnológica que influye positivamente en el éxito de las organizaciones ante la consecución de los objetivos previstos (Sadowski et al, 2002; Sainz, 2011; Sainz et al., 2011). Su utilización ha sido considerada como una estrategia que mejora el 
rendimiento de la organización (Lee y Runge, 2001). Es más, el incremento que se está produciendo en el uso de Internet como canal de distribución de servicios online ha sido impactante. El factor clave de este incremento está relacionado con el grado de aceptación de las tecnologías por parte de los usuarios.

Autores como Turoff et al. (1991), Trujillo (2005) y Sainz et al. (2011) afirman que el uso de Internet también favorece a los equipos de trabajo de las organizaciones ya que les aporta herramientas para acceder a la información de manera dinámica. Sin embargo, gran parte de dichas herramientas suelen contar únicamente con capacidad de navegación por Internet y un e-mail que se utiliza para poder contactar con los usuarios de los distintos sectores. De ahí que Sainz et al. (2011) afirmen que la carencia de infraestructuras tecnológicas sea una de las barreras que impiden la implantación de las TIC en el ámbito sanitario.

Nahar (2001) presenta otra ventaja derivada del uso de las nuevas tecnologías en las organizaciones. Afirma que la continua provisión de soporte y formación de los usuarios realzará y mejorará los servicios ofrecidos a través de Internet, las relaciones entre los usuarios y también incrementará las habilidades y la eficacia de los diferentes medios de comunicación virtuales como, por ejemplo, el e-mail.

Más tarde, Nahar et al. (2002) confirman, igualmente, que los beneficios de la implantación de las TIC, posibilitan la gestión de un trabajo integrado mediante el desarrollo de nuevas formas tecnológicas que mejoran la eficacia de los servicios ofrecidos por el personal de los distintos sectores, la habilidad para acceder a información actualizada y la reducción de las barreras de distancia y tiempo. 
Por último, en lo que respecta a las ventajas de las TIC, se destaca la aportación realizada por Malhotra (2000). Este autor afirma que las TIC aportan otra ventaja, y es que la información solicitada está disponible en el tiempo acordado. Sin embargo, la interpretación que los individuos hagan de la misma, va a afectar a las percepciones que los individuos tengan sobre el uso de las TIC. Estas circunstancias sugieren que es necesario la formación de los individuos para proveerles de un conocimiento que facilite la integración de tecnologías en la organización (Gold et al., 2001). Sin ello, la inclusión de las TIC supondría un problema para el sector sanitario y para el resto de sectores de la sociedad.

Estas circunstancias sugieren que las inversiones en TIC deben ir acompañadas de compromiso y del conocimiento necesario sobre la utilización de las mismas. De lo contrario, a pesar de realizar inversiones millonarias en ellas, puede ocurrir que los individuos no tengan la formación, compromiso e intención necesarios para utilizarlas. Como consecuencia, la implantación de las tecnologías no sólo aporta ventajas para las organizaciones, sino que pueden existir barreras que impidan su aceptación por parte de los usuarios externos e internos de cualquier organización (Trujillo, 2005; RuedaClausen, 2006; Sainz, 2011; Sainz et al., 2011).

La aparición de las TIC ha supuesto cambios significativos en la organización interna de los centros sanitarios en general, tales como nuevos servicios sanitarios y nuevas formas de relacionarse entre los usuarios externos (pacientes, cuidadores, familiares) e internos (personal sanitario) (Sainz et al., 2011). A su vez, ha necesitado de la integración y cooperación tanto de los usuarios internos, como de los externos a la organización para intercambiar la información de la que disponen. Esto ha supuesto una 
barrera para los centros sanitarios ya que no todos los usuarios aceptan los cambios que la implantación de las TIC conlleva en los procesos asistenciales (Rueda-Clausen, 2006; Sainz, 2011). De ahí que podamos afirmar la necesaria existencia de un contexto que permita la adaptación del conocimiento de los usuarios a la operativa de los centros. Se trata de una condición previa y necesaria para vencer y superar esta barrera organizacional sometida a la interpretación subjetiva de los agentes que participan activamente en dicho sector.

Con motivo de la necesidad que supone en la sociedad la implantación de las nuevas tecnologías, se hace necesario, en muchas ocasiones, la estandarización de las aplicaciones electrónicas con el fin de poder establecer formatos de intercambio de datos e información entre las distintas aplicaciones y sistemas operativos, lo cual supone una nueva barrera de carácter técnico en los centros sanitarios. De cualquier forma, es necesaria la adaptación de los medios de que dispone la sanidad pública a las nuevas tecnologías, ya que se trata de un factor decisivo para la viabilidad de nuevas gestiones sanitarias a través de las TIC.

No obstante, el paso del tiempo y los estudios realizados hasta el momento han dejado de relieve que la implantación de las tecnologías es un proceso más complejo de lo que puede parecer. Y es que, para implantar las TIC, las organizaciones necesitan cumplir una serie de requisitos que permitan abordar sus actuaciones de forma efectiva.

Estos requisitos están relacionados con los siguientes puntos:

- Capacitar y motivar a los usuarios en la aceptación del uso de las TIC. 
- Formar a los usuarios externos y/o internos de una organización para las nuevas prácticas y servicios sanitarios.

- Es necesario que los usuarios externos se apoderen de la tecnología como de una herramienta más de su práctica cotidiana, adaptando sus usos a las reglas ya presentes y proponiendo nuevas normas.

- Incentivar la necesidad de un cambio en los actuales procesos sanitarios.

- Los pacientes deben percibir la accesibilidad a la información como una herramienta fiable y segura que no permita distorsionar la información disponible en la web.

- Disponer económicamente de los medios necesarios para hacer frente al rediseño de los nuevos procesos que requiere el uso de servicios virtuales.

- Todos los centros sanitarios deben tener acceso a Internet para poder acceder al sistema y a la información necesaria en cada momento. Aún así, los problemas que surgen ante la práctica de Internet son numerosos debido a que se trata de sistemas innovadores que requieren de un largo periodo de tiempo para hacer frente a la totalidad de los cambios tecnológicos. Además, supone un cambio en el papel activo de los pacientes y del personal sanitario ante las nuevas prácticas virtuales que fomentan la eficiencia, efectividad y una mejor relación de coste/beneficio.

De ahí, que el no cumplimiento de estos requisitos pueda provocar problemas organizacionales entre los usuarios de las TIC, suponiendo una fuerte barrera que va a impedir la aceptación de las TIC por parte de aquellos miembros que vean dificultada la práctica de sus actuaciones cotidianas en la organización. Es por ello que se hace 
necesaria la aceptación de las TIC por parte de todos aquellos agentes y usuarios que pueden hacer uso de las mismas en el desarrollo de sus actividades (Sainz, 2011).

El estado inicial de la implantación de las TIC puede ser difícil pero si se considera que la mayoría de los obstáculos técnicos son eliminados gradualmente, la cuestión queda resumida al hecho de que los usuarios estén dispuestos a hacer uso de estas nuevas tecnologías (Aggelidis y Chatzoglou, 2009).

La falta de aceptación de las TIC ha sido un impedimento y una barrera para el éxito de los nuevos sistemas de información (Nickerson, 1981; Gould et al., 1991; McCarrol, 1991). A menudo, el factor determinante del éxito o fracaso de los proyectos de un sistema de información depende de la aceptación o rechazo del uso de las TIC (Davis, 1993).

Por tanto, la aceptación de las TIC ha sido objeto de estudio durante varias décadas (Igbaria, 1993). Por un lado, Venkatesh (2000) destaca que el incremento del rendimiento de los centros sanitarios viene motivado por la implantación de las TIC, sin embargo, si los sistemas tecnológicos fallan, podrían producirse importantes consecuencias para la sanidad como la pérdida financiera y principalmente, la insatisfacción entre los usuarios externos. Por otro lado, numerosos estudios han confirmado que la actitud positiva de los usuarios hacia la aceptación de las TIC repercute sobre el éxito de las organizaciones sanitarias (Al-Gahtani y King, 1999), el incremento de la productividad y el rendimiento de los empleados y de la organización (Davis et al., 1989; Venkatesh y Davis, 1996; Al-Somali et al., 2009). 
Según Al-Gahtani y King (1999), la habilidad para identificar, predecir y dirigir la aceptación de las personas hacia los nuevos sistemas de información basados en el uso de TIC, es el factor clave que permitirá la implantación y éxito de las TIC. Consecuentemente, existe una gran área de estudio dedicada a la investigación de la aceptación de las tecnologías.

\section{GESTIÓN DEL CONOCIMIENTO}

\subsection{EL CONOCIMIENTO}

En este momento, el factor que permite diferenciar y conseguir ser más competitivas a las organizaciones y a los diferentes sectores de la sociedad es "el conocimiento", que se encuentra no sólo en las empresas sino en las personas que integran las mismas.

Estamos en una economía altamente competitiva y cambiante, en la que únicamente sobreviven las organizaciones que crean nuevos conocimientos, los difunden e incorporan rápidamente a nuevos procesos, servicios y productos que son demandados principalmente por los individuos de la sociedad. Ante esto, el conocimiento se presenta como un recurso estratégico clave para competir eficazmente, por lo que saber cómo se genera, transmite y mantiene el conocimiento en la 
organización es imprescindible para aprovechar esta fuente de producción de valor (Grant, 2001).

Se trata, en definitiva de un nuevo contexto organizacional en el que la mejor fuente para obtener un recurso estratégico es el conocimiento y por tanto, la gestión del mismo. Según Serradel y Pérez (2006), esto explica la aparición de la denominada era de la información y sociedad del conocimiento, así como la aparición de la disciplina sobre la gestión del mismo y de un conjunto de categorías asociadas cuya conceptualización es casi imprescindible dominar para su adecuado manejo.

La sociedad del conocimiento consiste en la creación de capacidades estables para construir y aplicar conocimiento para el desarrollo humano y esto, a su vez, se basa en las capacidades para identificar, producir, procesar, transformar, diseminar y usar información (Núñez, 2009), una información cuya base procede del análisis de las necesidades del entorno.

La información se convierte en la herramienta que alimenta el conocimiento y es procesada por éste. En concreto, el conocimiento no puede funcionar por sí solo, sino que necesita procesar la información disponible para crear nuevos conocimientos o información de más valor para lograr un determinado objetivo (Rivero, 2002).

Ante lo anteriormente expuesto, la importancia del conocimiento como recurso estratégico y factor de ventaja competitiva sostenible supone un cambio en la forma de concebir la gestión de las organizaciones y, por tanto, la de los sistemas de dirección. Por ello, las organizaciones, conscientes de la necesidad de adaptación como clave de la 
supervivencia, han apostado por una constante y clara vocación hacia el aprendizaje ${ }^{18}$ continuo, elemento que les permite desarrollar una respuesta organizativa adecuada (Weerawardena et al., 2006; Hsu y Pereira, 2008), diferenciarse y obtener mejores resultados financieros y no financieros (Bapuji y Crossan, 2004; Jiménez y Cegarra, 2007; Skerlavaj et al., 2007), así como lograr ventajas competitivas sostenibles en el largo plazo (Kandemir y Hult, 2005; Kang et al., 2007).

Además, debemos considerar que el conocimiento es un conglomerado de creencias sobre cómo funcionan las cosas, teniendo en cuenta una relación causa y efecto. En este sentido cuando en el entorno o en la organización se producen cambios, se genera un desajuste en el conocimiento que estimula el desarrollo de los procesos de aprendizaje necesarios para propiciar el nuevo conocimiento que, una vez incorporado al conocimiento inicial, reduzca o elimine el desajuste anterior (Dixon et al., 2007). Consecuentemente, los procesos de aprendizaje generan un cambio en el conocimiento que acontece por medio de ajustes.

El conocimiento no ha surgido de la nada, obviamente, se ha encontrado siempre en todas las actividades que realizamos los humanos. Ha pasado por varias etapas, y su emergencia al primer plano ha sido el resultado de una serie de hechos que tienen lugar con la aparición de las TIC, lo que provoca la globalización ${ }^{19}$, que trae consigo una

18 El aprendizaje es el proceso que permite a los individuos adquirir conocimientos de su ambiente y sus relaciones en el transcurso de su vida. El aprendizaje está asociado además, a las capacidades individuales como la inteligencia, la memoria, la motivación, la necesidad y factores psicosociales como el comportamiento, las relaciones interpersonales, entre otros (Chiavenato, 1999).

${ }^{19}$ La globalización es un proceso económico, tecnológico, social y cultural a gran escala, que consiste en la creciente comunicación e interdependencia entre los distintos países del mundo unificando sus mercados, sociedades y culturas, a través de una serie de transformaciones sociales, económicas y políticas que les aporte un carácter global. 
mayor competencia a todos los niveles. No obstante, para competir hay que innovar y el principal motor de la innovación es el conocimiento.

Por otro lado, el fenómeno de la globalización es, hoy día, uno de los factores que más afectan al entorno genérico en el que operan algunas organizaciones. La globalización es el acto social de reproducir una cultura global e implica un proceso para las empresas de reestructuración de sus organizaciones para adaptarlas a escala mundial (Go, 1998). Según Smeral (1998), el término globalización se refiere al incremento en la interdependencia de los mercados y la producción en diferentes países a través del comercio de bienes y servicios, flujos internacionales de capital, alianzas estratégicas internacionales, cooperaciones, adquisiciones e intercambios de tecnología.

Para Qureshi (1996), la globalización es un fenómeno que se ve impulsado por la tendencia generalizada hacia la liberalización del comercio y los mercados de capital, la creciente internalización de las estrategias empresariales de producción y distribución y el avance tecnológico, gracias al cual se están eliminando rápidamente los obstáculos al intercambio de capital.

Algunas de las causas que motivan la globalización a diferentes factores son: la integración vertical y diagonal de la industria, la profesionalización de sus recursos humanos, el desarrollo de I+D+I a escala internacional, compartir Know-How ${ }^{20}$ o lo que es lo mismo, el saber hacer de las distintas organizaciones o de los diferentes sectores económicos de la sociedad, tal es el caso del sector sanitario, así como la rápida difusión y utilización de las nuevas tecnologías de la información y la comunicación que "saber hacer".

20 Know-How es una forma de transferencia de tecnología. Se traduce literalmente por "saber-cómo" o 
permiten la mejor coordinación entre las organizaciones, o entre los usuarios externos y/o internos de las mismas (por ejemplo, la comunicación vía e-mail entre doctores y pacientes, petición de citas telemáticas, etc.) (Weiermair, 1997).

\subsection{LA GESTIÓN DEL CONOCIMIENTO}

La gestión del conocimiento es un campo de investigación y acción de carácter interdisciplinar que surgió a partir de la integración de conocimientos procedentes de la psicología, la sociología, la administración de empresas, la economía, la informática y las ciencias de la documentación, entre otras disciplinas, en torno al problema de la administración del conocimiento en las organizaciones.

La gestión del conocimiento aparece como concepto clave para asegurar la competitividad en una sociedad en la que existe fácil acceso a los mercados de capital, trabajo, productos y servicios. Efectivamente, la abundancia de los recursos disponibles en el mercado hace que las empresas dependan menos de los recursos tradicionales humanos, materiales y financieros-y que su ventaja competitiva proceda sobre todo por la idiosincrasia ${ }^{21}$ de su comprensión de las demandas y ofertas existentes en la sociedad y de sus planes para aprovechar esa comprensión de forma pertinente e innovadora. o colectivo.

${ }^{21}$ Idiosincrasia es la personalidad, singularidad, naturaleza o los propios rasgos que definen a un individuo 
En definitiva, la información asimilada, el conocimiento, se convierte en la ventaja competitiva clave de cualquier organización — pública o privada - en el nuevo entorno social (García, 2003).

En la pasada década se han realizado amplias investigaciones sobre conocimiento y gestión de conocimiento. Con el rápido crecimiento de la nueva economía ${ }^{22}$, la gestión del conocimiento se ha desarrollado gradualmente en un campo académico independiente y un gran número de investigadores han comenzado a investigar sobre la misma (Marymalavi y Leidner, 2006; Bontis y Serenko, 2009; Serenko y Bontis, 2009).

Esta gestión ha evolucionado como una respuesta necesaria a las condiciones de las organizaciones. En los entornos organizacionales actuales de rápido cambio, las organizaciones deben encontrar nuevas formas de utilizar el conocimiento del que disponen, es por esto por lo que se puede decir que es indispensable gestionar el conocimiento.

La gestión del conocimiento se centra en descubrir lo que una organización ya conoce, cómo localizar a las personas que poseen conocimientos específicos y cómo puede la organización distribuir este conocimiento para que se use de una forma efectiva. En definitiva, se ocupa de proporcionar el conocimiento apropiado a las personas apropiadas en el momento apropiado para que puedan tomar sus decisiones y evitar errores o duplicaciones del trabajo (King, 2009).

22 El término nueva economía fue acuñado por el economista Brian Arthur, aunque fue popularizado principalmente por Kevin Kelly y se refiere a la evolución económica, en los Estados Unidos y otros países desarrollados, de una economía basada principalmente en la fabricación y la industria a una economía basada en el conocimiento, debido en parte a los nuevos progresos en tecnología y en parte a la globalización económica. 
Davenport y Prusak (1998) la definen como "el proceso sistemático de buscar, organizar, filtrar y presentar la información con el objetivo de mejorar la comprensión de las personas en una específica área de interés".

Según Maestre (2000) la gestión del conocimiento es "un conjunto de procedimientos, reglas y sistemas destinados a captar, tratar, recuperar, presentar y transmitir datos, informaciones y conocimientos de una organización”.

Para Malhotra (2002) la gestión del conocimiento involucra "el proceso organizacional que busca la combinación activa del tratamiento de datos e información a través de las capacidades de las tecnologías de información, en conjunto con las capacidades de creatividad e innovación de los seres humanos".

A su vez Rivero (2002) entiende por gestión del conocimiento, "el conjunto de prácticas, técnicas y procedimientos que permiten a una organización, identificar los conocimientos requeridos para llevar a cabo sus actividades actuales y futuras, además de los posibles cambios inesperados, conseguir hacerse con dichos conocimientos y aplicarlos de modo apropiado para conseguir los resultados deseados. La gestión del conocimiento evoluciona como una respuesta necesaria a las condiciones empresariales".

Para Ortiz de Urbina (2003), la gestión del conocimiento es el "conjunto de procesos que utilizan el conocimiento para la identificación y explotación de los recursos intangibles existentes en la empresa, así como para la generación de otros nuevos. Viene dado por la unión de las actividades e iniciativas específicas que se llevan a cabo para incrementar su volumen de conocimiento corporativo". 
Tanriverdi (2005) define la gestión del conocimiento como "una capacidad organizacional a través de la cual, las tecnologías de la información pueden influir en los resultados de una organización”. De igual forma, desde el punto de vista de las empresas multinacionales ${ }^{23}$, el estudio realizado por Tanriverdi (2005) examina cómo las tecnologías de la información de una empresa deben ser organizadas y dirigidas para mejorar la gestión del conocimiento de una organización y cómo la gestión del conocimiento influye en el rendimiento de la misma.

Más tarde, King (2009), basándose en la premisa de que al igual que los seres humanos no son capaces de aprovechar todo el potencial de su cerebro, las organizaciones generalmente no son capaces de aprovechar al máximo los conocimientos que poseen. Por ello, define la gestión del conocimiento como "el medio que permite a las organizaciones adquirir y crear conocimientos útiles, y hacer que éste esté disponible en el tiempo y lugar apropiado para lograr la mayor efectividad en el uso del mismo, con la finalidad de influir positivamente en el funcionamiento de la organización".

Según González (2010), la gestión del conocimiento se ha convertido en un instrumento básico para la gestión empresarial, incorpora las actuaciones orientadas a identificar y procurar los criterios y herramientas necesarios para aquellos empleados y profesionales de las organizaciones que se enfrentan a la difícil tarea de optimizar el control y gestión de su factor de producción más relevante.

23 La empresa multinacional se caracteriza por tener como ámbito de actuación el escenario global, independientemente de su tamaño, sector económico o actividad. Lo importante de estas empresas es la mentalidad que tienen, así como que superen las barreras y entiendan el mundo globalizado como el escenario actual donde desarrollar sus acciones empresariales (De León, 2009). 
Identifica y explota el conocimiento creado en la organización y el adquirido del exterior, generalizando las mejores prácticas, propiciando el incremento del capital intelectual $^{24}$ de la organización y su valor en el mercado, facilitando, la creación de nuevos conocimientos y su materialización en productos y servicios. Este proceso permite además, potenciar la imaginación, masificar la cultura tecnológica, ampliar la cultura general integral para integrar y aplicar los conocimientos adquiridos por la sociedad, cambiar el modo en que las personas trabajan y la manera en que usan y crean información.

Por lo tanto, para González (2010), gestionar el conocimiento implica determinar los conocimientos, incrementarlos y explotarlos para ganar magnitud competitiva; el hecho de compartir el conocimiento en la empresa propicia que aumenten sus niveles de rentabilidad y se cree un nuevo valor para el negocio, al unir a los integrantes de la organización y aprovechar sus conocimientos. Entre sus premisas fundamentales están: la eficiencia como objetivo central económico, el crecimiento y desarrollo, el empleo de técnicas modernas de dirección empresarial y el uso y conservación de los conocimientos adquiridos por los trabajadores.

A continuación se muestra la tabla 2, que contiene algunas de las definiciones realizadas a lo largo de los años por diversos autores.

\footnotetext{
${ }^{24}$ El capital intelectual es una expresión que combina, siguiendo a Edvinsson y Malone (1999), dos ideas fundamentales: la inteligencia o los resultados provenientes del ejercicio intelectual y la valoración de los empleados para explicar el capital financiero. Representa el valor total de los activos intangibles que posee la empresa en un momento dado del tiempo (se trata de documentos estáticos), igual que en su balance "habitual" aparece el valor de su recursos propios o el equivalente financiero de sus activos tangibles netos (Sanguino, 2003).
} 
Tabla 2. Definiciones sobre Gestión de Conocimiento.

\begin{tabular}{|c|c|c|}
\hline$A \tilde{N} O$ & AUTOR & DEFINICIÓN \\
\hline 1991 & Hubert & $\begin{array}{l}\text { Es la habilidad de desarrollar, mantener, influenciar y renovar los } \\
\text { activos intangibles, es decir, capital de conocimiento o capital } \\
\text { intelectual. }\end{array}$ \\
\hline 1998 & $\begin{array}{l}\text { Davenport y } \\
\text { Prusak }\end{array}$ & $\begin{array}{l}\text { Es el proceso sistemático de buscar, organizar, filtrar y presentar la } \\
\text { información con el objetivo de mejorar la comprensión de las } \\
\text { personas en una específica área de interés. }\end{array}$ \\
\hline 1999 & Arteche y Rozas & $\begin{array}{l}\text { Es el entorno dentro de una organización que permite la recogida, } \\
\text { agregación, gestión, distribución y análisis de un juego equilibrado de } \\
\text { información, para orientar positivamente las decisiones de los } \\
\text { gestores. }\end{array}$ \\
\hline 2000 & Maestre & $\begin{array}{l}\text { Conjunto de procedimientos, reglas y sistemas destinados a captar, } \\
\text { tratar, recuperar, presentar y transmitir datos, informaciones y } \\
\text { conocimientos de una organización. }\end{array}$ \\
\hline 2002 & Malhotra & $\begin{array}{l}\text { El proceso organizacional que busca la combinación activa del } \\
\text { tratamiento de datos e información a través de las capacidades de las } \\
\text { tecnologías de información, en conjunto con las capacidades de } \\
\text { creatividad e innovación de los seres humanos. }\end{array}$ \\
\hline 2002 & Rivero & $\begin{array}{l}\text { Conjunto de prácticas, técnicas y procedimientos que permiten a una } \\
\text { organización, identificar los conocimientos requeridos para llevar a } \\
\text { cabo sus actividades actuales y futuras, además de los posibles } \\
\text { cambios inesperados, conseguir hacerse con dichos conocimientos y } \\
\text { aplicarlos de modo apropiado para conseguir los resultados deseados. } \\
\text { La gestión del conocimiento evoluciona como una respuesta } \\
\text { necesaria a las condiciones empresariales. }\end{array}$ \\
\hline 2003 & Sanguino & $\begin{array}{l}\text { Refleja la dimensión creativa y operativa de la forma de generar y } \\
\text { difundir el conocimiento entre los miembros de la organización y } \\
\text { también con otros agentes relacionados. }\end{array}$ \\
\hline 2005 & Ditzel & $\begin{array}{l}\text { Implica identificación y transferencia de información de utilidad, } \\
\text { haciéndola accesible para quienes la necesitan para aplicarla con un } \\
\text { objetivo concreto. }\end{array}$ \\
\hline 2005 & Jardines & $\begin{array}{l}\text { El conocimiento es una herramienta crítica para la salud. } \\
\text { Posiblemente, en ningún otro sector la gestión del conocimiento } \\
\text { tenga tan decisiva importancia, si se entiende por gestión del } \\
\text { conocimiento en salud como la capacidad de traducir el conocimiento } \\
\text { en políticas, programas y prácticas que mejoren la calidad y la } \\
\text { esperanza de vida. }\end{array}$ \\
\hline 2005 & Tanriverdi & $\begin{array}{l}\text { Capacidad organizacional a través de la cual, las tecnologías de la } \\
\text { información pueden influir en los resultados de una organización. }\end{array}$ \\
\hline 2007 & Arias & $\begin{array}{l}\text { Proceso sistemático y organizacional para adquirir, construir y } \\
\text { comunicar conocimiento entre miembros de una organización, } \\
\text { haciendo uso del conocimiento previamente generado, para ser más } \\
\text { efectivos y eficientes en sus labores; a la vez, manteniendo una } \\
\text { dinámica continua de construcción de nuevo conocimiento. }\end{array}$ \\
\hline 2008 & Berrocal y Pereda & $\begin{array}{l}\text { La gestión del conocimiento obtenido en un momento y lugar } \\
\text { determinado, permite trasladar y aplicar dicho conocimiento a otro } \\
\text { lugar y momento para obtener los resultados esperados, en menos } \\
\text { tiempo y con menos errores. }\end{array}$ \\
\hline
\end{tabular}




\begin{tabular}{|c|l|l|}
\hline 2008 & Guerra & $\begin{array}{l}\text { Implica una habilidad basada en un equipo entrenado de personas, un } \\
\text { proceso determinado previamente y una tecnología adecuada que } \\
\text { permite capturar y aplicar pensamientos e ideas. La gestión del } \\
\text { conocimiento conecta las necesidades de conocimiento con la } \\
\text { estrategia de la empresa, dando acceso y representando el saber } \\
\text { individual y organizativo, haciendo que como activo cree valor por sí } \\
\text { mismo al ser aplicado en un proceso determinado. }\end{array}$ \\
\hline 2009 & King & $\begin{array}{l}\text { Medio que permite a las organizaciones adquirir y crear } \\
\text { conocimientos útiles, y hacer que éste esté disponible en el tiempo y } \\
\text { lugar apropiado para lograr la mayor efectividad en el uso del mismo, } \\
\text { con la finalidad de influir positivamente en el funcionamiento de la } \\
\text { organización }\end{array}$ \\
\hline 2010 & González & $\begin{array}{l}\text { Instrumento básico para la gestión empresarial, incorpora las } \\
\text { actuaciones orientadas a identificar y procurar los criterios y } \\
\text { herramientas necesarios para aquellos empleados y profesionales de } \\
\text { las organizaciones que se enfrentan a la difícil tarea de optimizar el } \\
\text { control y gestión de su factor de producción más relevante. Identifica } \\
\text { yexplota el conocimiento creado en la organización y el adquirido } \\
\text { del exterior, generalizando las mejores prácticas, propiciando el } \\
\text { incremento del capital intelectual de la organización y su valor en el } \\
\text { mercado, facilitando, la creación de nuevos conocimientos y su } \\
\text { materialización en productos y servicios. }\end{array}$ \\
\hline
\end{tabular}

Fuente: Elaboración propia.

Después de analizar las definiciones sobre gestión del conocimiento anteriormente expuestas, se observa que la concepción de cómo gestionar el conocimiento ha evolucionado cronológicamente y que no existe una definición reconocida internacionalmente del término. Para unos es un proceso, un conjunto de procesos, para otros es una disciplina, e incluso un método.

Lo que sí queda claro es la importancia creciente que tiene para el ámbito empresarial, académico y para toda la sociedad, el manejo adecuado de los conocimientos desde su captura, procesamiento, y transmisión, a fin de contribuir al desarrollo social y alcanzar niveles de competitividad (González, 2010).

La competición global, distribución rápida de productos y servicios y otras actitudes de mercado han convertido la distribución de conocimiento y su utilización en 
una necesidad organizacional para cualquier sector, por ejemplo, el sanitario. Al mismo tiempo, las organizaciones cubren la demanda del mercado con más servicios y productos basados en el conocimiento. En los entornos organizacionales actuales de rápido cambio, las organizaciones deben encontrar nuevas formas de utilizar el conocimiento del que disponen.

Es por ello, que la gestión del conocimiento requiere algo más que la mera distribución de información. Debe proporcionar también las bases para el aprendizaje y para utilizar dicho aprendizaje; esto es, la habilidad para crear inteligencia y finalmente comportamientos instintivos.

La importancia del aprendizaje en el conocimiento y en la gestión del mismo ha sido objeto de estudio durante años. Bueno (2002), definió la gestión del conocimiento, relacionándolo con el aprendizaje organizacional, como un enfoque global que integra los conceptos claves que se han derivado de las tres palabras protagonistas de la sociedad del conocimiento (información, conocimiento y aprendizaje) como son el capital intelectual, la gestión del conocimiento y el aprendizaje organizativo, alineados con la estrategia de la organización. Esta propuesta de naturaleza estratégica ha sido concretada en la denominada triada conceptual (figura 3). Su análisis define que el aprendizaje organizativo, la gestión del conocimiento y el capital intelectual son conceptos relacionados y complementarios. 


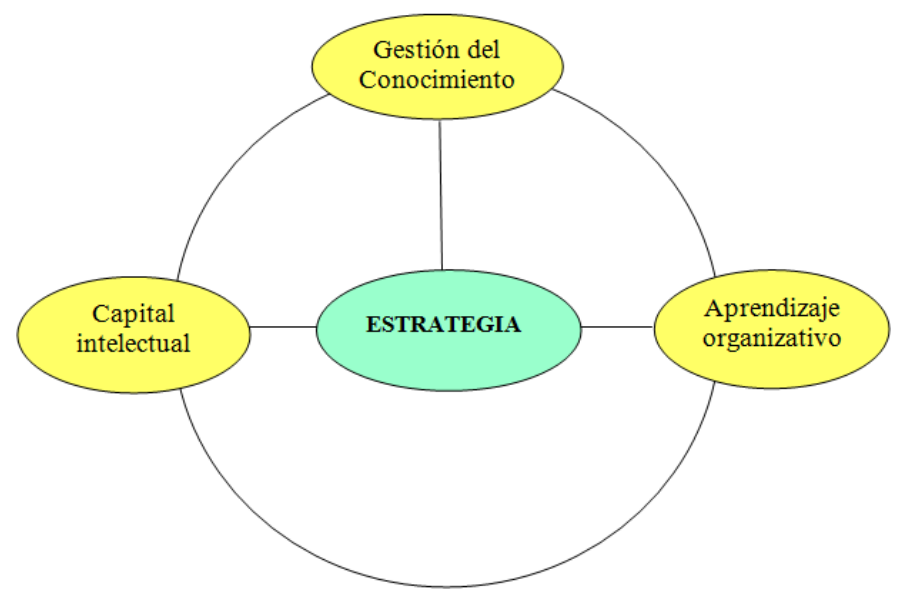

Figura 3. La triada conceptual (Bueno, 2002)

Ese mismo año, Aja (2002) planteó que las organizaciones basadas en el aprendizaje soportan su desarrollo en la gestión de información, son por excelencia organizaciones de conocimiento, que aprenden con sentimientos de pertenencia, de colectivo, que perfeccionan su cultura como organización, independientemente de su ejecutividad, competitividad y ganancia, que se regeneran a sí mismas mediante la creación de conocimientos, a partir de un aprendizaje a nivel de sistema. En la gestión del conocimiento existen factores comunes, imprescindibles para la supervivencia y el progreso de cualquier organización, entre los cuales se identifican la innovación, la capacidad de respuesta, la productividad y la competencia.

Por ende, el aprendizaje organizativo es la base de una buena gestión del conocimiento, y este conocimiento es la base para la generación de capital intelectual, capacidades organizativas (Caraballo et al., 2009). Una vez que la gestión del conocimiento sea parte concreta de la organización, los demás procesos (gestión del capital intelectual y adquisición del aprendizaje institucional) serán reconocidos por 
todos los miembros de la organización y evidentemente la institución estará en condiciones de aprender más, mediante un proceso de mejora continua. Los beneficios que se consiguen de la gestión del conocimiento propician el mejoramiento de los servicios y productos de una institución, en la medida en que éstos son el resultado del conocimiento existente tanto en el entorno como en el plano interno organizativo (Caraballo et al., 2009).

Estas consideraciones nos permiten justificar la interacción de la gestión de conocimiento con el paciente y el uso que éste hace de las tecnologías ante el desarrollo de los servicios sanitarios online. Y es que la gestión del conocimiento y sus empleos, la identificación, adquisición y creación de nuevo conocimiento, son frecuentemente citadas como los antecedentes necesarios para que se pueda proceder de manera eficiente a la implantación de los sistemas tecnológicos en el sistema sanitario (Choo, 1996).

\subsubsection{La gestión del conocimiento en el sector sanitario.}

Hoy día, se sabe que el dinamismo de la economía y de las organizaciones tiene su origen en la innovación de los conocimientos; precisamente por ello es necesaria su gestión (Otero, 2003).

La gestión del conocimiento se ha definido como una estrategia que convierte los valores intelectuales de las organizaciones en mayor productividad, valor añadido e 
incremento de la competitividad. Por ende, la gestión del conocimiento en una organización consistiría en la producción, distribución, almacenamiento, evaluación, disponibilidad, transferencia y puesta en práctica del conocimiento. Este conocimiento sería el resultado, tanto de la información proveniente del exterior, como de la creada por los propios componentes de la organización (Bravo, 2002)

En sanidad, como en otras organizaciones de servicios, el fin de la gestión del conocimiento sería distinto y podríamos decir que los objetivos serían mejorar la calidad asistencial, la equidad en la provisión de servicios, y la eficiencia en la gestión y como meta final, aumentar el nivel de salud de los ciudadanos (Davenport y Glaser, 2002).

En relación con el paciente, la gestión del conocimiento está relacionada con la información que se ofrece al mismo, el conocimiento que éste de forma individual o colectiva, puede aportar a las organizaciones sanitarias y la influencia de las nuevas tecnologías en aspectos como la relación médico - paciente o la organización de la asistencia sanitaria (Bravo, 2002).

Por tanto, los servicios sanitarios, por su naturaleza y función, pueden ser caracterizados como organizaciones intensivas en conocimiento. Este conocimiento se genera, difunde, almacena y aplica de forma individual y colectiva, en un entramado de interacciones sociales e interdependencias funcionales que es preciso definir, integrar, facilitar, encauzar y evaluar desde la función de gestión de conocimiento. Además, el conocimiento es el único activo fijo que proporciona ventajas distintivas y competitivas, a medio y largo plazo, que aumenta progresivamente su valor y que además no se agota 
cuando se socializa o utiliza en el entorno de trabajo; al contrario de lo que ocurre con otros bienes físicos (Otero, 2003).

Consecuentemente el conocimiento es una herramienta crítica para la salud. Posiblemente, en ningún otro sector la gestión del conocimiento tenga tan decisiva importancia, si se entiende por gestión del conocimiento en salud como la capacidad de traducir el conocimiento en políticas, programas y prácticas que mejoren la calidad y la esperanza de vida (Jardines, 2005).

En el actual sistema de salud, el conocimiento científico ${ }^{25}$ sobre la mejor manera de prestar asistencia no se pone en práctica ni inmediatamente ni sistemáticamente (Balas et al., 2000). Por tanto, el reto no está únicamente en crear nuevo conocimiento, sino también en organizarlo de manera que esté accesible. En consecuencia, el desafío está en ser capaces de desarrollar un sistema que pueda establecer modos para acceder a ese conocimiento ya existente. Todo ello necesita de un conocimiento básico sobre cómo llevar a cabo esta tarea y, cuando ésta se realice, crear incentivos adecuados que permitan compartir el conocimiento y que éste se difunda (Cepeda et al., 2010). El aspecto esencial a tener en cuenta a la hora de identificar y compartir prácticas eficientes está en el aprendizaje y reutilización del conocimiento y en evitar las pérdidas del mismo. (Cepeda et al., 2010).

Así, los conceptos capital intelectual, gestión del conocimiento y aprendizaje organizativo, que se representan en la «triada» conceptual (Bueno, 2002), permiten comprender mejor la complejidad del proceso dinámico de creación, integración,

${ }^{25}$ El conocimiento científico es un saber crítico, fundamentado, metódico, verificable, sistemático y racional que explica y predice hechos por medio de leyes. Es crítico porque trata de distinguir lo verdadero de lo falso. Se distingue por justificar sus conocimientos y por aportar pruebas que evidencien la realidad. 
transferencia, transformación, almacenamiento y renovación del conocimiento organizativo. Como señala Bueno (2002), «el capital intelectual permite explicar la eficacia del aprendizaje organizativo y evaluar la eficiencia de la gestión del conocimiento».

Esto es posible si el sistema de aprendizaje organizativo se constituye y revitaliza continuamente para incrementar las bases del capital intelectual, además, debe ser coherente con la propia misión de las instituciones sanitarias, ya que este hecho sería clave para que las personas y la organización pudiesen transformar la información en conocimiento (Bañegil y Sanguino, 2008). De igual modo, la gestión del conocimiento debe encargarse de determinar cómo el capital intelectual puede ser generado, aplicado y transferido (Swee, 2002; Rodríguez et al., 2008).

El papel del capital intelectual ha sido clave en el sector sanitario. Uno de sus integrantes, el capital humano, ha permitido a lo largo de los años, un constante intercambio de datos, que se estructuran como información médica y que se aplican como conocimientos de salud por las personas y las organizaciones del sector. De manera que la calidad de la atención, la docencia, las investigaciones y la administración de salud dependen en gran medida del uso adecuado de la información y de la gestión sistemática del conocimiento (Correa, 2009; Caballero, 2010; De Marco et al., 2010; González et al., 2010).

Es por ello, que autores como Vázquez y Hermida (2012) afirman que un buen profesional de la salud debe ser capaz de generar, codificar y transferir el conocimiento, 
para llevarlo desde lo tácito $^{26}$ hasta lo explícito $^{27}$ y viceversa. Esto permite que la información sea compartida, utilizada, valorada y asimilada por otros compañeros y otras organizaciones de las ciencias médicas. De ahí que la gestión de la información y el conocimiento se consideren como procesos que se desarrollan de manera simultánea, recopilando y administrando el conocimiento desde el lugar donde se genera hasta el lugar en que se va a usar (Balbón y Fernández, 2006; Santos et al., 2006).

El sector sanitario ha sido un sector de especial interés para el desarrollo e implantación de programas de gestión del conocimiento (Cepeda et al., 2010), ya que se caracteriza por un uso intensivo de información y una amplia transferencia de conocimiento, consecuencia tanto de su importante y relevante base científica como de la amplia gama de servicios altamente especializados que presta (Oteo y Repullo, 2003).

Actualmente, la transferencia de conocimiento en el ámbito sanitario se produce en un entorno caracterizado por el cambio constante, donde la sobrecarga de información convive con unas posibilidades inéditas de acceso al conocimiento (García, 2003). De ahí que el ámbito sanitario haya sido identificado como un campo privilegiado para aplicar y promover la gestión del conocimiento teniendo en cuenta las oportunidades que la sociedad del conocimiento ofrece en dicho ámbito para facilitar y gestionar la creación, transferencia y almacenamiento del mismo (García, 2003).

No obstante, la inversión en investigación en el área de la salud es notoriamente insuficiente; en parte por la falta de comprensión de la relevancia que tiene para mejorar

\footnotetext{
${ }^{26}$ Conocimiento tácito es conocimiento enraizado en la acción individual y en la experiencia, así como en los ideales, valores o emociones que el sujeto adopta (Nonaka, 1991; Nonaka y Takeuchi, 1995; Nonaka y Konno, 1998) y en su contexto.

${ }^{27}$ Conocimiento explícito es conocimiento que puede recogerse y compartirse en forma de datos, fórmulas, especificaciones y manuales (Byosiere, 1999).
} 
los servicios de salud, incorporar nuevas procedimientos, adaptar, modificar técnicas terapéuticas y recrear las políticas de salud sobre la base de información científica y de un desarrollo estratégico nacional y regional. En todos estos aspectos la investigación debe mirar hacia los aspectos viables que podemos alcanzar con los recursos que tenemos, avanzar y generar conocimiento que nos depare patentes y, por ende, se convierta la investigación e innovación en un proceso generador de riqueza social y económica en nuestro país (Zárate, 2010).

\subsection{PROCESOS BÁSICOS DE LA GESTIÓN DEL CONOCIMIENTO}

En la sociedad del conocimiento, una organización que desee hacer frente al cambio actual, necesita crear conocimientos además de procesos eficientes. Para ello, es necesario construir procesos sistemáticos para proceder a la gestión del conocimiento.

Se pueden definir cuatro procesos clave en la gestión del conocimiento: la creación del conocimiento, su distribución, su adopción y, finalmente, su posterior revisión.

\subsubsection{Creación de conocimiento}

En muchos aspectos, la creación de conocimiento científico-técnico no es un proceso del todo manipulable desde la planificación o el control (Lynn et al., 1996), por el contrario, generalmente la innovación es imprevisible. 
La generación de nuevo conocimiento no es sólo una cuestión de procesar una información subjetiva, sino que implica la posibilidad de asimilar con provecho las tácticas y a menudo muy subjetivas percepciones, intuiciones y corazonadas de los miembros del equipo investigador (Nonaka, 1991). Se trata, en definitiva, de un proceso de evolución continua, donde la motivación, inspiración e incluso la casualidad juegan un papel muy importante para crear conocimiento (Horgan, 1996).

Por lo tanto, una estrategia habitual de las organizaciones en la búsqueda de nuevo conocimiento es el de prueba y aprendizaje o ensayo/error. Por medio de un proceso interactivo de pruebas, de cada una de las cuales se va extrayendo conocimiento parcial, se va enfocando la investigación en el camino correcto hasta alcanzar el éxito. Lynn et al. (1996) exponen múltiples ejemplos al respecto. La fibra óptica, el scanner o el móvil son algunos de ellos.

\subsubsection{Distribución de conocimiento}

Con anterioridad al uso del conocimiento por parte de la organización, es necesario que el mismo sea compartido por los miembros de la organización (Nonaka, 1991). En este proceso de distribución juega un papel vital la cultura de la organización y su estructura organizativa.

Aquellas organizaciones con estructura estrictamente vertical, con fuerte mentalidad de supervisión y control, no son idóneas para fomentar la conformación de 
grupos de trabajo coordinado. Académicos como Broadbent y Lofgren (1993) señalan que la mejor manera de distribuir el conocimiento es elaborando canales informales sustentados en la confianza y en la cooperación. En este sentido, el establecimiento de grupos de investigación multidisciplinarios, donde se desborden las atribuciones formales de los diferentes departamentos y áreas de conocimiento, se adapta bastante bien a las recomendaciones de estos autores.

Ya que el conocimiento explícito es más dócil que el tácito para su transmisión, la organización debe encontrar la manera de externalizar éste, pudiendo hacerlo en este caso a través de las TIC. En este sentido, por ejemplo, Bahtt (2000) señala que las interfaces gráficas son más fáciles de emplear y son más expresivas y explícitas que las basadas en un texto: una imagen vale más que mil palabras. Si el conocimiento que se pretende transmitir es complejo, el medio en que se hace también ha de serlo.

\subsubsection{Adopción de conocimiento}

En cuanto el proceso de creación de conocimiento es complicado y presenta riesgos, muchas organizaciones optan por adquirirlo de fuentes externas. Es de notar que en la investigación científico-técnica también se pueden emplear experiencias aprendidas en otros proyectos de diferente naturaleza, de manera que el rendimiento sacado a ese conocimiento sea mayor. 
Esta estrategia de adquisición del conocimiento, a diferencia de la de la propia creación, permite a la organización la estructuración del mismo, ya que gran parte del conocimiento que se adopta ya ha sido creado previamente. Esto es, se trata de adoptar formas eficientes de almacenar, catalogar y validar el conocimiento. Para estas tareas habrán de tenerse en cuenta aspectos como la adaptabilidad del conocimiento a futuros problemas de la organización; su alcance hasta que el nivel de detalle sea capaz de proporcionar soluciones a diferentes problemas; su solidez y la modularidad de los componentes del conocimiento para que se sostenga la coherencia en la base de conocimiento de la organización y en los tipos de conocimiento que es menester generar en la misma.

\subsubsection{Revisión de conocimiento}

Desde la óptica de la gestión del conocimiento, una organización es como un entidad de conocimientos. Demsetz (1991) contempla a las organizaciones como un resultado en torno a una asimetría en la economía del conocimiento: adquirir conocimiento precisa de más especialización que emplearlo; y Spender (1996) la considera por su parte un sistema dinámico y cuasi-autónomo de producción y aplicación de conocimiento. Si este conglomerado de conocimientos no se revisa y renueva periódicamente, pierde aplicabilidad y su rendimiento decae. El efecto en las organizaciones es la pérdida de ventaja competitiva. 
A su vez, la revisión del conocimiento es pertinente para la obtención de rendimientos crecientes derivados de su naturaleza de bien público en ciertos aspectos, y para ser un recurso que se incrementa con el uso; por ende, la revisión del conocimiento permite evitar que el conocimiento de la organización quede en el olvido.

En la figura 4, se representa el modelo de procesos básicos de la gestión del conocimiento.

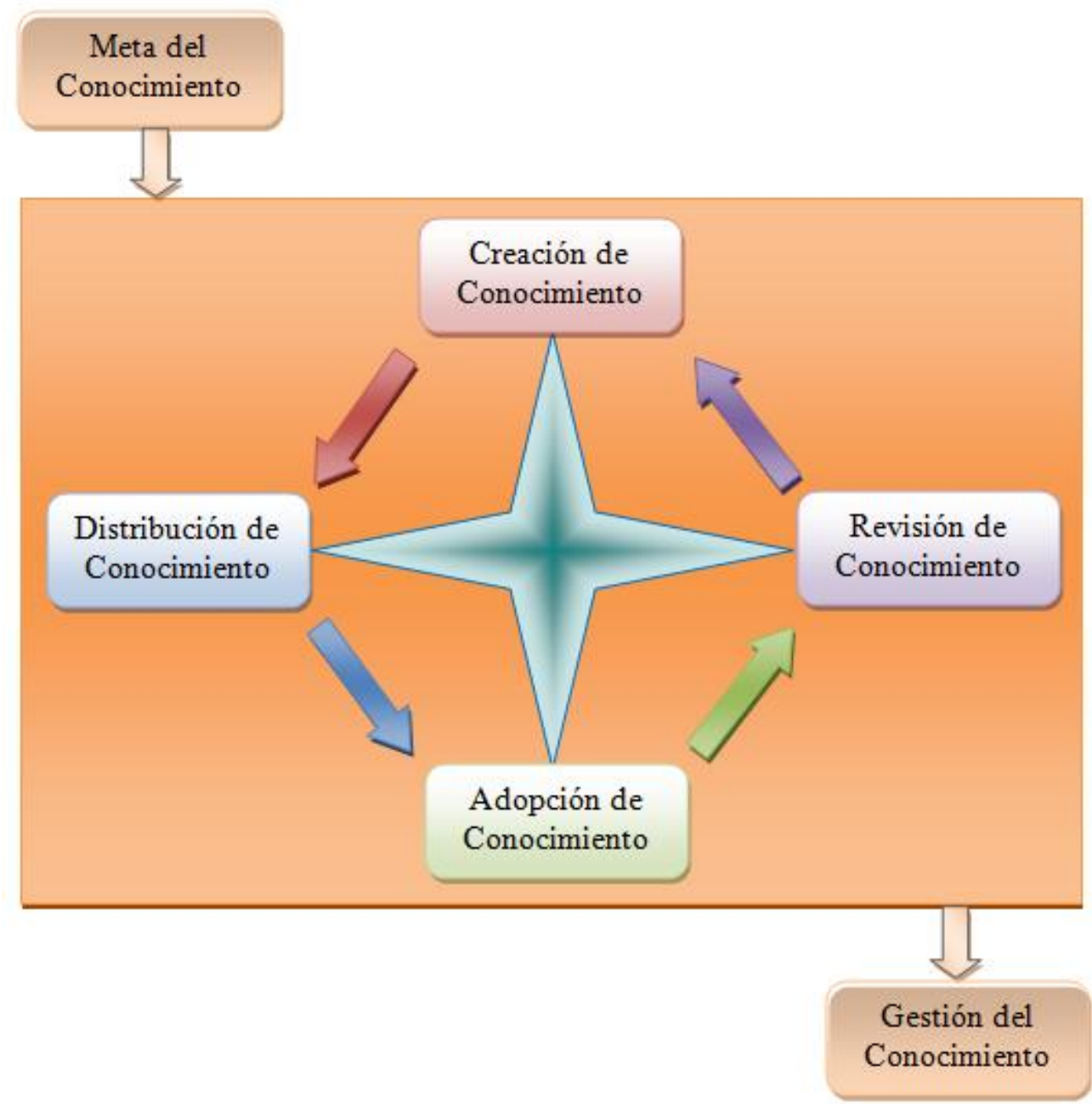

Figura 4. Modelo de procesos básicos de Gestión del Conocimiento (Elaboración propia). 


\section{RELACIÓN ENTRE TIC Y GESTIÓN DEL CONOCIMIENTO}

El valor de mercado de una organización resulta de la suma de los activos tangibles $^{28}$ más los activos intangibles ${ }^{29}$ (Edvinsson y Malone, 1997). Dicho valor se constituye a partir tanto de los conocimientos propios de las personas que forman parte de una organización (Prahalad y Hamel, 1991), como de los conocimientos que la organización hace suyos, y que son independientes de las personas (Hamel y Prahalad, 1994).

Cegarra (2005) afirma que las organizaciones crean conocimiento como consecuencia de las relaciones que sus agentes internos (por ejemplo, doctores, enfermeros y demás personal sanitario) mantienen con los agentes externos (tales como, pacientes, cuidadores, familiares). A este respecto, las organizaciones pueden utilizar múltiples herramientas para adquirir, distribuir y utilizar la información procedente de sus mencionadas relaciones, sin embargo, de entre todas ellas, son las TIC las más importantes (Arjonilla y Medina, 2002; Berenguer y Ramos, 2003).

De igual forma, la gestión de una organización, para ser eficaz, requiere una combinación adecuada de iniciativas que, en muchos casos, demanda una tecnología apropiada (Marwick, 2001) que ha sido ampliamente estudiada (Harrison et al, 1997; Lind et al, 2000; Martín y Matlay, 2001; Benamati y Lederer 2001).

28 Los activos tangibles son todos aquellos bienes de naturaleza material susceptibles de ser percibidos por los sentidos, tales como, la maquinaria, el mobiliario, etc.

29 Los activos intangibles son aquellos bienes de naturaleza inmaterial tales como, el Know-How, la relación con los pacientes, la tecnología de la información, la capacidad, habilidad o motivación de los usuarios en una organización, etc. 
La tecnología como un instrumento para el cambio organizacional e innovación (Rogers, 1962) y el crucial rol que juega la información (Shapiro y Varian, 1999) tienen una relevancia particular para las organizaciones. Sin embargo, las TIC por sí solas originan grandes barreras físicas y organizacionales entre los departamentos dedicados al procesamiento de datos y a la gestión del conocimiento.

Consecuentemente, las oportunidades que surgen mediante esa relación entre la gestión del conocimiento (GC) y la implantación de las TIC, conllevan importantes cambios organizacionales que corroboran la relación que existe entre ambos conceptos.

Son numerosas las investigaciones realizadas relativas a las TIC y a la gestión del conocimiento que abordan con claridad la relación y delimitación entre conocimiento, gestión de información y tecnología. Un ejemplo es el de los autores Núñez y Núnez (2005) que ofrecen para cada tipo de herramienta, una explicación sobre su función dentro del sistema de gestión del conocimiento, la lógica de sus operaciones internas, así como sus ventajas y desventajas.

Según Rodríguez (1999) la gestión del conocimiento puede definirse como "una nueva cultura empresarial, una nueva manera de gestionar las organizaciones, que sitúa los recursos humanos como el principal activo y sustenta su poder de competitividad en la capacidad de compartir la información, experiencias y conocimientos de manera sistemática y organizada, al conjunto de la organización, la información corporativa y los conocimientos". De ahí, que las herramientas que contribuyen a realizar las distintas tareas que implican la gestión del conocimiento, realmente gestionen información a partir de la cual el individuo forma su conocimiento (Núñez y Núnez, 2005). 
Orozco (1998) añade que "la informática nos ha dado acceso a todo tipo de información. La necesidad de convertir esa información en conocimiento ha generado multitud de herramientas de gestión de conocimiento y de empleados cuyo trabajo es tomar una gran cantidad de datos y hacerlos tangibles, accesibles y útiles”.

Por otra parte, los estudios previos sobre la gestión del conocimiento y las tecnologías de la información y la comunicación (TIC) subrayan que, dichas tecnologías deben ser aplicadas en un contexto organizacional. De ahí que, la gestión del conocimiento sea un paso previo para proceder a la implantación de las TIC en cualquier empresa con la finalidad de dirigir y comprender los cambios que van aconteciendo en las organizaciones de forma efectiva.

Además, Nevis et al. (1995) en sus investigaciones, destacaron que todas las organizaciones parten de un conocimiento inicial, pues poseen procesos y estructuras para la adquisición (en la que se produce el desarrollo o creación de capacidades, relaciones, etc.), la distribución (donde se produce la difusión del conocimiento adquirido) y la utilización de conocimientos y habilidades (una vez adquirido y distribuido el conocimiento, el nuevo conocimiento es adaptado a la propia operativa de la empresa) que les permiten implantar las TIC en los distintos contextos organizativos.

En la actualidad, ha habido una explosión de nuevas herramientas para llevar a cabo un nuevo mercado principalmente enfocado en la colaboración de los usuarios y en la toma de decisiones. Sin embargo, la evidencia sobre la implantación actual y la efectividad de estas nuevas herramientas es todavía muy débil (Cagliani et al., 2003), lo que hace difícil identificar los beneficios potenciales de estas nuevas herramientas tecnológicas. 
Por tanto, la implantación de las TIC para permitir la práctica de nuevos servicios electrónicos puede ser difícil, laboriosa y costosa para una organización. Es más, es necesaria la evidencia empírica para obtener conocimientos sobre este tema. Las TIC pueden ser una buena solución para una organización que está ampliamente dispersa y todavía valora la información compartida (Goodman y Darr, 1996). La tecnología facilita la comunicación horizontal y hace que parezca fácil para los usuarios compartir y acceder a la información y a la base de datos del conocimiento (Swee, 2002).

La implantación de los programas de gestión del conocimiento ha activado el uso de las TIC y ha incrementado el interés de las organizaciones (Buniyamin y Barber, 2004). La cantidad de conocimiento que es necesario para almacenar y compartir la información y la evolución dinámica de la misma, son algunos de los factores que hacen del uso de la gestión del conocimiento no sólo una opción sino algo indispensable cuando se implantan las TIC.

Finalmente, Nonaka y Takeuchi (1995), entre otros, de acuerdo con esta idea, sugieren que un paso previo para implantar las TIC involucra el uso de un proceso de gestión de conocimiento para articular, describir y explicar información. De acuerdo a esta revisión, podemos afirmar que a la hora de implantar las TIC es necesario tener en cuenta programas relacionados con la gestión del conocimiento.

Sin lugar a dudas, el crecimiento de un nuevo mundo electrónico requiere innovación y la generación de nuevos servicios sanitarios online con desarrollo e influencia de activos intangibles, incluyendo muchos tipos diferentes de nuevas habilidades, nuevas formas de integración, intensivas relaciones con entidades externas al sector sanitario, nuevos escenarios de actuación mantenidos por los usuarios externos 
y/o internos al ámbito sanitario, nuevos canales de información y suministradores de TIC y, naturalmente, nuevo conocimiento por parte de los usuarios potenciales del sector sanitario.

Sin embargo, la creación y el uso del conocimiento es una constante humana que requiere individuos para pensar y para razonar, y para hacer sentir la corriente y el emergente mundo alrededor de los individuos. Así, el contexto del conocimiento nunca es libre, es siempre creado, compartido e influenciado dentro de un contexto compartido por la historia de la organización, su modo de pensar, preocupaciones, conocimiento y el entorno competitivo externo. Por lo tanto, los servicios online que se ofrecen por parte del sector sanitario, deben ser estructurados alrededor de un contexto y partiendo de una adecuada gestión del conocimiento y de la creatividad necesaria para la integración de TIC.

De ahí que, el papel más importante en las nuevas pautas de actuación de las organizaciones sanitarias, lo jueguen la tecnología y el conocimiento, consideradas como importantes vehículos que permiten la transformación de los procesos organizativos (Agarwal et al., 1997), la mejora de la productividad y la eficiencia del sector sanitario, y las facilidades de la organización, colaboración y transacción (Teo et al., 2003). La rápida aceptación de la integración de ambos conceptos (tecnología y conocimiento) son de una importancia primordial para conseguir ventajas competitivas (Ravichandran, 2005). La relación entre ambos conceptos, ha sido objeto de numerosos estudios relacionados con diversas disciplinas, tales como la economía, la sociología, los sistemas de información, la dirección de ingeniería y el marketing. 
Consecuentemente, los gerentes de las organizaciones sanitarias se enfrentan a una serie de cuestiones complicadas concernientes a si utilizar las TIC o no. Mientras que por un lado, el conocimiento referente a la aplicación de las TIC puede ayudar a que los centros sanitarios adquieran una mayor ventaja competitiva de cara a los beneficios derivados de las TIC (Mata et al., 1995; Li et al., 2006), por otro lado, las innovaciones producidas por las TIC puede que lleguen a ser contraproducentes debido, principalmente, a la falta de fiabilidad percibida por los pacientes ante las actividades que se van realizando a través de nuevos servicios online ofrecidos por el sector sanitario (Leidner y Mackay, 2007).

Está fuera de toda duda que son muchas las oportunidades y ventajas que ofrecen las TIC, antes inviables o impensables. Quizás por ello, el sector sanitario está sujeto a una gran presión para invertir cantidades crecientes de recursos en tecnologías relacionadas, sobre todo, con el mundo de Internet. Estas cuestiones derivan en el progresivo descenso del coste de las TIC, el cual ha facilitado a una gran cantidad de organizaciones, entre ellas, los hospitales y centros sanitarios, el acceso a estas tecnologías, particularmente a Internet (Poon y Joseph, 2000).

Las inversiones en Internet pueden tomar múltiples formas y es la organización quien debe decidir la mejor o más adecuada según sus necesidades. En cualquier caso, desde la perspectiva del conocimiento, cualquier aplicación de TIC debe poner en marcha mecanismos de gestión normalizados, de forma que todos los integrantes de la cadena de valor (doctores, enfermeros, celadores o pacientes, entre otros) tengan acceso a sistemas coordinados capaces de llevar a la práctica el objetivo final (Cegarra et al., 2006). 
De ahí y partiendo de la gestión del conocimiento, existe una gran proporción de usuarios del sector sanitario que aceptan utilizar las tecnologías a través de los nuevos servicios sanitarios online (Colombo y Delmastro, 2001). Aunque la mayoría de las organizaciones han reconocido la necesidad de cambiar sus actuales prácticas por otras que faciliten la aceptación y utilización de las TIC, solamente una pequeña proporción de organizaciones europeas han tomado la iniciativa de aplicar las TIC en sus actuaciones. Esta resistencia a cambiar puede estar relacionada con temas de incertidumbre, confianza, fiabilidad, seguridad y carencia de conocimiento, lo cual dificulta la aplicación y uso de servicios sanitarios virtuales (e-health) (Nath et al., 1998), ya que el uso de los mismos requiere de un clima favorable a la innovación y de una percepción positiva sobre dicho uso (Jones et al., 2002; Yang et al., 2009).

La presencia del sector sanitario en este nuevo mundo virtual justifica que la creación de conocimiento se vuelva muy dependiente de las TIC y su gestión (Liebowitz, 2000; Davenport y Grover, 2001). Esta circunstancia explica la preocupación de los usuarios del sector sanitario, tanto externos como internos, por conocer las TIC que más influyen en la expansión, uso y gestión de su conocimiento organizacional.

No hay que olvidar que la relación y la colaboración para la creación y gestión del conocimiento, requiere de apropiadas infraestructuras en TIC, porque sin ellas se podría producir un rechazo hacia su uso (Martínez y Hermosilla, 2010; Sainz et al., 2011). Pero un incontrolado desarrollo de sistemas tecnológicos sin un compromiso por parte de los usuarios (gestión del conocimiento) es irrelevante, es decir, la implantación de las TIC sin un compromiso o un conocimiento previo y un nivel de aceptabilidad adecuado, es 
un desastre asegurado (Rueda-Clausen, 2006; Temprano y Gallego, 2009; Sainz, 2011). Por ello, es necesario un contexto previo que permita crear conocimiento.

El contexto para la creación y gestión de conocimiento resulta de la colaboración entre los entes del sector sanitario para poder desarrollar nuevos servicios sanitarios online, satisfacer las necesidades de los pacientes y crear nuevas innovaciones, sin olvidar que los pacientes son el eje central por el que se desarrollan las nuevas pautas de actuación.

De acuerdo con lo anterior, es de destacar también, que en el sector sanitario hay que tener en cuenta que la información dada es una cosa y el conocimiento utilizado por el usuario es otra. Por lo tanto, para reducir las posibles diferencias que pudiesen existir entre el conocimiento necesario para implantar un sistema sanitario basado en las TIC y el conocimiento actual, es esencial crear un proceso de gestión de conocimiento para que todo el mundo sepa dónde está el conocimiento útil y necesario para implantar las TIC.

Se trata pues de toda una serie de conceptos que ponen de relieve la necesidad de transformar el conocimiento para contribuir a la aceptación de las TIC. De ahí que los estudios sobre la aceptación de tecnologías hayan crecido sustancialmente y se hayan dirigido, principalmente, al uso de nuevos sistemas de información. La mayoría de las investigaciones sobre las TIC se han enfocado a dar a conocer las razones que han llevado al uso de nuevos sistemas de información (Agarwal, 2000). De igual forma, la cantidad de conocimiento que es necesario capturar y compartir y la dinámica evolución de la información han hecho de la gestión del conocimiento una opción indispensable cuando se produce la implantación de estas tecnologías. 


\section{CONCLUSIÓN Y REFLEXIÓN FINAL}

En este primer capítulo se ha procedido a la realización de un estudio dirigido, ante todo, a analizar y estudiar la relación de las TIC con la gestión del conocimiento en el ámbito sanitario.

En el primer apartado de este capítulo, se procede, en primer lugar, a realizar un estudio de los antecedentes de las TIC en el sector sanitario y, en segundo lugar, a analizar el estado actual de las mismas. Han sido muchos los avances logrados en los últimos años en este sector y muchos los servicios que se han desarrollado y que facilitan la toma de decisiones en determinados aspectos de la práctica clínica. En muchos casos es evidente que nos enfrentamos ante una situación de alta complejidad que exige un enfoque global por parte de las organizaciones sanitarias y que estamos al inicio de un proceso que generará profundos cambios en el sistema actual de actuación clínica y de la provisión de los servicios sanitarios. Es por ello, por lo que las TIC suscitan un gran interés tanto a nivel económico como social, poniendo de manifiesto la existencia de líneas de investigación sobre las TIC, así como de los beneficios y las barreras que derivan de la implantación de las mismas.

Por tanto, el segundo apartado ha sido dirigido al estudio de los beneficios y barreras que supone la implantación de las TIC en el sector sanitario, así como, de los pasos a seguir para que los usuarios del sector sanitario acepten utilizar las TIC de modo habitual, ya que, es obvia la existencia de importantes problemas en la difusión y aceptación de los servicios sanitarios online debido a que se trata de sistemas innovadores que requieren de un largo periodo de tiempo para hacer frente a la totalidad 
de los cambios tecnológicos. Además supone un cambio en el papel activo de los pacientes y del personal sanitario ante las nuevas prácticas virtuales que fomentan la eficiencia, efectividad y una mejor relación de coste y beneficio. Es más, algunos trabajos han señalado barreras y han emitido recomendaciones sobre las posibles actuaciones para favorecer la difusión de las aplicaciones sanitarias online en la actual sociedad de la información y la comunicación.

Aún así, resultan claras las ventajas derivadas de la potencialidad que Internet, las comunicaciones móviles, dispositivos portátiles e instrumentación electrónica, están teniendo en el desarrollo de servicios sanitarios online.

Por ende, las TIC por sí solas originan grandes barreras físicas y organizacionales, que nos conducen a crear un tercer apartado donde hacer especial hincapié en el concepto de gestión del conocimiento, ya que es uno de los tópicos frecuentemente utilizados durante los últimos tiempos, debido a que permite a las organizaciones tratar una cantidad de información cada vez superior.

Tras estos análisis, desarrollamos el cuarto apartado de este capítulo enfocado a definir tanto el concepto de TIC y de gestión del conocimiento, como a argumentar y corroborar la relación existente entre ambos conceptos.

Evidentemente, el paso del tiempo y los estudios realizados hasta el momento han puesto en relieve que la implantación de las tecnologías es un proceso más complejo de lo que en sí puede parecer y más teniendo en cuenta que los recursos tecnológicos desarrollados en los últimos años son muy diferentes a los de años pasados. 
No obstante, se plantea una nueva forma de actuar a través de los nuevos servicios online que favorecen el uso intensivo de las TIC y que desarrollan pautas de actuación y comunicación en red entre el personal sanitario y los pacientes. Y es que el entorno sanitario es un terreno abonado para la aplicación del enfoque estratégico del conocimiento (Picas-Vidal, 2000), pero a pesar de las oportunidades que surgen en este sector para aplicar una gestión basada en el conocimiento, la realidad demuestra que muy pocas organizaciones están preparadas para enfrentarse al manejo del saber de sus profesionales (Brakensiek, 2002). Consecuentemente, para que la implantación de las tecnologías de la información tenga éxito en el sector sanitario es necesaria la aceptación de las mismas por parte de los usuarios, tal y como afirman en diversos estudios Davis (1989) y Bhattacherjee (2001b).

Finalmente, por medio del desarrollo de este primer capítulo, hemos podido analizar las investigaciones que se han realizado a lo largo de los años en el sector sanitario abordando aspectos como las TIC y la gestión del conocimiento con el objetivo de implantar servicios sanitaros online que sean eficaces y eficientes para quienes los utilizan, especialmente para los usuarios externos (tales como, los pacientes, etc.).

La elección del sector sanitario ha venido motivada, principalmente, por ser un sector que se presenta como proveedor y productor de nuevos servicios caracterizados por un uso intensivo de información y transferencia de conocimiento. Precisamente por ello, se considera un ámbito de gran innovación donde se están produciendo una serie de cambios profundos que contribuyen de forma progresiva a mejorar la calidad de los 
servicios que ofrece evitando barreras geográficas, integrando datos, intercambiando información y gestionando el conocimiento hacia una correcta práctica clínica.

Todo ello es posible si se centra únicamente en aquella información que es generada a partir de las necesidades de los usuarios de dicho sector (tanto usuarios externos como internos), ya que sólo esa información será la que finalmente se transforme en un conocimiento valioso para el desarrollo de los nuevos servicios sanitarios online.

Una vez generado el conocimiento e interiorizado por los usuarios, dicho conocimiento tiende a ser gestionado. La gestión del mismo permitirá transformar el conocimiento en políticas y prácticas novedosas para el sector que mejorarán los servicios ofrecidos haciéndolos más eficientes y eficaces. De ahí que el ámbito sanitario haya sido considerado como un campo privilegiado para aplicar, probar y promover la gestión del conocimiento, teniendo en cuenta, las oportunidades que la sociedad de la información y el conocimiento aporta a dicha organización para facilitar y gestionar ese conocimiento.

Sin embargo, para que la gestión del conocimiento sea valiosa para el sector debe contar con un aprendizaje organizacional previo, es decir, si el sector cuenta con la suficiente capacidad de aprendizaje para transformar la información en conocimiento y hacer frente a los nuevos cambios que están aconteciendo con la aparición de las TIC, se estará favoreciendo la gestión del conocimiento y a su vez, el incremento del capital intelectual que el sector posee. Todo ello generará una serie de ventajas competitivas que darán lugar al desarrollo de los mencionados servicios sanitarios online. 
Es más, para que estas ventajas puedan realmente tener validez se requieren una serie de herramientas e instrumentos que las hagan posibles. Estos instrumentos son los relacionados con las TIC. Sólo a través de la complementariedad de ambos conceptos será posible crear nuevos servicios de información, de capacitación, de consulta, de asesoría, de discusión, de generación e intercambio de información y conocimiento, además de permitir la implantación de los nuevos servicios online cuyo desarrollo se prevé expansivo en un mundo globalmente conectado.

La figura 5 representa los factores que pueden incidir sobre el desarrollo y mejora de los servicios sanitarios online.

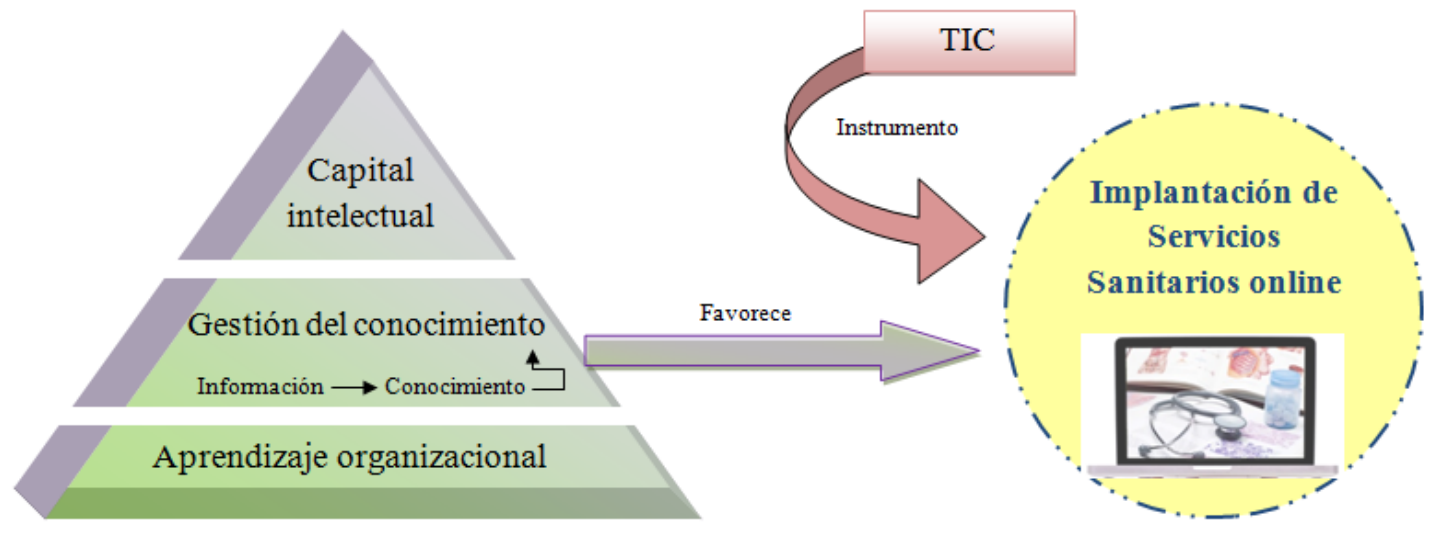

Figura 5. Factores que inciden sobre el desarrollo y mejora de los servicios sanitarios online (Elaboración propia).

A pesar de las investigaciones analizadas, se nos plantean varias cuestiones relacionadas, sobre todo, con las TIC, ya que, ¿es posible el desarrollo de estos nuevos servicios online sin tener en cuenta las percepciones que tienen los usuarios sobre el uso de las TIC? ¿Qué papel juega la aceptación de las mismas en el desarrollo de estos 
novedosos servicios? ¿En qué medida la implantación de los servicios sanitarios online dependen de la aceptación de las TIC?

De ahí, que se haga evidente la necesidad de proceder a realizar en el segundo capítulo, una revisión de los distintos modelos y teorías basados en la aceptación de las tecnologías, para poder conocer las variables que pueden influir en el mayor o menor grado en el uso de las TIC. Todo ello, permitirá sentar las bases para crear un tercer capítulo centrado en el desarrollo de un modelo teórico que contenga una serie de variables que hagan posible la e-lealtad (lealtad electrónica) hacia el uso continuado de los nuevos servicios sanitarios, posibles gracias a la expansión de las TIC y a la gestión del conocimiento. 

CAPÍTULO 2. MODELOS DE ACEPTACIÓN DE LA TECNOLOGÍA 



\section{OBJETIVO}

En el área de aceptación de innovaciones tecnológicas, el paso del tiempo ha puesto de manifiesto unas cifras reales que distan mucho de las expectativas que se pronosticaban en algunos estudios (Cannon, 1984; Clemmons y McFarlan, 1986), debido principalmente a que el nivel de uso es menor de lo que se esperaba inicialmente (Roach, 1992; Weiner, 1993; Johansen y Swigart, 1996; Hernández et al., 2007).

El desfase entre las expectativas que realzaban el uso de las TIC y el uso real que se está haciendo, es lo que nos ha llevado a plantear este segundo capítulo. De ahí que el objetivo principal sea poder llevar a cabo una revisión sobre los modelos y teorías que, a lo largo de los años, se han encargado de analizar qué variables influyen en la aceptación y uso de las TIC, y a su vez el grado en que dichas variables pueden influir en mayor o menor medida sobre el uso de las tecnologías.

De esta forma se podrá determinar qué variables son las que repercuten negativamente sobre la intención o la percepción de los usuarios a la hora de utilizar las tecnologías y poder llevar a cabo medidas que provoquen un cambio en las actitudes de dichos usuarios y que vean en las TIC, un medio fácil y cómodo para realizar las actividades sin necesidad de desplazamientos físicos, de una forma más eficaz y efectiva. 


\section{INTRODUCCIÓN}

La aparente discrepancia entre los beneficios esperados y los realmente percibidos se manifiesta especialmente en muchas herramientas de gestión relacionadas con las tecnologías de la información (Hernández et al., 2007). Numerosos estudios sugieren que la actitud de los usuarios hacia la aceptación de un nuevo sistema basado en las TIC tiene un impacto crítico en su éxito (Davis et al., 1989; Venkatesh y Davis, 1996; AlSomali et al., 2009). La aceptación de los sistemas tecnológicos puede incrementar la productividad de los empleados y mejorar el rendimiento individual y organizacional. Aún así, el uso de las nuevas tecnologías para mejorar la productividad de una empresa, requiere que cada uno de los componentes de una organización acepte y use estas tecnologías en su entorno.

Por tanto, la aceptación de las TIC por parte de los usuarios es una condición necesaria (Al-Gahtani y King, 1999) y, en consecuencia, conocer las motivaciones que empujan a los usuarios a la adopción de nuevas tecnologías se ha convertido en un aspecto crítico para investigadores y gestores, tratando de definir correctamente qué factores condicionan una decisión tan trascendente para las organizaciones (Taylor y Todd, 1995; Chau y Hu, 2002; Al-Somali et al., 2009).

La aceptación del uso de nuevas tecnologías es descrita con frecuencia como una de las áreas de investigación más madura en la literatura de los sistemas de la información contemporánea (Hu et al., 1999). Debido a ello, las investigaciones en esta área han resultado en varios modelos teóricos que explican la aceptación de tecnologías. La mayoría de estos estudios parten de teorías relacionadas con el comportamiento y 
desarrollan modelos contrastados empíricamente que explican el conjunto de actuaciones del individuo a partir de sus creencias y/o actitudes.

Sin embargo, el problema a la hora de analizar qué variables influyen en la aceptación y uso de las TIC está en que cada modelo y teoría escoge una gran cantidad y diversidad de dichas variables para plantear el grado de influencia de éstas sobre los usuarios. A modo de ejemplo, la Teoría de la Difusión de la Innovación (IDT), establece como su núcleo principal la ventaja relativa, la facilidad de uso, la imagen, la visibilidad, la compatibilidad, los resultados demostrables y la voluntariedad de uso, mientras que el Modelo de Aceptación de la Tecnología (TAM), considera la percepción de utilidad y la percepción de facilidad de uso. Además, son muy reducidos los modelos de aceptación de las TIC centrados en el ámbito sanitario.

Con lo cual, la solución sería que una vez que se hayan revisado estas teorías y modelos, se determinase qué variable es la que coincide en cada uno de ellos, aunque pueda aparecer con distinta nomenclatura, para considerarla como núcleo de un modelo teórico sobre el que basar nuestra investigación centrada en el sector sanitario, modelo que será desarrollado y analizado de forma detallada en el capítulo 3.

\section{TEORÍA DE LA ACCIÓN RAZONADA (Theory of Reasoned Action, TRA)}

Los estudios sobre los factores que influyen en las conductas hacia el uso y la asimilación de la tecnología se fundamentan en los trabajos de Fishbein y Ajzen, quienes presentaron la Teoría de la Acción Razonada (TRA por sus siglas en inglés) en 
1967, que posteriormente fue refinada, desarrollada y probada por estos mismos autores (Fishbein y Ajzen, 1975; 1980).

Es una teoría general de la conducta humana que trata la relación entre creencias, actitudes, intenciones y comportamiento, los cuales se encuentran relacionados con la toma de decisiones a nivel conductual. La teoría asevera que es posible predecir las conductas desde las actitudes, las intenciones conductuales y las creencias en relación a la influencia social y a la predisposición del sujeto hacia esta última. Es decir, el sujeto evalúa los atributos o las consecuencias de ejecutar la conducta objeto de la actitud.

La TRA afirma que la intención de una persona para llevar a cabo o no una conducta es la determinante inmediata de una acción. Esta intención es función de dos factores: su actitud, de naturaleza personal, y sus normas subjetivas, que reflejan la influencia social. La actitud está determinada por sus creencias sobre las consecuencias de esta conducta mediatizadas por su evaluación de dichas consecuencias. Las creencias se definen por la probabilidad subjetiva de que la realización de una conducta particular producirá resultados concretos. Por norma subjetiva se entiende la percepción que un individuo tiene de lo que los demás consideran que debe realizar o no (la presión del grupo).

La TRA considera que el mejor indicador del comportamiento es la intención porque muestra el esfuerzo que los individuos están dispuestos a invertir con el fin de desarrollar una acción. En definitiva, esta teoría se basa en la suposición de que los seres humanos son normalmente racionales y hacen un uso sistemático de la información de que disponen; y que la intención se sitúa en el equilibrio entre lo que se 
piensa que se debe hacer y lo que se percibe sobre lo que otros piensan que se debe hacer.

La TRA se puede representar en la figura 6:

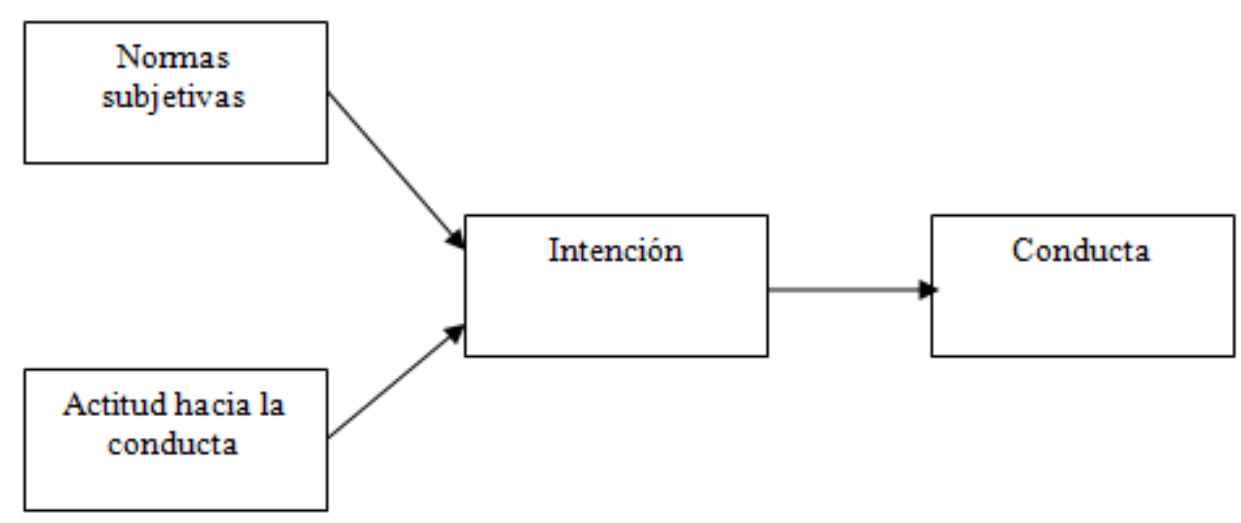

Figura 6. Modelo TRA (Ajzen y Fishbein, 1975)

El TRA es aplicable en diversas disciplinas y ha sido probado a lo largo de numerosos estudios que han demostrado su robustez a la hora de predecir las intenciones de adoptar o usar diversas tecnologías (por ejemplo, Sheppard et al., 1988; Hartwick y Barki, 1994; Bobbitt y Dabholkar, 2001; Bagchi et al., 2003; Jae-Nam y Young-Gul, 2005).

Sin embargo, el modelo tiene algunas limitaciones. La primera hace referencia al riesgo significativo de confusión entre las actitudes y las normas ya que las actitudes, a menudo, pueden ser reformuladas como normas y viceversa. Una segunda limitación es el supuesto de que cuando alguien forma una intención de actuar, será libre de actuar sin limitaciones. En la práctica, existen ciertas restricciones como la capacidad limitada, el tiempo, los límites ambientales o de organización y los hábitos inconscientes que 
podrían limitar la libertad de acción. Teorías posteriores, como la teoría del comportamiento planificado (TPB), intentan resolver estas limitaciones.

\section{MODELO DE ACEPTACIÓN DE LA TECNOLOGÍA (Technology Acceptance Model, TAM)}

El Modelo de Aceptación de la Tecnología (Technology Acceptance Model), desarrollado por Davis (1986), es uno de los modelos más frecuentemente empleados en la investigación sobre la aceptación de nuevas tecnologías. Durante dos décadas ha sido objeto de estudio en numerosas investigaciones relacionadas con el área de sistemas de información y se ha testado en un considerable número de trabajos (Rahimpour et al. 2008). El TAM sugiere que cuando los usuarios se enfrentan a una nueva tecnología, varios factores determinan su decisión sobre cómo y cuándo harán uso de esa tecnología (Davis, 1989).

El TAM es un modelo adaptado de la TRA que reemplaza las creencias actitudinales definidas en la TRA por dos determinantes denominadas facilidad de uso y utilidad, bajo el supuesto de que se trata de creencias relevantes que impactan en la formación de actitudes y, en consecuencia, influyen en la intención y en la conducta de un individuo hacia el uso de la tecnología (Davis, 1989). Por tanto, la intención de usar una tecnología está directamente determinada por dos conductas claves: la percepción de la utilidad y la percepción de la facilidad de uso. 
La percepción de la utilidad (PU) es definida por Davis et al. (1989) como "la probabilidad subjetiva de que usando una aplicación determinada se mejorará el funcionamiento y el rendimiento de una organización". La percepción de facilidad de uso (PEOU) se define como el "grado en que los usuarios perciben que el uso de un sistema concreto está libre de esfuerzo" (Davis et al., 1989). Ambas variables determinan la actitud al uso de la tecnología (A). Davis (1989) la define como "el sentimiento positivo o negativo hacia el uso de la tecnología de la información". La actitud, en cambio, guía al usuario en su intención de comportamiento (BI) para usar la tecnología de la información. Finalmente, el actual sistema de uso está determinado por BI.

Mientras la PU parece ser una característica extrínseca ${ }^{30}$ de las tecnologías de la información basada, por ejemplo, en la forma en que estas tecnologías pueden ayudar a conseguir sus objetivos tales como tareas eficientes y efectivas, la PEOU, examina las características intrínsecas $^{31}$ de las tecnologías de la información tales como la facilidad de aprendizaje, la flexibilidad o la claridad de las tareas a realizar dentro de cada organización (Gefen y Straub, 2000).

El modelo TAM también discute sobre el impacto que tiene la PEOU sobre PU, así como la relación existente entre ambas variables, es decir, hace referencia a la facilidad que presenta un sistema al utilizarlo o el menor esfuerzo que requiere el uso del mismo para el desarrollo de una tarea específica (Davis et al., 1989). Esto marca la relación existente entre PEOU y PU. Concretamente, la PEOU influye positivamente en

${ }^{30}$ Características extrínsecas son aquellas características que un servicio ofrece únicamente en relación a otros servicios y/o entorno.

${ }^{31}$ Características intrínsecas son aquellas características que un servicio tiene por su propia naturaleza, con independencia de la situación en la que se ofrezca. 
la PU mejorando la percepción de los usuarios hacia la adopción de las TIC, cuestión que ha sido apoyada por autores como Adam et al. (1992), Venkatesh y Davis (1994), Keil et al. (1995) o Gefen (2000).

El TAM ha sido ampliamente aplicado a lo largo de los años y utilizado frecuentemente en numerosos estudios relacionados con la aceptación de las tecnologías de la información. Por un lado, autores como Davis (1986), Davis et al. (1989), Mathieson (1991), Adam et al. (1992) y Taylor y Todd (1995) entre otros, han aplicado este modelo para documentar el papel de algunas de las variables del TAM en los sistemas que se han enfocado hacia la conducta de uso, incluyendo factores individuales, de dirección y organizacionales.

Davis (1993) además sugiere que se pueden añadir variables externas como un modo de mejorar el poder predictivo del modelo. Numerosos investigadores han introducido variables adicionales al TAM incluyendo factores tecnológicos [por ejemplo, sistemas de calidad (Adamson y Shine, 2003), personalización (Kim y Chang, 2007), coste (Rahimpour et al., 2008)], factores individuales [por ejemplo, participación (Yu y Yang, 2006), formación (Aggelidis y Chatzoglou, 2009), características demográficas (Al-Gahtani y King, 1999)], o factores organizacionales [por ejemplo, confianza (Klein, 2007), apoyo de la gerencia (Quaddus y Xu, 2005), resistencia al cambio (Pérez et al., 2004)].

La figura 7, que se muestra a continuación, representa el TAM original. 


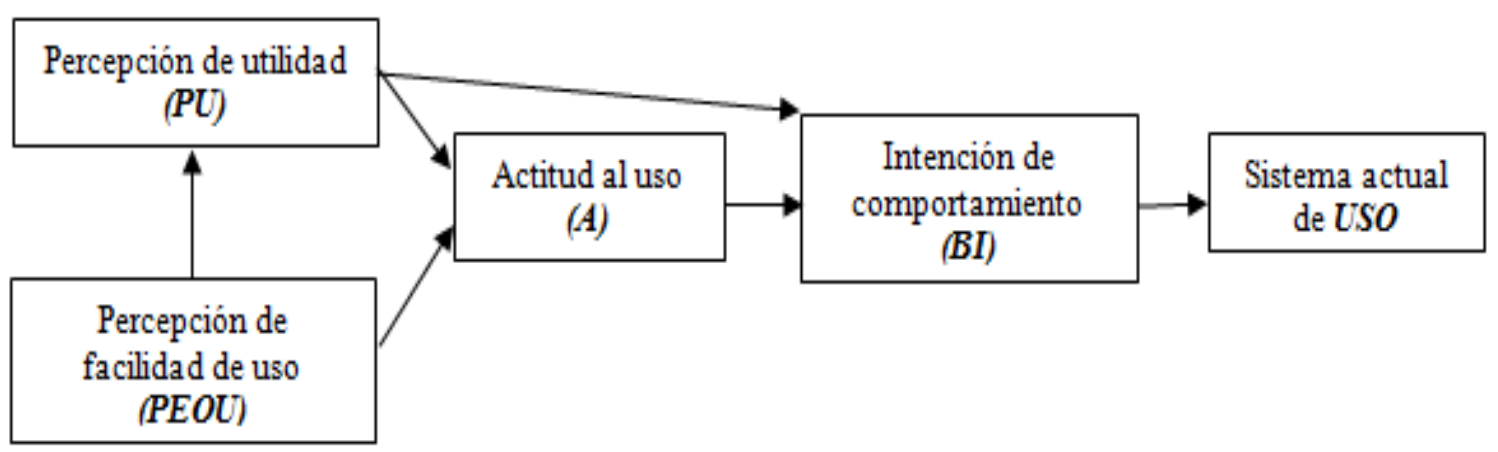

Figura 7. TAM (Davis, 1989)

Por otro lado, varios investigadores han replicado el estudio original de Davis (1989) para proporcionar evidencias empíricas de las relaciones entre facilidad de uso, utilidad y la variable a explicar, que puede ser el uso real, la intención de aplicar una tecnología o la actitud adoptada hacia ella (Hernández et al., 2008). Otros investigadores han testado extensiones del modelo en un amplio rango de aplicaciones de las tecnologías de la información (Pérez et al., 2004), por ejemplo, en sistemas ERP ${ }^{32}$ (Amoako-Gyampah y Salam, 2004), en teletrabajo (Pérez et al., 2004), en banca electrónica ${ }^{33}$ (Al-Somali et al., 2009) o en comercio electrónico (Sejin y Stoel, 2009).

32 ERP (Enterprise Resource Planning), traducido como planificación de recursos empresariales, se considera un recurso estratégico de las organizaciones (Yen y Sheu, 2004) debido a su percepción de que los sistemas ERP pueden proporcionar un alto nivel de competitividad a través de la adquisición de una posición fuerte en el mercado (Tchokogue et al., 2005).

33 La banca electronica es un tipo de banca que desarrolla sus actividades utilizando las tecnologías. Se trata de la banca a través de Internet. Esta nueva forma de actuar de los bancos les permite retener a sus actuales clientes, mejorar su satisfacción, aumentar su cuota de mercado, reducir sus costes administrativos y mejorar su posición competitiva (Almogbil, 2005; Khalfan et al., 2006). 


\section{MODELO MOTIVACIONAL (Motivational Model, MM)}

El Modelo Motivacional (MM) se desarrolló para dar una explicación del comportamiento del ser humano. La motivación se identifica como un determinante clave del comportamiento en una amplia variedad de contextos según los estudios realizados por Deci y Ryan (1985). Estos autores encontraron que la motivación está determinada por dos variables principales: la motivación intrínseca y la motivación extrínseca. La motivación intrínseca se refiere al placer y a la satisfacción inherente derivada de una actividad específica (Deci, 1975; Vallerand, 1997), mientras que la motivación extrínseca enfatiza en la percepción del funcionamiento de un comportamiento o conducta, quedando definida como el instrumento que permite obtener unos resultados distintos pero válidos según la actividad a realizar (Vroom, 1964). Mediante la relación de ambas motivaciones se influye en la intención de los individuos a la hora de desarrollar una actividad, así como el funcionamiento o rendimiento actual de dicha actividad (Deci, 1975).

Han sido numerosas las aplicaciones del Modelo Motivacional. En el contexto de la tecnología, Davis et al. (1992) probaron un modelo motivacional sobre el uso de la tecnología. Consistentemente con la investigación basada en la búsqueda de nuevas conductas, estos autores identificaron que tanto la motivación extrínseca como la intrínseca son operadores claves en la intención de un individuo y actúa sobre la conducta. 
Davis et al. (1992) utilizan la motivación extrínseca para usar una tecnología específica, en un lugar de trabajo concreto, con el fin de actuar en una serie de actividades de trabajo y poder incrementar su productividad. De esta forma, los trabajadores eran recompensados por sus buenos comportamientos y su creciente productividad con bonos y subidas salariales.

Consecuentemente, si se percibe que una tecnología se utiliza para ayudar a incrementar la productividad de los individuos, es probable que también tenga cierta motivación extrínseca para utilizar una tecnología dada que, en principio, no es percibida como útil, posiblemente por sufrir desventajas en el rendimiento de su trabajo e inhibir así su habilidad para trabajar y obtener recompensas (Davis et al., 1992).

Además de las ganancias de productividad obtenidas por el uso de una tecnología concreta, algunos individuos pueden tener una motivación intrínseca para interactuar con las tecnologías. Este tipo de motivación intrínseca fue definida por Davis et al. (1992) como "disfrute percibido", es decir, el factor determinante de la intención conductual que tiene una persona hacia el uso de las tecnologías. A pesar del apoyo empírico que tiene el modelo motivacional de Davis et al. (1992), se carecen de estudios específicos sobre los principales factores que pueden influir en la motivación extrínseca e intrínseca, factores que podrían ser la clave principal del uso de la tecnología. 


\section{TEORÍA DEL COMPORTAMIENTO PLANIFICADO (Theory of Planned Behavior, TPB )}

La Teoría del Comportamiento Planificado (TPB o TCP) fue desarrollada por Ajzen $(1985,1989)$ para predecir el comportamiento a través de muchos escenarios y poder ser aplicada al uso de los sistemas de información. Esta teoría es una extensión del TRA. El TPB incluye los constructos teóricos del TRA e incorpora uno nuevo: "el control de percepción del comportamiento”.

Este modelo nos ayuda a comprender cómo podemos cambiar el comportamiento de una persona. Se trata de uno de los modelos teóricos psicosociales más ampliamente utilizado y con mayor apoyo empírico en una gran variedad de conductas. Sostiene que la conducta humana es voluntaria y está determinada por la intención conductual, la cual a su vez se construye a partir de tres procesos principales: actitudes sociales, norma subjetiva y control conductual percibido (Ajzen, 1985, 1991). Las actitudes sociales surgen de la interacción entre las expectativas conductuales y su valoración por parte de cada sujeto, en tanto que la norma subjetiva sería el modo en que el sujeto recibe e interpreta lo que dicen las personas y los grupos que considera relevantes acerca de lo que debería hacer en relación con la conducta y la motivación para acomodarse a estas opiniones.

El control de percepción del comportamiento contiene las creencias que poseen los sujetos sobre su propia capacidad para realizar una determinada conducta. 
Finalmente, estos componentes se conforman de acuerdo a creencias que parten de la experiencia directa o medida.

La figura 8 muestra la representación gráfica del modelo TPB.

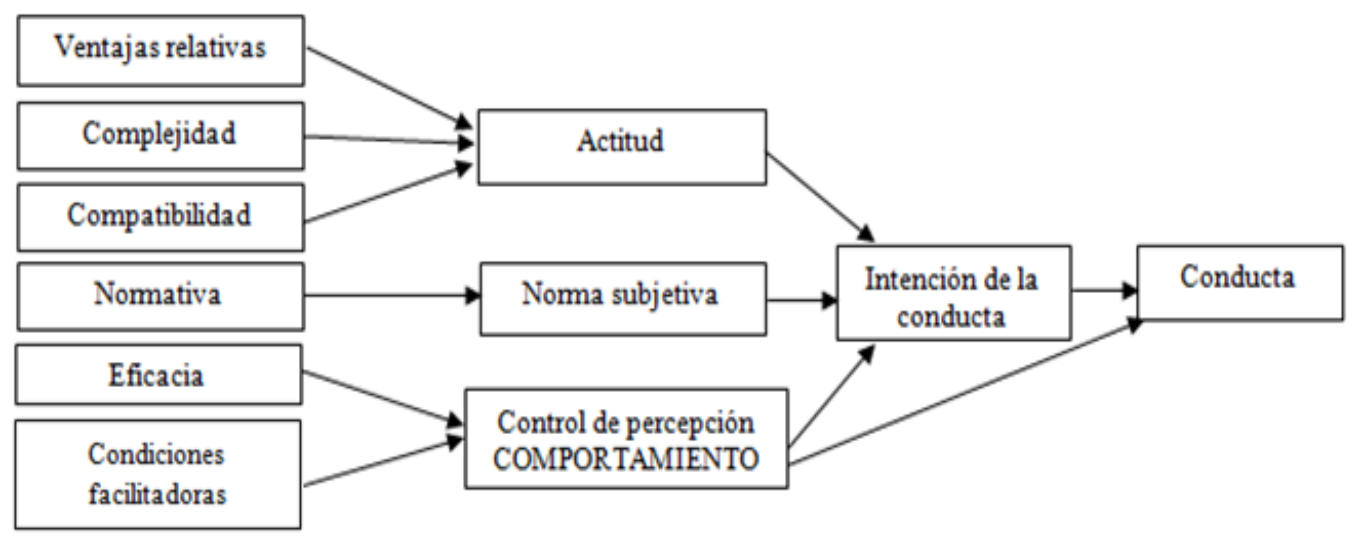

Figura 8. Modelo TPB (Ajzen, 1991)

La inclusión de un nuevo concepto como determinante de la intención y de la conducta fue ampliamente estudiada por Ajzen y Madden (1986). Estudios previos definieron el control de percepción del comportamiento como la percepción del individuo sobre la presencia o ausencia de recursos y oportunidades necesarias para ejecutar una conducta o comportamiento (Ajzen, 1985, 1991; Ajzen y Driver, 1992). El control de percepción del comportamiento se determina en función de dos componentes: eficacia y condiciones facilitadoras. La eficacia parte de la auto-confianza del individuo en su habilidad para realizar correctamente una conducta (Bandura, 1982; Ajzen, 1991). Las condiciones facilitadoras se determinan dependiendo de la disponibilidad de los recursos (tiempo, dinero, etc.) que se tengan para influir en el comportamiento. 
Una gran cantidad de estudios avalan la TPB y las revisiones meta-analíticas han confirmado su elevada capacidad predictiva. Además, ha sido aplicado en una gran variedad de situaciones. Mathieson (1991) previó la intención de las personas para utilizar un sistema de información específico.

Beck y Ajzen (1991) utilizaron la TPB para la predicción de acciones deshonestas, siendo necesario que estudiantes universitarios completaran un cuestionario para evaluar las actitudes, normas subjetivas, la percepción de control del comportamiento, intenciones y percepciones de las obligaciones morales, así como los auto-informes de comportamiento con respecto a hacer trampa en exámenes, robar y mentir.

Terry y O’Leary (1995) realizaron un estudio para evaluar la utilidad de la TPB basándose en la capacidad de control de la conducta y las expectativas de eficacia para predecir la intención de participar en el ejercicio regular y el comportamiento del ejercicio actual de las personas.

Taylor y Todd (1995) usaron el TPB para predecir el uso que los estudiantes hacen del ordenador.

Posteriormente, el TPB fue aplicado para comprender el grado de la aceptación individual y el uso de las diferentes tecnologías (Harrison et al., 1997).

George (2004), utilizando la teoría de la conducta planificada como base, analiza las relaciones entre las creencias acerca de la privacidad en Internet y la confiabilidad, junto con las creencias acerca de la percepción de control del comportamiento y el comportamiento de compra online. 
Más tarde, Paulov y Fygenson (2006), extendiendo la TPB de Ajzen (1991), realizaron un estudio para explicar y predecir el proceso de adopción del comercio electrónico por los consumidores.

Sin embargo, esta teoría psicosocial no ha estado exenta de críticas (Eagly y Chaiken, 1993). Para el presente estudio, entre las más importantes figuran que: i) ofrece una visión en exceso racionalista de las personas respecto a la toma de decisiones, ii) hace demasiado hincapié en la consideración única de los procesos individuales en la toma de decisión y iii) enfatiza el factor cognitivo sin considerar los aspectos emocionales (Leventhal y Cameron, 1987; Echebarría, 1991; Echebarría y Valencia, 1994). Además, distintos investigadores cuestionan alguno de los componentes básicos de la TPB, como por ejemplo la solidez teórica de la norma subjetiva en el modelo y la concepción general de las creencias normativas (Leventhal y Cameron, 1987; Johnston y White, 2003).

\section{MODELO DE COMBINACIÓN DEL TAM Y EL TPB (Modelo Combining the Technology Acceptance Model and the Theory of Planed Behavior, C - TAM - TPB)}

El modelo C-TAM-TPB de Taylor y Todd (1995), es un modelo híbrido que combina los predictores del TPB de Ajzen (1985, 1989) para predecir el comportamiento del individuo, con la percepción de la utilidad del TAM diseñado por Davis (1986), para predecir el uso de un sistema de información. 
Con el TAM tenemos una cierta ventaja empírica ya que es más fácil de aplicar, pero sólo provee información general sobre la opinión de los usuarios acerca de un determinado sistema de información. De modo alternativo, el TPB aporta una información más específica sobre la opinión de los usuarios y, por tanto, es el que mejor puede guiar el desarrollo de las predicciones sobre la intención de uso de un determinado sistema de información (Mathieson, 1991).

El modelo está determinado por variables tales como: actitud hacia el comportamiento, norma subjetiva, control de la percepción del comportamiento y percepción de la utilidad. La actitud en este modelo queda definida como la evaluación que hace el usuario sobre el uso de las tecnologías en un sistema. Las normas subjetivas reflejan las opiniones percibidas de personas o grupos de personas cuyas valoraciones pueden ser importantes para un individuo. El control de percepción del comportamiento queda definido por las percepciones sobre la presencia o ausencia de recursos $u$ oportunidades necesarias para llevar a cabo una conducta determinada (Ajzen y Madden, 1986). La utilidad es considerada como la probabilidad subjetiva de que usando un sistema específico se incremente el rendimiento del trabajo en un contexto organizacional.

La representación del modelo se muestra en la figura 9: 


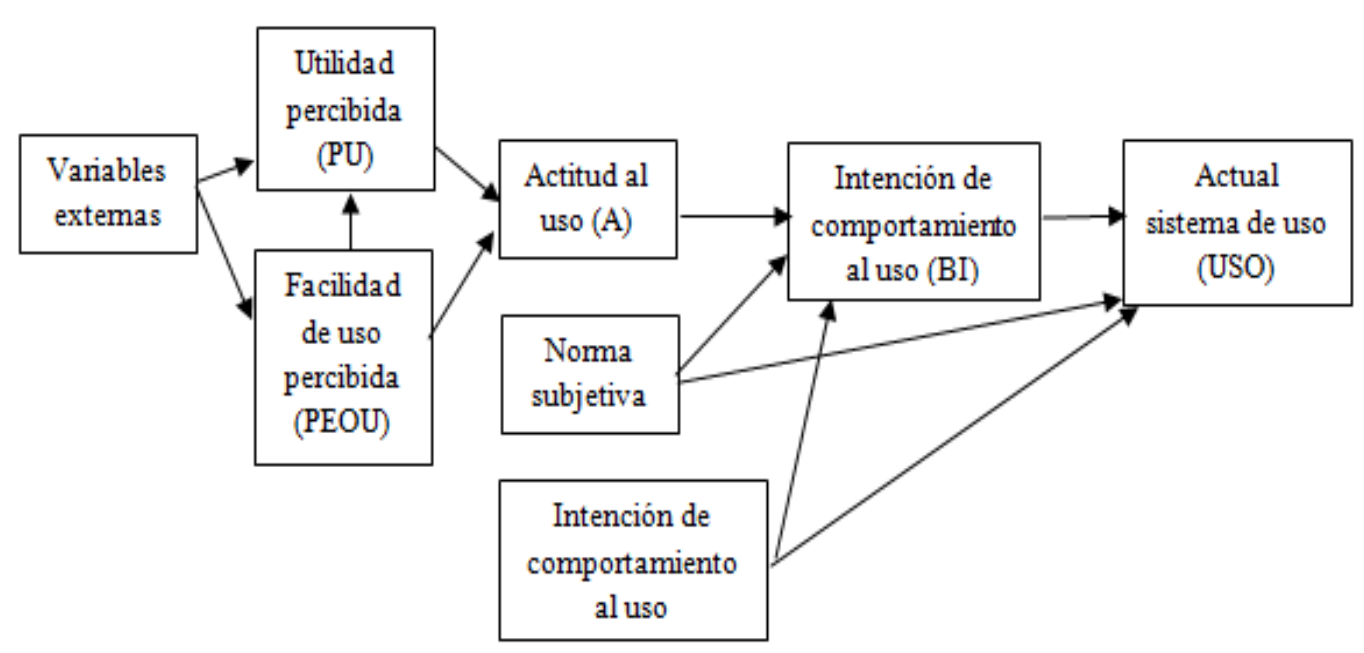

Figura 9. Modelo C-TAM-TPB (Taylor y Todd, 1995)

A pesar de que ambos modelos predicen la intención de uso de una tecnología bastante bien, hay tres diferencias principales entre ellos que dificultan su combinación (Mathieson, 1991). Concretamente, las diferencias existentes entre ambos están relacionadas con:

1. Grado de generalidad: el TAM asume que las creencias sobre la utilidad y la facilidad de uso son siempre los determinantes esenciales de las decisiones de uso (Davis, 1989). Sin embargo, el TPB usa las creencias que son específicas para cada una de las situaciones que se pueden presentar ya que, aunque algunas creencias pueden generalizarse, hay otras para las que no es posible (Mathieson, 1991). La diferencia entre los modelos se eleva a tres conceptos clave. El primero defiende que en algunas situaciones pueden existir distintas variables a la facilidad de uso y a la utilidad que predicen la intención. La segunda es aquella que parte de la dificultad del TPB para aplicar, a través de los distintos usuarios, los contextos que puede explicar el TAM. El 
tercer y último concepto es el que se basa en que el TPB requiere un comportamiento explícito alternativo si se quiere que el modelo sea lo más específico posible (Mathieson, 1991).

2. Variables sociales: La principal diferencia oscila en que el TAM no incluye explícitamente ninguna variable social.

3. Control del comportamiento: se refiere a la habilidad, oportunidad y recursos necesarios para usar un sistema. La única variable incluida en el TAM es la facilidad de uso (Davis, 1989). Aunque la posesión de requerir ciertas habilidades es importante, algunas veces otros controles pueden ser más efectivos. Ajzen (1985) diferencia entre los factores de control internos que son característicos, la habilidad y el poder. Al mismo tiempo incluye factores externos como el tiempo, las oportunidades y la cooperación con el resto de individuos que participan en el mismo proceso (Mathieson, 1991).

\section{MODELO DE UTILIZACIÓN DEL ORDENADOR PERSONAL (Model Personal Computer Utilization, MPCU)}

El Modelo de Utilización del Ordenador Personal (MPCU), desarrollado por Thompson et al. (1991), está basado en la Teoría de la Conducta Humana (Theory of Interpersonal Behavior, TIB) desarrollada por Triandis $(1971,1980)$ en un intento de superar las deficiencias encontradas en las teorías TRA y TPB. Por ejemplo, mientras Fishbein y Ajzen (1975) consideran en su teoría todas las opiniones que una persona 
puede tener sobre un comportamiento, Triandis (1980) hace una distinción entre las opiniones que enlazan las emociones a los actos y las que enlazan una actuación con las consecuencias que dicha actuación pueda tener en el futuro. Según Triandis (1980) las intenciones de una persona están influenciadas por lo que le gustaría hacer (afecto), lo que piensa que debería hacer (factores sociales) y las consecuencias esperadas de su comportamiento (consecuencias percibidas). La conducta actual está determinada por lo que la persona hace habitualmente (hábitos), por sus intenciones y por las condiciones facilitadoras.

La figura 10 muestra el Modelo de Triandis:

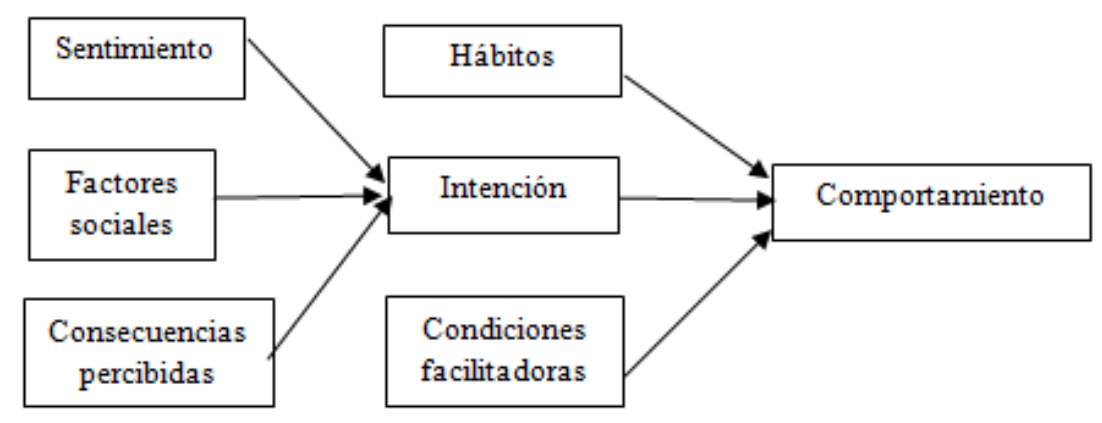

Figura 10. Modelo Triandis (Adaptado de Triandis)

A pesar de la aceptación de la teoría de Triandis (1980) dentro de la literatura psicológica, no ha sido utilizada en el contexto de los sistemas de información. Por ello, Thompson et al. (1991) propusieron una adaptación de la misma al contexto del uso del ordenador personal (PC) por parte de los trabajadores. La teoría del MPCU se centra en el uso que puede hacer un trabajador cualificado de un PC y con unos conocimientos previos sobre PC, sabiendo que su uso es opcional. Se trata de conocer las influencias 
que tiene el trabajador para usar el PC y que a su vez, pueden estar motivadas por aspectos tales como: los sentimientos que el individuo tiene sobre el uso de los PC, las normas sociales que existen en el trabajo concernientes al uso de los mismos, los hábitos asociados con el uso del ordenador, las consecuencias esperadas sobre el uso del PC y las condiciones facilitadoras del medio que conducen al uso del ordenador (Thompson et al., 1991).

Thompson et al. (1991) realizaron varias modificaciones sobre el modelo de Triandis (1980) que permitieron establecer un modelo en el contexto de los sistemas informáticos:

- La primera modificación consiste en la identificación de tres componentes cognitivos de las consecuencias percibidas: la complejidad (el grado en el que una innovación es considerada como relativamente difícil de entender y usar), la forma de trabajo (medida en la que usando un PC se puede mejorar el rendimiento del trabajo) y las consecuencias a largo plazo del uso del PC.

- La segunda modificación es que el constructo del hábito o costumbre fue excluido en el modelo establecido por Thompson et al. (1991) porque no se consideró que fuese un claro influyente de la conducta.

A partir de estas modificaciones surge el modelo MCPU mostrado en la figura 11: 


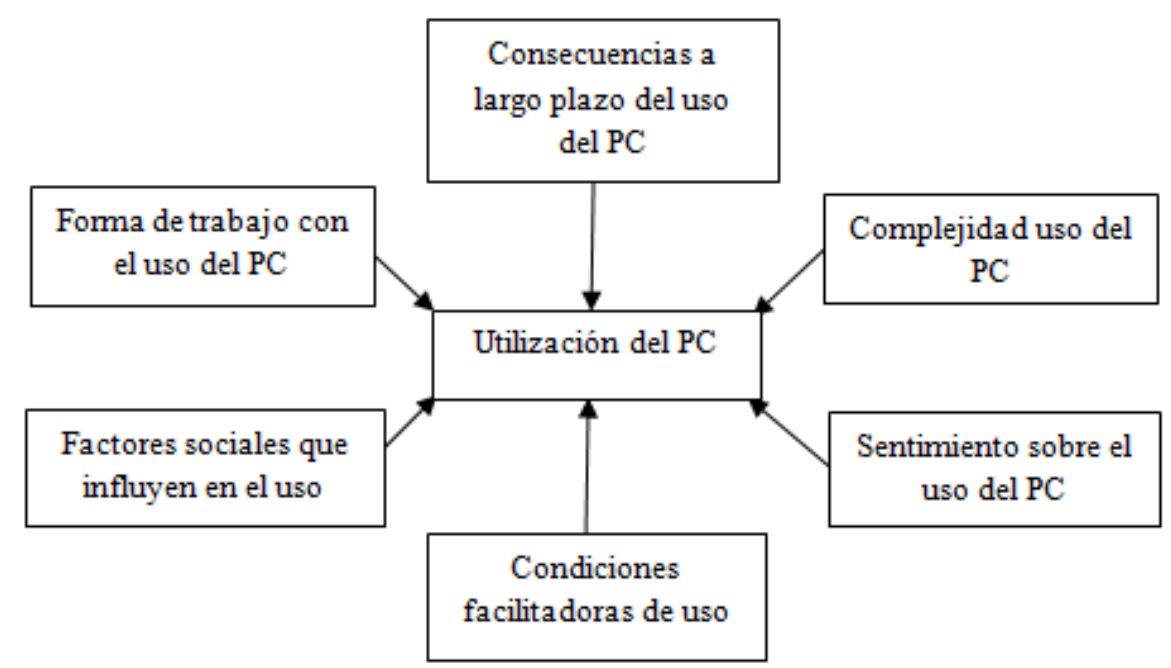

Figura 11. Modelo MPCU. (Thompson et al., 1991).

Aunque los estudios realizados a lo largo del tiempo, han mostrado que los factores sociales, la complejidad, la forma de trabajo y las consecuencias a largo plazo tienen efectos significativos en el uso del PC, no hay evidencias de que los sentimientos y las condiciones facilitadoras afecten al uso o no de los mismos. La explicación de estos resultados parte de que "los ordenadores son vistos como simples herramientas y no como algo que deba gustar o no, sino que es necesario para el actual desarrollo del trabajo" (Thompson et al., 1991).

Se trata también, de una línea de estudio inconsistente con la teoría de Davis et al. (1989) que encuentra un efecto significativo entre la actitud y el comportamiento hacia el uso de la tecnología. Aunque el componente afectivo de la actitud no es significativo en relación con el concepto de la utilización, "los componentes cognitivos son medidos por la consecuencias percibidas como predictores significativos de la utilización del PC" (Thompson, 1991). 


\section{TEORÍA DE LA DIFUSIÓN DE LA INNOVACIÓN (Innovation Diffusion Theory, IDT)}

Rogers (1962) recogió y formalizó las diferentes teorías sobre difusión de la innovación en la denominada Teoría de la Difusión de la Innovación (IDT), la cual sintetiza más de 3.800 publicaciones sobre teorías de difusión. Esta teoría explica un amplio rango de aspectos relacionados con la adopción de la tecnología, como son el proceso de decisión de la innovación, los determinantes del ritmo de adopción y las diferentes categorías de adoptantes. Esta teoría ha sido especialmente diseñada para medir las percepciones que un individuo tiene, las cuales le llevarán a adoptar una innovación en el ámbito de las tecnologías de la información (Moore y Benbasat, 1991). La IDT intenta ser una herramienta para estudiar la adopción inicial y la eventual difusión de las innovaciones tecnológicas dentro de las organizaciones.

Rogers (1962) identifica cinco atributos que influyen en la tasa de adopción de la tecnología, la cual se puede predecir midiendo las percepciones que tienen las personas de dichos atributos:

- Ventaja relativa: Es el grado en el que una innovación es percibida como mejor que su precursora.

- Compatibilidad: Es el grado en el que una innovación es percibida como más consistente con los valores, necesidades y experiencias pasadas de los posibles individuos que adopten dicha innovación. 
- Complejidad: Es el grado en el que una innovación es percibida como difícil de usar.

- Observabilidad: Es el grado en el que los resultados de una innovación son observables para otros.

- $\quad$ Experimentación: Es el grado en que una innovación puede ser probada por sus futuros adoptantes.

En conclusión, para que una innovación sea adoptada con mayor rapidez debe contar con un nivel alto de percepción de ventaja relativa, compatibilidad, observabilidad y experimentación, mientras que debe poseer una baja complejidad.

Algunos investigadores han señalado las similitudes entre el TAM y la IDT. Por ejemplo, el constructo "ventaja relativa" empleado en la IDT es considerado a menudo como equivalente al constructo "utilidad percibida" del TAM. Además, el constructo “complejidad" de la IDT es similar al constructo "facilidad de uso percibida".

Por ello, Moore y Benbasat (1991) combinaron la IDT y el TAM para desarrollar un instrumento para medir la aceptación de la tecnología. Renombraron el constructo de la IDT “complejidad” como "facilidad de uso". Introdujeron el constructo "imagen" que representa el grado en el que el uso de una innovación sirve para favorecer la imagen o estatus de un sistema. Además, el constructo "observabilidad" se separó en dos partes: resultados demostrables, es decir, la tangibilidad de los resultados al usar la innovación, incluidos la observabilidad y la comunicabilidad, y la visibilidad, que se centra en la 
presencia física de la innovación en el entorno organizacional. Por tanto, los constructos usados por Moore y Benbasat (1991) son la ventaja relativa, la compatibilidad, la imagen, la facilidad de uso, los resultados demostrables, la visibilidad y la experimentación.

\section{TEORÍA SOCIAL COGNITIVA (Social Cognitive Theory, SCT )}

La Teoría Social Cognitiva presentada por Bandura (1977), proporciona un marco para entender, predecir y cambiar el comportamiento humano. La teoría considera al comportamiento humano como una interacción entre el entorno, el comportamiento y factores personales.

El entorno incluiría influencias ambientales tales como las presiones sociales o las características de una situación única, cognitiva o de otros factores como la personalidad o las características demográficas. Los individuos eligen el entorno en que desean desenvolverse y además pueden verse influenciados por cada situación en particular. Por otra parte, el comportamiento de una persona en una situación determinada se puede ver afectado por el medio y por las características de la situación. Es más, el comportamiento suele verse influido por aspectos cognitivos o por factores personales concretos. Esta relación, a la que Bandura (1986) se refiere como "reciprocidad triádica", se muestra en la figura siguiente: 


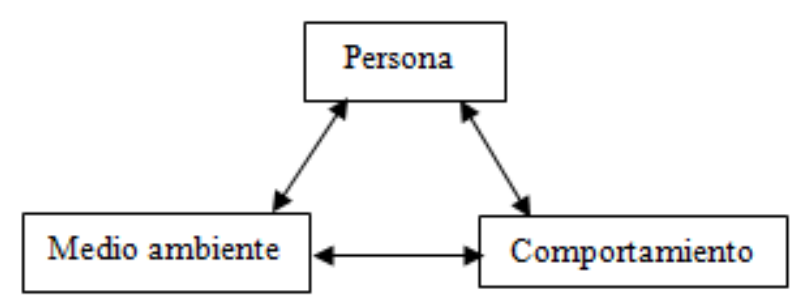

Figura 12. Determinismo recíproco o reciprocidad triádica (Bandura, 1986)

Mientras que la teoría cognitiva tiene muchas dimensiones, Bandura (1986) se preocupa en mayor medida, por el papel de los factores cognitivos en la conducta individual, destacando dos conjuntos de expectativas que se definen como las principales fuerzas cognitivas del comportamiento.

El primer conjunto de expectativas se relaciona con los resultados, ya que las personas son más proclives a emprender unas actividades conductuales con las que creen que se incrementará el valor de los resultados en una serie de consecuencias facilitadoras (Bandura, 1986). El segundo conjunto de expectativas abarca lo que Bandura (1986) denomina "auto-eficacia", definida como la capacidad para llevar a cabo un comportamiento particular. La auto-eficacia influye en las decisiones que se han de tomar sobre los comportamientos de esfuerzo y de persistencia que se han de adquirir para hacer frente a los obstáculos que se oponen a ejercer un cierto comportamiento (Compeau y Higgins, 1995).

El constructo de la utilidad medido por Davis (1989) y Davis et al. (1989) refleja las expectativas sobre los resultados. El modelo MCPU de Thompson et al. (1991) 
incluye, asimismo, las consecuencias percibidas como un determinante central de comportamiento.

Mientras estas expectativas han sido consideradas por muchos investigadores en el campo de los sistemas de información, el papel de la auto-eficacia ha recibido una menor atención (Compeau y Higgins, 1995). Unos pocos estudios (por ejemplo, Cheney y Nelson, 1988) han intentado desarrollar medidas para alcanzar habilidades con el ordenador. Estas medidas incorporaron algunos aspectos de la auto-eficacia del equipo, pero se diseñaron para medir la capacidad real y no la auto-eficacia. Inicialmente fueron escasos los estudios explícitos que tuvieron en cuenta el papel de la auto-eficacia en el comportamiento de la computación ${ }^{34}$ (Burkhardt y Brass, 1990; Hill et al., 1987; Webster y Martocchio, 1992; Webster y Martocchio 1993). Se trata de unos estudios que proporcionan una clara evidencia inicial de que la auto-eficacia tiene una gran influencia en las reacciones individuales sobre la tecnología.

Posteriormente, ha llegado a corroborarse que la auto-eficacia se une a las expectativas de los resultados, los sentimientos o la inquietud de los individuos para utilizar los sistemas informáticos (Compeau y Higgins, 1995). En consonancia con el resto de investigaciones, trabajos como el de Compeau et al. (1999) demuestran que la auto-eficacia y las respuestas emocionales, como el sentimiento y la ansiedad, influyen en el éxito de una tecnología. Además, Compeau y Higgins (1995) y Compeau et al. (1999) detectan una clara división que afecta a las expectativas de resultados. Por un lado, las expectativas personales identificadas con el sistema de recompensas y, por otro lado, aquellas expectativas de resultados o de mejora en el trabajo que permiten

34 La computación es una ciencia fundamental para el desarrollo de la sociedad ya que, puede desarrollar nuevas formas de procesamiento de datos. 
potenciar la eficiencia y la eficacia, por ejemplo, en el uso de los ordenadores como proponen en su modelo.

\section{TEORÍA UNIFICADA DE ACEPTACIÓN Y USO DE LA TECNOLOGÍA (Unified Theory of Acceptance and Use of Technology, UTAUT)}

La Teoría Unificada de Aceptación y Uso de la Tecnología (UTAUT) de Venkatesh et al. (2003) es un modelo integrado que fue formulado con los cuatro determinantes principales de la intención y el uso y por cuatro moderadores claves de las relaciones (género, edad, sexo, experiencia y voluntariedad de uso). Más tarde, el UTAUT fue utilizado para superar a uno o más de los modelos individuales descritos con anterioridad. Los cuatro constructos de los que parte el modelo juegan un papel significativo como determinantes directos de la aceptación de los usuarios y de su comportamiento. Se trata de la expectativa de rendimiento, expectativa de esfuerzo, influencia social y las condiciones facilitadoras (Venkatesh et al., 2003) que se muestran en la figura 13 y que son definidas a continuación:

- Las expectativas de rendimiento se definen como el grado en el que un individuo cree que utilizando un sistema determinado se verá beneficiado para conseguir los objetivos fijados en el trabajo. Se trata del predictor de la intención más fuerte y consistente (Agarwal y Prasad, 1998). Esta variable está compuesta por varios de los constructos que explican diversos modelos entre los que se encuentran: la percepción de utilidad de los modelos TAM y C-TAM-TPB (Davis, 1989; Davis et al., 
1992), la motivación extrínseca del MM aplicada al ámbito tecnológico (Davis et al., 1992), la forma de trabajo del modelo MPCU (Thompson et al., 1991), las ventajas relativas del modelo IDT (Moore y Benbasat, 1991) y las expectativas de resultados que quedan definidas en el modelo SCT (Compeau y Higgins, 1995).

- Las expectativas de esfuerzo se definen como el grado de facilidad asociado al uso del sistema. Recoge tres constructos derivados de los modelos TAM, MPCU e IDT: la percepción de la facilidad de uso (Davis, 1989; Davis et al., 1992), la complejidad (Thompson et al., 1991) y la facilidad de uso (Moore y Benbasat, 1991).

- La influencia social es el grado en que un individuo percibe que el uso del nuevo sistema es importante para otras personas. A su vez, esta variable viene influida por otros constructos que se derivan de diversos modelos. Por un lado se compone de la norma subjetiva del TRA, TPB y del C-TAM-TPB. Esta variable deriva principalmente de Ajzen (1991), quien a su vez la define como el grado en que un individuo percibe lo que cree que es importante para otros, la creencia de que se debería usar el nuevo sistema. Por otro lado, se consideran los factores sociales que derivan del MPCU, y que se caracterizan por la internacionalización individual de la cultura del grupo de referencia y del acuerdo internacional que los individuos hacen entre sí (Thompson et al., 1991).

Finalmente, la influencia social está compuesta también por la imagen que proviene del modelo IDT. Moore y Benbasat (1991) la definieron como el grado en que se percibe que el uso de una innovación puede favorecer la imagen o el estatus de alguien en el entorno social. 
- Las condiciones facilitadoras se definen como el grado en que un individuo considera que la infraestructura organizacional y técnica existe para apoyar el uso de un sistema. Esta definición facilita la incorporación de tres constructos diferentes. El primero de ellos es la percepción del control del comportamiento, definido como la percepción de las restricciones internas y externas del propio comportamiento, y que viene incorporado en modelos tales como el TPB y el C-TAM-TPB (Ajzen, 1991; Taylor y Todd, 1995). Otro constructo es el de condiciones facilitadoras definido por Thompson et al. (1991). Este concepto se deriva del modelo MPCU, definido como los factores objetivos del medio ambiente por el que los observadores acuerdan realizar un acto fácil de hacer, incluyendo la provisión de soporte informático. Por último, está la variable de compatibilidad definida por Moore y Benbasat (1991) y que surge a partir del modelo IDT como el grado en que una innovación se percibe consistente con los valores, las necesidades y la experiencia de los usuarios potenciales.

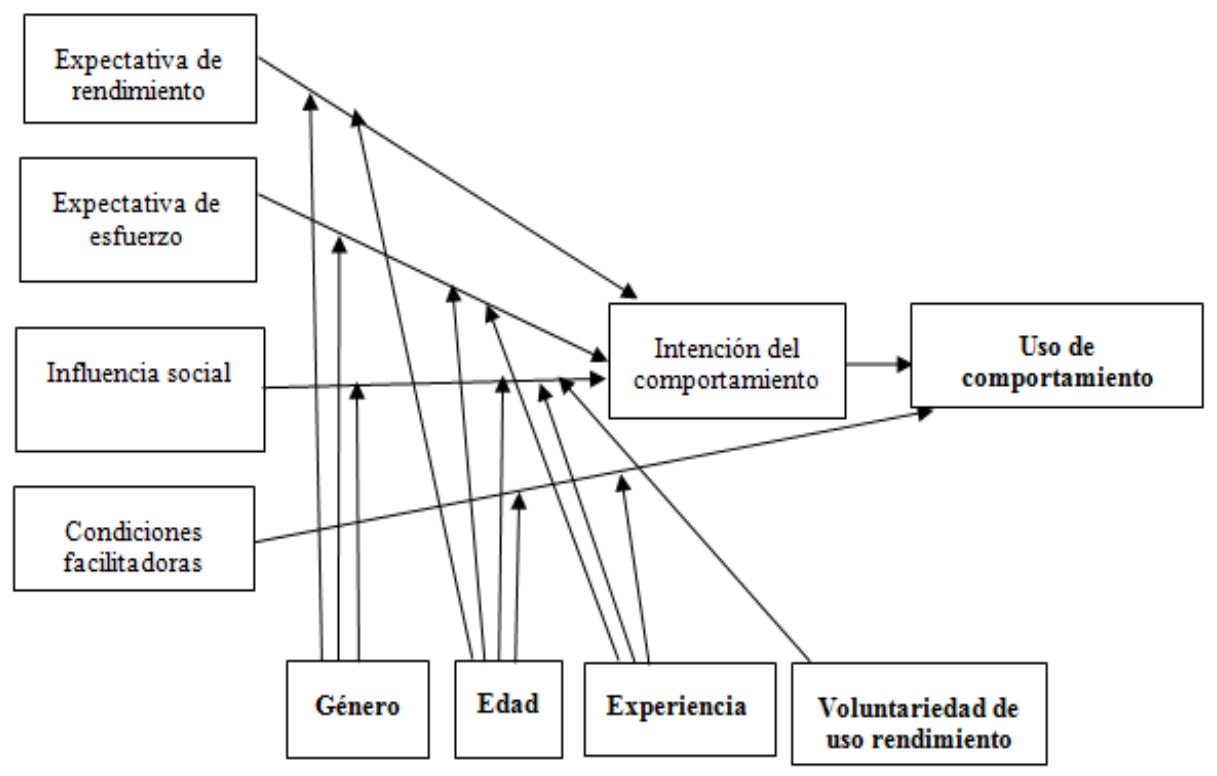

Figura 13. Modelo UTAUT (Venkatesh et al., 2003) 
Las diversas aplicaciones que se han hecho del modelo UTAUT han permitido llegar a la conclusión de que los tres primeros constructos tienen una relación directa con la intención del comportamiento (Venkatesh et al, 2003). El uso del comportamiento viene definido en función de la intención de comportamiento y las condiciones facilitadores que regirán el fin básico del modelo UTAUT.

A pesar de tratarse de un modelo completo en lo referente a la información aportada y a las variables que lo definen, sigue considerándose que las líneas de investigación futuras del modelo UTAUT deberían de ir dirigidas a analizar el éxito que tiene el comportamiento de uso con la adopción de las TIC.

\section{COMPARACIÓN DE MODELOS}

En la siguiente tabla se realiza una comparación de los modelos descritos en los apartados anteriores.

Tabla 3. Comparación de los modelos.

\begin{tabular}{|c|c|c|}
\hline \multicolumn{3}{|c|}{ TRA - Teoría de la Acción Razonada } \\
\hline Características Básicas & Núcleo constructo & Definición \\
\hline \multirow{2}{*}{$\begin{array}{l}\text { Diseñado a partir de la psicología } \\
\text { social, el TRA es una de las teorías más } \\
\text { influyentes y fundamentales del } \\
\text { comportamiento humano. Se ha utilizado para } \\
\text { predecir una amplia serie de comportamientos } \\
\text { (Sheppard et al., 1988). }\end{array}$} & $\begin{array}{l}\text { - Actitud hacia el } \\
\text { comportamiento. }\end{array}$ & $\begin{array}{l}\text { Sentimiento positivo o negativo } \\
\text { que se da en un individuo sobre } \\
\text { el cumplimiento del objetivo del } \\
\text { comportamiento. }\end{array}$ \\
\hline & $\begin{array}{l}\text { - Modelo subjetivo o } \\
\text { norma subjetiva. }\end{array}$ & $\begin{array}{l}\text { Percepción de las personas que } \\
\text { la mayoría de gente cree que no } \\
\text { debería formar parte del } \\
\text { comportamiento en cuestión. }\end{array}$ \\
\hline
\end{tabular}




\section{TAM - Modelo de Aceptación de la Tecnología}

\begin{tabular}{|c|c|c|}
\hline Características Básicas & Núcleo constructo & Definición \\
\hline $\begin{array}{l}\text { El TAM desarrollado por Davis (1986), } \\
\text { se confeccionó para el contexto del sistema de } \\
\text { información, y fue diseñado para predecir la } \\
\text { aceptación y el uso de la tecnología de la }\end{array}$ & - Percepción de utilidad. & $\begin{array}{l}\text { Es el grado en que una persona } \\
\text { cree que usando un sistema } \\
\text { particular mejorará el } \\
\text { funcionamiento de su trabajo. }\end{array}$ \\
\hline $\begin{array}{l}\text { TRA, el TAM incluye la percepción de } \\
\text { utilidad y de facilidad de uso como dos nuevas } \\
\text { variables que influyen en la intención de uso } \\
\text { de las tecnologías. }\end{array}$ & $\begin{array}{l}\text { - Percepción de facilidad } \\
\text { de uso. }\end{array}$ & $\begin{array}{l}\text { Es el grado en que una persona } \\
\text { cree que usando un sistema } \\
\text { particular debería de estar libre } \\
\text { de esfuerzo. }\end{array}$ \\
\hline
\end{tabular}

\section{MM - Modelo Motivacional}

\begin{tabular}{|c|c|c|}
\hline Características Básicas & Núcleo constructo & Definición \\
\hline $\begin{array}{l}\text { Dentro del dominio de los sistemas de } \\
\text { información, Davis et al. (1992) y Venkatesh } \\
\text { y Speier (1999), aplicaron la teoría } \\
\text { motivacional para comprender la adopción y } \\
\text { el uso de la nueva tecnología. Dos amplías } \\
\text { clases de motivación han sido definidas y } \\
\text { examinadas a través de diversos contextos. } \\
\text { Ambas, de manera conjunta, influyen en la }\end{array}$ & - Motivación extrínseca. & $\begin{array}{l}\text { Percepción que los usuarios } \\
\text { querrán para poner en marcha } \\
\text { una actividad porque es } \\
\text { percibido para ser un } \\
\text { instrumento que genere un valor } \\
\text { que permita mejorar el } \\
\text { funcionamiento de su trabajo o } \\
\text { su promoción. }\end{array}$ \\
\hline $\begin{array}{l}\text { actividad y en su desempeño real (Deci, } \\
\text { 1975). Una parte significativa de la } \\
\text { investigación hecha en psicología ha apoyado } \\
\text { la teoría motivacional como una explicación } \\
\text { para el comportamiento. Varios estudios han } \\
\text { examinado la teoría motivacional y la han } \\
\text { adaptado a contextos más específicos. }\end{array}$ & - Motivación intrínseca. & $\begin{array}{l}\text { Percepción que los usuarios } \\
\text { querrán para poner en marcha } \\
\text { una actividad sin el esfuerzo } \\
\text { aparente que el proceso de la } \\
\text { actividad persigue. }\end{array}$ \\
\hline
\end{tabular}

\section{TPB - Teoría del Comportamiento Planificado}

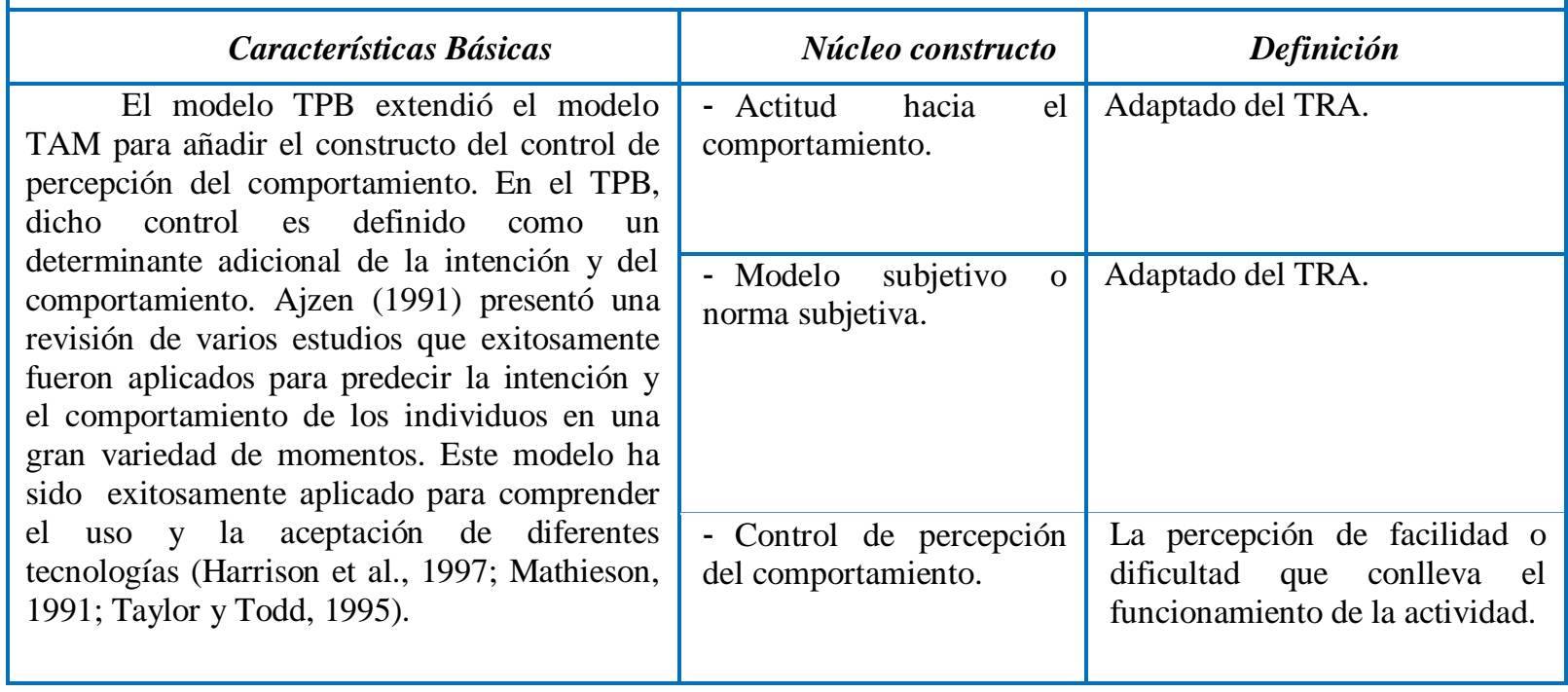




\section{C-TAM-TPB - Modelo de Combinación del TAM y el TPB}

\begin{tabular}{|c|c|c|}
\hline Características Básicas & Núcleo constructo & Definición \\
\hline \multirow{4}{*}{$\begin{array}{l}\text { Este modelo combina los predictores } \\
\text { del TPB con la percepción de utilidad desde el } \\
\text { TAM para proveer un modelo híbrido (Taylor } \\
\text { y Todd, 1995). Su principal finalidad era } \\
\text { poder predecir el uso de un sistema de } \\
\text { información. }\end{array}$} & $\begin{array}{l}\text { - Actitud hacia el } \\
\text { comportamiento. }\end{array}$ & Adaptado del TRA/TPB. \\
\hline & $\begin{array}{l}\text { - Modelo subjetivo o } \\
\text { norma subjetiva. }\end{array}$ & Adaptado del TRA/TPB. \\
\hline & $\begin{array}{l}\text { - Control de percepción } \\
\text { del comportamiento. }\end{array}$ & Adaptado del TRA/TPB. \\
\hline & $\begin{array}{l}\text { - Percepción de la } \\
\text { utilidad. }\end{array}$ & Adaptado del TAM. \\
\hline \multicolumn{3}{|c|}{ MPCU - Modelo de Utilización del Ordenador Personal } \\
\hline Características Básicas & Núcleo constructo & Definición \\
\hline \multirow{6}{*}{$\begin{array}{l}\text { Este modelo deriva de la teoría del } \\
\text { comportamiento humano de Triandis (1977). } \\
\text { Thompson et al. (1991) adaptaron el modelo } \\
\text { de Triandis al contexto de los sistemas de } \\
\text { información y utilizaron el modelo para } \\
\text { predecir el uso de los PC. Sin embargo, la } \\
\text { naturaleza del modelo lo hace particularmente } \\
\text { adecuado para predecir la aceptación y uso de } \\
\text { los individuos, hacia una serie de tecnologías } \\
\text { de la información. }\end{array}$} & - Forma de trabajo. & $\begin{array}{l}\text { Extiende la creencia individual } \\
\text { que cree que usando una } \\
\text { tecnología puede mejorar el } \\
\text { funcionamiento de su trabajo. }\end{array}$ \\
\hline & - Complejidad. & $\begin{array}{l}\text { Grado en que una innovación es } \\
\text { percibida como de una } \\
\text { dificultad relativa para su } \\
\text { comprensión y uso. }\end{array}$ \\
\hline & $\begin{array}{l}\text { - Consecuencias a largo } \\
\text { plazo. }\end{array}$ & $\begin{array}{l}\text { Resultados que se han de pagar } \\
\text { en el futuro. }\end{array}$ \\
\hline & - Actitud hacia el uso. & $\begin{array}{l}\text { Sentimiento del encanto, } \\
\text { agrado, disgusto o de odio } \\
\text { asociado por el acto de un } \\
\text { individuo en particular. }\end{array}$ \\
\hline & - Factores sociales. & $\begin{array}{l}\text { Factores como la internalización } \\
\text { del individuo de la cultura del } \\
\text { grupo de referencia y del } \\
\text { acuerdo de las especificaciones } \\
\text { interpersonales que el individuo } \\
\text { hace con los demás en una } \\
\text { situación específica. }\end{array}$ \\
\hline & $\begin{array}{l}\text { - Condiciones } \\
\text { facilitadoras. }\end{array}$ & $\begin{array}{l}\text { Se trata de los principales } \\
\text { objetivos del medio que } \\
\text { observan el grado en que un } \\
\text { acto es fácilmente desarrollado. }\end{array}$ \\
\hline
\end{tabular}




\begin{tabular}{|c|c|c|}
\hline \multicolumn{3}{|c|}{ IDT - Teoría de la Difusión de la Innovación } \\
\hline Características Básicas & Núcleo constructo & Definición \\
\hline \multirow{7}{*}{$\begin{array}{l}\text { Basado en aspectos sociológicos, el } \\
\text { modelo IDT (Rogers, 1962) ha sido utilizado } \\
\text { desde } 1960 \text { para estudiar la variedad de } \\
\text { innovaciones. Dentro de los sistemas de } \\
\text { información, Moore y Benbasat (1991) } \\
\text { adaptaron la IDT y redefinieron una serie de } \\
\text { constructos que podrían ser utilizados para } \\
\text { estudiar la aceptación de la tecnología. }\end{array}$} & - Ventaja relativa. & $\begin{array}{l}\text { Grado en que una innovación es } \\
\text { percibida como mejor que su } \\
\text { precursora. }\end{array}$ \\
\hline & - Facilidad de uso. & $\begin{array}{l}\text { Grado en que una innovación es } \\
\text { percibida como difícil de usar. }\end{array}$ \\
\hline & - Imagen. & $\begin{array}{l}\text { Grado en que el uso de una } \\
\text { innovación es percibida para } \\
\text { favorecer una imagen o estatus } \\
\text { en un sistema social. }\end{array}$ \\
\hline & - Visibilidad. & $\begin{array}{l}\text { Grado en que algo puede ser } \\
\text { visto para otros usos en el } \\
\text { sistema de una organización. }\end{array}$ \\
\hline & - Compatibilidad. & $\begin{array}{l}\text { Grado en que una innovación es } \\
\text { percibida como consistente con } \\
\text { los valores, necesidades y } \\
\text { experiencias pasadas existentes } \\
\text { por sus posibles usuarios. }\end{array}$ \\
\hline & $\begin{array}{l}\text { - Resultados } \\
\text { demostrables. }\end{array}$ & $\begin{array}{lr}\text { Tangibilidad de los resultados } \\
\text { obtenidos por usar una } \\
\text { innovación, incluyendo su } \\
\text { observabilidad } & \text { y } \\
\text { comunicabilidad. } & \end{array}$ \\
\hline & - Voluntariedad de uso. & $\begin{array}{l}\text { Grado en que el uso de la } \\
\text { innovación es percibido como } \\
\text { algo voluntario o de uso libre. }\end{array}$ \\
\hline \multicolumn{3}{|l|}{ SCT - Teoría Social Cognitiva } \\
\hline \multirow{6}{*}{$\begin{array}{l}\text { Características Básicas } \\
\text { La Teoría Social Cognitiva, presentada } \\
\text { por Bandura, (1977), proporciona un marco } \\
\text { para entender, predecir y cambiar el } \\
\text { comportamiento humano. Compeau y Higgins } \\
\text { (1995) aplicaron y extendieron el SCT al } \\
\text { contexto de la utilización de los ordenadores, } \\
\text { pero la naturaleza del modelo y su teoría } \\
\text { permiten extenderlo a la aceptación y el uso } \\
\text { del contexto de la tecnología de la } \\
\text { información. El modelo de Compeau y } \\
\text { Higgins (1995) utilizó el uso como la variable } \\
\text { dependiente pero manteniendo el espíritu de la } \\
\text { predicción de la aceptación individual. }\end{array}$} & Núcleo constructo & Definición \\
\hline & $\begin{array}{l}\text { - Expectativas de } \\
\text { resultados - rendimiento. }\end{array}$ & $\begin{array}{lll}\text { Las consecuencias } & \text { relativas del } \\
\text { rendimiento } & \text { de } \\
\text { comportamiento. } & \end{array}$ \\
\hline & $\begin{array}{l}\text { - Expectativas } \\
\text { resultados - personales. }\end{array}$ & $\begin{array}{l}\text { Las consecuencias personales } \\
\text { del comportamiento de un } \\
\text { individuo. }\end{array}$ \\
\hline & - Auto eficacia. & $\begin{array}{l}\text { Juicio que se hace de la } \\
\text { habilidad para utilizar las } \\
\text { tecnologías. }\end{array}$ \\
\hline & - Sentimiento. & $\begin{array}{l}\text { Inclinación de un individuo } \\
\text { hacia un comportamiento en } \\
\text { particular. }\end{array}$ \\
\hline & - Ansiedad. & $\begin{array}{l}\text { Evocar ansiedad o reacciones } \\
\text { emocionales cuando se realiza } \\
\text { un comportamiento. }\end{array}$ \\
\hline
\end{tabular}




\begin{tabular}{|c|c|c|}
\hline \multicolumn{3}{|c|}{ UTAUT - Teoría Unificada de Aceptación y Uso de la Tecnología } \\
\hline Características Básicas & Núcleo constructo & Definición \\
\hline \multirow{4}{*}{$\begin{array}{l}\text { Se trata de un modelo integrado } \\
\text { definido por Venkatesh et al. (2003) que se } \\
\text { desarrolla a través de cuatro constructos que } \\
\text { tienen un papel significativo como } \\
\text { determinantes directos de la aceptación y uso } \\
\text { del comportamiento. }\end{array}$} & $\begin{array}{l}\text { - Expectativa } \quad \mathrm{de} \\
\text { rendimiento. }\end{array}$ & $\begin{array}{l}\text { Grado en que un individuo cree } \\
\text { que utilizando un sistema } \\
\text { obtendrá un mayor rendimiento } \\
\text { en su trabajo. }\end{array}$ \\
\hline & - Expectativa de esfuerzo. & $\begin{array}{l}\text { Grado de facilidad asociado con } \\
\text { el uso de un sistema. }\end{array}$ \\
\hline & - Influencia social. & $\begin{array}{l}\text { Grado en que un individuo } \\
\text { percibe que el uso del nuevo } \\
\text { sistema es importante para } \\
\text { otros. }\end{array}$ \\
\hline & $\begin{array}{l}\text { - Condiciones } \\
\text { facilitadoras. }\end{array}$ & $\begin{array}{l}\text { Grado en que una persona } \\
\text { considera que la infraestructura } \\
\text { puede apoyar el uso de un } \\
\text { sistema. }\end{array}$ \\
\hline
\end{tabular}

Fuente: Elaboración propia.

\section{CONCLUSIÓN Y REFLEXIÓN FINAL}

Una de las áreas más investigadas dentro del campo de los sistemas de información a lo largo de los años, ha sido la aceptación del uso de las nuevas tecnologías. Consecuentemente, han sido numerosos los estudios que han explicado la aceptación de los sistemas de información y comunicación a través de diferentes modelos que han permitido contrastar las actitudes y comportamientos de los usuarios ante los mismos.

Por un lado, Fishbein y Ajzen (1967) presentaron la Teoría de la Acción Razonada (TRA) para estudiar los factores que influyen en las conductas hacia el uso y la aceptación de la tecnología. Esta teoría afirma que es posible predecir la conducta a 
partir de las actitudes, intenciones y creencias, y además, corrobora que la intención de una persona para llevar a cabo o no una conducta es la determinante inmediata de una acción.

Posteriormente surgió un modelo adaptado de la TRA, desarrollado por Davis (1986) y denominado Modelo de Aceptación de la Tecnología (TAM). Se trata de uno de los modelos más ampliamente utilizados en las investigaciones realizadas sobre la aceptación de las nuevas tecnologías que sugiere la existencia de varios factores que determinan el uso de una tecnología concreta. Reemplaza la variable de las creencias actitudinales definidas en la TRA por dos determinantes que son fundamentales en su estudio, la facilidad de uso y la utilidad, dos variables que impactan en la actitud y en consecuencia, en la intención y en la conducta de un individuo hacia el uso de la tecnología (Davis, 1989).

Otro modelo que permitió dar una explicación del comportamiento del ser humano es el Modelo Motivacional (MM). Según los estudios realizados por Deci y Ryan (1985), la motivación se identifica como un determinante clave del comportamiento. No obstante, se trata de un modelo que carece de estudios que identifique los factores que pueden influir en la motivación y que podrían ser la clave del uso de la tecnología.

La Teoría del Comportamiento Planificado (TPB o TCP) desarrollado por Ajzen (1985, 1989), apareció para predecir el comportamiento de los individuos y poder ser aplicado al uso de los sistemas de información. Este modelo surgió como una extensión del TRA, y cuenta con la diferencia principal de la incorporación de una nueva variable, el "control de percepción del comportamiento percibido". Se trata de uno de los 
modelos teóricos psicosociales más ampliamente utilizado y con mayor apoyo empírico en una gran variedad de conductas.

Más adelante, a partir de la unión del TAM y del TPB surgió el modelo C-TAMTPB para predecir el comportamiento del individuo. Fue aplicado por Mathieson (1991) para evaluar las intenciones de los usuarios sobre el uso de un sistema de información concreto.

Thompson et al. (1991) desarrollaron el Modelo de Utilización del Ordenador Personal (MPCU), que está basado en la Teoría de la Conducta Humana (Theory of Interpersonal Behavior, TIB) desarrollada por Triandis (1971, 1980) para intentar superar las deficiencias de las teorías TRA y TPB.

Rogers (1962) recogió y formalizó las diferentes teorías sobre difusión de la innovación en la denominada Teoría de la Difusión de la Innovación (IDT) intentando explicar un amplio rango de aspectos relacionados con la adopción de la tecnología. Esta teoría ha sido especialmente diseñada para medir las percepciones que un individuo tiene, las cuales le llevarán a adoptar una innovación en el ámbito de las tecnologías de la información (Moore y Benbasat, 1991).

Bandura (1977) aportó la Teoría Social Cognitiva con el propósito de proporcionar un marco que permitiera entender, predecir y cambiar el comportamiento humano. Compeau y Higgins (1995) ampliaron el SCT al contexto del uso de los ordenadores. No obstante, debido a la naturaleza del modelo y a la teoría subyacente, fue posible su extensión al contexto de la aceptación y uso de la tecnología de la información en general. 
Finalmente, surgió la Teoría Unificada de Aceptación y Uso de la Tecnología (UTAUT) de Venkatesh et al. (2003) como un modelo integrador formulado por cuatro determinantes principales de la intención y el uso y por cuatro moderadores claves de las relaciones (género, edad, sexo, experiencia y voluntariedad de uso).

En definitiva, se trata de una gran número de estudios que se han desarrollado a lo largo de los años y que han permitido dar una explicación de las variables que afectan al comportamiento humano en diferentes ámbitos, y que a su vez han determinado los constructos que repercuten sobre el grado de aceptación y uso de los usuarios de nuevas tecnologías.

A partir del análisis de estos modelos de aceptación de las tecnologías se sientan las bases que permitirán desarrollar un nuevo modelo de aceptación de la tecnología, basado en la variable de valor percibido como núcleo del modelo, una variable que bajo diversas denominaciones se refiere a un mismo concepto, cuyo objetivo principal será el usuario externo del sector sanitario y que será desarrollado en el capítulo 3 de este estudio. 

CAPÍTULO 3. DESARROLLO DE UN MODELO DE ACEPTACIÓN DE TECNOLOGÍAS EN USUARIOS EXTERNOS DEL SECTOR SANITARIO 



\section{OBJETIVO}

El objetivo de este capítulo es desarrollar, siguiendo la línea de Ventakesh et al. (2003), un modelo de aceptación de las TIC a partir de los modelos previos, enfocado a los usuarios externos del sistema sanitario (pacientes, cuidadores,...). En concreto, se trata de centrar el modelo en una de las variables recogidas en los modelos analizados previamente, con diversas acepciones pero reflejando el mismo concepto: el valor percibido.

El hecho de que esta variable esté presente en todos los modelos previos refleja su importancia como antecedente de la aceptación y uso de las tecnologías. Partiendo de esa variable, se pretende introducir una serie de variables que influyen en el valor percibido por los usuarios externos (en adelante, pacientes, cuidadores o familiares) de las TIC.

Igualmente, se estudia la implicación que el valor percibido tiene sobre la satisfacción de los pacientes una vez que utilizan los servicios sanitarios online y cómo esta variable influye en la lealtad electrónica o e-lealtad de los pacientes, es decir, en su intención de volver a utilizar servicios sanitarios online, ya que la e-lealtad se puede considerar como la clave del éxito de los servicios sanitarios online. La elección de dichas variables se realizará desde un enfoque de gestión del conocimiento y, por tanto, reflejarán flujos e intercambios de conocimiento entre la organización y el usuario. 


\section{INTRODUCCIÓN}

En el capítulo anterior se hizo un recorrido por los principales modelos desarrollados por los investigadores con el objetivo de mejorar la teoría sobre la aceptación de la tecnología. Así, Davis et al. (1992) y Venkatesh y Speier (1999) aplicaron la teoría motivacional para entender la adopción y uso de nuevas tecnologías desarrollando un Modelo Motivacional (MM).

La extensión de la Teoría de la Acción Razonada (TRA) añadiendo el constructo de control del comportamiento percibido proporcionó la Teoría del Comportamiento Planificado (TPB) (Ajzen, 1985, 1991) que ayuda a entender cómo podemos cambiar el comportamiento de las personas. Davis (1986) también se basó en la TRA para desarrollar el Modelo de Aceptación de la Tecnología (TAM), uno de los modelos más frecuentemente empleados en la investigación sobre la aceptación de nuevas tecnologías.

El modelo C-TAM-TPB, es un modelo híbrido que combina los predictores de la TPB con la percepción de utilidad del TAM (Taylor y Todd, 1995). Thompson et al. (1991) presentaron el Modelo de Utilización del Ordenador Personal (MPCU) basado en la teoría de comportamiento humano de Triandis, el cuál es adecuado para predecir la aceptación individual de un amplio rango de tecnologías de la información. Moore y Benbasat (1991) adaptaron la Teoría de la Difusión de la Innovación (IDT) de Roger y Shoemaker (1971) para estudiar la aceptación individual de la tecnología. Bandura (1986) presentó la Teoría Social Cognitiva para estudiar el comportamiento humano y Compeau y Higgins (1995) la aplicaron al contexto de utilización de ordenadores. Sin 
embargo, este modelo y su teoría subyacente permiten su extensión al área de la aceptación y uso de tecnologías de la información en general.

Como se observa, estos modelos comparten teorías y variables. De hecho, dadas las similitudes entre ellos, Ventakesh et al. (2003) propusieron una Teoría Unificada de Aceptación y Uso de Tecnologías (UTAUT). Dicha teoría fue desarrollada mediante la revisión y consolidación de los constructos de las teorías y modelos citados anteriormente.

El problema surge ante los escasos modelos de aceptación de las tecnologías que han ido enfocados al sector sanitario. Hoy en día, este sector se está viendo inmerso en una serie de cambios que surgen ante el desarrollo de las nuevas tecnologías y es a través de ellas por lo que emergen los nuevos servicios sanitarios online.

Para cumplir con el objetivo propuesto y dar solución al problema planteado, en este capítulo se justifica, en primer lugar, la elección del valor percibido como variable dependiente del modelo a desarrollar. En segundo lugar, se definen las variables independientes seleccionadas, se analiza su relación con el valor percibido y se desarrollan las primeras hipótesis. En tercer lugar, se procede a la definición y caracterización de una variable de carácter afectivo denominada satisfacción, y se realiza la conceptualización de la variable final, denominada e-lealtad (una variable de carácter conductual). Posteriormente, se analiza la relación entre estas variables y las hipótesis finales de esta investigación. Finalmente, se muestra el modelo desarrollado que será contrastado en los siguientes capítulos. 


\section{ELVALOR PERCIBIDO}

En el análisis de los diferentes modelos de aceptación de la tecnología que fue realizado en el capítulo anterior, se observa que algunas variables son contempladas en varios de dichos modelos. En concreto, existe una variable que, aunque toma diferentes denominaciones y es definida de forma distinta, recoge el mismo concepto. Esa variable es denominada "percepción de utilidad" en el modelo TAM de Davis (1989) y en el modelo C-TAM-TPB de Taylor y Todd (1995), "motivación extrínseca" en el Modelo Motivacional, "forma de trabajo" en el modelo MPCU, "ventajas relativas" en el modelo IDT y “expectativas de rendimiento" en la Teoría Social Cognitiva y el modelo UTAUT.

Tal y como muestra la tabla 4, en las diferentes definiciones propuestas en dichos modelos se hace referencia a conceptos como mejoras de funcionamiento, generación de valor o aumento del rendimiento.

Tabla 4. Diferentes acepciones y definiciones del valor percibido.

\begin{tabular}{|l|l|l|}
\hline \multicolumn{1}{|c|}{ MODELO } & \multicolumn{1}{|c|}{ ACEPCIÓN } & \multicolumn{1}{c|}{ DEFINICIÓN } \\
\hline TAM & Percepción de utilidad & $\begin{array}{l}\text { Es el grado en que una persona cree que usando un sistema } \\
\text { particular mejorará el funcionamiento de su trabajo. }\end{array}$ \\
\hline $\begin{array}{l}\text { Modelo } \\
\text { Motivacional }\end{array}$ & Motivación extrínseca & $\begin{array}{l}\text { Percepción que los usuarios querrán para poner en marcha una } \\
\text { actividad porque es percibido para ser un instrumento que genere } \\
\text { un valor que permita mejorar el funcionamiento de su trabajo o su } \\
\text { promoción. }\end{array}$ \\
\hline C-TAM-TPB & Percepción de utilidad & Tomado del TAM. \\
\hline MPCU & Forma de trabajo & $\begin{array}{l}\text { Creencia individual que cree que usando una tecnología puede } \\
\text { mejorar el funcionamiento de su trabajo. }\end{array}$ \\
\hline $\begin{array}{l}\text { IDT } \\
\text { Teoría Social } \\
\text { Cognitiva } \\
\text { (TSC) }\end{array}$ & $\begin{array}{l}\text { Expectativas de } \\
\text { resultados }- \\
\text { rendimiento. }\end{array}$ & $\begin{array}{l}\text { Grado en que una innovación es percibida como mejor que su } \\
\text { precursora. }\end{array}$ \\
\hline $\begin{array}{l}\text { Modelo } \\
\text { UTAUT }\end{array}$ & $\begin{array}{l}\text { Expectativas de } \\
\text { rendimiento }\end{array}$ & consecuencias relativas del rendimiento de \\
\hline
\end{tabular}

Fuente: Elaboración propia. 
La mayoría de los modelos de aceptación de la tecnología se desarrollaron inicialmente para su aplicación en usuarios internos (tales como doctores, enfermeros o personal sanitario en general) que debían afrontar el uso de una nueva tecnología en sus puestos de trabajo. Si se extrapola el concepto hacia la figura del usuario externo o usuario final (pacientes, cuidadores, familiares, entre otros pertenecientes al sector sanitario), podría ser denominado "valor percibido".

Existen numerosas definiciones del concepto "valor percibido". Por ejemplo, para Nielsen (1992) "el valor percibido es la expresión del consumidor de los beneficios del producto”. Woodruff (1997) detalla más el concepto definiendo el valor percibido por el consumidor como "una preferencia y evaluación percibida de los atributos del producto/servicio, de los atributos de los resultados y de las consecuencias derivadas del uso que facilita alcanzar los objetivos y propósitos del consumidor cuando los utiliza”. Adaptando estas definiciones a la aceptación de la tecnología por parte de usuarios externos, se podría definir el valor percibido como:

El valor percibido es la evaluación percibida de los atributos de una tecnología y de los beneficios derivados del uso de la misma que facilita alcanzar los propósitos del usuario externo cuando la utiliza.

Aunque son numerosos los estudios que determinan que esta variable tiene una mayor influencia y un papel más relevante en la aceptación de la tecnología que otras variables (por ejemplo, Davis et al., 1989; Igbaria et al., 1995; Karahanna y Straub, 1999; Teo et al., 1999; Devaraj et al., 2002; Roca et al., 2006), existen muy pocas 
investigaciones que se hayan centrado en cómo y porqué el valor percibido repercute sobre la aceptación de la tecnología (Venkatesh y Davis, 1994; Chen et al., 2008; Rahimpour et al., 2008; Aggelidis y Chatzoglou, 2009), déficit que es más patente si se desea entender cómo se forma esa percepción desde un enfoque de gestión del conocimiento.

Es por ello que el modelo teórico a desarrollar en esta investigación se centra en el valor percibido de los usuarios externos ante la aceptación y uso de las TIC en el sector sanitario y trata de determinar los factores que influyen en crear dicho valor.

\section{FACTORES QUE INFLUYEN EN EL VALOR PERCIBIDO}

Con el objetivo de mejorar el poder predictivo de los modelos de aceptación de la tecnología, los investigadores han añadido numerosas variables externas y adicionales a los constructos básicos. Dichas variables pueden englobarse en tres grandes grupos: factores tecnológicos - que incluyen características propias de la tecnología que debe ser aceptada por el usuario-, factores individuales - que incluyen características, aptitudes, habilidades y comportamientos de los usuarios de la tecnología-, y factores organizativos - que engloban características, aptitudes y comportamientos a nivel de la organización que permitan implantar la tecnología.

La tabla 5 resume los factores más importantes que han sido examinados durante los últimos años. 
Tabla 5. Variables adicionales a los constructos principales de los modelos de aceptación de la tecnología.

\begin{tabular}{|c|c|c|}
\hline \multicolumn{3}{|c|}{ VARIABLES ADICIONALES } \\
\hline FACTORES & Variables & Autor (Año) \\
\hline \multirow{4}{*}{$\begin{array}{l}\text { Factores } \\
\text { Tecnológicos }\end{array}$} & $\begin{array}{l}\text { Compatibilidad con las necesidades de } \\
\text { los usuarios }\end{array}$ & Moore y Benbasat (1991) \\
\hline & Calidad del sistema & $\begin{array}{l}\text { Al-Somali et al. (2009) } \\
\text { Sathye (1999) }\end{array}$ \\
\hline & Capacidad de personalización & $\begin{array}{l}\text { Kim y Chang (2007) } \\
\text { Rubin (1998) }\end{array}$ \\
\hline & Costes & Rahimpour et al. (2008) \\
\hline \multirow{7}{*}{$\begin{array}{c}\text { Factores } \\
\text { Individuales }\end{array}$} & Actitud hacia el uso de un sistema & Yu y Yang (2006) \\
\hline & Autoeficacia & $\begin{array}{l}\text { Yu y Yang (2006) } \\
\text { Wang et al. (2003) } \\
\text { Eastin (2002) } \\
\text { Bandura (1977) } \\
\text { Davis et al. (1989) }\end{array}$ \\
\hline & $\begin{array}{c}\text { Inquietud hacia el descubrimiento de } \\
\text { nuevos sistemas, servicios o } \\
\text { conocimientos }\end{array}$ & Yu y Yang (2006) \\
\hline & $\begin{array}{c}\text { Conocimiento de los servicios que } \\
\text { ofrece una organización a sus usuarios }\end{array}$ & $\begin{array}{c}\text { Pikkarainen et al. (2004) } \\
\text { Sathye (1999) } \\
\text { Howcroft et al. (2002) }\end{array}$ \\
\hline & Nivel de participación & $\begin{array}{c}\text { Yu y Yang (2006) } \\
\text { Hartwick y Barki (1994) }\end{array}$ \\
\hline & Formación tecnológica & $\begin{array}{c}\text { Aggelidis y Chatzoglou (2009) } \\
\text { Thompson (1995) } \\
\text { Igbaria et al. (1989) } \\
\end{array}$ \\
\hline & Características demográficas & $\begin{array}{c}\text { Al-Gahtani y King (1999) } \\
\text { Sathye (1999) } \\
\text { Lai y Li (2005) } \\
\text { Burke (2002) } \\
\text { Alagheband (2006) }\end{array}$ \\
\hline \multirow{6}{*}{$\begin{array}{c}\text { Factores } \\
\text { Organizacionales }\end{array}$} & Confianza & $\begin{array}{c}\text { Klein (2007) } \\
\text { Yousafzai et al. (2003) } \\
\text { Suh y Han (2002) } \\
\text { Mukherjee y Nath (2003) }\end{array}$ \\
\hline & $\begin{array}{l}\text { Experiencia en el uso de sistemas de } \\
\text { información }\end{array}$ & Igbaria et al. (1989) \\
\hline & $\begin{array}{c}\text { Apoyo organizacional para disponer de } \\
\text { asistencia e instrucción ante nuevas } \\
\text { aplicaciones de la empresa }\end{array}$ & $\begin{array}{c}\text { Traynor (1999) } \\
\text { McCaughan et al. (2002) } \\
\text { Berwick (2003) }\end{array}$ \\
\hline & $\begin{array}{c}\text { Motivación de los trabajadores en el } \\
\text { desempeño de sus funciones }\end{array}$ & $\begin{array}{c}\text { Traynor (1999) } \\
\text { McCaughan et al. (2002) } \\
\text { Berwick (2003) }\end{array}$ \\
\hline & Apoyo de la alta dirección & $\begin{array}{l}\text { Quaddus y Xu (2005) } \\
\text { Igbaria (1990) }\end{array}$ \\
\hline & Resistencia al cambio de los usuarios & $\begin{array}{l}\text { Pérez et al. (2004) } \\
\text { Sathye (1999) } \\
\text { Wallis Report (1997) } \\
\text { Daniel (1999) }\end{array}$ \\
\hline
\end{tabular}

Fuente: Elaboración propia. 
Son numerosos los factores que pueden influir en el valor percibido en un sistema tecnológico para gestionar el conocimiento por parte de los usuarios externos. En esta investigación se han seleccionado dos factores individuales y dos factores tecnológicos, incluidos en las variables externas, tal y como se explica a continuación.

\subsection{CAPACIDAD INNOVATIVA}

El potencial desarrollo de las nuevas tecnologías requiere de usuarios externos (pacientes, cuidadores o familiares) que no presenten resistencia al cambio y que posean un nivel motivacional elevado, es decir, de usuarios abiertos ante los nuevos conocimientos, procesos y procedimientos que conlleva el uso de las nuevas tecnologías (Robinson et al., 2005) en el sistema sanitario. Es necesario pues, que se desarrolle en el paciente una actitud positiva hacia la innovación y a cambiar sus principios así como a evitar su posible rechazo a desempeñar funciones distintas de las que estaba acostumbrado a realizar cuando aún no se habían desarrollado en la práctica los nuevos usos que conlleva la aparición de nuevas herramientas tecnológicas.

Rogers (1962) conceptualizó a los individuos innovadores como aquellos que adoptan innovaciones antes que los demás. En un contexto tecnológico, la capacidad de innovación personal se define como el deseo de un individuo a probar una nueva tecnología (Agarwal y Prasad, 1998; Flynn y Goldsmith, 1993; Midgley y Dowling, 1978). La variable de capacidad innovativa en el ámbito de las tecnologías de la información implica tanto al ámbito teórico como al práctico. Desde el punto de vista práctico, la capacidad innovativa permite a los usuarios externos, principalmente, 
adoptar una tecnología nueva antes que otros. Estos individuos pueden incentivar la difusión de la tecnología al resto de los usuarios externos (Rogers, 1962). Desde una perspectiva teórica, la capacidad innovativa sirve para explicar el papel que tienen los individuos en la adopción de una tecnología (Agarwal y Prasad, 1998).

A partir de estas definiciones se puede sugerir que la gente más abierta y propensa a la adopción de nuevas ideas, conocimientos o procesos, desarrolla un comportamiento positivo que influye en las percepciones que tienen sobre una tecnología en concreto (Robinson et al., 2005). Así, la capacidad innovadora que las personas poseen, puede favorecer el uso de las tecnologías o minimizar el grado de resistencia al cambio ante la utilización de las mismas (Conner y Rumelt, 1991; Parthasarathy y Hampton, 1993). No obstante, la disponibilidad de ciertos servicios de apoyo debería repercutir positivamente en la idea de la funcionalidad de un tecnología particular (Robinson et al., 2005).

Varias investigaciones (por ejemplo, Jones et al., 2002; O’Cass y Fenech, 2003) se han centrado en la capacidad innovativa personal innata para explicar las diferencias en la adopción y uso de la innovación tecnológica entre los individuos. Por tanto, algunas personas son más proclives a adoptar nuevas tecnologías mientras que otras siguen el ejemplo de personas con gran capacidad innovativa (Limayen et al., 2000) ya que las personas tienen diferentes grados de voluntad para probar tecnologías innovadoras (Rogers, 1962; Bhatnagar et al., 2000; Eastin, 2002).

Según Rogers (1962), aquellos usuarios que poseen una mayor capacidad innovativa, son más propensos a generar una actitud favorable hacia las tecnologías ya que las perciben como un instrumento cuyo uso puede dar lugar a mayores ventajas de 
las que aportaban los procedimientos anteriores y además están más dispuestos a utilizar las nuevas tecnologías en su vida diaria con independencia del nivel de incertidumbre que conlleva la innovación tecnológica.

Leonard-Barton y Deschamps (1988) argumentan que es más probable que los usuarios más innovativos perciban las ventajas y la utilidad de usar una determinada tecnología mientras que es menos probable que los individuos menos innovativos perciban su valor, la acepten y la usen.

Más tarde, Agarwal y Prasad (1998) demostraron que la relación entre las percepciones de los usuarios de Internet y su intención de uso puede variar en función de la capacidad innovativa.

Posteriormente, Jones et al. (2002) determinaron que el grado de uso de la tecnología de un individuo está determinado por su capacidad innovativa personal.

De manera similar, O’Cass y Fenech (2003) sugieren que los usuarios de webs con una alta capacidad innovativa tienden a desarrollar una actitud más positiva hacia nuevas tecnologías.

Sin embargo, independientemente de las investigaciones anteriores, la variable capacidad innovativa ha sido débilmente analizada en el ámbito sanitario (Yang et al., 2009) a pesar de que una persona innovadora puede ser un agente clave para cambiar y facilitar la difusión de una nueva tecnología, introducir nuevas ideas (Rogers, 1962) y conseguir que se haga algo que antes no se hacía en el sector sanitario. Se trata de un problema emergente, dentro de este sector, que debería ser gestionado de forma inmediata (Yang et al., 2009). 
No obstante, existen investigaciones como la realizada por Damanpour (1987) que afirma que los roles y la personalidad de cada individuo, tal como, la capacidad innovativa de cada uno de ellos, afecta al grado de adopción de las innovaciones tecnológicas. Por otro lado, Yang et al. (2009), definieron la capacidad innovativa como una variable necesaria para incrementar el valor percibido de los individuos ante el desarrollo de los servicios sanitarios online. Este autor parte del contexto de que la aceptación de los servicios sanitarios online necesita un proceso de implantación, donde los usuarios estén concienciados con la utilidad del sistema y su facilidad para ponerlo en práctica. Por lo tanto, un usuario innovador es más propenso al uso de estos sistemas si el valor que esta persona percibe de los servicios online es elevado (Yang et al., 2009).

Consecuentemente, tal y como muestra la figura 14, la capacidad innovativa de las personas puede incrementar el valor percibido que éstas tienen sobre los servicios sanitarios online.

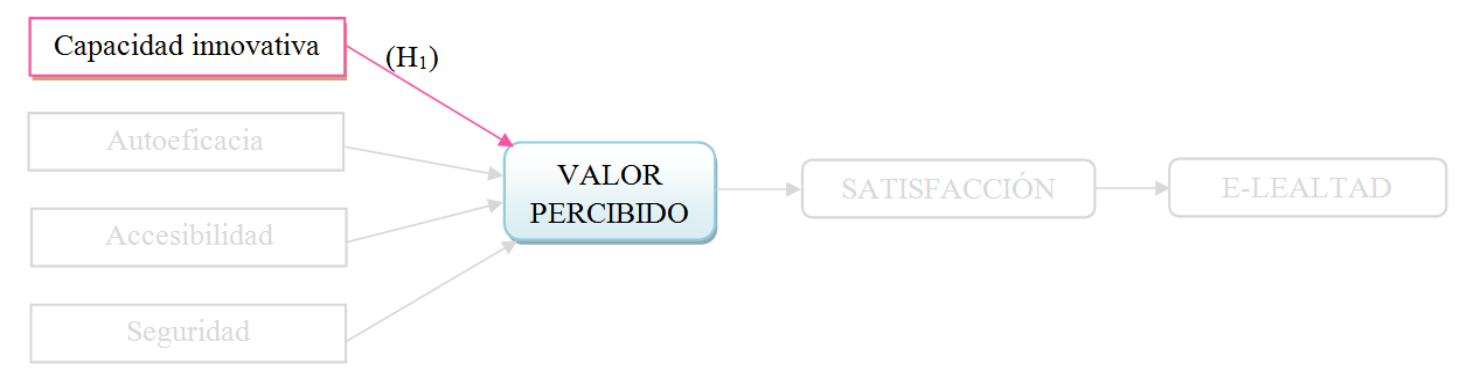

Figura 14. Relación entre capacidad innovativa y valor percibido (Elaboración propia).

Estos argumentos nos llevan al planteamiento de la primera de las hipótesis que se desarrollan en este estudio: 
H1: La capacidad innovativa de los usuarios externos tiene una relación positiva con el valor percibido de los servicios sanitarios online.

\subsection{AUTOEFICACIA HACIA NUEVAS TECNOLOGÍAS}

La autoeficacia percibida se define como los juicios que cada individuo hace sobre sus capacidades, habilidades y conocimientos, en base a los cuales organizará y ejecutará sus actos (Bandura, 1986). Esta variable no se refiere a las capacidades que posee un individuo sino a lo que él cree que puede hacer con las capacidades que posee.

En el campo de los sistemas de información, Compeau et al. (1999) definen la autoeficacia hacia los ordenadores como las percepciones de un individuo sobre sus habilidades para usar ordenadores con el fin de realizar una tarea específica. Eastin y LaRose (2000) actualizan el concepto definiendo la autoeficacia en Internet como la creencia que un individuo tiene de poder realizar con éxito una serie de conductas necesarias para establecer, mantener y utilizar efectivamente Internet, para lo que es necesario unas competencias distintas y superiores a las competencias básicas en ordenadores personales.

Varios estudios han examinado la autoeficacia con respecto al uso de ordenadores y su aceptación (Compeau y Higgins, 1991; Ellen et al., 1991; Martocchio y Webster, 1992; Webster y Martocchio, 1992). Además, numerosos estudios han demostrado la evidencia de una relación entre la autoeficacia y la realización de cursos de informática 
en las universidades (Hill et al., 1987), la adopción de productos de alta tecnología (Hill et al., 1986), la innovación (Burkhardt y Brass, 1990), y el rendimiento que supone la formación en software (Gist et al., 1989; Webster y Martocchio, 1992; Compeau y Higgins, 1996).

Otros estudios han demostrado que la autoeficacia influye en las decisiones relativas al uso y adopción de las tecnologías (Leonard-Barton y Kraus, 1985; Davis et al., 1989; Compeau y Higgins, 1991). Dada la importancia de la autoeficacia para predecir y mejorar el rendimiento en el trabajo y en la conducta (Bandura, 1982; Bandura, 1986; Gist, 1992), son muchos los investigadores que discuten sobre la necesidad de buscar más investigaciones que examinen el papel de la autoeficacia en la conducta hacia las nuevas tecnologías.

Gist (1989) sugiere que la autoeficacia es una variable motivacional que afecta al esfuerzo, la persistencia y la motivación de los individuos. La relación entre la autoeficacia y la utilidad percibida está presente en el efecto que tiene la autoeficacia en la motivación y en las expectativas de resultados. Además, las personas que no se sienten capaces de manejar una determinada situación pueden mostrar resistencia ante los cambios esperados. Por otro lado, las personas que muestran una alta autoeficacia percibirán que el sistema es fácil y útil debido al efecto que tiene la autoeficacia en el grado de esfuerzo, la persistencia y el nivel de aprendizaje que tiene lugar.

Sobre la base de la autoeficacia, se deduce que las organizaciones deberían de proveer usuarios (pacientes) adaptados y con una formación de calidad para facilitar que el uso de las nuevas tecnologías no sea una carga para ellos (Xu y Quaddus, 2007). Y es que las horas extras que cada individuo utilice encaminadas a la consecución de 
formación sobre las tecnologías, permitirá incrementar el rendimiento de las organizaciones y una mayor aceptación de las tecnologías por parte de los usuarios (Mahmood et al, 2000; Bedard et al, 2003).

Según Compeau et al. (1999), puesto que la autoeficacia hacia las nuevas tecnologías incrementa las habilidades de las personas sobre el uso y la facilidad percibida en la utilización de las mismas, la aceptación indirecta hacia dichas tecnologías se hará evidente con el paso del tiempo. Consecuentemente, se requiere un conocimiento apropiado y suficiente para mejorar las pautas de aceptación de los nuevos sistemas tecnológicos. Concretamente, Agarwal y Prasad (1999) y Compeau et al. (1999), afirman que la autoeficacia hacia las nuevas tecnologías tiene efectos significativos y positivos sobre el valor percibido, tal y como se muestra en la figura 15.

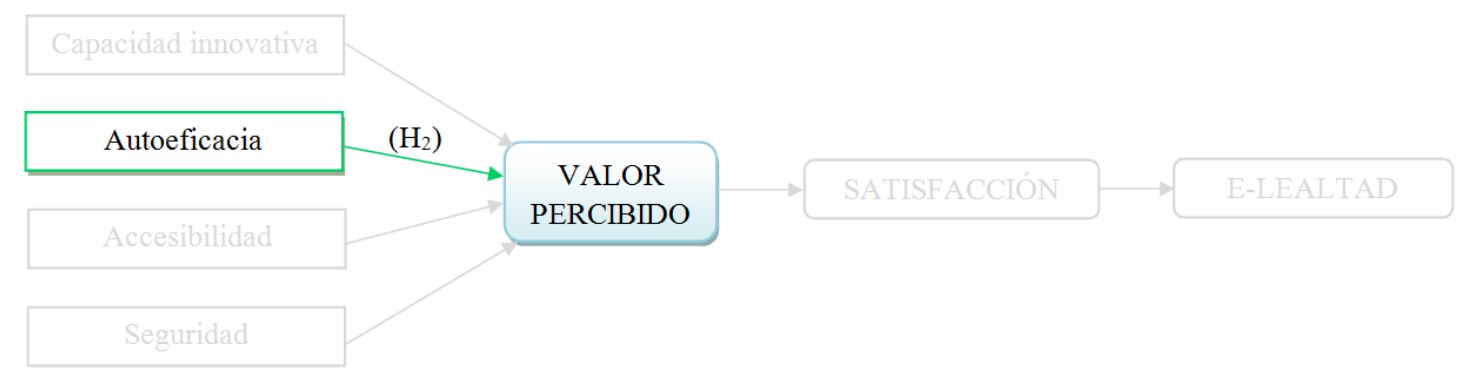

Figura 15. Relación entre autoeficacia y valor percibido (Elaboración propia).

Es por este motivo por el que surge una segunda hipótesis:

H2: La autoeficacia hacia las nuevas tecnologías por parte de los usuarios externos tiene un efecto positivo sobre el valor percibido de los servicios sanitarios online. 


\subsection{ACCESIBILIDAD}

Las TIC están cambiando la forma de actuar de la mayoría de las organizaciones de nuestro entorno. Consecuentemente, se necesita que todo el conocimiento creado en la fase de transferencia de la información sea adaptado a la propia operativa de las organizaciones, concretamente a la operativa de los centros sanitarios que están viendo modificadas las formas tradicionales de actuación debido a la emergencia de los servicios sanitarios online.

Una organización no podrá explotar una tecnología existente si previamente no ha explorado o investigado sobre ella ya que, cuanto mayores sean los esfuerzos operacionales y las habilidades tecnológicas necesarias para acceder a la información, menor será el uso de las TIC así como la intención de uso en un futuro (Tan y Teo, 2000) y, por tanto, menor será el uso de los servicios sanitarios online. De ahí la importancia de la accesibilidad como paso previo al uso de las tecnologías.

El acceso a la información se ha convertido en un componente de calidad para los servicios online (Liu y Arnett, 2000), unos servicios que requieren de usuarios capacitados para poder acceder a la información necesaria, en el formato necesario y en el momento requerido, lo cual repercutirá en una mejora en la agilidad para adquirir conocimientos, experimentar, desenvolverse ante nuevos retos y conseguir una exactitud y precisión en los resultados (Yong et al., 2010).

Esta capacidad de los usuarios para transferir y buscar información requiere la implantación de las TIC ya que el uso de estas tecnologías puede llegar a mejorar 
incluso las estrategias de gestión (Rahimpour et al., 2008). De ahí que se afirme que el uso de los servicios sanitarios online será factible si se dispone de infraestructura tecnológica de fácil y rápido acceso (Chau y Lai, 2003). Así pues, aquellos usuarios externos que perciban los servicios sanitarios online como una herramienta compleja que dificulta el día a día, la considerarán como una amenaza más que como una oportunidad, obviando los beneficios que se desprenden de la adopción de dichos servicios.

La accesibilidad tanto a los servicios como a la información es un prerrequisito del contexto organizativo en el momento de considerar la implantación de las TIC. Y es que un sistema tecnológico debe ser accesible para todo el mundo que pretenda utilizarlo y así poder generar valor y servir de apoyo para el sistema de trabajo diario del sector sanitario ante los nuevos servicios online. De hecho, los pacientes deberían de tener acceso a las experiencias pasadas y al conocimiento e ideas de otros pacientes que ya han accedido a los servicios online. La accesibilidad de las TIC ha sido asociada con el uso de la información en estudios previos (Culnan, 1984; Karahanna y Straub, 1999; Chau y Lai, 2003).

De acuerdo con Karahanna y Limayen (2000), la accesibilidad incluye tanto el acceso físico a la tecnología como el acceso a la información. De esta forma, mientras que la accesibilidad física se refiere al grado en el que alguien tiene acceso físico al hardware necesario para usar un sistema tecnológico, la accesibilidad a la información se refiere a la capacidad para obtener la información deseada del sistema.

Han sido varios los estudios que han definido la accesibilidad como un factor que afecta a la percepción de uso de una tecnología, un concepto que ha sido sugerido y 
apoyado empíricamente por Karahanna y Straub (1999). En su estudio, la accesibilidad es una variable multidimensional que enfatiza en el acceso que se produce en términos físicos y en la habilidad de los usuarios para usar un sistema. Ellos argumentan que una mayor accesibilidad a los sistemas de información requiere un menor esfuerzo en el uso de los mismos y facilita una mayor percepción de utilidad.

En el contexto de servicios online del sector sanitario, la accesibilidad no sólo se refiere al acceso físico de las conexiones a Internet, sino también al acceso global al que pueden acceder todos los pacientes que dispongan de Internet. Bajo estas circunstancias, la accesibilidad se ha convertido en un recurso necesario para facilitar que la información esté disponible en el tiempo y en el lugar requerido (Chen et al., 2008) permitiendo el intercambio de conocimiento.

Sathye (1999) determinó que el acceso a Internet es uno de los factores que más influyen en la adopción de servicios virtuales. Este autor explicó que sin una adecuada conexión y acceso a Internet o a los servicios virtuales ofrecidos por las organizaciones, el uso de estas nuevas tecnologías no es posible.

Por su parte, Tan y Teo (2000) postularon que la accesibilidad a través de Internet facilita la implantación de los servicios virtuales debido a la capacidad que tienen los usuarios para percibir el uso de la tecnología como algo necesario y favorable.

Almogbil (2005) se centró en la relación existente entre el acceso y el uso que se hace tanto de la información como de los servicios virtuales que se encuentran en las organizaciones. Su estudio le permitió confirmar que existe una relación significativa entre la rapidez de acceso a Internet y el uso de los servicios virtuales. 
Estos estudios implican que los servicios tradicionales ofrecidos por las organizaciones deben ser transformados para llegar a ser más abiertos, accesibles y flexibles y así poder crear ventajas para los usuarios que utilicen las nuevas tecnologías, de manera que éstos perciban positivamente el valor de las TIC.

A partir estos argumentos, se propone la tercera hipótesis:

H3: La accesibilidad de los servicios sanitarios online tiene una relación positiva con el valor percibido por los usuarios externos.

La cuál queda reflejada en la figura 16:

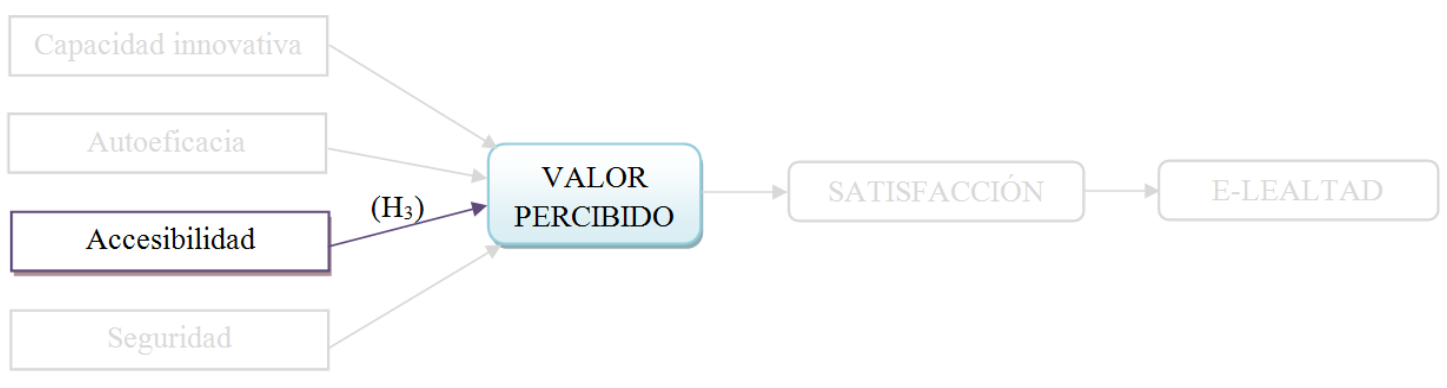

Figura 16. Relación entre accesibilidad y valor percibido (Elaboración propia).

\subsection{SEGURIDAD}

La tecnología permite la creación de bases de datos donde la información puede ser estandarizada fácilmente, permitiendo acceder a ella y revisarla de manera más rápida. Aunque las organizaciones que deciden informatizar sus datos incurren en costes iniciales, esta transformación puede incrementar el acceso y la seguridad de los datos, 
reducir errores y producir ahorro. Además, los datos electrónicos pueden permitir un servicio en tiempo real y facilitar una respuesta rápida.

Sin embargo, los aspectos relacionados con la confidencialidad, y por tanto, con la seguridad de la información son cada vez más sensibles en la era digital: algunas características de los datos electrónicos presentan importantes amenazas de seguridad ya que, la información puede ser copiada, transportada (por ejemplo, mediante ordenadores portátiles o dispositivos pendrive) y diseminada (por ejemplo, mediante el correo electrónico o la publicación de mensajes en webs) con facilidad y rapidez, empleando una gran variedad de redes, por cualquier parte del mundo, a muy poco o ningún coste, en muy poco tiempo y sin posibilidad de rastro (Myers et al., 1998). De ahí que surja una necesidad de adquirir y adoptar medidas de seguridad apropiadas para los sistemas tecnológicos (Xu y Quaddus, 2007).

Es más, el acceso a la información puede no estar controlado o que los controles de acceso o de seguridad fallen. Este hecho podría provocar que los datos electrónicos se pudiesen borrar fácilmente ocasionando una pérdida de información. Por tanto, una infraestructura tecnológica debe tener mecanismos para mitigar los riesgos e incertidumbre derivados de la utilización de información o conocimiento (Desouza et al., 2005).

Son numerosos los estudios empíricos que se han enfocado al estudio de la seguridad (Suh y Han, 2002; Gefen, 2004; Klein, 2007; Xu y Quaddus, 2007). McKnight y Chervany (2001) asocian la seguridad al grado en el que una persona cree que el uso de una nueva tecnología será de confianza y creíble. Por otro lado, Suh y Han (2002) afirman que la clave para el desarrollo y el uso de servicios online está en la 
seguridad que se perciba de ellos. Según Yousafzai et al. (2003), la confianza de los usuarios en las transacciones que realizan a través de los servicios virtuales ha sido la clave para el desarrollo de los mismos.

Muchos investigadores están de acuerdo en que la seguridad es esencial para que tenga lugar la utilización de los servicios virtuales con naturalidad. En el ámbito sanitario, los servicios sanitarios online requieren de máximos niveles de seguridad, ya que a través de Internet se transfieren archivos e información confidencial que debe ser tratada cuidadosamente. Mukherjee y Nath (2003) corroboran que la seguridad tiene una influencia bastante positiva en el compromiso que han de adquirir los usuarios de los servicios virtuales y las organizaciones en general. Finalmente, Klein (2007) afirma que en ausencia de normas y regulaciones, la seguridad en los servicios virtuales juega un papel muy importante.

Mientras que la variable seguridad es un principio clave en las relaciones organizacionales (Moorman et al., 1992; Sultan y Mooraj, 2001), esta variable es más crítica con los servicios ofrecidos virtualmente (Reichheld y Schefter, 2000). Esto es debido a que a través del sistema virtual no se produce una interacción cara a cara entre la organización y el usuario externo.

Una percepción de riesgo por parte de los individuos puede conllevar a un efecto negativo en el valor percibido de una tecnología, de ahí que la seguridad sea una de las herramientas más efectivas para reducir los riesgos (Suh y Han, 2002; Pavlou, 2003) y generar confianza en los usuarios. A este respecto, algunos estudios empíricos (Pavlou, 2003; Gefen, 2004) la incorporan como antecedentes del valor percibido, tal como se representa en la figura 17. 


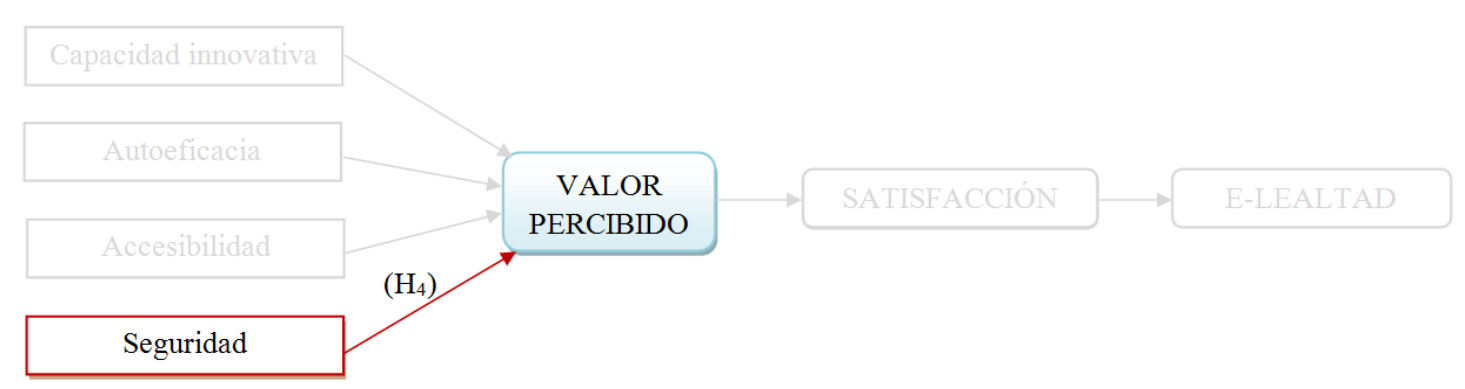

Figura 17. Relación entre seguridad y valor percibido (Elaboración propia).

De estos razonamientos se deriva la cuarta hipótesis en esta investigación.

H4: La seguridad tiene un efecto positivo sobre el valor percibido por los usuarios externos en el uso de los servicios sanitarios online.

\section{SATISFACCIÓN}

La aceptación de las TIC por parte de los usuarios externos se estudia desde tres perspectivas distintas. Por un lado, se tienen en cuenta las actitudes de los usuarios, por otro lado, el uso que se hace de las TIC, y por último, la aceptación de las TIC que también se mide desde el punto de vista de la satisfacción.

La satisfacción de los usuarios se ha definido, a lo largo de los años, de diversas formas. Desde el punto de vista de las TIC, Goodhue y Straub (1991) la definen como "una variable que representa el grado en que el usuario percibe que sus necesidades personales y la necesidad de realizar tareas específicas se cumplen de manera satisfactoria utilizando los sistemas de información”. Por otro lado, Al-Gahtani y King 
(1999) la definen como "la reacción positiva que tienen los individuos hacia el uso de las TIC".

Esto nos lleva a pensar que la satisfacción pueda ser una variable que venga motivada e influenciada por el valor percibido que tienen los pacientes, entre otros, cuando utilizan los servicios sanitarios online y más aún teniendo en cuenta la definición propuesta en el punto uno de este capítulo, que considera el valor percibido como "la evaluación percibida de los atributos de una tecnología y de los beneficios derivados del uso de la misma que facilita alcanzar los propósitos del usuario externo cuando la utiliza".

Hay algunos modelos teóricos que intentan explicar la relación entre satisfacción y valor percibido. Uno de ellos es el estudio hecho por DeLone y McLean (1992). Estos autores proponen un modelo interactivo como marco para conceptualizar y poner en funcionamiento un sistema de información exitoso basado en la revisión de las definiciones existentes del éxito de los sistemas de información y sus medidas correspondientes. El modelo incluye como variables de éxito de los sistemas de información, la calidad del sistema, la calidad de la información, el uso, la satisfacción del usuario, el impacto individual y el impacto organizacional.

Sin embargo, DeLone y McLean no proporcionan la validación empírica del modelo y, de hecho, sugieren un mayor desarrollo y validación del mismo (DeLone y McLean, 1992). Por ello, desde 1992, una gran variedad de estudios (Seddon y Kiew, 1994; Jurison, 1996; Igbaria y Tan, 1997) han probado de forma explícita las relaciones entre las variables del modelo propuesto por DeLone y McLean. 
Por un lado, Seddon (1997) procedió a ampliar la versión del modelo de DeLone y McLean (1992) por tratarse de un modelo demasiado amplio y confuso que mezclaba el proceso y las explicaciones causales del éxito de un sistema de información, para ofrecer una visión más clara de las variables del éxito de dichos sistemas de información. Así, reemplaza el uso de estos sistemas del modelo de DeLone y McLean (1992) por el valor percibido que sirve para medir las percepciones de los usuarios sobre un sistema determinado. De esta forma, incluye la variable adicional de percepción de utilidad (valor percibido) del TAM como determinante de la satisfacción del usuario, estableciendo una relación directa entre ambos conceptos.

Por otro lado, Igbaria y Tan (1997) sugieren que la satisfacción de los usuarios (pacientes, cuidadores, etc) es un factor importante que afecta al uso de un sistema en concreto y por lo tanto, tiene un efecto significativo sobre la satisfacción de los individuos. Más tarde, Bhattacherjee (2001a: 2001b) propuso un nuevo modelo de aceptación basado en el uso continuo de un sistema para explicar y predecir la continuidad de los usuarios a la hora de utilizar un sistema concreto de forma habitual, sugiriendo, en primer lugar, la necesidad de aceptar la tecnología, y en segundo lugar, tomando el valor percibido como determinante significativo de la satisfacción de los usuarios.

Rai et al. (2002) sugirieron que la percepción de facilidad de uso, el valor percibido y la calidad de la información se consideran como antecedentes de la satisfacción. En ese mismo año, Devaraj et al. (2002) encontraron que el valor percibido y la percepción de la facilidad de uso son dos antecedentes significativos de la satisfacción de los usuarios. 
Asimismo, Hayashi et al. (2004) indicaron que el valor percibido tiene una correlación positiva con la variable de satisfacción en el entorno de los sistemas de formación online.

Consecuentemente, surge una nueva relación entre dos variables, tal y como se muestra en la figura 18.

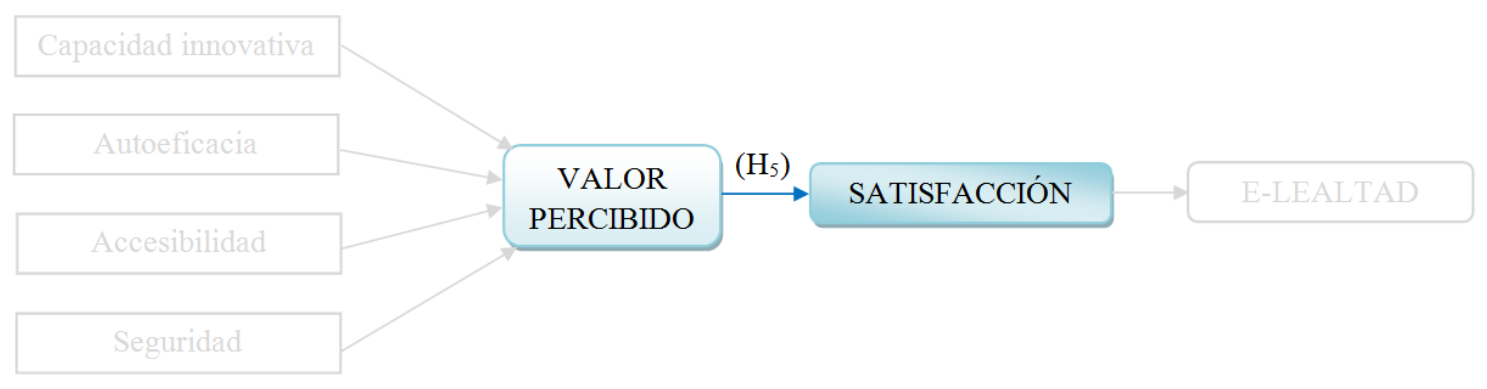

Figura 18. Relación entre valor percibido y satisfacción (Elaboración propia).

Estos análisis nos llevan al planteamiento de la quinta hipótesis que se desarrolla en esta investigación:

H5: El valor percibido por los usuarios externos respecto a los servicios sanitarios online afecta positivamente a su satisfacción. 


\section{E-LEALTAD}

El concepto de lealtad ha sido ampliamente estudiado a lo largo de los años y hay estudios que afirman que la e-lealtad es conceptualmente similar a la variable de lealtad del consumidor en el área de marketing de dónde parte nuestra definición. De acuerdo a la literatura de marketing, la lealtad se presenta cuando se manifiestan actitudes favorables hacia una marca a través de una conducta de compra repetitiva (Keller, 1993). Adaptando esta definición al sector sanitario, la e-lealtad puede ser definida como la actitud favorable de un paciente hacia un servicio sanitario basado en el uso de las TIC que deriva en el uso repetitivo de dicho servicio.

No obstante, son numerosos los estudios relacionados con la lealtad. Brown (1952), quién considera la lealtad como un comportamiento de compra repetitivo, llevó a cabo un estudio sobre la lealtad. Este investigador clasificó a la lealtad en cuatro categorías, (a) lealtad indivisible, (b) lealtad divisible, (c) lealtad inestable y (d) lealtad inexistente.

Otros autores como Lipstein (1959) y Kuehn (1962), midieron la lealtad por la probabilidad de que se produzca la continuidad de los usuarios a la hora de comprar un producto de forma habitual.

Algunos autores como Day (1969) y Jacoby y Chestnut (1978), sugirieron que las anteriores definiciones no eran suficientes porque no distinguían entre la verdadera lealtad y la falsa lealtad, debido a la falta de factores de elección de los usuarios. En 
respuesta a estas críticas, dichos investigadores han propuesto medidas que incorporan el componente actitudinal y conductual para estudiar el comportamiento humano.

Por esta razón, otros autores definieron la lealtad aplicando diferentes conceptos. Jacoby (1971) la definió como "un proceso repetitivo de compras que resultaba de un proceso psicológico". Assael (1992) definió la lealtad como "una actitud favorable hacia la compra de un producto a lo largo del tiempo" que incitaría al usuario a comprar dicho producto de forma continua en su vida diaria.

La variable e-lealtad no es tan empleada para medir el éxito de los sistemas de información como lo son, generalmente, el valor percibido o la satisfacción. A pesar de ello, en un entorno en el que se utilizan los servicios sanitarios online de manera voluntaria por parte de los pacientes, la e-lealtad es claramente un indicador importante de los beneficios organizacionales que aportan las TIC al sistema sanitario. Incluso en un entorno en que su uso fuese obligatorio, la e-lealtad seguiría siendo una medida válida para poder conocer los beneficios que aportan en el sector sanitario el uso continuo de los servicios de salud online. De ahí que la e-lealtad de los pacientes sea clave para el éxito de los servicios sanitarios online.

Existen numerosos trabajos relacionados con la aceptación de la tecnología. De ahí que se hayan encontrado en el ámbito de las TIC, una considerable cantidad de investigaciones empíricas que examinan los variables que afectan a la aceptación del uso de las mismas (por ejemplo, Venkatesh, 2000; Jiang et al., 2002; Heo y Han, 2003; Hsu y Chiu, 2004a; Shih y Fang, 2004). 
Además, mientras la e-lealtad ha sido estudiada ampliamente en el área de la tecnología de la información, las investigaciones se han concentrado de forma extensa en las respuestas de los consumidores a las ventas online (por ejemplo, Reichheld y Schefter, 2000; Anderson y Srinivasan, 2003; Wang, 2007). Los pocos estudios dirigidos al sector sanitario están limitados al análisis de páginas webs de información sanitaria (por ejemplo, Gummerus et al., 2004; Kim y Chang, 2007).

A pesar de esto, hay una gran variedad de modelos teóricos que tratan de explicar la relación entre la actitud de los usuarios, la satisfacción y la intención de volver a utilizar un sistema. Entre estos modelos, está el TAM propuesto por Davis (1989) u otros que tratan de analizar el éxito que la satisfacción tiene sobre el uso de las TIC (Bailey y Pearson, 1983; Ives et al., 1983; Doll y Torkzadeh, 1988; DeLone y McLean, 1992).

En el sector sanitario, el uso de los servicios sanitarios online basados en las TIC aporta beneficios tales como, un ahorro de tiempo para el paciente, requiere menos esfuerzos y servicios más accesibles. Además, ofrecen métodos más rápidos de comunicación entre los profesionales sanitarios (médicos, etc.) y los pacientes. En resumen, el uso de los servicios sanitarios online permite ahorrar costes e incrementar la satisfacción de los pacientes. Sin embargo, estas mejoras sólo son posibles si los pacientes usan los servicios sanitarios online de forma regular, integrándolos en su vida diaria.

La teoría de la expectativa de la disconfirmación (the expectancy disconfirmation Theory - EDT) de Oliver (1980), surge como una teoría importante para explicar las variables que motivan a los individuos para seguir utilizando las TIC (Bhattacherjee, 
2001a, 2001b; Khalifa y Liu, 2002a, 2002b; McKinney et al., 2002; Hayashi et al., 2004; Chiu et al., 2005; Lin et al., 2005). El modelo EDT propone la relación causal existente entre las percepciones de los usuarios, su disconformidad, su satisfacción y la intención de volver a utilizar las TIC.

Bhattacherjee (2001a) es uno de los primeros investigadores que utilizan el EDT en el contexto de las TIC. En su estudio sobre la continuidad de los usuarios a la hora de utilizar los sistemas de banca electrónica, encontró que el antecedente más significativo y que más incrementa e incentiva a la e-lealtad es la satisfacción, es decir, el grado en que un usuario percibe que sus necesidades personales o de realizar alguna tarea específica se cumplen de manera satisfactoria utilizando las TIC, donde a su vez ésta, se ve influenciada de manera positiva por la variable de valor percibido.

La relación entre satisfacción y e-lealtad parece casi intuitiva. Son numerosos los investigadores que han encontrado, a través de sus investigaciones, que la satisfacción conduce a la e-lealtad (por ejemplo, Anderson y Srinivasan, 2003; Wang, 2007). Autores como Van Riel et al. (2001), Taylor y Hunter (2002) y Yoon (2002) definen la satisfacción como una variable que tiene una influencia positiva en lo referente a la retención de usuarios, la probabilidad de recomendar algo a alguien, o la probabilidad de que los usuarios vuelvan a utilizar un sistema (lealtad). A su vez, la satisfacción de los pacientes puede influir a la hora de utilizar de nuevo las TIC (Menachemi et al., 2009). Además, Yang y Peterson (2004) y Yen y Gwinner (2003) comprobaron que existía un impacto positivo de la satisfacción sobre la e-lealtad. 
Las investigaciones anteriores indican que la satisfacción tiene un efecto positivo sobre la intención de volver a utilizar un servicio en el futuro, es decir, se incrementa la e-lealtad hacia los nuevos servicios online. Esta relación se muestra en la figura 19:

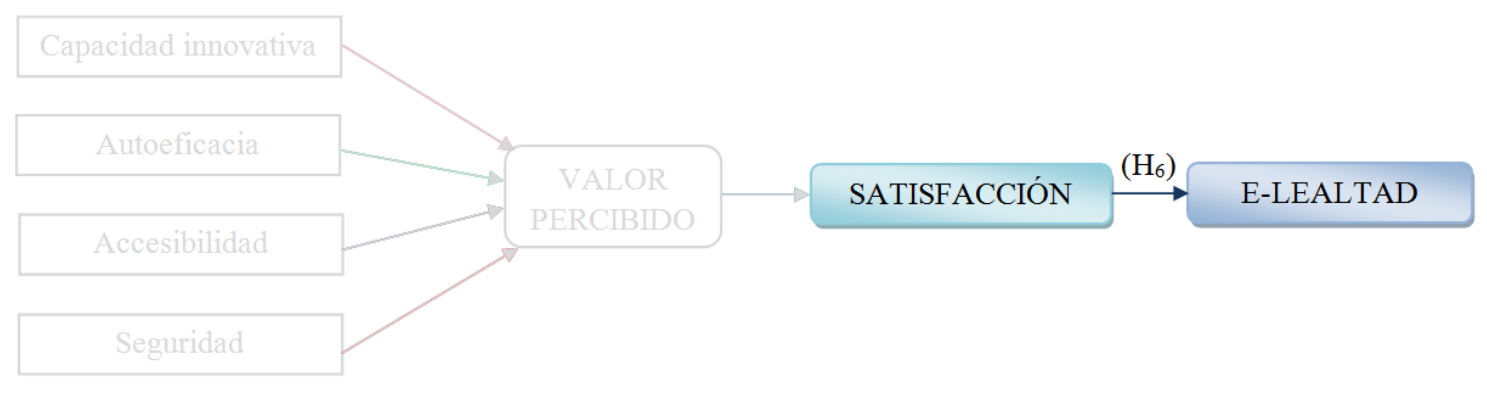

Figura 19. Relación entre satisfacción y e-lealtad (Elaboración propia).

A partir de estos estudios previos se propone para nuestra investigación una nueva hipótesis que relaciona la satisfacción de los usuarios con el uso de los servicios sanitario online y la e-lealtad hacia el uso de los mismos.

H6: La satisfacción de los usuarios de servicios sanitarios online está positivamente asociada a la e-lealtad.

\section{MODELO PROPUESTO}

La figura 20 representa gráficamente las hipótesis planteadas: en primer lugar, se observa la influencia de la capacidad innovativa en el valor percibido de los servicios sanitarios online (hipótesis uno - H1); en segundo lugar, se analiza el efecto de la autoeficacia sobre el valor percibido (hipótesis dos $-\mathrm{H} 2$ ); en tercer lugar, se representa la relación de la accesibilidad sobre el valor percibido (hipótesis tres - H3), en cuarto 
lugar, se plantea la hipótesis que relaciona el efecto de la seguridad de los servicios sanitarios online sobre el valor percibido de las tecnologías (hipótesis cuatro - H4), en quinto lugar se estudia la relación existente entre la variable valor percibido sobre la satisfacción (hipótesis cinco - H5) y, por último, se plantea la hipótesis que relaciona el efecto de la satisfacción sobre la e-lealtad (es decir, la lealtad electrónica) hacia el uso de los servicios sanitarios online (hipótesis seis - H6).

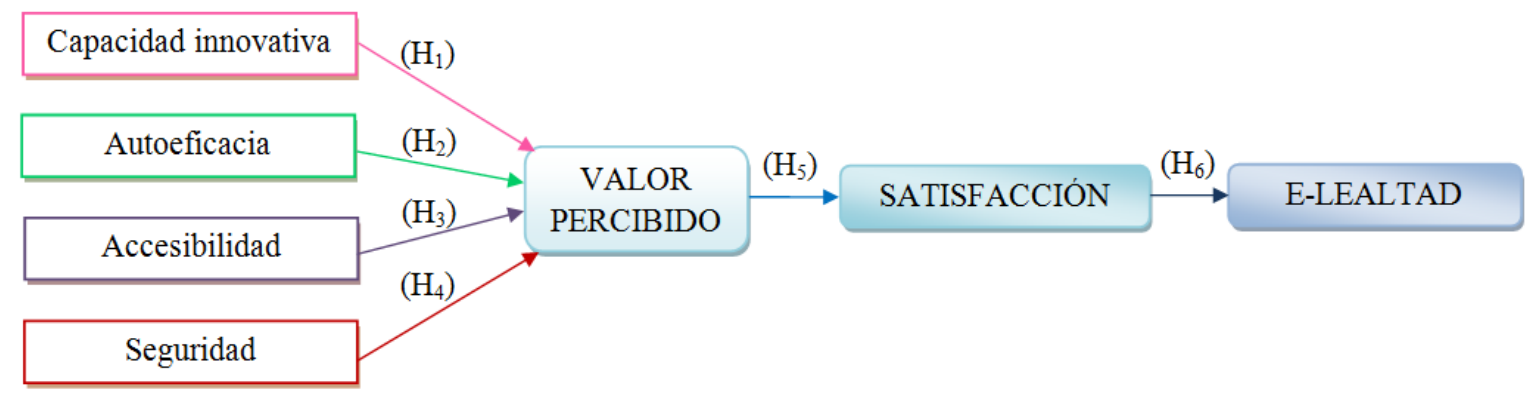

Figura 20. Modelo teórico propuesto.

\section{CONCLUSIÓN Y REFLEXIÓN FINAL}

Tras realizar un estudio sobre la evolución de las TIC y su relación con la gestión del conocimiento, y de evaluar los modelos de aceptación de las TIC desarrollados por un elevado número de investigadores, en este capítulo se ha desarrollado un modelo de aceptación de las TIC enfocado a los usuarios externos del sector sanitario para conocer las variables que conducen a un mayor o menor grado de e-lealtad electrónica hacia los servicios online ofrecidos por este sector. 
Para el desarrollo del modelo propuesto, se ha tomado como variable intermedia del mismo una variable que, tomando diferentes denominaciones en los distintos modelos analizados en el capítulo anterior, recoge el mismo concepto. Se trata de la variable denominada "valor percibido". Por consiguiente una primera aportación del modelo presentado sería crear un lenguaje común orientado a la variable "valor percibido".

A este respecto, pensamos que al desarrollar un lenguaje de adaptación de tecnologías común, los diferentes interlocutores podrán extrapolar los acontecimientos de un determinado modelo, por ejemplo, el TAM, al modelo C-TAM-TPB o MPCU. Además, la variable valor percibido tiene información adicional sobre riesgos y oportunidades que surgen de cara al usuario final. El modelo general del que hemos partido, tiene en cuenta el valor percibido entre los distintos agentes usuarios, generando un intercambio de información que muestra la más clara ilustración de adquirir conocimiento, el cual debe ser transferido y adaptado a la operativa de la institución sanitaria.

Por otra parte, a pesar del elevado número de investigaciones que determinan que esta variable tiene un papel significativo sobre la aceptación de la tecnología (por ejemplo, Karahanna y Straub, 1999; Roca et al., 2006; Devaraj et al., 2008), son mínimos los estudios que tratan de explicar esta percepción desde la gestión del conocimiento. De ahí, que ese enfoque sea uno de los objetivos principales de nuestro estudio y nos lleve a realizar un análisis de los factores que pueden influir sobre el valor percibido de los pacientes a la hora de utilizar de manera continua estos servicios online, seleccionado una serie de variables que recogen los flujos de conocimiento. 
Los principales beneficiarios de la utilización del conocimiento de los usuarios sobre las TIC sanitarias deben de ser los propios usuarios y a su vez las instituciones sanitarias. Existe una relación positiva como indica la figura 20, entre el conocimiento creado por los usuarios (valor percibido) y la satisfacción del uso de la infraestructura tecnológica de que dispone la institución sanitaria.

A nuestro entender, la utilización de conocimiento conduce a mejores relaciones con las instituciones sanitarias basándose en la participación en actividades, tales como foros, "educlick", "weblogs", "wikis" y la prevención de problemas derivados de las tecnologías disponibles. Además, el conocimiento puede permitir llevar a cabo nuevos servicios online sin problemas y a su vez ofrecer un mejor servicio al usuario. De cara a lograr esa integración entre el conocimiento del usuario y un mejor aprovechamiento de la infraestructura de TIC, nos hemos planteado varias variables facilitadoras.

La primera de ellas es la variable que hemos denominado "capacidad innovativa". La elección de esta variable se centra en la premisa de que el desarrollo de las TIC requiere de usuarios externos, tales como los pacientes, con una actitud positiva hacia la innovación y con poca resistencia al cambio ante los nuevos conocimientos, procesos y procedimientos que conlleva el uso de las TIC (Robinson et al., 2005) en el sistema sanitario tras el desarrollo de servicios online.

La segunda variable es la "autoeficacia", definida por Compeau et al. (1999) como la percepción de los individuos sobre la habilidad que tienen para utilizar las tecnologías a la hora de realizar un tarea específica. Se trata de un constructo utilizado en un gran número de investigaciones para predecir y mejorar el rendimiento de un usuario en el trabajo y en su conducta (Bandura, 1982; Bandura, 1986; Gist, 1992). Esto 
nos lleva a considerarla, como una variable que podría afectar también al grado de valor percibido de los pacientes ante el uso de los servicios sanitarios online.

La tercera variable externa que hemos considerado tras los numerosos estudios que demuestran la influencia que la misma tiene sobre el valor percibido de los usuarios ante el uso de las TIC, es la "accesibilidad". Esta relación se basa principalmente en estudios previos como los realizados por Culnan (1984) y Chau y Lai (2003) que confirman la relación entre la accesibilidad de las TIC y el uso que se hace de las mismas. Por otra parte, Karahanna y Straub (1999) apoyan empíricamente esta relación argumentando que cuanta mayor accesibilidad se tenga a los sistemas de información, menor esfuerzo se requiere al utilizarlos y mayor utilidad se percibirá del uso de los mismos. Se trata de una serie de investigaciones que nos permiten establecer la accesibilidad, como una de las variables a analizar en nuestro modelo como determinante directa del valor percibido que los pacientes tienen ante el uso de los servicios online.

Como cuarta variable externa, cabe mencionar el papel que la "seguridad" tiene sobre el valor percibido de los servicios sanitarios online. Varios investigadores han apoyado empíricamente esta relación (Mukherjee y Nath, 2003; Pavlou, 2003; Gefen, 2004) y más aún, teniendo en cuenta que autores como Suh y Han (2002) la consideraron como variable clave para el desarrollo y uso de servicios online.

Una vez analizadas las variables externas que afectan positivamente al valor percibido, queda justificar la elección de la variable "satisfacción" como variable dependiente del valor percibido. De acuerdo a Bitner et al., (2002), la efectividad y el éxito de los servicios online han sido diseñados para mejorar la satisfacción de los 
usuarios y mantenerlos motivados hacia el uso de las TIC ya que, al tratarse de una variable de carácter afectivo, se verá condicionada por las percepciones que un individuo puede tener a la hora de utilizar un servicio. De esta forma, si el usuario percibe que dicho servicio cumple con sus expectativas, estará satisfecho con él y probablemente volverá a utilizarlo. De ahí que se afirme la existencia de una conexión positiva entre el valor percibido y la satisfacción.

En último lugar, se justifica la relación de la satisfacción con la variable final del modelo propuesto, "e-lealtad".

Este estudio sugiere que la e-lealtad, es decir, la actitud favorable de los pacientes a la hora de utilizar los servicios sanitarios basados en el uso de las TIC de forma repetitiva, puede ser una medida más del éxito de los servicios sanitarios online.

La relación entre la satisfacción y la e-lealtad parece casi intuitiva, y varios investigadores han encontrado que la satisfacción conduce de forma directa a la lealtad electrónica (Oliver, 1999; Bhattacherjee, 2001b; Anderson y Srinivasan, 2003; Wang, 2008) a la hora de volver a utilizar las TIC en lo que se refiere al uso de los servicios online ofrecidos por el sector sanitario. De esta forma, la satisfacción se considera como un antecedente de e-lealtad.

De acuerdo a estos argumentos, se puede afirmar la existencia de una serie de procesos que surgen en paralelo y que son consecuencia de una serie de relaciones causa efecto que nos llevan a plantear tres grupos de hipótesis distintas: 
(1) Las hipótesis que relacionan una serie de variables externas, tales como, capacidad innovativa, autoeficacia, accesibilidad y seguridad con la variable "valor percibido".

(2) La hipótesis que incorpora la variable cognitiva de "valor percibido" como antecedente de la variable afectiva de "satisfacción".

(3) La última hipótesis es la que muestra la relación entre la "satisfacción" de los pacientes y la variable de carácter conductual denominada "e-lealtad", es decir, la lealtad electrónica de los pacientes hacia el uso de los servicios sanitarios online.

En el capítulo siguiente, tomando como referencia las aportaciones realizadas a lo largo de los tres primeros capítulos, así como las hipótesis formuladas en este último, se procederá a realizar el estudio empírico y metodológico de las hipótesis planteadas que permita en el capítulo cinco, contrastar y exponer los resultados que afectarán al modelo planteado. Finalmente, en el último capítulo se recogerán las conclusiones, aportaciones, limitaciones y líneas futuras de investigación que surgen tras la evaluación final de esta investigación. 

CAPÍTULO 4. REVISIÓN DE LA LITERATURA EMPÍRICA Y METODOLOGÍA 



\section{OBJETIVO}

El objetivo de este capítulo consiste en hacer una revisión de la literatura empírica y en presentar un modelo de medida que resuma todo el proceso metodológico. Para ello, nuestra propuesta se centrará en la medición del grado de dependencia de las variables seleccionadas en el capítulo 3. Estas variables son:

- Capacidad innovativa.

- Autoeficacia.

- Accesibilidad.

- Seguridad.

- Valor percibido.

- Satisfacción.

- E-lealtad.

\section{INTRODUCCIÓN}

Para el desarrollo de lo expuesto anteriormente, el presente capítulo se ha estructurado en seis partes. En primer lugar se realiza una revisión de la literatura empírica.

En segundo lugar se justifica el sector escogido, el sector sanitario público, para realizar el estudio empírico sobre el mismo. En concreto, la unidad de análisis en este estudio son los usuarios externos del sistema sanitario público (pacientes, cuidadores, 
familiares, etc.). La elección del mencionado sector y, particularmente, de los usuarios externos, se justificarán razonadamente.

En tercer lugar se describe la población seleccionada, la Región de Murcia. La Consejería de Sanidad de la Región de Murcia ha realizado una clara apuesta para explotar las TIC como apoyo a los procesos asistenciales y a su modelo de gestión. Las razones de su elección así como las características de la población se detallan en este tercer apartado.

En cuarto lugar, se describen las características de la muestra de esta investigación así como los pasos seguidos para la recolección de datos. Posteriormente, se presentan los instrumentos de medición empleados. Finalmente, se explica la principal técnica estadística empleada para estudiar la relación entre las variables independientes y dependientes objeto de estudio y poder realizar el análisis de los datos en el campo que nos afecta: la regresión lineal.

\section{REVISIÓN EMPÍRICA}

Debido a la carencia de trabajos empíricos que relacionan la adquisición, distribución y utilización del conocimiento con la implantación de tecnologías de la información, se ha decidido revisar, por un lado, trabajos empíricos dedicados a la adquisición, distribución y utilización del conocimiento y, por otro lado, trabajos empíricos dedicados a la implantación de tecnologías de la información. 


\subsection{ADQUISICIÓN, TRANSFERENCIA Y UTILIZACIÓN DEL CONOCIMIENTO. ESTUDIOS EMPÍRICOS.}

Como trabajo conceptual podemos destacar el de O`Dell y Grayson (1998), quienes realizaron entrevistas en 20 organizaciones pertenecientes al American Productivity and Quality Center. Investigaron la manera en que las empresas mejoran sus beneficios empresariales por la distribución del conocimiento. La evidencia empírica muestra como el conocimiento facilita la comunicación entre los distintos agentes. Cuanto mayor sea la diferencia de los contextos de los agentes, más difícil será la transferencia de información.

Fiddler (2000) investiga la transferencia interna del conocimiento en equipos de trabajo de seis organizaciones londinenses del sector informático, mediante entrevistas y 116 cuestionarios, usando el análisis de regresión y ecuaciones estructurales. Las conclusiones del estudio de Fiddler señalan que la principal barrera de la transferencia interna es el conocimiento tácito y que los factores contextuales, en particular los mecanismos de comunicación mediante los cuales las empresas transfieren sus competencias con alto porcentaje de conocimiento tácito, son particularmente significativos para el éxito de las transferencias internas.

Por otro lado, Tsai (2001) discute que, en una organización con múltiples unidades organizativas, estas unidades pueden realizar más innovaciones y disfrutar de mejores beneficios si ocupan una posición central en los sistemas intraorganizativos de la empresa, una posición que les permite el acceso a un nuevo conocimiento 
desarrollado por otras unidades organizativas; lo que depende de su capacidad de asimilación o su habilidad para reproducir con éxito un nuevo conocimiento. Para ello, este autor analiza 24 unidades de negocio en una empresa petroquímica y 36 unidades de negocio en una empresa alimentaria utilizando un método de análisis de regresión jerárquico. Los resultados muestran que el acceso al conocimiento externo y la capacidad de aprendizaje interno son importantes para la mejora en la adquisición de nuevos conocimientos y en los beneficios de una unidad organizativa.

Por otra parte, el estudio de Soo et al. (2002) examina el proceso de adquisición del conocimiento, así como los usos y beneficios de la gestión del conocimiento en seis organizaciones de diferentes sectores (servicios e industrial). A través de 357 cuestionarios y 150 entrevistas, los autores identifican que los sistemas informales son una fuente importante de adquisición y transferencia de conocimiento, pero su dependencia puede ser perjudicial. Para evitar la aleatoriedad en el uso de este tipo de sistemas, los autores proponen que éstas deben ser más estructuradas en tiempo y espacio y concluyen que la adquisición de conocimiento es posible cuando la organización cuenta con un sólido sistema de comunicación informal, la cual es apoyada por un sistema de mecanización de información idóneo y cuando la alta dirección está convencida del beneficio que se obtiene al fomentar este proceso.

También Nerkar (2003) analizó 15.345 patentes de 33 empresas farmacéuticas durante un periodo de 7 años y, mediante un análisis de regresión, sugirió que los beneficios de las empresas en situaciones competitivas se maximizan con la exploración (adquisición de conocimiento) de las patentes más que con la explotación de las mismas. 
En el estudio de Cummings (2004) se discute que los beneficios por compartir conocimiento externo entre los miembros de un grupo de trabajo se incrementa cuando los grupos de trabajo cuentan con una diversidad estructural. Esto es, existen diferencias en la situación geográfica, en las tareas funcionales, en los jefes a quienes informar del desarrollo de sus actividades y en las unidades de negocio. El estudio contempla una investigación cualitativa y una investigación cuantitativa. En la primera se emplean documentos, bases de datos y 20 entrevistas. En investigación cuantitativa se realizan 182 cuestionarios a líderes de grupo y 957 cuestionarios a miembros de grupo de trabajo usando el análisis logit. El estudio concluye diciendo que la distribución de conocimiento externo entre los miembros de un mismo grupo de trabajo está fuertemente relacionada con los beneficios cuando existe diversidad estructural, específicamente en las diferencias que existen en las tareas funcionales y en los jefes a quienes informan sobre el desarrollo de sus actividades.

Según el estudio realizado por González (2010), existe una importancia creciente en el ámbito empresarial, académico y para toda la sociedad, sobre el manejo adecuado del conocimiento, desde su captura y procesamiento hasta su transmisión para contribuir al desarrollo social y alcanzar niveles de competitividad. Para la realización de su estudio se utilizó el método de análisis documental clásico a fin de conocer los referentes teóricos del conocimiento, e identificar los principales enfoques sobre los sistemas de gestión del conocimiento. Se concluye afirmando que a pesar de la existencia de sistemas que facilitan la transferencia de conocimientos sin importar las barreras geográficas y permitir la creación de repositorios de todo tipo, no es suficiente implementarlos en una determinada organización, ya que esto no garantiza que el 
conocimiento fluya eficientemente, sino que se requiere de un ambiente propicio para el descubrimiento de las necesidades individuales, pero con capacidad de respuesta colectiva, lo cual propiciará el intercambio eficiente y efectivo de información y generación de nuevo conocimiento, así como de la apropiación del ya existente.

\subsection{TECNOLOGÍAS ORIENTADAS A LA ADQUISICIÓN, TRANSFERENCIA Y UTILIZACIÓN DE LA INFORMACIÓN. ESTUDIOS EMPÍRICOS.}

Lee y Runge (2001) estudiaron 71 pequeños almacenes al por mayor de electrodomésticos, muebles, industrias de electrónica, examinando su adopción de tecnologías de la información. Mediante un modelo de ecuaciones estructurales, ellos distinguieron entre el acercamiento tradicional para adoptar sistemas de información y aplicaciones de Internet y definieron tres variables independientes como factores positivos de adopción de la empresa de tecnologías de la información: (1) Los propietarios perciben las tecnologías de la información para obtener una ventaja relativa. (2) La adopción de tecnologías de la información da prestigio. (3) La innovación está relacionada con el uso de tecnologías de la información. Se estableció un modelo de ecuaciones estructurales que buscaba la explicación de la adopción de tecnologías de la información. De nuevo, los autores notaron la importancia de la percepción de los propietarios del valor de la adopción de tecnologías de la información.

Por otro lado, Mehrtens et al. (2001) realizaron un estudio sobre la adopción de las tecnologías de la información en PYMEs. Ellos usaron la metodología del estudio de 
casos, analizando siete empresas en Nueva Zelanda. Compararon cuatro compañías relacionadas con empresas de tecnologías de la información y tres compañías que no tenían incorporadas tecnologías de la información. Se identificaron tres factores claves para la adopción de las tecnologías de la información: los beneficios percibidos, la preparación organizacional para asimilar tecnologías de la información y las presiones externas del medio ambiente empresarial. Para los beneficios percibidos, ellos enfatizaron que las tecnologías de la información son un medio económico y fácil de usar para propósitos de comunicación externa e interna. Esto permite contactar con clientes y suministradores. Es también una forma efectiva de estrechar diferencias sobre competidores, nuevos productos, etc. Las tecnologías de la información son también herramientas útiles para promocionar la imagen de la empresa tanto a nivel local como en el extranjero.

En cuanto a la preparación organizacional para asimilar tecnologías de la información, los directivos conocen las medidas más efectivas para incorporar tecnologías de la información. Los directivos sabían la importancia de tener buenos sistemas informáticos para adoptar tecnologías de la información y que las empresas se ponían manos a la obra ante la idea de la implantación de tecnologías de la información como una herramienta de comunicación cuando sabían que sus clientes, suministradores y empleados potenciales las usaban.

El estudio realizado por Sadowski et al. (2002) se refería al uso estratégico de las tecnologías de la información por las PYMEs. Ellos usaron un ejemplo de 264 empresas holandesas de varios sectores y eligieron seis proposiciones con el propósito de hacer comparaciones empíricas: (1) La adopción de internet es más normal que la 
medida de la presencia de páginas web. (2) Los negocios que tratan con pedidos para largos volúmenes de información hacen más uso estratégico de las tecnologías de la información. (3) Las tecnologías de la información tienden a ser usadas más estratégicamente cuando la competición es enseñada. (4) Los buenos apoyos e incentivos animan a las PYMES a usar tecnologías de la información de una manera estratégica. (5) El uso estratégico de las tecnologías de la información es más probable en grandes PYMEs. (6) El uso estratégico de las tecnologías de la información es más frecuente en sectores de una industria avanzada que en empresas de servicios.

La principal conclusión fue que el uso de las tecnologías de la información habían sido más oportunistas que estratégicas. Esto es soportado por el hecho de que muchas de las empresas en el estudio usaban Internet para llevar a cabo muy específicas investigaciones para obtener información. Ellos no usaban las tecnologías de la información de modo intensivo para crear nuevos clientes y tampoco había alguna evidencia de presión competitiva y ayudas para proveer incentivos para un uso más estratégico de las tecnologías de la información.

Gargallo y Pérez (2009) realizaron un estudio con el objetivo de analizar el impacto de la implantación de las tecnologías en las cooperativas de trabajo asociado, las cuales constituyen un caso concreto muy importante, a la vez que representativo de las entidades de la Economía Social ${ }^{35}$. Para su estudio recogieron la información de la base de datos de la Encuesta sobre Estrategias Empresariales (ESEE), encuesta elaborada por la Fundación de la Empresa Pública (FEP). Los datos corresponden a 20

35 Según el Comité Científico de CIRIEC-España, dentro de la Economía Social se incluyen aquellas empresas que actúan en el sector de mercado con la finalidad de producir, asegurar, financiar o distribuir bienes o servicios, pero en las que el reparto de beneficios no está directamente relacionado con el capital aportado por cada miembro, las decisiones no se toman teniendo en cuenta el capital de cada socio y el peso a la hora de tomar decisiones es el mismo para todos, independientemente del capital aportado. 
empresas que toman como forma jurídica la cooperativa de trabajo asociada. Respecto a los patrones de adopción de las TIC, se observó que era mayor el porcentaje de empresas cooperativas que no invierten en TIC que el de aquellas que sí lo hacen. El estudio confirma por un lado, la importancia de estas tecnologías en los resultados organizacionales y, por otro, muestra la similar contribución de las cooperativas frente al resto de formas jurídicas al no reflejar diferencias significativas en el coeficiente que recoge la incidencia de dicha forma organizativa en la eficiencia.

Según Sainz et al. (2011), una mejora en las TIC permite un desarrollo adecuado de las tecnologías en el área de la salud, gracias al cual el paciente se encuentra más informado y próximo a su médico por la posibilidad de concertar citas a través de Internet, realizar consultas médicas por e-mail, solicitar diagnósticos a distancia, etc., constituyendo una herramienta eficaz para la mejora de la calidad en la atención sanitaria. Finalmente concluyen afirmando que dado que una gran mayoría de la población mundial tiene acceso a un móvil frente al $26 \%$ de la población que no dispone de acceso a Internet a través del ordenador, no es extraño apostar por las tecnologías como el futuro de la medicina online.

No obstante, hay un gran volumen de investigación en el área de la clasificación, desarrollo e implantación de las TIC. Wager et al. (2005) sugirió dos criterios principales para clasificar las tecnologías utilizadas en medicina: la primera es llamada "almacenamiento y reenvío" y se usa para transferir documentos de un lugar a otro; la otra es "la televisión interactiva bidireccional", la cual sólo es posible mediante la videoconferencia. Alternativamente Bhatt et al. (2005) identifica tres dimensiones: las tecnologías que ayudan a capturar, almacenar y manipular la información, las que 
permiten distribuir y compartir la información y las que permiten que la gente separada geográficamente trabaje en equipo y tenga la oportunidad de modificar y revisar los supuestos y premisas del conocimiento para la coordinación de las tareas de la organización. Más tarde, Tulu et al. (2007) clasificaron sistemáticamente los esfuerzos en telemedicina usando cinco dimensiones: finalidad de la aplicación, aplicación de la zona, entorno ambiental, infraestructura de comunicación y opciones de entrega.

Siguiendo las sugerencias de Moffett y McAdam (2003), en el presente trabajo las tecnologías se han clasificado a través de tres niveles para proveer la información organizacional:

1. El primer nivel engloba a las tecnologías orientadas a la adquisición de información. Estas tecnologías (por ejemplo Internet) permiten a los empleados del sector sanitario (doctores, enfermeros, celadores, entre otros) y a los usuarios externos (pacientes, cuidadores o familiares) tener acceso a la información sobre los servicios sanitarios online ofrecidos por las propias instituciones sanitarias de forma instantánea y sin necesidad de desplazamiento (Cegarra et al., 2007), circunstancia que favorece el traspaso rápido de conocimiento interno y externo (Córdoba y Cegarra, 2010).

2. El segundo nivel recoge a las tecnologías orientadas a la distribución de información. Córdoba y Cegarra (2010) sugieren el uso de redes de trabajo para proveer grupos de colaboración con la habilidad de unir gran número de unidades de información de una manera dinámica. Estas tecnologías permiten a los agentes que interaccionan (por ejemplo, doctores o pacientes) dar significado a la información disponible en el nivel uno. La necesidad de estas herramientas surge como consecuencia del acceso a la información mediante un sitio web. Bajo este contexto, al ser humano se 
le generan dudas y cuestiones. Por ello, se deben facilitar herramientas que den sentido y soluciones a las mismas (por ejemplo, el correo electrónico).

3. Por último, el tercer nivel corresponde a TIC orientadas a la utilización de la información. Incluye herramientas que engloban las aplicaciones de automatización y áreas online de atención al usuario. Estas herramientas puestas a disposición de los agentes externos (pacientes, cuidadores o familiares) por parte de hospitales o centros sanitarios mejoran las relaciones entre agentes internos y externos y posibilitan la implantación de la información adquirida en los niveles uno y dos. Los servicios ofrecidos vía Internet tales como, hacer sugerencias, enviar una queja o pedir una cita online son los más relevantes que un centro sanitario puede realizar en este nivel.

Cada una de estas TIC posibilita que los pacientes puedan valorar diferentes alternativas y puedan tener voz en los procesos de asistencia sanitaria, lo cual presumiblemente aumentará su satisfacción y el rendimiento de los sistemas sanitarios.

En los apartados siguientes describimos brevemente cada uno de estos tres niveles.

\subsubsection{Tecnologías orientadas a la adquisición de información}

Podemos considerar a las TIC orientadas a la adquisición de información como herramientas tecnológicas individuales o unidireccionales. Este tipo de herramientas únicamente requieren de la participación del usuario externo (paciente, cuidador o 
familiar). Él es quién hace uso de ellas y encuentra lo que busca sin la participación de ningún otro usuario externo o interno del ente con el que intercambia la información. Por tanto, el flujo de conocimiento es unidireccional, del servicio específico al usuario concreto (figura 21).

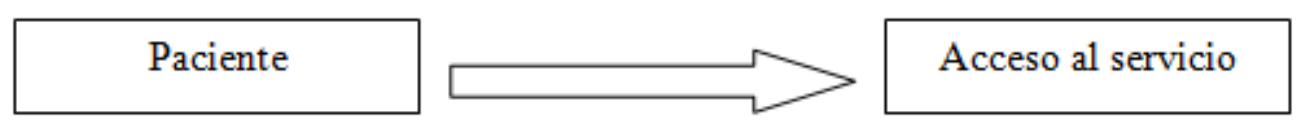

Figura 21: Funcionamiento de tecnologías unidireccionales (Elaboración propia).

Tomando como referencia los trabajos de Cegarra y Sabater (2005a: 2005b) en los que se realiza una clasificación de herramientas tecnológicas orientadas, a la adquisición de la información, a su distribución y a la utilización de la misma, en esta investigación se propone otra nueva clasificación adaptada a los servicios sanitarios online. Así, en primer lugar se presenta una clasificación de las herramientas tecnológicas orientadas hacia la adquisición de información tal como se muestra en la tabla 6. 
Tabla 6. Herramientas tecnológicas orientadas a la adquisición de información

\begin{tabular}{|c|c|}
\hline $\begin{array}{l}\text { HERRAMIENTAS } \\
\text { TECNOLÓGICAS }\end{array}$ & SERVICIOS QUE OFRECE \\
\hline 1. Conexión a Internet & $\begin{array}{l}\text { Internet se ha convertido en una herramienta diaria de trabajo y ha llegado } \\
\text { para quedarse y desarrollarse en cada una de las organizaciones. Esta nueva } \\
\text { herramienta virtual de Internet ha servido como un medio para proveer } \\
\text { servicios médicos de calidad, independientemente de la ubicación física, } \\
\text { realizar acciones como: intercambio de imágenes, voz, datos y vídeo, } \\
\text { realizar diagnósticos, dar opiniones, acceder a base de datos, realizar } \\
\text { consultas o intercambiar información, etc. }\end{array}$ \\
\hline 2. Sitio web & $\begin{array}{l}\text { Presenta un conjunto de páginas webs relacionadas. Además, un centro } \\
\text { sanitario puede publicar en su sitio web información sobre sus programas y } \\
\text { actividades (cursos sobre prevención de enfermedades, hábitos de } \\
\text { alimentación), o sobre cuáles serán los próximos eventos o proyectos que } \\
\text { llevarán a cabo (nuevos programas de vacunas), o de qué forma puede el } \\
\text { público colaborar con el centro, etc. (Figura 22). }\end{array}$ \\
\hline 3. Página web & $\begin{array}{l}\text { Constituye la tarjeta de presentación de un ente sanitario frente a sus } \\
\text { potenciales usuarios externos, ya que, en ella se incorpora, principalmente, } \\
\text { información básica sobre los servicios ofrecidos por el centro y otros datos } \\
\text { de contacto tales como, el teléfono o la dirección. }\end{array}$ \\
\hline 4. Mapa de la web & $\begin{array}{l}\text { Es una lista de páginas de un sitio web accesible para buscadores y usuarios } \\
\text { de una organización. A su vez, es una herramienta de planificación que } \\
\text { ayuda a los usuarios a hallar las páginas de un sitio web. Refleja la } \\
\text { estructura de información de un sitio web concreto y permiten al usuario } \\
\text { orientarse en la globalidad de la información o dirigirse hacia otras páginas } \\
\text { webs. }\end{array}$ \\
\hline 5. Página de contenidos & $\begin{array}{l}\text { Es una estrategia competitiva de las organizaciones que permiten recoger, } \\
\text { ordenar, explotar y manipular información para obtener de ella un valor } \\
\text { añadido. (Figura 23). }\end{array}$ \\
\hline 6. Motor de búsqueda & $\begin{array}{l}\text { Un motor de búsqueda apropiado facilita el acceso a la información } \\
\text { adecuada en el momento adecuado, además de que facilita la búsqueda de } \\
\text { información por parte de los usuarios. }\end{array}$ \\
\hline $\begin{array}{l}\text { 7. Enlaces o banners a } \\
\text { otros sitios webs sanitarios }\end{array}$ & $\begin{array}{l}\text { Son herramientas para vincular dos o más sitios en Internet. Se utilizan para } \\
\text { enlazar con otra página, lo que le permite a las organizaciones enlazar con } \\
\text { otras organizaciones colaboradoras o suministradoras. Por ello, los usuarios } \\
\text { externos y/o internos del sector sanitario pueden obtener más información } \\
\text { sobre otros centros sanitarios, otras webs sanitarias o sobre las listas de } \\
\text { espera en cada uno de los centros, entre otros. }\end{array}$ \\
\hline 8. Tablón de anuncios & $\begin{array}{l}\text { Los tablones de anuncios incorporan novedades, ofertas de última hora, } \\
\text { posibilidades de trabajo, etc. y permiten obtener información actualizada. De } \\
\text { ahí que los usuarios puedan permanecer mejor informados sobre temas } \\
\text { organizacionales, de formación o de actualidad a través de las notas de } \\
\text { prensa que se van publicando de forma constante en la web del centro } \\
\text { sanitario. }\end{array}$ \\
\hline
\end{tabular}

Fuente: Elaboración Propia 
A continuación se muestra en la figura 22, un ejemplo de sitio web del Servicio Murciano de Salud y en la figura 23 un ejemplo de página de contenidos:

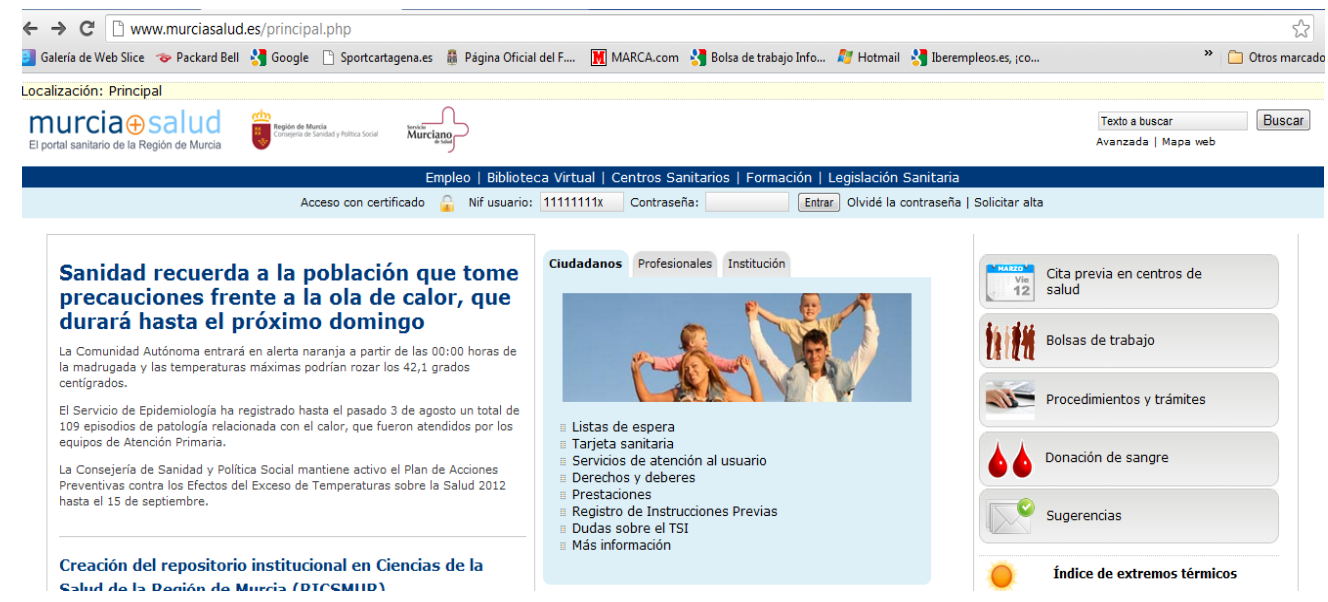

Figura 22. Sitio web del Servicio Murciano de Salud.

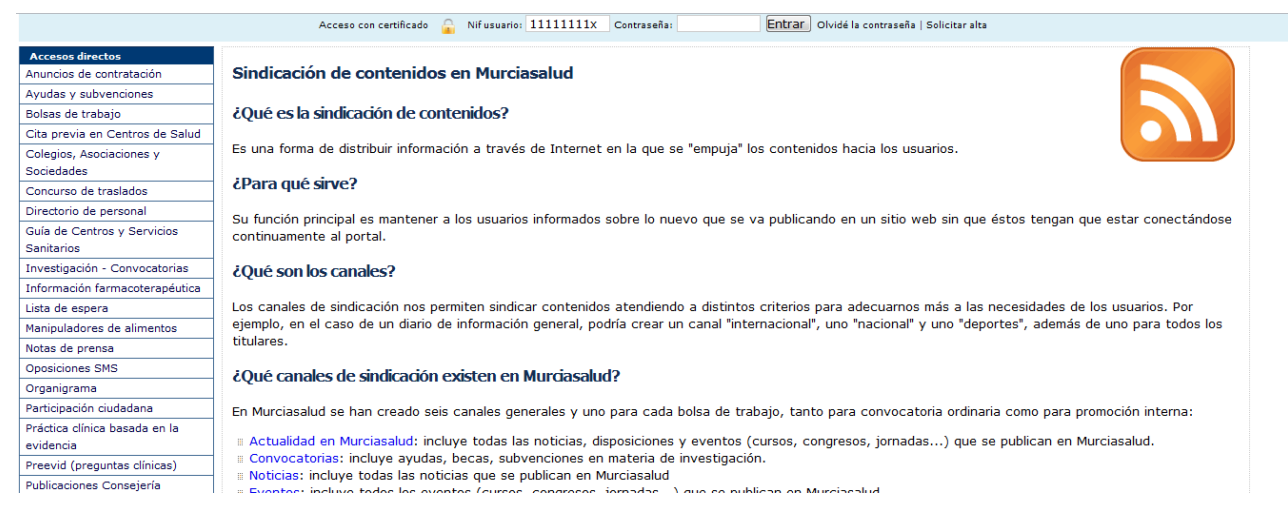

Figura 23. Página de contenidos del Servicio Murciano de Salud.

\subsubsection{Tecnologías orientadas a la distribución de información}

Las tecnologías orientadas a la distribución de información se pueden definir como herramientas tecnológicas colectivas o bidireccionales. Este tipo de tecnologías implica la participación de dos importantes componentes: de un lado, el usuario externo 
(paciente, cuidador o familiar), y del otro, los usuarios internos (médicos, enfermeros, etc) del sector sanitario. Para que se pueda aplicar este tipo de herramientas, se necesita que haya una retroalimentación por parte de los integrantes del proceso. Por tanto, el flujo de conocimiento es bidireccional, de la organización al usuario interno y/o al usuario externo y viceversa (figura 24).

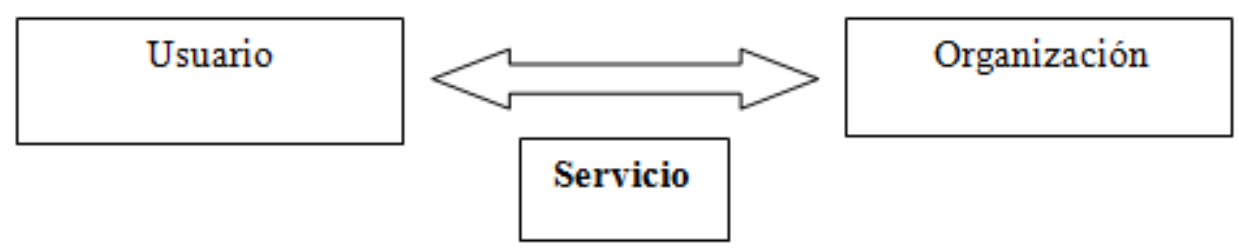

Figura 24: Funcionamiento de las tecnologías orientadas a la distribución de información (Elaboración propia).

Las demandas de formalidad de las tecnologías pueden impedir relaciones informales más productivas. El objeto de estas herramientas tecnológicas es crear un contexto que salte las fronteras de los grupos e individuos del centro sanitario. Un centro sanitario tendrá una buena conexión de trabajo cuando ponga a disposición de sus agentes (internos y externos) herramientas que les permitan solicitar (o incluso recoger directamente) información detallada y trabajar hasta cierto punto con dicha información. Dicho de otro modo, el centro permitirá a sus agentes colaborar con los miembros de la organización en el tratamiento de la información.

Esta colaboración no ofrece a la organización rentabilidad directa, aunque afianza las relaciones con los agentes, y en cierta medida, propicia que la organización genere conocimiento útil, si bien este conocimiento se quedará entre miembros de la 
organización que trabajen directamente con el paciente o empleado sanitario (usuarios de las herramientas).

De acuerdo con Nahar et al. (2002), los beneficios de implantación de las herramientas que posibilitan la red social de trabajo incluyen entre otros: mejorar la eficacia, la habilidad para la resolución de enfermedades, la habilidad para acceder a información actualizada y reducir las barreras de distancia y tiempo. De nuevo, tomando como referencia las contribuciones de Cegarra y Sabater (2005a: 2005b), se ha propuesto una segunda clasificación en la tabla 7 que recoge las herramientas tecnológicas orientadas a la distribución de la información centradas en los servicios online ofrecidos por el sector sanitario. Gracias a estas herramientas, los agentes pueden desarrollar efectivas y eficientes directrices de relación y reducir las reuniones directas dando significado a la información y transformándola en conocimiento. 
Tabla 7. Herramientas Tecnológicas orientadas a la distribución de información

\begin{tabular}{|c|c|}
\hline $\begin{array}{l}\text { HERRAMIENTAS } \\
\text { TECNOLÓGICAS }\end{array}$ & SERVICIOS QUE OFRECE \\
\hline 1. Correo electrónico & $\begin{array}{l}\text { Es el modo más sencillo de comunicación directa de un usuario a otro } \\
\text { usuario y permite enviar y recibir textos, imágenes, sonidos y, en general, } \\
\text { cualquier tipo de información digitalizada. El uso del e-mail facilita la } \\
\text { creación de flujos de conocimiento. Otro uso del correo electrónico para los } \\
\text { profesionales es la transferencia de la información interna organizacional. } \\
\text { Se trata de un recurso imprescindible que puede ser utilizado para contestar } \\
\text { a preguntas rutinarias y a menudo puede ser el único método disponible para } \\
\text { entrar en contacto con pacientes y personal sanitario en posiciones remotas o } \\
\text { en zonas de tiempo distantes. (Figura 25). }\end{array}$ \\
\hline $\begin{array}{l}\text { 2. Agenda a disposición } \\
\text { del paciente }\end{array}$ & $\begin{array}{l}\text { El objetivo principal de la agenda es optimizar los servicios sanitarios online } \\
\text { aplicando al máximo las ventajas de Internet. La presencia de agendas } \\
\text { mejora la comunicación entre los usuarios, proporcionándoles información } \\
\text { clave y la organización de la información disponible. }\end{array}$ \\
\hline $\begin{array}{l}\text { 3. Reposición } \\
\text { documentos }\end{array}$ & $\begin{array}{l}\text { Mediante los repositorios de documentos, la información puede ser } \\
\text { almacenada, recuperada y comunicada de una forma más fácil y eficaz. Es } \\
\text { un buen ejemplo de sistemas de TIC que sirven para memorizar hechos. } \\
\text { Mediante estas aplicaciones, la cantidad de información que la organización } \\
\text { puede gestionar se incrementa significativamente. }\end{array}$ \\
\hline $\begin{array}{l}\text { 4. Herramienta de } \\
\text { solicitud de información }\end{array}$ & $\begin{array}{l}\text { Pueden ser utilizadas para las consultas realizadas por los pacientes y para } \\
\text { solventar la complejidad de los problemas que vayan surgiendo por el uso de } \\
\text { los servicios sanitarios online. Permiten integrar la información generada en } \\
\text { la organización con la que poseen los usuarios de la misma. Captura } \\
\text { información importante y suministra datos según las especificaciones y } \\
\text { criterios seleccionados previamente según las necesidades de los usuarios. }\end{array}$ \\
\hline $\begin{array}{l}\text { 5. Acceso a bases de datos } \\
\text { compartidas }\end{array}$ & $\begin{array}{l}\text { La presencia de bases de datos compartidas aporta una considerable rapidez } \\
\text { a la recolección de datos. Se componen de información estructurada y } \\
\text { almacenada en un archivo especial para un propósito determinado. } \\
\text { Últimamente los centros sanitarios están desarrollando bases de datos para } \\
\text { almacenar documentación e informes. Se crean de manera que la } \\
\text { información pueda desplegarse rápidamente de forma flexible albergando } \\
\text { gran cantidad de información y proporcionando búsquedas eficientes y } \\
\text { rápidas a través de ellas. (Figura 26). }\end{array}$ \\
\hline
\end{tabular}

Fuente: Elaboración propia.

A continuación se muestra la figura 25 donde se presenta una dirección de correo

electrónico del Servicio Murciano de Salud y la figura 26 de acceso a una base de datos, concretamente a la base de datos Proquest Medical Collection. 


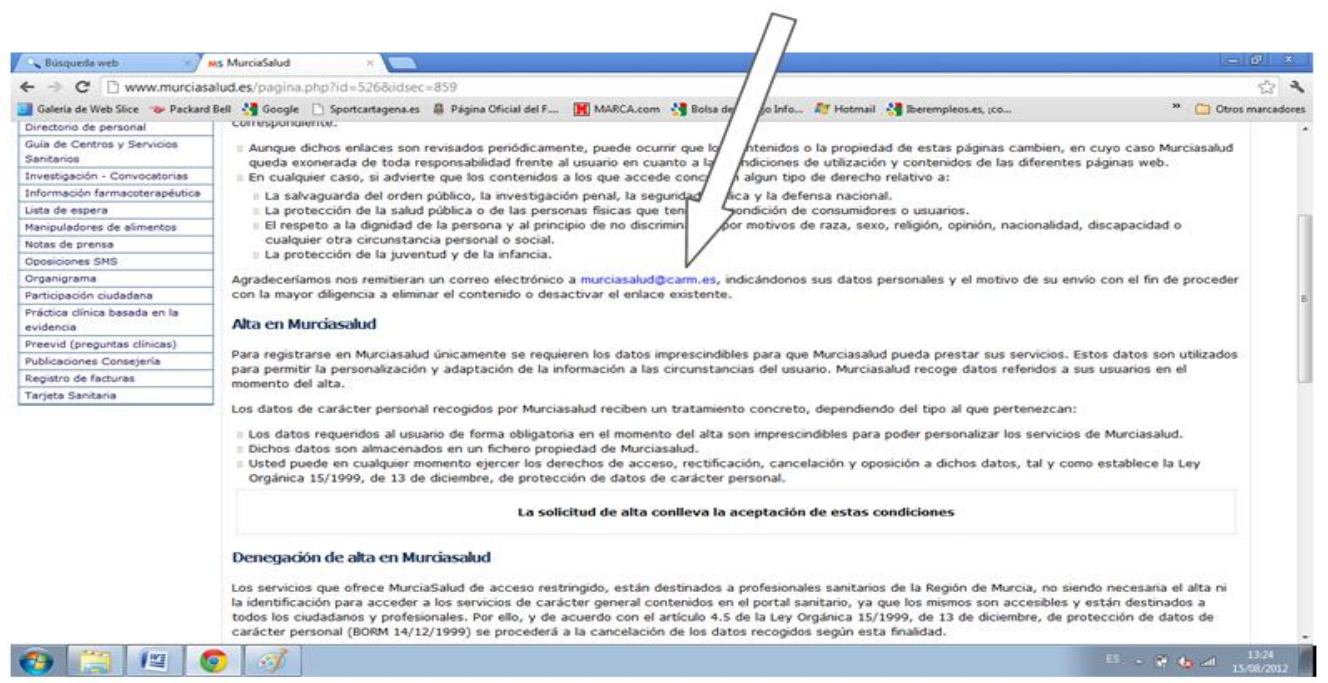

Figura 25. Dirección de correo electrónico del Servicio Murciano de Salud (murciasalud@ carm.es).

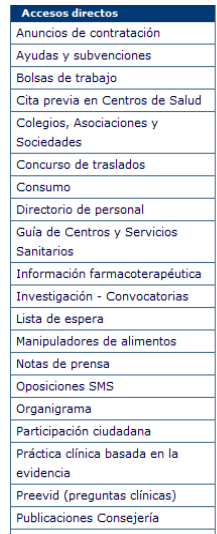

Buscador Murciasalud: búsqueda en todo murciasalud

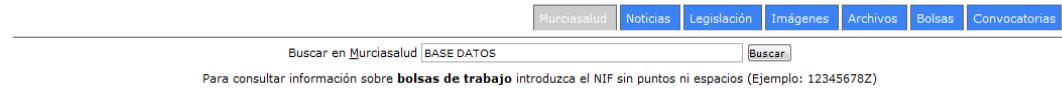

Página 1: Resultados del 1 al 10 de 180 elementos encontrados.

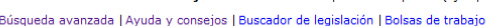

\section{\begin{tabular}{l|l|l|l|l|l|l|l|l}
1 & 2 & 3 & 4 & 5 & 6 & ... & 18 & siguiente
\end{tabular}}

Acceso a la base de datos proquest Medical Collection (Identifcados)

Resolución de la Agencia Española del Medicamente (AEM), relativa al concurso público, procedimiento abierto, de consultoría y asistencia para la

explotación y validación de la base de datos BIFAP.

Convocatoria de beca de investigación para el establecimiento y desarrollo de una base de datos de enfermos renales

restigación Vigilancia y Control de las

Bacteriemias en Pacitotos Hos

INFORMÁTICA AVANZADA

Resolución de la Dirección General de Recursos

evaluación de la base de datos del Conjunto...

$\checkmark$ jornadas de presentación e introducción al uso de las bases de datos de la web of Knowledge

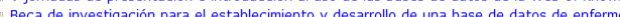

Murcia.

Pánina 1: Resultados del 1 al 10 de 180 elementos encontrados.

Figura 26. Ejemplo de enlace a la base de datos de Proquest Medical Collection.

\subsubsection{Tecnologías orientadas a la utilización de información}

Las tecnologías orientadas a la utilización de información pueden considerarse, al igual que las tecnologías orientadas a la distribución de la información, como herramientas tecnológicas colectivas o bidireccionales, ya que el flujo de conocimiento es bidireccional, de la organización al usuario y viceversa. 
Partiendo de la clasificación inicial llevada a cabo por Cegarra y Sabater (2005a: 2005b), la tabla 8 recoge una nueva propuesta de herramientas tecnológicas orientadas a la utilización de la información en el sector sanitario. Estas herramientas se centran en permitir a los usuarios realizar servicios y procesos sanitarios a través de la red. Ello supone principalmente modificar los modos en que los usuarios del sector sanitario acceden a la información relevante, posibilitando el acceso a las listas de incidencias, de quejas, de sugerencias o a la petición de citas, entre otros muchos servicios sanitarios online.

Tabla 8. Herramientas tecnologías orientadas a la utilización de información

\begin{tabular}{|c|c|}
\hline $\begin{array}{l}\text { HERRAMIENTAS } \\
\text { TECNOLÓGICAS }\end{array}$ & SERVICIOS QUE OFRECE \\
\hline 1. Cookies & $\begin{array}{l}\text { Por medio de las cookies, se puede obtener sin necesidad de saber ni el } \\
\text { nombre ni la dirección postal, ni siquiera la dirección de correo electrónico } \\
\text { de ese usuario potencial, información acerca de los gustos e intereses de esa } \\
\text { dirección. }\end{array}$ \\
\hline $\begin{array}{l}\text { 2. Estado de las listas de } \\
\text { espera }\end{array}$ & $\begin{array}{l}\text { El objetivo de consultar el estado de las listas de espera de manera online es } \\
\text { el de optimizar la prestación de los servicios sanitarios. De esta forma los } \\
\text { usuarios externos pueden conocer en cualquier momento el estado de las } \\
\text { listas de los especialistas del sector aprovechando al máximo las ventajas } \\
\text { que ofrecen las TIC. Permite mejorar la comunicación interna y externa de } \\
\text { una organización anticipándose a los problemas y proporcionando } \\
\text { información clave de las listas de espera de los especialistas. }\end{array}$ \\
\hline $\begin{array}{l}\text { 3. Sistema de quejas y } \\
\text { sugerencias }\end{array}$ & $\begin{array}{l}\text { Los sistemas de respuesta a sugerencias son una oportunidad para } \\
\text { aproximarse al paciente, incrementar la flexibilidad y la habilidad } \\
\text { competitiva del centro sanitario público. Por ello, los sistemas de respuesta a } \\
\text { sugerencias mejoran los procesos para trabajar con centros sanitarios a } \\
\text { distancia, reduciendo el riesgo de coste de presupuestos e incrementando el } \\
\text { nivel y calidad de servicio al paciente. } \\
\text { Las listas de incidencias y los sistemas de respuesta a sugerencias son dos } \\
\text { herramientas que facilitan la creación de nuevo conocimiento a través de las } \\
\text { TIC (Cegarra y Dewhurst, 2005). (Figura 27). }\end{array}$ \\
\hline 4. Petición de citas & $\begin{array}{l}\text { Estos servicios han permitido mejorar significativamente la forma en la que } \\
\text { se efectúan los servicios sanitarios online. Mejoran tanto el comportamiento } \\
\text { como la predisposición por parte del usuario para continuar utilizando este } \\
\text { servicio, el cual le supone a los centros sanitarios un ahorro considerable en } \\
\text { sus costes, sobre todo, en los servicios relacionados con la atención al } \\
\text { paciente. (Figura 28). }\end{array}$ \\
\hline
\end{tabular}

Fuente: Elaboración propia 
A continuación se muestra la figura 27 un ejemplo de enlace al sistema de quejas y sugerencias de la web del Servicio Murciano de Salud y en la figura 28 los accesos a la petición de citas previas del Servicio Murciano de Salud.

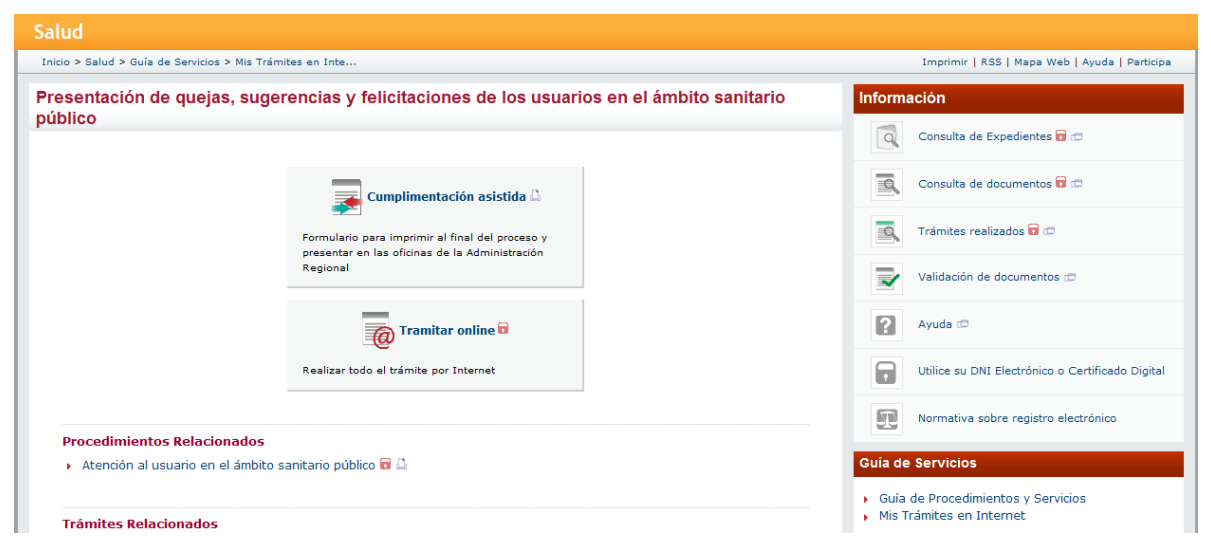

Figura 27. Enlace al sistema de quejas y sugerencias del Servicio Murciano de Salud.

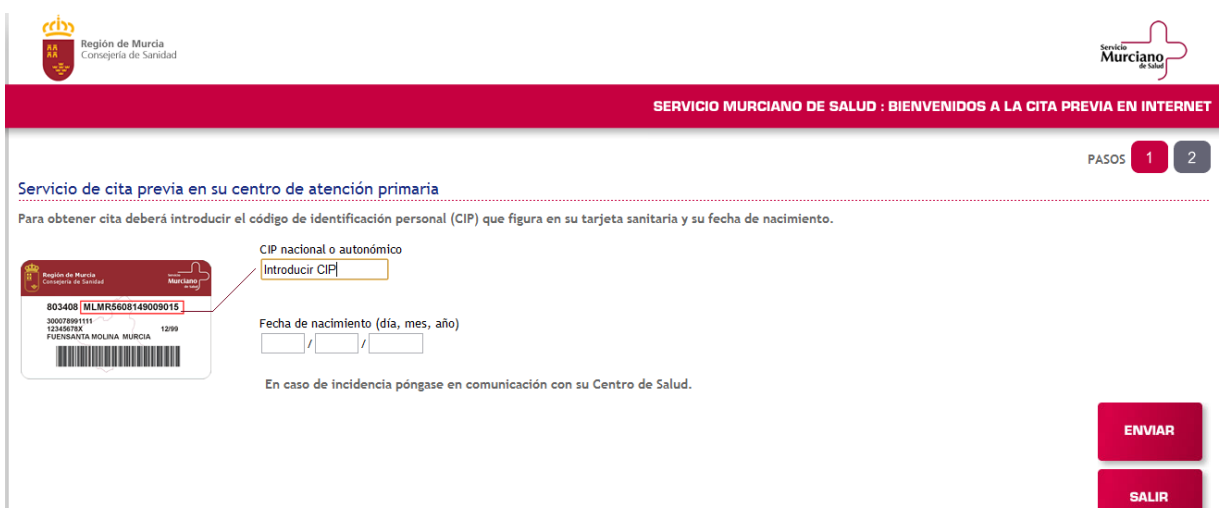

Figura 28. Servicio de cita previa en su centro de atención primaria.

\section{JUSTIFICACIÓN DEL SECTOR}

Para realizar el estudio empírico nos hemos centrado en un único sector, el sector sanitario público, ya que esto puede favorecer la profundización en el mismo y la 
adaptación de un cuestionario concreto para el sector sanitario, lo que podría aportar mayor validez a las conclusiones del análisis empírico. En concreto, la unidad de análisis en este estudio fueron los usuarios finales del sistema sanitario público (pacientes, cuidadores, familiares, etc.). La elección del mencionado sector y, particularmente, de los usuarios externos, se encuentra justificada por diversas razones:

a) El entorno sanitario es un terreno abonado para la aplicación de las TIC desde un enfoque estratégico del conocimiento (Picas-Vidal, 2000).

Consecuentemente, la elección del sector sanitario queda justificada por el éxito que las TIC y los servicios virtuales, están teniendo en las prácticas sanitarias centradas en dar respuesta a las exigencias de los pacientes de satisfacer una mayor demanda de servicios de salud, con mejor calidad, haciéndolo compatible con las limitaciones existentes de recursos.

Para la aplicación de las TIC al sector sanitario ha sido fundamental ligar a la evolución general de la sociedad, las propuestas que se están planteando de rediseño de las instituciones sanitarias que utilizan habitualmente las TIC mediante el desarrollo de trabajo en red con otros recursos sanitarios y con la participación activa del paciente en las nuevas prácticas sanitarias.

Esta cuestión ha sido objeto, a lo largo de los años, de considerables debates, sobre todo en temas relacionados con el uso de los servicios online o el valor percibido de los mismos (Kim y Chang, 2007; Aggelidis y Chatzoglou, 2009). 
Por ejemplo, varios estados miembros de la Unión Europea ya han constatado el fracaso de la aplicación de las TIC a sus sistemas sanitarios. Concretamente, en administración de empresas justifican este fracaso de la implantación de las TIC a que la mayoría de las empresas han procedido únicamente a introducir las nuevas tecnologías sin tener en cuenta aspectos relacionados con la cultura o el conocimiento de los usuarios existente en la organización (Cegarra et al., 2007).

La implantación de las TIC en el sector sanitario requiere de un ajuste entre los sistemas tecnológicos y el conocimiento previo. Es el caso del programa danés MEDCOM que por el momento está obteniendo los mejores resultados, a diferencia del programa EVISAND que se desarrolla en España, el SJUNET desarrollado en Suecia o el HYGEIANET de Grecia.

b) Las implicaciones del uso de las TIC en el sector sanitario: Mejora de la eficiencia y reducción de costes.

El sector sanitario es un ámbito de gran innovación, donde se esperan cambios profundos que nos obligarán a afrontar retos como: nuevos problemas de salud, asegurar la satisfacción de los ciudadanos desde sistemas sanitarios complejos, ofrecer los servicios de forma priorizada y equitativa, o avanzar en la idea de llevar a la práctica nuevos servicios sanitarios online. La gestión del conocimiento y las TIC brindan una oportunidad sin precedentes al sector sanitario para utilizar conectividad y contenido a fin de mejorar y modernizar los servicios sanitarios mientras contiene los costes aumentando su eficiencia operativa. 
Concretamente, el uso de las TIC en el sector sanitario ofrece un gran potencial para mejorar la calidad y la eficacia de los servicios, así como la eficiencia del personal, pero también para reducir los tiempos de espera de los centros sanitarios. Es por ello, por lo que las instituciones públicas de salud están haciendo grandes esfuerzos para desarrollar servicios sanitarios online en un intento de mejorar su efectividad. Unos servicios que favorecen al paciente porque les permite ahorrar en tiempo y esfuerzo.

c) Las limitaciones existentes en los estudios previos sobre la aceptación de servicios sanitarios online dirigidas al paciente.

Las aplicaciones de las TIC en el sector sanitario son numerosas. Esta investigación se refiere específicamente a los servicios online ofrecidos por la sanidad pública a todos los ciudadanos, tales como solicitar citas, comprobar listas de espera, realizar consultas a médicos, realizar quejas, sugerencias o preguntas, compartir información con otras personas con los mismos problemas de salud (por ejemplo, mediante foros), y consultar información online sobre centros y recursos sanitarios (personal médico de un hospital o centro médico, servicios ofertados, especialidades médicas, recursos), aspectos organizativos (horarios, localización, instrucciones para admisión, normas), o información sobre salud (novedades, eventos, temas de salud).

A pesar del gran volumen de trabajos relacionados con la aceptación de las tecnologías, muy pocas investigaciones se han centrado en el área sanitaria (Aggelidis y Chatzoglou, 2009). Los pocos estudios enfocados en este sector están limitados principalmente al análisis de webs de información sanitaria (por ejemplo, Gummerus et al., 2004; Kim y Chang, 2007). Otros estudios se han centrado en la intención de uso de 
las TIC por parte del personal del hospital (Aggelidis y Chatzoglou, 2009) o en la actitud que hacia los sistemas de aprendizaje e-learning tiene el personal médico (Yu y Yang, 2006), pero no en el usuario final (pacientes, cuidadores, familiares).

\section{POBLACIÓN}

Para desarrollar el estudio se seleccionó la Región de Murcia. Se escogió esta región porque la Consejería de Sanidad de la Región de Murcia ha realizado una clara apuesta para explotar las TIC como apoyo a los procesos asistenciales y a su modelo de gestión. Esta apuesta se formalizó en el desarrollo del Plan Director de Sistemas de Información (PDSIS) del Servicio Murciano de Salud (SMS) elaborado en el año 2003 y que planteaba un ambicioso proyecto de inversión e implantación de sistemas de información que ha permitido que la Región de Murcia ocupe puestos de liderazgo en el conjunto del Sistema Nacional de Salud.

El PDSIS incluye la implantación de una red corporativa de comunicaciones que ha permitido dotar a los centros del SMS con una red robusta y rápida, con capacidad para transmitir voz, datos e imagen entre todos los centros, asegurando la integridad, la disponibilidad continua, la confidencialidad y autenticidad en el almacenamiento y transmisión de datos. Esta red ha permitido la implantación de la Historia Clínica Electrónica que contiene toda la información clínica sobre la historia de salud de un ciudadano y es accesible desde cualquier centro (hospitales, consultorios de atención primaria, etc.). 
El PDSIS aglutina además numerosos procesos de modernización en los Sistemas Informáticos Departamentales de apoyo al Diagnóstico Hospitalario como el Sistema de Almacenamiento y Distribución de Imágenes Digitales, el Sistema de Información de Farmacia Hospitalaria, Anatomía Patológica, el Banco de Sangre, la Descentralización del control del Tratamiento Anticoagulante Oral (TAO), los Proyectos de Accesibilidad en Atención Primaria, la cita web, la central de llamadas, otros proyectos de accesibilidad en atención especializada, como la citación desde primaria en agendas de atención especializada, los proyectos de emergencias y transporte sanitarios, la telemedicina en las unidades medicalizadas de emergencias o la coordinación del transporte.

La presente investigación se centra, en concreto, en los servicios online ofertados por el Servicio Murciano de Salud a los pacientes, sus familiares y/o sus cuidadores.

Dichos servicios son los siguientes:

- Información online sobre centros y recursos sanitarios: personal médico de un hospital o centro médico, cartera de servicios ofertados, especialidades médicas, equipamiento.

- Información online sobre aspectos organizativos: horarios, localización, instrucciones para usuarios.

- Información online sobre salud (promoción y prevención, información farmacoterapéutica, biblioteca virtual, boletines informativos).

- Consulta online de listas de espera.

- Trámites administrativos (por ejemplo, solicitud de cambio de domicilio en el registro de vacunas y otros programas de salud pública, solicitud de certificado de datos 
vacunales, solicitud de donación de órganos y tejidos, notificación de sospecha de reacción adversa a un medicamento, consulta de expedientes, solicitud de documentación clínica).

- Tablón de anuncios virtual del centro médico u hospital.

- Petición de cita previa para médico de familia y pediatra.

- Realización de consultas a través del correo electrónico.

- Presentación de quejas, sugerencias y felicitaciones.

La posición de liderazgo alcanzada por el Servicio Murciano de Salud fruto de la implantación de TIC no ha estado exenta de problemas vinculados tanto al nivel de desarrollo de las aplicaciones informáticas como a la madurez de la organización en asumir e interiorizar una innovación de este calado. Estos problemas han provocado que las fases previstas inicialmente en el PDSIS se hayan ido cumpliendo con cierto retraso e, incluso, que en algunos ámbitos se haya considerado que existen problemas de enfoque en la definición del proyecto.

Es por ello que los usuarios del Servicio Murciano de Salud, en concreto, los pacientes, sus familiares y/o cuidadores, a quienes van dirigidos los servicios descritos, constituyen una población idónea para el análisis de un modelo de aceptación de la tecnología que permita que los usuarios asuman estas innovaciones tecnológicas.

Para estimar la población objeto de estudio, en concreto, los ciudadanos mayores de edad con acceso al sistema sanitario público de la Región de Murcia y que utilizan Internet, se consultaron estadísticas de la Consejería de Sanidad y Consumo, en particular, de la Dirección General de Planificación, Ordenación Sanitaria y 
Farmacéutica e Investigación de la Región de Murcia, así como la "Encuesta sobre equipamiento y uso de tecnologías de la información y comunicación en los hogares 2010” del Instituto Nacional de Estadística. A partir de dichas estadísticas se estimó una población de 858.181’673 personas.

\section{MUESTRA}

Los participantes fueron escogidos aleatoriamente en distintas zonas de la Región de Murcia seleccionando una muestra que fuese representativa de la población según diversos criterios demográficos, tales como la edad, sexo, estudios y nivel de ingresos. Como paso previo a participar en el estudio, se preguntó a los posibles participantes si eran mayores de edad y si habían utilizado alguna vez los servicios online del Servicio Murciano de Salud. Si contestaban afirmativamente a las dos cuestiones, se les invitaba a participar en el estudio.

A los participantes se les informó sobre el objetivo de la investigación y se les aseguró su carácter estrictamente científico y confidencial, así como el tratamiento global y anónimo de los datos.

La recogida de datos se realizó durante tres meses, desde principios de Septiembre hasta finales de Noviembre de 2010. La recopilación de datos se realizó a través de 277 cuestionarios de los cuales 256 fueron válidos.

A continuación se muestra el resumen técnico de la investigación empírica (tabla 9). 
Tabla 9. Ficha técnica de investigación empírica

Población

Usuarios mayores de edad de servicios online del

Servicio Murciano de Salud dirigidos a la población.

Población estimada: 858.181'673 personas.

Tipo de recogida de datos Cuestionarios por contacto personal

Tamaño de la muestra 256 cuestionarios válidos

Error absoluto de estimación $\quad \pm 0$ 051 (Intervalo de confianza del 95\%)

Fecha del trabajo de campo Septiembre/Noviembre de 2010.

Fuente: Elaboración Propia

La edad media era de 33'57 años, de un rango que va desde los 18 a los 81 años.

Según los datos cuantitativos de nuestro estudio, el $52 \%$ de los encuestados fueron hombres y el $48 \%$ mujeres.

Basándonos en los datos estadísticos recopilados tanto por el Servicio Murciano de Salud como del Padrón Municipal de Habitantes, podemos decir que la muestra es representativa de la población objeto de estudio. Las figuras 29, 30 y 31 muestran las distribuciones de edad y sexo de dicha población.

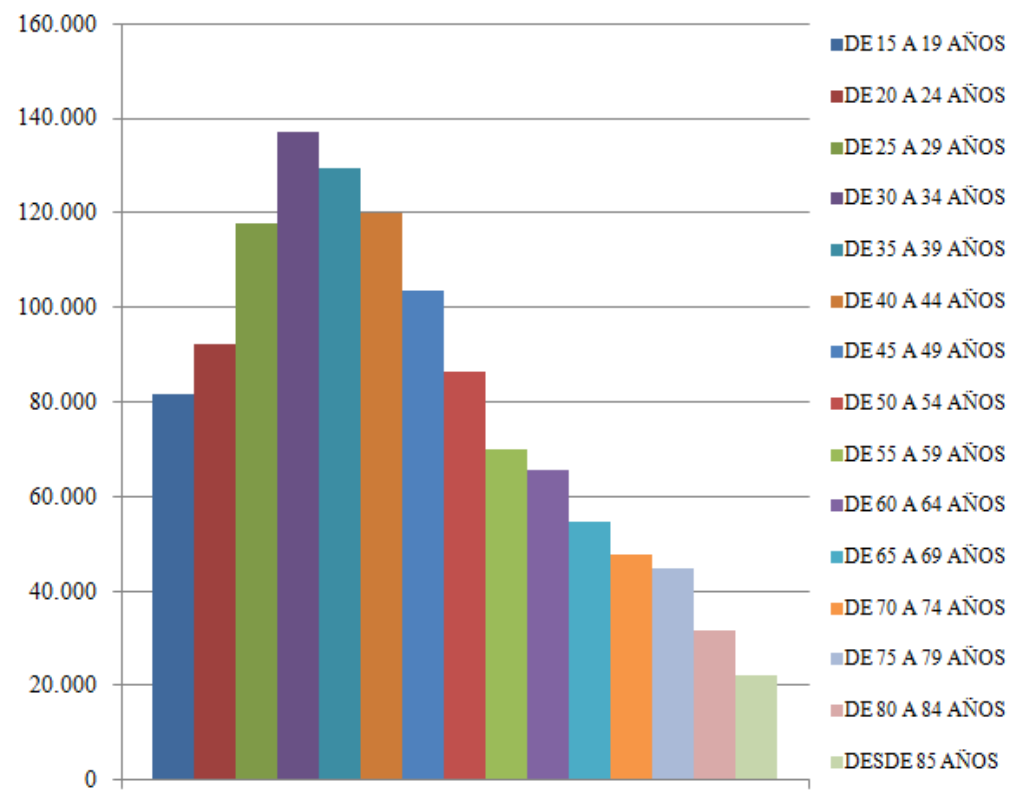

Figura 29. Población de la Región de Murcia. Usuarios del Servicio Murciano de Salud (SMS) distribuidos por edades (Elaboración propia). 


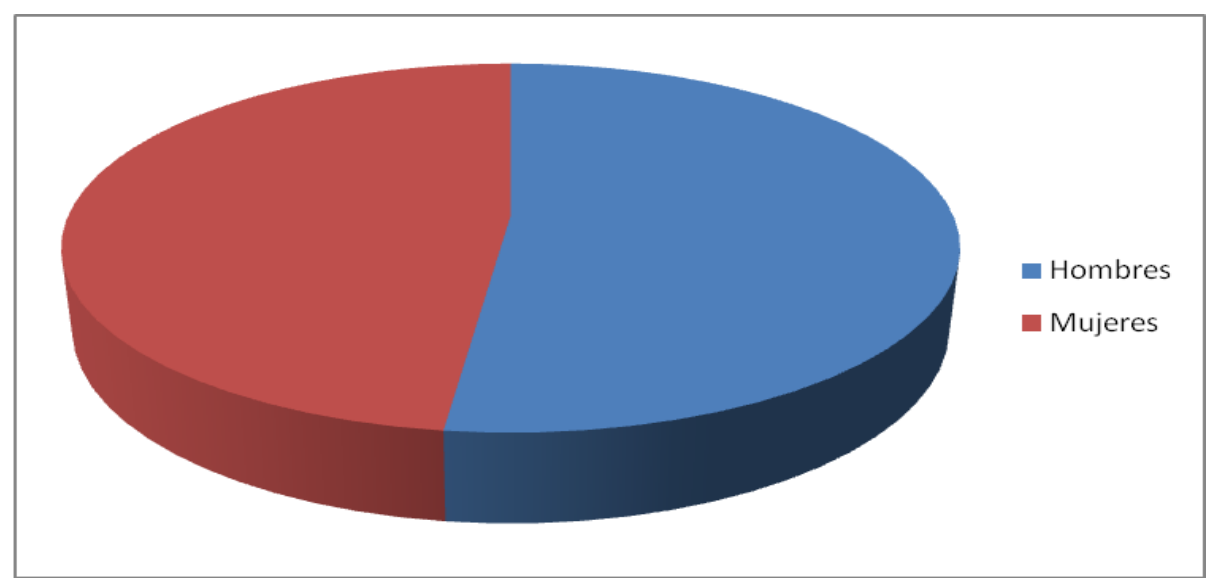

Figura 30. Distribución por sexos de los usuarios del SMS (Elaboración propia).

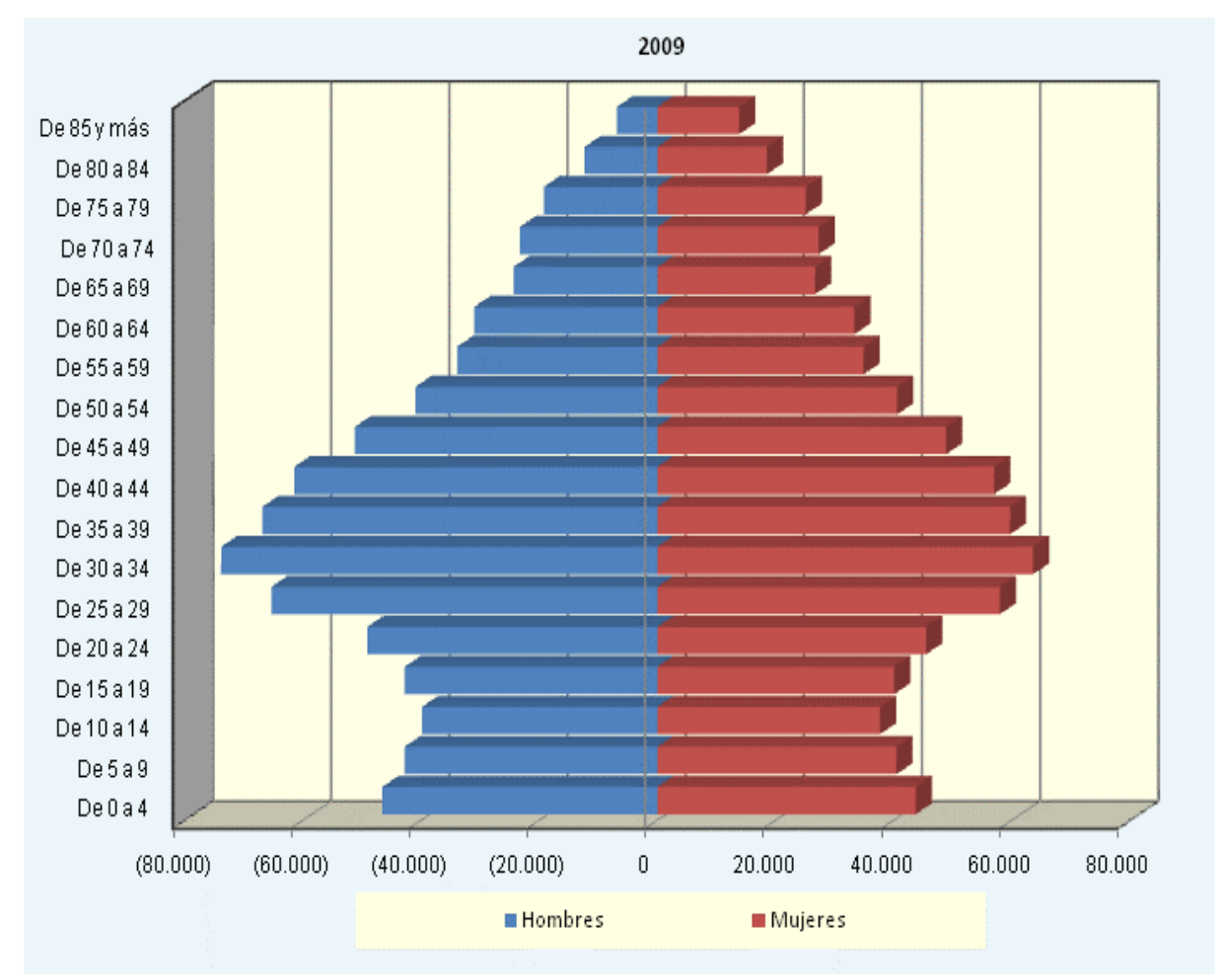

Figura 31. Pirámide de edad (CREM. Padrón Municipal de Habitantes) 


\section{MEDICIÓN DE VARIABLES}

Para la recogida de datos se utilizó un cuestionario formado por una combinación de escalas basadas en diversos estudios empíricos sobre la aceptación de la tecnología. Se seleccionaron los ítems más relevantes para este estudio con el fin de poder elaborar una lista inicial de 45 ítems que permitieran iniciar un estudio sobre las variables que pueden afectar al valor percibido, satisfacción y e-lealtad sobre el uso continuado de los servicios sanitarios online.

Elaborado el cuestionario, se congregó un panel de expertos formado por un grupo de académicos del Departamento de Economía de Empresa de la Universidad Politécnica de Cartagena, que evaluaron el cuestionario con el fin de depurar, mejorar la redacción o incluso, en algunos casos, reducir los ítems propuestos para hacer el cuestionario más operativo y fácil de responder. Asimismo, se testó el cuestionario en una pequeña muestra de usuarios de los servicios sanitarios online.

El cuestionario final se trataba de un modelo de encuesta sencillo, comprensible y rápido formado por 25 ítems referentes a las variables del modelo a contrastar así como por 4 variables de control: edad, sexo, nivel de ingresos y estudios. Los entrevistados manifestaban el fácil entendimiento y comprensión de la encuesta concluyéndose que era apropiada (el tiempo medio para realizarla oscilaba entre cinco y diez minutos). Por tanto, el equipo investigador, decidió dar por bueno el formato del mismo.

A continuación se describen los 25 ítems del cuestionario definitivo que recogen cada una de las variables del modelo. 
La variable Capacidad Innovativa está definida en función de 3 ítems que han sido adaptados de la escala diseñada por Robinson et al. (2005). De acuerdo con estos autores, los ítems que representan la Capacidad Innovativa están relacionados con la predisposición a experimentar y usar nuevos servicios online (tabla 10).

Tabla 10. Ítems que representan la Capacidad Innovativa

Capacidad Innovativa (1=totalmente desacuerdo y $7=$ totalmente de acuerdo)

CI1 Si oigo hablar de los nuevos servicios online, buscaría la manera de experimentar con ellos.

CI2 Ante otros, usualmente soy el primero en probar, los nuevos servicios online.

CI3 Me gusta experimentar con los nuevos servicios online.

Elaboración propia

Para establecer los ítems que representan la Autoeficacia de nuestro modelo, nos hemos centrado en 3 ítems empleados en el estudio realizado por Al-Somali et al. (2009). De acuerdo con las ideas principales de estos autores, la Autoeficacia nos permite identificar el grado en que una persona es capaz por sí misma de utilizar una tecnología nueva (tabla 11).

Tabla 11. Ítems que representan la Autoeficacia

Autoeficacia (1=totalmente desacuerdo y $7=$ totalmente de acuerdo)

A1 Yo podría utilizar los nuevos servicios online si tuviera únicamente un manual de usuario.

A2 Yo podría utilizar los nuevos servicios online si veo a alguien más utilizarlos antes de probar por mí mismo.

A3 Podría utilizar los nuevos servicios online si pudiera llamar a alguien para que me ayudara si tengo problemas.

Elaboración propia 
La variable de Accesibilidad a la información y a los servicios se define en función de 4 ítems empleados por Wang (2007) para el desarrollo de un sistema exitoso de implantación del comercio electrónico. Estos ítems permiten analizar el grado en que la información suministrada por las TIC en el sector sanitario es accesible para los usuarios potenciales (tabla 12).

Tabla 12. Ítems que representan la Accesibilidad

Accesibilidad ( $1=$ totalmente desacuerdo y $7=$ totalmente de acuerdo)

\begin{tabular}{ll}
\hline ACC1 & Los servicios online me proporcionan la información que necesito. \\
\hline ACC2 & La información obtenida cubre mis necesidades. \\
\hline ACC3 & Creo que los resultados obtenidos son fiables. \\
\hline ACC4 & $\begin{array}{l}\text { Los servicios prestados a través los servicios sanitarios online tienen la información suficiente } \\
\text { para responder a mis cuestiones. }\end{array}$ \\
\hline Elaboración propia
\end{tabular}

Autores como Sejin y Stoel (2009) y Martínez-Torres et al. (2008) definieron tres ítems mediante los que se lograría explicar la variable de seguridad. En sus estudios analizaron la conveniencia de aceptación de las TIC en servicios virtuales relacionados con el comercio y la formación autónoma de las personas. A través de los ítems propuestos por los anteriores autores, hemos desarrollado la variable de Seguridad para evaluar el grado en que los usuarios potenciales perciben los servicios online como un instrumento seguro y fiable (tabla 13). 
Tabla 13. Ítems que representan la Seguridad

\begin{tabular}{ll}
\hline \multicolumn{2}{c}{ Seguridad (1=totalmente desacuerdo y $7=$ totalmente de acuerdo) } \\
\hline S1 & Siento que puedo confiar en los servicios online. \\
\hline S2 & Los servicios online tienen características de seguridad adecuadas. \\
\hline S3 & Confío en la seguridad del sistema \\
\hline
\end{tabular}

Elaboración propia

La variable de Valor Percibido está determinada por los ítems propuestos por Klein (2007). Se trata de cuatro ítems que han permitido evaluar las percepciones que tienen los pacientes sobre el uso de las TIC en el sistema sanitario. Con ellos se ha medido el valor de los servicios online que perciben los usuarios finales (tabla 14).

Tabla 14. Ítems que representan el Valor Percibido

\begin{tabular}{ll}
\hline \multicolumn{3}{c}{ Valor Percibido (1=totalmente desacuerdo y 7 = totalmente de acuerdo) } \\
\hline VP1 & Los servicios online me permiten hacer cosas más fácilmente. \\
\hline VP2 & Los servicios online mejoran la efectividad a la hora de hacer las cosas. \\
\hline VP3 & El uso de los servicios online hace que sea más fácil hacer las cosas. \\
\hline VP4 & El uso de los servicios online me permite lograr mis objetivos más rápidamente. \\
\hline Elaboración propia
\end{tabular}

Elaboración propia

La variable satisfacción está determinada por los ítems propuestos por Wang (2007) y Roca et al. (2006). Se trata de cuatro ítems que han permitido evaluar el grado de satisfacción de los usuarios externos (pacientes) con el uso de las TIC en el sistema sanitario. Con ellos se han valorado las percepciones de calidad, cumplimiento de expectativas y satisfacción que reportan el uso de los servicios online a los usuarios del mismo (tabla 15). 
Tabla 15. Ítems que representan la Satisfacción

\begin{tabular}{ll}
\hline & Satisfacción (1=totalmente desacuerdo y $7=$ totalmente de acuerdo) \\
\hline SAT1 & Estoy satisfecho con el rendimiento de los servicios online. \\
\hline SAT2 & Los servicios online son de alta calidad. \\
\hline SAT3 & Los servicios online cumplen mis expectativas. \\
\hline SAT4 & Estoy contento con la experiencia sobre el uso de los servicios online. \\
\hline
\end{tabular}

Elaboración propia

La variable de e-lealtad está determinada por cuatro ítems propuestos por Wang (2007) y Roca et al. (2006). Se trata de unos ítems que han permitido evaluar la intención que tienen los usuarios externos del sector sanitario de volver a usar los servicios online. En concreto nos centramos en los siguientes ítems que cuestionan la regularidad de uso futuro, la intención de volver a utilizar los servicios, la frecuencia y la recomendación de uso de los mismos a otros usuarios (tabla 16).

Tabla 16. Ítems que representan la E-lealtad

\section{E-lealtad (1=totalmente desacuerdo y $7=$ totalmente de acuerdo)}

EL1 Usaré los servicios online regularmente en el futuro.

EL2 Asumiendo que tenga acceso al uso de los servicios online, intentaré utilizarlos.

EL3 Utilizaré los servicios online con frecuencia en el futuro.

EL4 Recomendaré encarecidamente a otros su uso.

Elaboración propia 


\section{ANÁLISIS}

Para realizar los análisis relativos al contraste de las hipótesis obtenidas en el capítulo 3, hemos decidido centrar nuestro análisis en el modelo de Regresión Lineal. Según diversos estudios, este modelo se ha destacado como la principal técnica estadística para estudiar la relación entre las variables independientes y dependientes objeto de estudio y poder realizar el análisis de los datos en el campo que nos afecta.

Se trata de una técnica que se utiliza para predecir un amplio rango de fenómenos, desde medidas económicas hasta diferentes aspectos del comportamiento humano.

Tanto en el caso de dos variables como en el de más de dos variables, el análisis de regresión lineal puede utilizarse para explorar y cuantificar la relación entre una variable llamada dependiente o criterio (Y) y una o más variables llamadas independientes o predictoras $(\mathrm{X} 1, \mathrm{X} 2, \mathrm{X} 3, \ldots)$, así como para desarrollar una ecuación lineal con fines predictivos.

Además, el análisis de regresión lleva asociados una serie de procedimientos de diagnóstico (análisis de los residuos, puntos de influencia,...) que informan sobre la estabilidad e idoneidad del análisis y que proporcionan pistas sobre cómo perfeccionarlo. Esto permite, en primer lugar, evaluar la adecuación del modelo teórico bajo estudio con respecto a los datos empíricos y, en segundo lugar, examinar el significado de los pasos (hipótesis) específicos en el modelo. 
El uso de esta técnica en la presente investigación permite probar la dependencia o independencia de las variables comprobando la adecuación de los supuestos del análisis de regresión y la forma de proceder cuando se incumplan.

Uno de los aspectos más importantes a tener en cuenta al plantear un modelo de regresión lineal es que se trata de una técnica estadística que permite estudiar la relación entre una variable dependiente y una o más independientes con un doble propósito:

1. Averiguar en qué medida la variable dependiente puede estar explicada por la(s) variable(s) independiente(s).

2. Obtener predicciones en la variable dependiente a partir de la(s) variable(s) independiente(s).

Este procedimiento implica, básicamente, obtener la ecuación mínimo-cuadrática que mejor expresa la relación entre la variable dependiente y la(s) variable(s) independiente(s) y estimar mediante el coeficiente de determinación, la calidad de la ecuación de regresión obtenida. Estos dos pasos deben ir acompañados de un chequeo del cumplimiento de las condiciones o supuestos que garantizan la validez y fiabilidad del procedimiento, para poder obedecer a una justificación basada en la teoría, en la experiencia o en la práctica obtenida por la observación del mundo real (Luque, 2000).

Tal y como se desprende de los capítulos anteriores, las hipótesis de este estudio fueron derivadas de la teoría existente, considerándose como el principal estadístico el uso del modelo de regresión lineal para evaluar el grado en el que los datos empíricos apoyan las relaciones descritas en las citadas hipótesis. 
Esta técnica requiere del cumplimiento de ciertos aspectos para poder revisar posibles inconsistencias en los datos que puedan violar alguno de los supuestos básicos del análisis de regresión lineal. Su incumplimiento afectará negativamente a los resultados. Algunos de los factores que deben considerarse en los análisis de regresión lineal para garantizar la validez del modelo, se citan a continuación:

1. Normalidad. La existencia de normalidad es imprescindible para garantizar que los valores críticos que determinan el significado de cada coeficiente del modelo y la del modelo en su conjunto sean correctos (Cea, 2001). Los estadísticos en conjunto apoyan la existencia de normalidad. Para cada valor de la variable independiente (o combinación de valores de las variables independientes), los residuos se distribuyen normalmente con un media cero. En el capítulo siguiente se analizan los estadísticos univariantes del conjunto de datos: media, desviación típica y moda.

2. Homocedasticidad. Para cada valor de la variable independiente (o combinación de valores de las variables independientes), la varianza de los residuos es constante.

3. Independencia. Los residuos son independientes entre sí, es decir, los residuos constituyen una variable aleatoria y es posible encontrarse con residuos autocorrelacionados cuando se trabaja con series temporales.

4. Ausencia de colinealidad entre las variables. La estimación de un análisis de regresión lineal, implica la no existencia de una relación lineal exacta entre ninguna de las variables independientes. La colinealidad ha de ser la mínima posible por su efecto negativo en los errores típicos de los coeficientes de las variables (Cea, 
2001). El incumplimiento de este supuesto da origen a colinealidad o multicolinealidad.

5. Tamaño muestral. El tamaño de la muestra tiene un efecto directo sobre el poder explicativo del modelo de ecuaciones estructurales. El procedimiento de estimación de parámetros de máxima verosimilitud precisa de un tamaño muestral mínimo de 100 observaciones para conseguir una buena estimación (Luque, 2000).

6. Linealidad. La ecuación de regresión adopta una forma particular. La variable dependiente es la suma de un conjunto de elementos: el origen de la recta, una combinación lineal de variables independientes y los residuos. El incumplimiento del supuesto de linealidad suele denominarse error de especificación. Algunos ejemplos son: omisión de variables independientes importantes, inclusión de variables independientes irrelevantes, no linealidad, parámetros cambiantes, no aditividad, etc.

Para el desarrollo del análisis de regresión lineal, ha sido necesario transferir y analizar los datos a través del sistema Statistical Package for the Social Sciencies, versión 15.0 (SPSS Institute, Inc., Chicago, IL), ya que este programa permite incluir aspectos tales como la frecuencia, el porcentaje, la desviación típica y el análisis de los coeficientes del modelo en cuestión que nos han permitido obtener los datos que son necesarios para el posterior análisis de los resultados que tiene lugar en el siguiente capítulo.

La figura 32, que se muestra a continuación, resume la metodología seguida en esta investigación: 


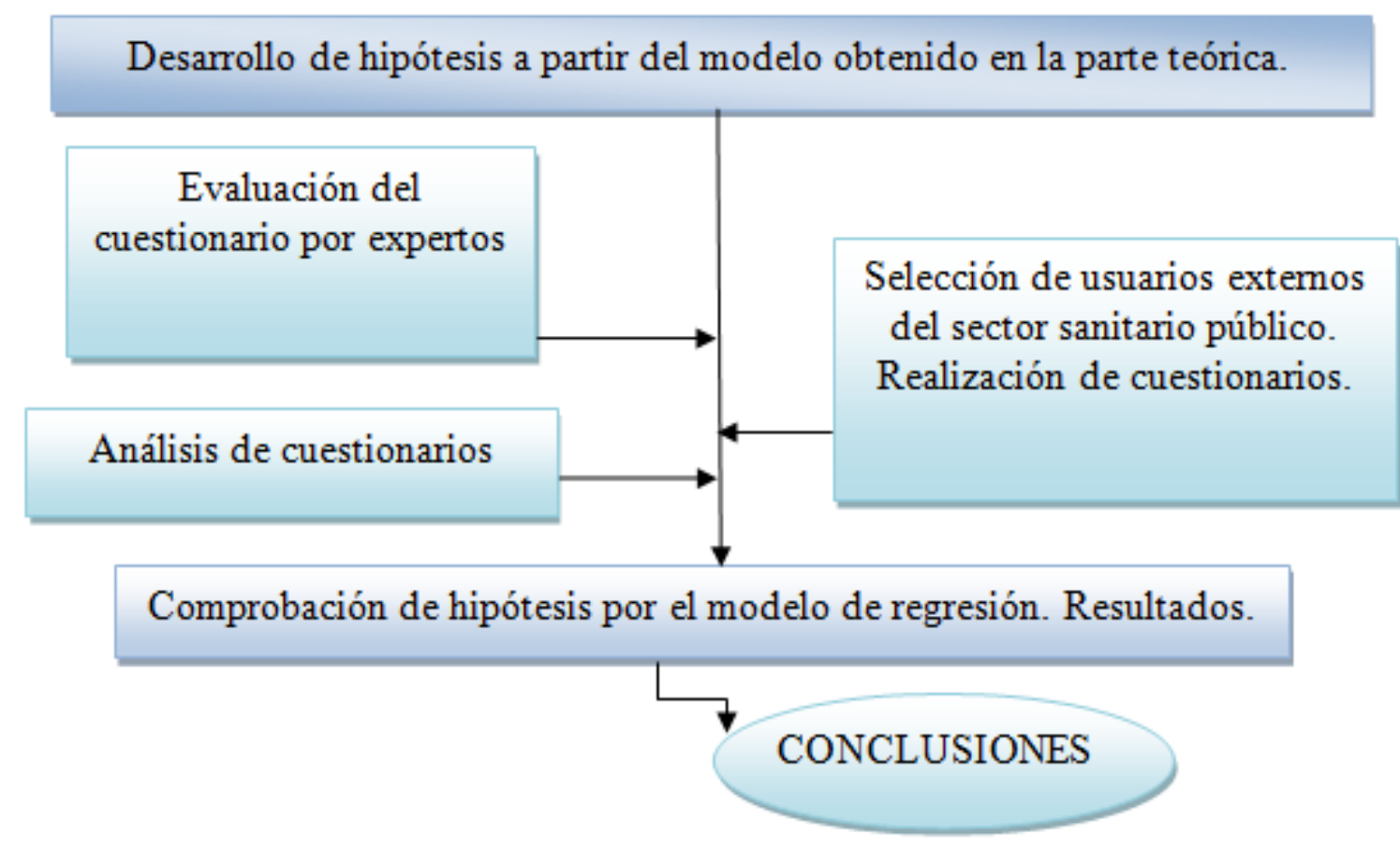

Figura 32. Metodología de la investigación (Elaboración Propia)

\section{CONCLUSIÓN Y REFLEXIÓN FINAL}

El presente capítulo explica las diferentes fases de la metodología seguidas para el contraste de las hipótesis planteadas en el capítulo anterior, de la siguiente manera:

- Revisión de la literatura empírica relacionada con los conceptos de conocimiento y tecnologías de la información y la comunicación.

- Justificación del sector escogido (sector sanitario). Centrarnos en un único sector nos da la posibilidad de conocer con mayor profundidad el sector, de apreciar las implicaciones que sobre el mismo han tenido el uso de las TIC y 
de adaptar el cuestionario al sector investigado, lo que aporta mayor validez a las conclusiones del análisis empírico.

- Descripción de la población. Tras centrar nuestra investigación en los servicios online ofertados por el Servicio Murciano de Salud a los pacientes, sus familiares y/o sus cuidadores, se hace necesario constituir a los mismos como población idónea para el análisis de un modelo de aceptación de las TIC que permita a los usuarios, tras su primer uso de los servicios online, continuar usándolos con frecuencia.

- Características de la muestra. Una vez recogidos los datos de 256 cuestionarios y tras analizar la muestra según las variables de control (edad, sexo, estudios y nivel de ingresos), se procedió a la elaboración de una ficha técnica de investigación empírica donde vienen recogidas las principales características de la muestra.

- Variables objeto de estudio. En este apartado del capítulo, se procedió a definir las variables objeto de estudio y los ítems que forman parte de cada una de ellas para posteriormente, en el capítulo siguiente, proceder al contraste de las hipótesis planteadas por el modelo propuesto.

- Procedimiento seguido para la colección de datos (Detalle de los instrumentos de medición utilizados y elección de la técnica estadística empleada).

Tras la mencionada revisión y análisis, se desprende que el modelo de regresión lineal es la principal técnica a emplear para el análisis de los datos en el campo que nos 
afecta y para determinar la relación entre la variable dependiente con otras variables explicativas (independientes) a través del desarrollo ecuaciones. La justificación de la misma se basa en que constantemente en la práctica de la investigación estadística, se encuentran variables que de alguna manera están relacionadas entre sí, por lo que es posible que una de las variables pueda relacionarse matemáticamente en función de otra u otras variables. Estas posibles relaciones son las que se analizarán en el capítulo posterior.

Consecuentemente, en el capítulo siguiente, el modelo obtenido en el capítulo 3 es probado empíricamente a través de la investigación cuantitativa, utilizando el modelo de regresión lineal, que permite evaluar las relaciones entre variables. Así se analizarán los resultados de los indicadores de fiabilidad y validez del modelo propuesto y a continuación se realizará el contraste de las hipótesis planteadas para, en un capítulo posterior, proceder a la redacción de las conclusiones finales. 

CAPITULO 5. ANÁLISIS DE LOS RESULTADOS 



\section{OBJETIVO E INTRODUCCIÓN}

El objetivo de este capítulo es el de exponer los análisis realizados para contrastar las hipótesis planteadas en el modelo teórico desarrollado en el capítulo 3, así como sus resultados.

En primer lugar, se realizan pruebas previas para asegurar la fiabilidad y validez de las herramientas de medida. Para ello se ha empleado el alfa de Cronbach y el análisis factorial, respectivamente.

Posteriormente, tras comprobar la inexistencia de multicolinealidad entre las variables analizadas, se procede a contrastar las hipótesis mediante un análisis de regresión. Finalmente, se analizan los resultados obtenidos.

\section{FIABILIDAD Y VALIDEZ DE LAS ESCALAS.}

Antes de realizar los análisis estadísticos pertinentes para contrastar las hipótesis es necesario asegurar que se están utilizando herramientas adecuadas para medir los conceptos que pretendemos analizar. Para ello, se ha de comprobar que las escalas utilizadas son fiables y válidas. Por tanto, a continuación, se comprobarán la fiabilidad y la validez de las escalas que se han empleado para medir las distintas variables de este estudio. 


\subsection{FIABILIDAD}

La fiabilidad de una escala consiste fundamentalmente en asegurar que dicha escala va a medir siempre igual lo que permanezca igual. Para medir la fiabilidad utilizamos el alfa de Cronbach. El acuerdo general sobre el límite inferior para el alfa de Cronbach es de 0,70 aunque se acepta un mínimo de 0’6 para el caso de creación de nuevas escalas (Nunnally, 1978).

Para evitar correlaciones entre ítems espuriamente altas, seguiremos el criterio de la correlación ítem-total para determinar si un ítem debe ser eliminado. Así, se eliminará un ítem cuando dicho valor sea inferior a 0’30 que es el mínimo generalmente aceptado para este parámetro (Nunnally y Bernstein, 1994).

Siguiendo estos criterios se llegan a los resultados mostrados en la tabla 17 para cada una de las variables de este estudio. 
Tabla 17. Análisis de fiabilidad a través del alfa de Cronbach y correlación ítem-total.

\begin{tabular}{|c|c|c|c|c|}
\hline Descripción de Ítem & & $\begin{array}{l}\mathrm{N}^{\mathrm{o}} \text { de Items } \\
\text { iniciales }\end{array}$ & $\begin{array}{c}\text { Alfa de } \\
\text { Cronbach }\end{array}$ & $\begin{array}{l}\text { Correlación } \\
\text { ítem-total }\end{array}$ \\
\hline \multicolumn{5}{|l|}{ Capacidad Innovativa } \\
\hline & CI 1 & 3 & 0,770 & 0,604 \\
\hline & CI 2 & & & 0,610 \\
\hline & CI 3 & & & 0,597 \\
\hline \multicolumn{5}{|l|}{ Autoeficacia } \\
\hline & A 1 & 3 & 0,755 & 0,523 \\
\hline & A 2 & & & 0,648 \\
\hline & A 3 & & & 0,588 \\
\hline \multicolumn{5}{|l|}{ Accesibilidad } \\
\hline & ACC 1 & & 0790 & 0,606 \\
\hline & ACC 2 & 4 & 0,190 & 0,683 \\
\hline & ACC 3 & & & 0,623 \\
\hline & $\mathrm{ACC} 4$ & & & 0,494 \\
\hline \multicolumn{5}{|l|}{ Seguridad } \\
\hline & $\mathrm{S} 1$ & 3 & 0,867 & 0,788 \\
\hline & $\mathrm{S} 2$ & & & 0,766 \\
\hline & S 3 & & & 0,686 \\
\hline \multicolumn{5}{|l|}{ Valor Percibido } \\
\hline & VP 1 & 4 & 0882 & 0,720 \\
\hline & VP 2 & 4 & 0,882 & 0,790 \\
\hline & VP 3 & & & 0,738 \\
\hline & VP 4 & & & 0,729 \\
\hline \multicolumn{5}{|l|}{ Satisfacción } \\
\hline & SAT 1 & 4 & 0838 & 0,646 \\
\hline & SAT 2 & 4 & 0,858 & 0,608 \\
\hline & SAT 3 & & & 0,742 \\
\hline & SAT 4 & & & 0,686 \\
\hline \multicolumn{5}{|l|}{ E-lealtad } \\
\hline & EL 1 & 4 & 0.800 & 0,732 \\
\hline & EL 2 & 4 & 0,800 & 0,705 \\
\hline & EL 3 & & & 0,780 \\
\hline & EL 4 & & & 0,658 \\
\hline
\end{tabular}

Los resultados indican que en todas las variables los valores de alfa de Cronbach así como de correlación ítem-total son adecuados y, por tanto, no es necesario eliminar ningún ítem. 


\subsection{VALIDEZ}

La validez de una escala consiste fundamentalmente en asegurar que los conceptos medidos son lo que realmente se pretendían medir. Se puede medir desde varios puntos de vista (Judd y Kenny, 1981; Nunnally y Bernstein, 1994):

1. Validez de contenido. No es evaluable numéricamente, pues representa si el instrumento utilizado es una medida comprensiva de la satisfacción del estudiante. Su determinación es subjetiva y depende de si el instrumento ha sido realizado basándose en una amplia revisión de la literatura existente y de si ha sido previamente evaluado por personas del mundo académico. Consideramos que nuestras escalas cumplen aceptablemente con estos requisitos.

2. Validez de constructo. Representa el grado en el que el constructo teórico ha sido satisfactoriamente operacionalizado (Judd y Kenny, 1981). Los criterios habitualmente utilizados para evaluar la validez de un constructo son la validez discriminante y la validez convergente.

La validez discriminante se refiere al hecho de que una escala sólo cuantifica las características del concepto que trata de medir y no cualquier característica de cualquier otro concepto (Sánchez y Sarabia, 1999). Para medirla tradicionalmente se utiliza el análisis factorial por el método de los componentes principales para cada una de las dimensiones definidas en la escala. Mediante este procedimiento se analiza si cada dimensión está compuesta por un solo factor con un autovalor mayor que 1. En este caso se confirmaría que cada dimensión está midiendo un único concepto. 
Para mejorar la validez discriminante de un instrumento a través de un análisis factorial se deben eliminar los ítems con una carga factorial no significativa. En efecto, el contraste de unidimensionalidad debe mostrar que los ítems de cada dimensión cargan de forma elevada en un único factor.

Antes de proceder al análisis factorial se ha evaluado la conveniencia del modelo empleando el estadístico de Kaiser-Meyer-Olkin o KMO y el contraste de esfericidad de Barlett. Se trata de dos estadísticos que permiten valorar la bondad de ajuste o adecuación de los datos analizados a un modelo factorial.

Concretamente, la medida de adecuación muestral de Kaiser-Meyer-Olkin es un índice que compara la magnitud de los coeficientes de correlación observados con los coeficientes de correlaciones parciales para el conjunto de las variables. Su expresión matemática es la siguiente:

$$
\mathrm{KMO}=\frac{\Sigma \mathrm{r}_{\mathrm{ij}}^{2}}{\Sigma \mathrm{r}^{2}{ }_{\mathrm{ij}}+\Sigma \mathrm{r}^{2}{ }_{\mathrm{ij} \mathrm{m}}}
$$

Este estadístico KMO varía entre 0 y 1 . Los valores pequeños indican que el análisis factorial puede no ser una buena idea, dado que las correlaciones entre los pares de variables no pueden ser explicadas por otras variables. Un valor de 0'5 es el límite por debajo del cual se considera inaceptable el análisis puesto que las correlaciones se darían entre pares de variables, de tal forma que en tales correlaciones no intervendrían otras variables y no habría estructura de correlación (Luque, 2000). 
Por otro lado, la prueba de esfericidad de Barlett es una prueba para detectar la presencia de correlaciones entre las variables. Este test contrasta la hipótesis nula de que las variables observadas son mutuamente no correlacionadas y el modelo factorial no sería pertinente. Es más, este estadístico se distribuye según el modelo de probabilidad chi - cuadrado y es una transformación del determinante de la matriz de correlaciones. Si el nivel crítico (Sig.) es mayor que 0’05, no podremos rechazar la hipótesis nula de esfericidad y, consecuentemente, no podremos asegurar que el modelo factorial sea adecuado para explicar los datos. Por tanto, se puede rechazar esta hipótesis a partir de un nivel de significación inferior a 0’05 (Luque, 2000).

\subsubsection{Análisis de KMO y prueba de esfericidad de Barlett}

Una vez explicados los conceptos de ambos estadísticos, es necesario pasar a evaluar los resultados que proceden de estos dos análisis para cada una de las variables incorporadas en el modelo propuesto.

Tabla 18. KMO y prueba de Bartlett para la Capacidad Innovativa

\begin{tabular}{|c|c|c|}
\hline \multicolumn{2}{|c|}{$\begin{array}{c}\text { Medida de adecuación muestral de Kaiser-Meyer- } \\
\text { Olkin. }\end{array}$} & 0,700 \\
\hline \multirow{2}{*}{$\begin{array}{c}\text { Prueba de esfericidad de } \\
\text { Bartlett }\end{array}$} & $\begin{array}{c}\text { Chi-cuadrado } \\
\text { aproximado }\end{array}$ & 197,479 \\
\cline { 2 - 3 } & gl & 3 \\
\cline { 2 - 3 } & Sig. & 0,000 \\
\hline
\end{tabular}


Los resultados de la tabla 18 presentan la información siguiente: Por un lado tenemos el índice KMO que muestra un valor de 0'700 superior al 0’5 exigido. Por otro lado, se obtuvieron datos similares a través del test de Barlett donde la Chi-cuadrado presenta un valor de 197'479 y una $\mathrm{p}=0$ '000. De este modo, la tabla 18 muestra que los resultados son satisfactorios para la escala que mide la Capacidad Innovativa, tanto para el KMO como para la prueba de esfericidad de Barlett.

Tabla 19. KMO y prueba de Bartlett para la Autoeficacia

\begin{tabular}{|c|c|r|}
\hline \multicolumn{2}{|c|}{$\begin{array}{c}\text { Medida de adecuación muestral de Kaiser-Meyer- } \\
\text { Olkin. }\end{array}$} & 0,672 \\
\hline \multirow{2}{*}{$\begin{array}{c}\text { Prueba de esfericidad de } \\
\text { Bartlett }\end{array}$} & $\begin{array}{c}\text { Chi-cuadrado } \\
\text { aproximado }\end{array}$ & 194,181 \\
\cline { 2 - 3 } & $\mathrm{gl}$ & 3 \\
\cline { 2 - 3 } & Sig. & 0,000 \\
\hline
\end{tabular}

Los resultados de la tabla 19 presentan la información siguiente: Por un lado tenemos el índice KMO que muestra un valor de 0’672 superior al 0’5 exigido. Por otro lado, se obtuvieron datos similares a través del test de Barlett donde la Chi-cuadrado presenta un valor de 194'181 y una $\mathrm{p}=0$ '000. De este modo, la tabla 19 muestra que los resultados son satisfactorios para la escala que mide la Autoeficacia, tanto para el KMO como para la prueba de esfericidad de Barlett.

Tabla 20. KMO y prueba de Bartlett para la Accesibilidad

\begin{tabular}{|c|c|r|}
\hline \multicolumn{2}{|c|}{$\begin{array}{c}\text { Medida de adecuación muestral de Kaiser-Meyer- } \\
\text { Olkin. }\end{array}$} & 0,763 \\
\hline \multirow{2}{*}{$\begin{array}{c}\text { Prueba de esfericidad de } \\
\text { Bartlett }\end{array}$} & $\begin{array}{c}\text { Chi-cuadrado } \\
\text { aproximado }\end{array}$ & 306,102 \\
\cline { 2 - 3 } & gl & 6 \\
\cline { 2 - 3 } & Sig. & 0,000 \\
\hline
\end{tabular}


Los resultados de la tabla 20 presentan la información siguiente: Por un lado tenemos el índice KMO que muestra un valor de 0’763 superior al 0’5 exigido. Por otro lado, se obtuvieron datos similares a través del test de Barlett donde la Chi-cuadrado presenta un valor de 306'102 y una $\mathrm{p}=0$ '000. De este modo, la tabla 20 muestra que los resultados son satisfactorios para la escala que mide la Accesibilidad, tanto para el KMO como para la prueba de esfericidad de Barlett.

Tabla 21. KMO y prueba de Bartlett para la Seguridad.

\begin{tabular}{|c|c|r|}
\hline \multicolumn{2}{|c|}{$\begin{array}{c}\text { Medida de adecuación muestral de Kaiser-Meyer- } \\
\text { Olkin. }\end{array}$} & 0,720 \\
\hline \multirow{2}{*}{$\begin{array}{c}\text { Prueba de esfericidad de } \\
\text { Bartlett }\end{array}$} & $\begin{array}{c}\text { Chi-cuadrado } \\
\text { aproximado }\end{array}$ & 384,313 \\
\cline { 2 - 3 } & gl & 3 \\
\cline { 2 - 3 } & Sig. & 0,000 \\
\hline
\end{tabular}

Los resultados de la tabla 21 presentan la información siguiente: Por un lado tenemos el índice KMO que muestra un valor de 0’720 superior al 0’5 exigido. Por otro lado, se obtuvieron datos similares a través del test de Barlett donde la Chi-cuadrado presenta un valor de 384'313 y una $\mathrm{p}=0$ '000. De este modo, la tabla 21 muestra que los resultados son satisfactorios para la escala que mide el nivel seguridad, tanto para el KMO como para la prueba de esfericidad de Barlett. 
Tabla 22. KMO y prueba de Bartlett para el Valor Percibido

\begin{tabular}{|c|c|r|}
\hline \multicolumn{2}{|c|}{$\begin{array}{c}\text { Medida de adecuación muestral de Kaiser-Meyer- } \\
\text { Olkin. }\end{array}$} & 0,835 \\
\hline \multirow{3}{*}{ Prueba de esfericidad de Bartlett } & $\begin{array}{c}\text { Chi-cuadrado } \\
\text { aproximado }\end{array}$ & 537,177 \\
\cline { 2 - 3 } & gl & 6 \\
\cline { 2 - 3 } & Sig. & 0,000 \\
\hline
\end{tabular}

Los resultados de la tabla 22 presentan la información siguiente: Por un lado tenemos el índice KMO que muestra un valor de 0’835 superior al 0’5 exigido. Por otro lado, se obtuvieron datos similares a través del test de Barlett donde la Chi-cuadrado presenta un valor de 537'177 y una $\mathrm{p}=0$ '000. De este modo, la tabla 22 muestra que los resultados son satisfactorios para la escala que mide el Valor Percibido.

Tabla 23. KMO y prueba de Bartlett para la Satisfacción

\begin{tabular}{|c|c|r|}
\hline \multicolumn{2}{|c|}{$\begin{array}{c}\text { Medida de adecuación muestral de Kaiser-Meyer- } \\
\text { Olkin. }\end{array}$} & 0,788 \\
\hline \multirow{3}{*}{ Prueba de esfericidad de Bartlett } & $\begin{array}{c}\text { Chi-cuadrado } \\
\text { aproximado }\end{array}$ & 403,067 \\
\cline { 2 - 3 } & gl & 6 \\
\cline { 2 - 3 } & Sig. & 0,000 \\
\hline
\end{tabular}

Los resultados de la tabla 23 presentan la información siguiente: Por un lado tenemos el índice KMO que muestra un valor de 0’788 superior al 0’5 exigido. Por otro lado, se obtuvieron datos similares a través del test de Barlett donde la Chi-cuadrado presenta un valor de 403'067 y una $\mathrm{p}=$ 0’000. De este modo, la tabla 23 muestra que los resultados son satisfactorios para la escala que mide la Satisfacción. 
Tabla 24. KMO y prueba de Bartlett para la E-lealtad

\begin{tabular}{|c|c|r|}
\hline \multicolumn{2}{|c|}{$\begin{array}{c}\text { Medida de adecuación muestral de Kaiser-Meyer- } \\
\text { Olkin. }\end{array}$} & 0,800 \\
\hline \multirow{3}{*}{ Prueba de esfericidad de Bartlett } & $\begin{array}{c}\text { Chi-cuadrado } \\
\text { aproximado }\end{array}$ & 503,260 \\
\cline { 2 - 3 } & gl & 6,000 \\
\cline { 2 - 3 } & Sig. & 0, \\
\hline
\end{tabular}

Finalmente, los resultados de la tabla 24 presentan la información siguiente: Por un lado tenemos el índice KMO que muestra un valor de 0'800 superior al 0'5 exigido. Por otro lado, se obtuvieron datos similares a través del test de Barlett donde la Chicuadrado presenta un valor de 503'260 y una $\mathrm{p}=0$ ’000. De este modo, la tabla 24 muestra que los resultados son satisfactorios para la escala que mide la E-lealtad.

\subsubsection{Análisis factorial}

A continuación se procede a realizar los análisis factoriales para cada una de las escalas del modelo objeto de estudio.

Tabla 25. Análisis factorial para la variable Capacidad Innovativa

\begin{tabular}{lc}
\hline & Factores \\
\hline & 1 \\
\hline $\begin{array}{l}\text { P 1 - Si oigo hablar de los nuevos servicios online, buscaría la manera } \\
\text { de experimentar con ellos. }\end{array}$ & 0,828 \\
P 2 - Ante otros, usualmente soy el primero en probar, los nuevos & 0,832 \\
servicios online. & 0,823 \\
P 3 - Me gusta experimentar con los nuevos servicios online.
\end{tabular}

Método de extracción: Análisis de componentes principales. 
Tabla 26. Análisis factorial para la variable Autoeficacia

\begin{tabular}{lc}
\hline & Factores \\
\hline $\begin{array}{c}\text { P } 4 \text { - Yo podría utilizar los nuevos servicios online si tuviera } \\
\text { únicamente un manual de usuario. }\end{array}$ & 1 \\
P 5 - Yo podría utilizar los nuevos servicios online si veo a alguien & 0,772 \\
más utilizarlos antes de probar por mí mismo. & 0,862 \\
P 6 - Podría utilizar los servicios online si pudiera llamar a alguien & 0,828 \\
para que me ayudara si tengo problemas. & \\
\hline
\end{tabular}

Método de extracción: Análisis de componentes principales.

Tabla 27. Análisis factorial para la variable Accesibilidad

\begin{tabular}{cc}
\hline & Factores \\
\hline & 1 \\
\hline Pecesito. & 0,798 \\
P 8 - La información obtenida cubre mis necesidades. & 0,843 \\
P 9 - Creo que los resultados obtenidos son fiables. & 0,803 \\
P 10 - Los servicios prestados a través de los servicios online tienen la & 0,692 \\
\hline información suficiente para responder a mis cuestiones. & \\
\hline
\end{tabular}

Método de extracción: Análisis de componentes principales.

Tabla 28. Análisis factorial para la variable Seguridad.

\begin{tabular}{lc}
\hline & Factores \\
\hline P 11 - Siento que puedo confiar en los servicios online. & 1 \\
\hline P12- Los servicios online tienen características de seguridad adecuadas. & 0,901 \\
P 13 - Confío en la seguridad del sistema. & 0,912 \\
\hline
\end{tabular}

Método de extracción: Análisis de componentes principales. 
Tabla 29. Análisis factorial para la variable Valor Percibido.

\begin{tabular}{lc}
\hline & Factores \\
\hline & 1 \\
\hline P 14 - Los servicios online me permiten hacer cosas más fácilmente. & 0,844 \\
P 15 - Los servicios online mejoran la efectividad a la hora de hacer las & 0,889 \\
cosas. & 0,856 \\
cosas. $\quad$ P 16 - El uso de los servicios online hace que sea más fácil hacer las \\
P 17 - El uso de Los servicios online me permite lograr mis objetivos
\end{tabular}

Método de extracción: Análisis de componentes principales.

Tabla 30. Análisis factorial para la variable Satisfacción

\begin{tabular}{cc}
\hline & Factores \\
\hline P 18 - Estoy satisfecho con el rendimiento de Los servicios online. & 1 \\
P 19- Los servicios online son de alta calidad. & 0,804 \\
P 20 - Los servicios online cumplen mis expectativas. & 0,774 \\
P 21 - Estoy contento con la experiencia sobre el uso de los servicios & 0,870 \\
\hline
\end{tabular}

Método de extracción: Análisis de componentes principales.

Tabla 31. Análisis factorial para la variable E-lealtad

\begin{tabular}{cc}
\hline & Factores \\
\hline P 22 - Usaré los servicios online regularmente en el futuro. & 1 \\
\hline $\begin{array}{c}\text { P 23 - Asumiendo que tenga acceso al uso de los servicios online, } \\
\text { intentaré utilizarlos. }\end{array}$ & 0,855 \\
P 24 - Utilizaré los servicios online con frecuencia en el futuro. & 0,839 \\
P 25 - Recomendaré encarecidamente a otros su uso. & 0,803 \\
\hline
\end{tabular}

Método de extracción: Análisis de componentes principales. 
Los análisis factoriales realizados para cada una de las escalas definidas muestran que dentro de cada dimensión subyace un único factor. Esto es indicativo de que cada escala mide un único concepto. Por otra parte, todos los ítems tienen una carga factorial superior a 0’6, por lo que no hay que eliminar ninguno de ellos.

Basándonos en estos resultados, podemos concluir que la fiabilidad y la validez de nuestras medidas son adecuadas para continuar con el análisis del modelo.

\section{CONTRASTE DE HIPÓTESIS}

Un paso previo a contrastar las hipótesis consiste en comprobar la inexistencia de multicolinealidad entre las variables. Esta decisión se encuentra justificada porque en ciertas ocasiones son comunes los problemas de multicolinealidad en las regresiones jerárquicas, especialmente debidos a la existencia de relaciones aproximadamente lineales entre los regresores del modelo, causando que los estimadores obtenidos y la precisión de éstos se vean seriamente afectados.

Para llevar a cabo el diagnóstico de multicolinealidad se van a emplear los procedimientos que gozan de mayor soporte en la literatura econométrica actual: el factor de inflación de varianza (FIV), el índice de condición y la proporción de descomposición de la varianza.

Los valores de tolerancia de cada uno de los regresores es definida como $\mathrm{T}=(1-$

$\mathrm{R}_{\mathrm{i}}{ }^{2}$ ), donde $\mathrm{R}_{\mathrm{i}}$ es el coeficiente de correlación múltiple al cuadrado de dicho regresor 
con los restantes. Para que haya multicolinealidad dicha correlación ha de ser alta, o lo que es lo mismo, la tolerancia baja. Además otro índice relacionado con éste y que nos da una idea del grado de aumento de la varianza es el Factor de Inflación de la Varianza, y es precisamente el recíproco de la tolerancia. Su valor es:

$$
\mathrm{FIV}=\frac{1}{\left(1-\mathrm{R}^{2}{ }_{\mathrm{i}}\right)}
$$

Se conoce con este nombre por el hecho de intervenir en el cálculo de la varianza de los coeficientes, de modo que cuanto mayor sea este factor mayor será la varianza. Una de las características de este estadístico es el hecho de que cuanto más pequeña sea la tolerancia de las mismas y mayor, por tanto, el FIV, más probable que sean una combinación lineal de otra u otras variables del mismo.

Una regla empírica, citada por Kleinbaum et al. (1988), consiste en considerar que existen problemas de colinealidad si algún FIV es superior a 10, que corresponde a alguna $T_{i}<0,1$. Aunque puede existir colinealidad con FIV bajos, además puede haber colinealidades que no impliquen a todas las variables independientes y que, por tanto, no son bien detectadas por el FIV. Otra manera, más completa, de detectar colinealidad es realizar un análisis de los índices de condición y la proporción de descomposición de varianza.

El índice de condición es un estadístico basado en los autovalores. El número de autovalores nulos indica el número de variables que son combinación lineal de otras (el 
número de colinealidades exactas) y autovalores próximos a cero indican problemas graves de colinealidad. El cálculo de los autovalores permite, por lo tanto, determinar no sólo la existencia de colinealidad, sino también el número de colinealidades. Para determinar cuándo un autovalor pequeño está suficientemente próximo a cero se usa su valor relativo con respecto al mayor, en este sentido, para cada autovalor se define el índice de condición como la raíz cuadrada del cociente entre el mayor de ellos y dicho autovalor.

Para Belsley (1991) índices de condición entre 5 y 10 están asociados con una colinealidad débil, mientras que índices de condición entre 30 y 100 señalan una colinealidad moderada a fuerte.

Una vez determinada la presencia y el número de colinealidades, es conveniente averiguar qué variables están implicadas en ellas. Usando ciertas propiedades de las matrices se puede calcular la proporción de la varianza de las variables sobre cada componente. Si dos o más variables tienen una proporción de varianza alta en un componente, indica que esas variables están implicadas en la colinealidad y, por tanto, la estimación de sus coeficientes está degradada por la misma.

Belsley (1991) propone usar conjuntamente los índices de condición y la proporción de descomposición de varianza para realizar el diagnóstico de colinealidad, usando como umbral de proporción alta 0’5 de modo que, si los índices de condición son inferiores a 10 y las proporciones de descomposición de varianza son inferiores a 0'5, se pueden descartar problemas de multicolinealidad. De acuerdo con los estudios realizados por Belsley (1991), tanto con datos observados como con datos simulados, el problema de la multicolinealidad es grave cuando el número de condición toma un valor 
entre 20 y 30. Naturalmente, si este indicador superase el valor de 30, el problema sería ya manifiestamente grave.

En nuestro análisis los valores de FIV son inferiores a 10 y los niveles de tolerancia superiores a 0’10, lo que muestra la inexistencia de multicolinealidad entre las variables, dichos valores se muestran en la tabla 32 .

Tabla 32. Estadísticos de colinealidad

\begin{tabular}{|c|c|c|}
\cline { 2 - 3 } \multicolumn{1}{c|}{} & Tolerancia & FIV \\
\hline $\mathrm{CI}$ & 0,744 & 1,344 \\
\hline $\mathrm{A}$ & 0,897 & 1,115 \\
\hline $\mathrm{ACC}$ & 0,692 & 1,445 \\
\hline $\mathrm{S}$ & 0,801 & 1,249 \\
\hline
\end{tabular}

Por otro lado, los índices de condición y la proporción de la varianza de los coeficientes de regresión están dentro de los límites establecidos, excepto para los dos últimos índices de condición que presentan valores algo superiores al máximo aconsejado por Belsley (1991) pero sin llegar a ser un problema grave, ya que, ambos índices están dentro del rango que oscila entre 2 y 20. Además los valores de las proporciones de las varianzas son correctos ya que se encuentran todos ellos bajo el 0’50 establecido como límite máximo y que permite descartar problemas de multicolinealidad (tabla 33). 
Tabla 33. Diagnósticos de colinealidad de las Variables Externas con respecto al Valor Percibido

\begin{tabular}{|c|c|c|c|c|c|c|}
\hline \multirow{2}{*}{ Dimensión } & \multirow{2}{*}{ Índice de condición } & \multicolumn{5}{|c|}{ Proporciones de la varianza } \\
\cline { 3 - 7 } & & (Constante) & CI & A & ACC & S \\
\hline 1 & 1,000 & 0,00 & 0,00 & 0,00 & 0,00 & 0,00 \\
2 & 8,519 & 0,00 & 0,01 & 0,48 & 0,02 & 0,27 \\
3 & 9,563 & 0,01 & 0,41 & 0,07 & 0,01 & 0,34 \\
4 & 11,946 & 0,24 & 0,25 & 0,12 & 0,36 & 0,38 \\
5 & 14,114 & 0,75 & 0,03 & 0,10 & 0,41 & 0,00 \\
\hline
\end{tabular}

De igual forma, tras proceder al análisis de multicolinealidad entre las variables de valor percibido y satisfacción podemos afirmar la inexistencia de problemas de multicolinealidad entre ambas variables, tal como se puede comprobar en las tablas $34 \mathrm{y}$ 35 respectivamente.

Tabla 34. Estadísticos de colinealidad de Valor Percibido a Satisfacción

\begin{tabular}{|c|c|c|}
\cline { 2 - 3 } \multicolumn{1}{c|}{} & Tolerancia & FIV \\
\hline VP & 1,000 & 1,000 \\
\hline
\end{tabular}

Tabla 35. Diagnósticos de colinealidad de VP a SAT

\begin{tabular}{|c|c|}
\hline Dimensión & Índice de condición \\
\hline 1 & 1,000 \\
2 & 9,444 \\
\hline
\end{tabular}

Igualmente, tras realizar dichos análisis con las variables de satisfacción y elealtad se han obtenido unos resultados que también permiten detectar la ausencia de problemas de multicolinealidad entre dichas variables, tal y como se muestra en las tablas 36 y 37. 
Tabla 36. Estadísticos de colinealidad de Satisfacción a E-lealtad

\begin{tabular}{|c|c|c|}
\cline { 2 - 3 } \multicolumn{1}{c|}{} & Tolerancia & FIV \\
\hline SAT & 1,000 & 1,000 \\
\hline
\end{tabular}

Tabla 37. Diagnósticos de colinealidad de SAT a EL

\begin{tabular}{|c|c|}
\hline Dimensión & Índice de condición \\
\hline 1 & 1,000 \\
2 & 9,396 \\
\hline
\end{tabular}

Finalmente, ambos análisis muestran unos índices de condición inferiores a 10, unos niveles de tolerancia superiores a 0'10 y un FIV inferior a 10, por lo que se pueden descartar problemas de colinealidad entre las variables incluidas en las tablas 34, 35, 36 y 37.

Una vez marcadas las propiedades psicométricas de las medidas, el siguiente paso es proceder a contrastar las hipótesis planteadas en nuestro modelo. Para ello se realiza un análisis de regresión que incluye tanto variables de control (edad, estudios, sexo y nivel de ingresos) como el resto de variables independientes de nuestro modelo. En primer lugar, tenemos como variables independientes con respecto al valor percibido la capacidad innovativa, la autoeficacia, la accesibilidad y la seguridad. En segundo lugar, tenemos la satisfacción como variable dependiente de valor percibido y en tercer lugar, tenemos la variable de e-lealtad que depende de la satisfacción.. 
Las tablas 38, 39 y 40 recogen un resumen de los resultados obtenidos de acuerdo a los coeficientes no estandarizados y estandarizados, así como los datos obtenidos mediante la t-student y su grado de significación.

Tabla 38. Análisis de regresión de las Variables Externas al Valor Percibido

\begin{tabular}{|c|c|c|c|c|c|}
\hline \multirow{2}{*}{ Modelo de Regresión } & \multicolumn{2}{|c|}{$\begin{array}{c}\text { Coeficientes no } \\
\text { estandarizados }\end{array}$} & $\begin{array}{c}\text { Coeficientes } \\
\text { estandarizados }\end{array}$ & $\mathrm{t}$ & Sig. \\
\cline { 2 - 6 } & $\mathrm{B}$ & Error típ. & Beta & $\mathrm{B}$ & Error típ. \\
\hline (Constante) & 7,389 & 2,048 & $-0,049$ & 3,607 & 0,000 \\
Edad & $-0,156$ & 0,200 & 0,032 & $-0,782$ & 0,435 \\
Estudios & 0,222 & 0,423 & 0,053 & 0,524 & 0,600 \\
Sexo & 0,456 & 0,481 & $-0,062$ & $-1,133$ & 0,345 \\
Ingresos & $-0,435$ & 0,384 & 0,149 & 2,435 & $0,016^{*}$ \\
CI & 0,166 & 0,068 & 0,156 & 2,787 & $0,006^{* *}$ \\
A & 0,173 & 0,062 & 0,321 & 5,053 & $0,000^{* * *}$ \\
ACC & 0,329 & 0,065 & 0,142 & 0,402 & $0,017^{*}$ \\
S & 0,160 & 0,067 & & \\
\hline \multicolumn{7}{|c|}{$\mathrm{R}=0,312$} \\
\end{tabular}

$* \mathrm{p}<0,05 * * \mathrm{p}<0,01 * * * \mathrm{p}<0,000$

Según estos datos la ecuación de regresión resultante se muestra a continuación:

$$
\begin{gathered}
\mathrm{Y}=\mathrm{B} 0+\mathrm{B}_{1} \mathrm{X}_{1}+\mathrm{B}_{2} \mathrm{X}_{2}+\mathrm{B}_{3} \mathrm{X}_{3}+\mathrm{B}_{4} \mathrm{X}_{4} \\
\mathbf{V P}=\mathbf{7 , 3 8 9}+\mathbf{0 , 1 6 6} \mathrm{CI}+\mathbf{0 , 1 7 3} \mathrm{A}+\mathbf{0 , 3 2 9} \mathrm{ACC}+\mathbf{0 , 1 6 0 ~ S}
\end{gathered}
$$

Tabla 39. Análisis de regresión de VP a SAT

\begin{tabular}{|c|c|c|c|c|c|}
\hline \multirow{2}{*}{ Modelo de Regresión } & \multicolumn{2}{|c|}{$\begin{array}{c}\text { Coeficientes no } \\
\text { estandarizados }\end{array}$} & $\begin{array}{c}\text { Coeficientes } \\
\text { estandarizados }\end{array}$ & $\mathrm{t}$ & Sig. \\
\cline { 2 - 6 } & $\mathrm{B}$ & Error típ. & Beta & $\mathrm{B}$ & Error típ. \\
\hline (Constante) & 6,666 & 0,938 & 0,646 & 13,464 & 0,000 \\
VP & 0,613 & 0,045 & 0,000 \\
\hline \multicolumn{5}{c}{$\begin{array}{c}\mathrm{R}^{2}=0,417 \\
\mathrm{~F}=181,269 \\
\mathrm{P}=0,000\end{array}$} \\
\hline
\end{tabular}


Según estos datos la ecuación de regresión de la variable satisfacción como dependiente de valor percibido son los siguientes:

\section{$\mathrm{Y}=\mathrm{B} 0+\mathrm{B}_{1} \mathrm{X}_{1}$ \\ $\mathrm{SAT}=6,666+0,613 \mathrm{VP}$}

Tabla 40. Análisis de regresión de SAT a EL

\begin{tabular}{|c|c|c|c|c|c|}
\hline \multirow{2}{*}{ Modelo de Regresión } & \multicolumn{2}{|c|}{$\begin{array}{c}\text { Coeficientes no } \\
\text { estandarizados }\end{array}$} & $\begin{array}{c}\text { Coeficientes } \\
\text { estandarizados }\end{array}$ & $\mathrm{t}$ & Sig. \\
\cline { 2 - 6 } & $\mathrm{B}$ & Error típ. & Beta & $\mathrm{B}$ & Error típ. \\
\hline (Constante) & 7,959 & 1,007 & & 7,905 & 0,000 \\
SAT & 0,688 & 0,052 & 0,641 & 13,294 & 0,000 \\
\hline \multicolumn{7}{|c}{$\mathrm{R}^{2}=0,411$} \\
$\mathrm{~F}=176,720$ \\
$\mathrm{P}=0,000$
\end{tabular}

Según los datos de la tabla 40, la ecuación de regresión de la variable e-lealtad como dependiente de satisfacción son los siguientes:

\section{$\mathrm{Y}=\mathrm{B} 0+\mathrm{B}_{1} \mathrm{X}_{1}$ \\ $\mathrm{EL}=7,959+0,688 \mathrm{SAT}$}

De este modo, se concreta el grado de dependencia de cada una de las variables dependientes con respecto a cada una de las correspondientes variables independientes relacionadas en cada hipótesis del modelo, así como la importancia de cada una de ellas con respecto al "valor percibido", "satisfacción" y"e-lealtad".

En las tablas 38, 39 y 40 se muestran los datos relativos a la $t$ de Student y su nivel de significación. En este test se asume que la hipótesis nula se rechaza en el caso 
de que la significación estadística sea inferior al 5\%, es decir, el nivel de significación debe ser inferior a 0’05.

Siguiendo este criterio se descarta que las variables de control (edad, estudios, sexo e ingresos) puedan explicar el valor percibido (VP), ya que sus valores de significación son superiores a 0’05.

Se confirma únicamente que se tendrán en cuenta para el desarrollo del modelo, la dependencia existente entre el valor percibido y el resto de variables independientes (CI, A, ACC y S) ya que estas variables muestran niveles de significación inferiores a 0’05 (0’016; 0’006; 0’000; 0’017 respectivamente). Asimismo se confirma la dependencia existente entre satisfacción y la variable de valor percibido con un nivel de significación de 0’000, así como la dependencia de e-lealtad con respecto a satisfacción, de nuevo se muestra un valor inferior al 0’05 exigido para rechazar la hipótesis nula, concretamente en este caso es de 0’000 al igual que en el caso anterior.

Para ver el ajuste del modelo consideramos el coeficiente de determinación $\mathrm{R}^{2}$, el estadístico F de Snédecor y su nivel de significación. El valor $\mathrm{R}^{2}$ es una cantidad que puede interpretarse como un factor de reducción de la incertidumbre cuando son conocidas las variables independientes. Expresa la proporción de varianza de la variable dependiente que está explicada por la variable independiente, de manera que cuanto más se acerque a uno, más poder explicativo tendrá el modelo. Los resultados obtenidos tras el análisis fueron una $\mathrm{R}^{2}=0$ 0’312 para la capacidad innovativa, la autoeficacia, la accesibilidad y la seguridad, un $\mathrm{R}^{2}=0^{\prime} 417$ para el valor percibido y un $\mathrm{R}^{2}=0$ '411 para la variable satisfacción y, por tanto, se puede concluir afirmando que es un dato que muestra una buena interpretación de la proporción de la variación de la variable 
dependiente que es explicada en este modelo. Concretamente, la $\mathrm{R}^{2}$ explica el $31 \%$ de la varianza que muestra la dependencia del valor percibido con respecto a las variables consideradas independientes. La $\mathrm{R}^{2}$ explica el $42 \%$, aproximadamente, de la varianza para la relación de la quinta hipótesis y el $41 \%$ para la relación de las variables relacionadas en la sexta hipótesis.

El estadístico F, permite contrastar la hipótesis nula de que el valor poblacional de $\mathrm{R}$ es cero. Cuando el nivel crítico asociado a este estadístico tenga un valor muy pequeño (generalmente inferior a 0 ’05) se puede rechazar la hipótesis lo que implica que las variables están linealmente relacionadas. En nuestro caso tenemos un valor $\mathrm{F}=13$ '975 y un p-valor menor que 0'05. Esto permite el rechazo de la hipótesis nula y la aceptación de la hipótesis alternativa que corrobora que hay algún tipo de relación entre las variables independientes (capacidad innovativa, autoeficacia, accesibilidad y seguridad) y la variable dependiente (valor percibido) en el primero de los casos (hipótesis 1 a la hipótesis 4). De igual forma corrobora que existe una relación entre la variable de valor percibido con una variable de carácter afectivo denominada satisfacción (hipótesis 5) y también confirma la dependencia de la variable satisfacción con una variable de carácter conductual como es la e-lealtad (hipótesis 6).

Finalmente, y para valorar la importancia relativa que cada una de las variables independientes del modelo pueden tener para explicar las variables dependientes, es necesario el apoyo de los datos obtenidos por coeficientes de regresión estandarizados Beta. Los datos muestran que la variable que más influye en el valor percibido es la accesibilidad con un valor de 0’321. La siguiente variable que mejor explica el valor percibido es la autoeficacia con un valor de 0'156. A continuación, la siguiente variable explicativa es la capacidad innovativa con un resultado de 0'149. La variable 
independiente que menos influencia tiene sobre el valor percibido es la seguridad con un coeficiente beta de 0 ' 142 .

En las siguientes relaciones se muestra la influencia que tiene el valor percibido sobre la satisfacción con un valor de 0’646 y la influencia de la satisfacción sobre la elealtad con un coeficiente estandarizado de beta de 0'641.

Este análisis de los resultados ha permitido proporcionar un soporte completo para la confirmación de la dependencia que la variable valor percibido tiene respecto al resto de variables independientes. Y la dependencia de la satisfacción con el valor percibido y de la e-lealtad con la satisfacción.

La tabla 41 muestra un resumen del contraste de hipótesis: por un lado, se corrobora la $\mathrm{H} 1$ que confirma que la capacidad innovativa tiene un efecto positivo sobre el valor percibido. Lo mismo ocurre con la $\mathrm{H} 2$ que indicaba que la autoeficacia repercute positivamente en el valor percibido. Asimismo, se confirma la $\mathrm{H} 3$ y $\mathrm{H} 4$ que indican que tanto la accesibilidad como la seguridad influyen positivamente sobre la variable dependiente de valor percibido. Igualmente, se corrobora, por un lado, la H5 que indica que el valor percibido influye en la satisfacción, y por otro lado, la H6 que afirma que la satisfacción influye positivamente sobre la e-lealtad. 
Tabla 41. Resultados del contraste de hipótesis

Hipótesis

Apoyo empírico

H1: La capacidad innovativa influye de manera positiva en el valor percibido.

SÍ

H2: La autoeficacia hacia las TIC influye de manera positiva en el valor percibido.

SÍ

H3: La accesibilidad tiene una influencia positiva sobre el valor percibido.

SÍ

H4: La seguridad afecta positivamente sobre el valor percibido.

SÍ

H5: El valor percibido afecta positivamente en la satisfacción.

SÍ

H6: La satisfacción afecta positivamente en la e-lealtad.

SÍ

Fuente: Elaboración propia.

\section{CONCLUSIÓN Y REFLEXIÓN FINAL}

El entorno competitivo en el que mueve la sociedad de la gestión del conocimiento y los resultados obtenidos por numerosos estudios que corroboran que la inversión en TIC por parte de cualquier sector (sanitario, entre otros) no se asocia a una mejora en los resultados organizacionales (Cragg y Zinatelli, 1995; Johnson, 1997; McGowan y Madey, 1998), es lo que lleva a autores como, Chiasson y Lovato (2001) a sugerir que la implantación de las TIC es un proceso complejo que está influenciado por numerosos factores.

El presente trabajo ha justificado que la e-lealtad (lealtad electrónica) de los usuarios externos (pacientes, cuidadores, etc.) al sistema sanitario, dependen en gran 
medida de la satisfacción que les reporta utilizar servicios sanitarios online. Esta satisfacción está influenciada por el valor percibido de los pacientes ante el uso de los servicios online y que a su vez depende de otras variables independientes como son la capacidad innovativa, la autoeficacia, la accesibilidad y la seguridad desarrolladas en el modelo propuesto.

Analizando hipótesis a hipótesis, los resultados muestran que la e-lealtad de los pacientes ante el uso de las TIC con los nuevos servicios online, viene asociada a diversas dependencias entre variables que se explican a continuación a través de las hipótesis planteadas.

Los resultados de las hipótesis $\mathrm{H} 1, \mathrm{H} 2, \mathrm{H} 3$ y $\mathrm{H} 4$ revelan la asociación significativa y la dependencia entre las variables capacidad innovativa, autoeficacia, accesibilidad y seguridad (CI, A, ACC y S) con el valor percibido. Esto reafirma lo expresado por autores tales como Jones et al. (2002) que determinaron que el grado de uso de la tecnología de un individuo está determinado por su capacidad innovativa personal. Agarwal y Prasad (1998) demostraron que la relación entre las percepciones de los usuarios de Internet y su intención de uso puede variar en función de la capacidad innovativa. Leonard-Barton y Deschamps (1988) argumentan también que es más probable que los usuarios más innovativos perciban las ventajas y la utilidad de usar una determinada tecnología mientras que es menos probable que los individuos menos innovativos perciban su valor, la acepten y la usen. Se trata de una serie de autores y estudios que confirman la H1.

En lo que respecta a la confirmación de la dependencia de VP con respecto A, se corrobora el planteamiento de autores como Compeau y Higgins (1991) que relacionan 
la autoeficacia con la aceptación del uso de los ordenadores y los numerosos estudios que demuestran que la autoeficacia influye en las decisiones relativas al uso y adopción de las tecnologías (Leonard-Barton y Kraus, 1985; Davis et al., 1989; Compeau y Higgins, 1991) y por tanto a su valor percibido.

Autores como Tan y Teo (2000), apoyando la H3, postularon que la accesibilidad a la banca electrónica facilita la implantación de los servicios virtuales debido a la capacidad que tienen los usuarios para percibir el uso de la tecnología como algo necesario y favorable, afirmando la relación planteada en la $\mathrm{H} 3$ de nuevo, que a su vez se ve apoyada por el estudio de Sathye (1999) que determinó que el acceso a Internet es uno de los factores que más influyen en la adopción de servicios virtuales. Este autor explicó que sin una adecuada conexión y acceso a Internet o a los servicios virtuales ofrecidos por las organizaciones, el uso de estas nuevas tecnologías no es posible. Estudio que más tarde corroboró, de forma idéntica, Almogbil (2005). Este autor se centró en un estudio que relacionaba el acceso y el uso que se hace tanto de la información como de los servicios virtuales que se encuentran en las organizaciones. Su estudio le permitió confirmar que existe una relación significativa entre la rapidez de acceso a Internet y el uso de los servicios virtuales.

Finalmente, la hipótesis cuarta y su validación empírica viene apoyada por estudios como los de Suh y Han (2002) que confirman que la clave para el desarrollo y el uso de servicios online está en la seguridad que se pueda percibir de ellos. Muchos investigadores están de acuerdo en que la seguridad es esencial para que tenga lugar la utilización de los servicios online de forma segura (Luhmann, 1979; McKnight y Chervany, 2001). 
En lo que concierne a H5, los resultados muestran que la variable de satisfacción (SAT) depende en gran medida del valor percibido (VP). DeLone y McLean (1992) proponen un modelo que incluye como una de las variables de éxito de los sistemas de información la satisfacción del usuario. Sin embargo, DeLone y McLean no proporcionan la validación empírica del modelo, de hecho, sugieren un mayor desarrollo y validación del mismo (DeLone y McLean, 1992).

Más tarde, Seddon (1997) procedió a ampliar la versión del modelo DeLone y McLean para ofrecer una visión más clara entre las variables de éxito de los sistemas de información. Este autor afirma, pues, que el uso que se hace de los sistemas de información es un comportamiento, no una medida de éxito, y reemplaza el uso de los sistemas de información del modelo de DeLone y McLean por el valor percibido que sirve para medir las percepciones de los usuarios de un sistema. A su vez, establece una conexión directa entre el valor percibido y la satisfacción del usuario. Validación que también fue confirmada por Rai et al. (2002) que extendió el modelo de Seddon en el que la percepción de facilidad de uso, la percepción de la utilidad (valor percibido), y la calidad de la información son consideradas como antecedentes de la satisfacción.

Respecto a la sexta hipótesis (H6), los resultados de este estudio confirman que en el contexto de la gestión del conocimiento y más concretamente en el sector de las TIC, la variable de e-lealtad (EL) depende en gran medida de la satisfacción (SAT). Esta conclusión está de acuerdo con la gran variedad de estudios que tratan de explicar la relación entre la actitud de los usuarios, la satisfacción y la intención de volver a utilizar un sistema. Entre estos modelos está el TAM propuesto por Davis (1989) u otros que tratan de explicar el éxito de la satisfacción sobre el uso de las TIC (Bailey y 
Pearson, 1983; Ives et al., 1983; Doll y Torkzadeh, 1988; DeLone y McLean, 1992). No obstante, recientemente, ha surgido la teoría EDT de Oliver (1980) para explicar las variables que motivan a los individuos para seguir utilizando las TIC (Bhattacherjee, 2001a, 2001b; Khalifa y Liu, 2002a, 2002b; McKinney et al., 2002; Hayashi et al., 2004; Chiu et al., 2005; Lin et al., 2005). Modelo que propone la relación causal existente entre las percepciones de los usuarios, su disconformidad, su satisfacción y la intención de volver a utilizar las TIC (denominada en nuestro estudio e-lealtad).

En conclusión, los pacientes son más proclives a utilizar las TIC ante la aparición de los nuevos servicios sanitarios online. Su grado de aceptación hacia el uso de dichas tecnologías (TIC) incrementará en mayor o menor medida según su grado de capacidad innovativa a la hora de utilizar un servicio novedoso, su autoeficacia en la práctica de las TIC, el grado de accesibilidad que tenga sobre la información que buscan y la que es ofrecida y el acceso al sistema, así como el grado de seguridad que confiera el uso de los servicios online para el tratamiento de datos confidenciales de la salud de los pacientes o la seguridad de que el servicio es útil y válido con respecto a las necesidades de los usuarios externos (pacientes, cuidadores o familiares). Estas variables a su vez también influyen sobre el valor percibido de los pacientes ante el uso de los servicios sanitarios online. Dicha variable influirá en la satisfacción de los usuarios del sistema sanitario y esto incrementará su grado de e-lealtad, es decir, de lealtad electrónica a la hora de utilizar los servicios online de forma habitual y sistemática a lo largo del tiempo.

Por lo tanto, se considera que este trabajo aporta una relación entre distintas variables dependientes e independientes no establecidas previamente a este estudio que 
analiza el porqué de la dependencia entre las diversas variables y valora en qué medida el grado de aceptación y de valoración de las TIC y de los servicios online favorece el uso continuado de un sistema online en el sector sanitario.

Finalmente, en el capítulo siguiente se procederá a la redacción de las conclusiones obtenidas tras los diversos estudios y análisis realizados a lo largo de estos cinco capítulos, para concluir por un lado, con el estudio de las limitaciones y líneas futuras de investigación, y por otro lado, con las aportaciones realizadas en esta investigación. 

CONCLUSIONES, LIMITACIONES, LIINEAS FUTURAS DE

INVESTIGACIÓN Y APORTACIONES 



\section{CONCLUSIÓN}

Ante los cambios que se están produciendo de manera global ante la revolución de las TIC y la aparición de la denominada sociedad del conocimiento, surge la necesidad de analizar el concepto de TIC y el de gestión del conocimiento, así como la relación existente entre ambos conceptos. Conocimiento y TIC han sido consideradas como activos que permiten a las organizaciones mantener una ventaja competitiva frente al resto de sus competidores. El uso de TIC dentro de una organización (por ejemplo, las sanitarias) ha sido identificado como una herramienta importante para la gestión y el intercambio de conocimiento dentro de la misma con el fin de mejorar su rendimiento. A su vez, las decisiones que conciernen a la aceptación de las TIC requieren de una adecuada gestión del conocimiento en dicha organización.

En el área de aceptación de innovaciones tecnológicas, el paso del tiempo ha puesto de manifiesto unas cifras reales que distan mucho de las expectativas que se pronosticaban en algunos estudios, debido principalmente a que el nivel de uso es menor de lo que se esperaba inicialmente. A pesar de los beneficios, las organizaciones dedican la mayor parte de sus recursos, esfuerzos y tiempo a la implantación indiscriminada de aplicaciones informáticas, sin plantearse dónde reside el conocimiento necesario para implantar y aceptar las TIC, y cómo transformar y usar ese conocimiento en los nuevos sistemas de información.

La aceptación de las TIC por parte de los usuarios es una condición necesaria para su éxito y, en consecuencia, conocer las motivaciones que empujan a los usuarios a la 
adopción de nuevas TIC se ha convertido en un aspecto crítico para investigadores y gestores, tratando de definir correctamente qué factores condicionan una decisión tan trascendente para las organizaciones. Como consecuencia se han desarrollado varios modelos teóricos que explican la aceptación de sistemas de información y de tecnología. La mayoría de estos estudios parten de teorías relacionadas con el comportamiento, y desarrollan modelos contrastados empíricamente que explican el conjunto de actuaciones del individuo a partir de sus creencias y/o actitudes.

En nuestro estudio, partiendo de los ocho principales modelos de aceptación de las tecnologías hemos desarrollado un modelo orientado a la lealtad electrónica. A partir de dicho modelo, se ha propuesto un modelo que toma como una de las variables principales el valor percibido, una variable presente en todos los modelos previos analizados en el capítulo 2 de este trabajo, lo que refleja su importancia como antecedente de la aceptación y uso de las tecnologías. Partiendo de esta variable, se han introducido, por un lado cuatro variables independientes que reflejan flujos e intercambios de conocimiento entre las organizaciones sanitarias y el usuario de las tecnologías. Dichas variables son la capacidad innovativa, la autoeficacia hacia las nuevas tecnologías, la accesibilidad a los servicios y a la información y la seguridad. Según el modelo propuesto, estas variables tienen una influencia positiva sobre el valor percibido por un usuario externo (pacientes, cuidadores, familiares, entre otros) en los servicios online ofrecidos por el sector sanitario.

El repaso a la bibliografía, también nos muestra que a pesar de la abundancia de estudios de evaluación comparativa de TIC en el sector sanitario, estos se han centrado 
fundamentalmente en la "administración sanitaria", prestando poca atención a los usuarios finales y muy pocos de ellos consideran el grado de adopción o uso real de los servicios por los ciudadanos, es decir, solamente se evalúa la oferta sin tener en cuenta la "compra" o el uso real de estos servicios por las personas como indicador de medida.

A este respecto, cabe destacar la incorporación de dos nuevas variables que incluyen una actitud e intención del usuario a la hora de usar las TIC en dicho sector. En primer lugar, se incluye la variable de satisfacción, influida positivamente por el valor percibido. Ambas están relacionadas por ser variables que consideran la percepción que los usuarios externos tienen sobre los servicios sanitarios online. En segundo lugar, se incorpora como variable final de nuestro modelo la lealtad electrónica o e-lealtad, variable conductual influida positivamente por la satisfacción de los usuarios ante el uso de servicios sanitarios online.

El modelo propuesto ha sido contrastado en el contexto de los servicios online que son proporcionados por las organizaciones del sector sanitario público y dirigidos a usuarios externos (pacientes, cuidadores, familiares). Estos servicios son una herramienta valiosa en las instituciones de salud pública para mejorar su eficacia. Sin embargo, como los pacientes pueden elegir entre los servicios sanitarios basados en la tecnología o el tradicional cara a cara, es necesario que perciban un valor añadido en el uso de la tecnología para que puedan seleccionar esa opción y se incremente la intención de volver a utilizarla siempre que sea necesaria, provocando una lealtad hacia el uso de la misma. 
En concreto se empleó una muestra de 256 usuarios de servicios online proporcionados por el Servicio Murciano de Salud. Los resultados del análisis de regresión efectuado señalan que las variables independientes del modelo (capacidad innovativa, autoeficacia, accesibilidad y seguridad) tienen una relación significativa y positiva con la variable de valor percibido. A su vez se muestra una relación positiva de dicha variable con la satisfacción de los usuarios externos y de ésta con la variable final de este trabajo, la e-lealtad.

La primera contribución de este trabajo consiste en realizar un análisis comparativo de los modelos de aceptación de las tecnologías existentes con el fin de determinar una variable clave para la aceptación de la tecnología que permita incrementar la actitud y la intención de los usuarios hacia el uso de los servicios sanitarios online. Así hemos definido la variable valor percibido como una de las variables fundamentales de nuestra investigación. Esta variable es denominada “percepción de utilidad" en el modelo TAM de Davis (1989) y el modelo C-TAM-TPB de Taylor y Todd (1995), “motivación extrínseca” en el Modelo Motivacional, “forma de trabajo" en el modelo MPCU, "ventajas relativas" en el modelo IDT y "expectativas de rendimiento" en la Teoría Social Cognitiva y el modelo UTAUT. En esta investigación se han unificado las acepciones anteriores bajo el concepto de valor percibido, que pretende ser una extrapolación hacia la figura del cliente externo o usuario final, siguiendo la literatura del área de marketing.

Tomando en consideración lo anterior, el presente trabajo nos ayuda a crear un lenguaje común orientado a la variable "valor percibido". Al desarrollar un lenguaje de 
adaptación de tecnologías común, los diferentes interlocutores podrán extrapolar los acontecimientos de un determinado modelo, por ejemplo, el TAM, al modelo C-TAMTPB o MPCU. Además, la variable valor percibido tiene información adicional sobre riesgos y oportunidades que surgen de cara al usuario final. El modelo general del que hemos partido, tiene en cuenta el valor percibido entre los distintos agentes usuarios, generando un intercambio de información que muestra la más clara ilustración de adquirir conocimiento, el cual debe ser transferido y adaptado a la operativa de la institución sanitaria.

La segunda contribución consiste en incluir en el modelo las variables seleccionadas como variables independientes desde un enfoque de gestión del conocimiento. Así, dichas variables reflejan el conocimiento de los usuarios externos y su intercambio con el conocimiento de la organización. En particular, la capacidad innovativa muestra la disposición de los usuarios a adoptar nuevos conocimientos fruto del uso de una nueva tecnología; la autoeficacia hacia las nuevas tecnologías refleja el nivel de conocimiento que debe poseer el usuario para poder utilizar de manera efectiva una nueva tecnología; la accesibilidad hace referencia a la facilidad con la que los usuarios externos pueden extraer conocimiento de la organización sanitaria e intercambiar conocimiento con ella; y la seguridad es esencial para generar e incrementar la confianza en los usuarios para que realicen actividades de intercambio de conocimiento y adquisición, distribución y utilización de información entre los usuarios externos al sector sanitario y la propia organización sanitaria con referencia a los servicios ofrecidos por la misma. 
La tercera contribución de esta investigación es la de analizar las variables de satisfacción y lealtad electrónica. Se trata de variables que explican el incremento de la utilización de los servicios sanitarios basados en las TIC. La satisfacción, definida por Al-Gahtani y King (1999) como una reacción positiva de los usuarios hacia el uso de las TIC, marca el inicio de una nueva relación entre una variable de carácter cognitivo, valor percibido, y otra de carácter afectivo, satisfacción, relación contrastada posteriormente donde se confirma la influencia del valor percibido por los usuarios externos (pacientes, entre otros) cuando utilizan los servicios sanitarios online sobre la satisfacción derivada de dicho uso. Por otro lado, se plantea y contrasta la relación de la variable satisfacción con la variable conductual de e-lealtad, definida como una actitud favorable por parte de los usuarios externos (pacientes) hacia la utilización de los servicios sanitarios online que concluye en un uso repetitivo de los mismos. Al igual que en estudios previos, (por ejemplo, Bhattacherjee 2002) se ha confirmado el impacto positivo de la satisfacción en la lealtad electrónica y, por tanto, el valor de la satisfacción como un enlace necesario entre la variable valor percibido y e-lealtad.

La cuarta contribución de esta investigación es haber testado el modelo en usuarios externos (pacientes, familiares, cuidadores, etc.). Las investigaciones previas en aceptación de la tecnología se han realizado principalmente en entornos de trabajo y, en particular, con el personal de hospitales. En este contexto, las intenciones, actitudes y comportamientos de las personas pueden estar influidos por autoridades y directivos (Lanseng y Andreassen 2007). En esta investigación, los participantes son libres para formar sus propias percepciones, creencias y actitudes, lo que refuerza la validez del modelo. 
Por otra parte, los resultados obtenidos sugieren las siguientes implicaciones prácticas:

1. Dado que la accesibilidad es la variable que tiene mayor influencia en el valor percibido por los usuarios respecto a los servicios online, se deben tomar medidas para fomentar el acceso de los usuarios tanto a la información como a los servicios. En primer lugar, para facilitar que la población pueda acceder a la información que desea, y dado que los ciudadanos, usuarios externos, tienen diferentes niveles de conocimiento tecnológico, las entidades de salud deben diseñar interfaces amigables y aplicaciones fáciles de usar. Por otra parte dichas aplicaciones deben ofrecer bases de conocimiento requerido por los ciudadanos. En segundo lugar, para facilitar la accesibilidad física, las autoridades deberían poner en marcha programas que faciliten la conexión a Internet así como la adquisición de ordenadores u otros dispositivos para acceder a Internet, por parte de los ciudadanos. A este respecto, consideramos que las TIC deben ser aplicadas en un contexto de relación entre los agentes usuarios, ya que no funcionan en el vacío sino en un contexto cultural, histórico, etc., que necesitan de un determinado nivel de desarrollo social y económico, caracterizado por la participación de los agentes usuarios, dispuestos a generar, difundir y usar la información para la producción de conocimiento útil.

Como alternativa, se deberían fomentar políticas que potenciaran la dotación de estos recursos en centros públicos de libre acceso. En caso contrario se puede dar lugar a una brecha digital que implicaría que sólo puedan beneficiarse de los servicios online parte de los ciudadanos, lo que, por otra parte, restaría eficiencia a los servicios online 
ya que parte de la ciudadanía se vería obligada a continuar utilizando los tradicionales servicios presenciales.

2. La autoeficacia es la segunda variable que más influye en el valor percibido. Representa la percepción de un usuario sobre su capacidad y habilidades para poder usar los servicios sanitarios online. Las personas que no se sienten capaces de manejar estos servicios pueden mostrar resistencia ante ellos. Por ello, para aumentar el valor percibido por los usuarios respecto a los servicios sanitarios online, sería conveniente dotar a los usuarios de formación de calidad para facilitar que el uso de estos nuevos servicios no sea una carga para ellos. Asimismo, sería de utilidad proporcionar un servicio de apoyo técnico ante dudas sobre el manejo de los servicios, así como la elaboración y difusión de guías de uso de dichos servicios.

3. La capacidad innovativa es la tercera variable que más influye en el valor percibido. Es por ello necesario que los ciudadanos desarrollen una actitud positiva hacia la innovación y a cambiar sus principios. Acciones formativas como guías, panfletos, posters o tareas de promoción, pueden ayudar a familiarizar a los ciudadanos con los servicios sanitarios online y desarrollar una actitud positiva hacia ellos. Por otra parte, las autoridades sanitarias deben prestar especial atención a los usuarios con mayor capacidad innovativa y desarrollar campañas de promoción dirigidas específicamente a estos ciudadanos con interés potencial en usar los servicios online. Estas personas pueden constituir la semilla que difunda e incremente el uso de los servicios online entre el resto de la población. 
4. Por un lado, dado que la seguridad influye en el valor percibido, los gerentes y directivos de las entidades sanitarias deberían dar instrucciones para desarrollar aplicaciones totalmente seguras, que garanticen la confidencialidad de los datos de los ciudadanos, el acceso seguro a la información, y que eviten pérdidas de la misma. Por otra parte, la información proporcionada a los ciudadanos no debe contener errores y debe ser suministrada con rapidez. En un aspecto tan sensible como éste, fallos en la seguridad pueden hacer que los usuarios pierdan la confianza en los servicios online, disminuya su percepción sobre el valor que éstos tienen, y no vuelvan a usarlos.

5. Si uno de los objetivos de las TIC en el sector sanitario es mejorar los servicios, es imprescindible conocer las necesidades de los usuarios antes de emprender cualquier acción. El valor percibido debe estar organizado conociendo la perspectiva del usuario, no sólo desde la institución sanitaria. Las organizaciones sanitarias pueden proporcionar lo que quieren los usuarios y no lo que el organismo público piensa que quieren los usuarios. Debido a la influencia que tiene el valor percibido sobre la satisfacción del usuario externo del sector sanitario y la repercusión de ésta sobre la lealtad electrónica, es esencial conseguir que gran parte de la población utilice los servicios sanitarios basados en las TIC y asegure la e-lealtad del uso de los mismos en la mayoría de los ciudadanos. Ante las crecientes expectativas de los usuarios externos (pacientes, cuidadores, etc) del sector sanitario ante las nuevas prácticas ofrecidas por dicho sector, los responsables sanitarios deben de llevar a cabo una serie de medidas que favorezcan el uso repetitivo de los servicios sanitarios online para hacer posible la fidelización de los usuarios hacia el uso de estos nuevos servicios online. 
Por un lado, estas medidas deben ir dirigidas a publicitar los servicios sanitarios online basados en las TIC entre los usuarios externos, esta publicidad debe ser exacta y completa para que los usuarios conozcan de manera clara y concisa los nuevos servicios ofrecidos por el sector sanitario. Por otro lado, los responsables sanitarios deben hacer hincapié en la facilidad de uso de los servicios online ofrecidos por el sector sanitario y del tratamiento personalizado que supone el uso de dichos servicios. Estas políticas podrían suponer un incremento del valor percibido de los usuarios externos que implicaría un incremento de la satisfacción de los mismos al percibir que sus necesidades personales y la necesidad de utilizar los servicios sanitarios sin necesidad de acudir a los centros físicamente, se cumplen de manera satisfactoria utilizando las TIC.

Finalmente, al incrementarse la satisfacción del usuario externo, se podría producir un uso sucesivo y continuo de los servicios sanitarios online que repercutiría sobre la e-lealtad hacia el uso de los mismos en la mayoría de los ciudadanos. De ahí que la e-lealtad sea fundamental para que los usuarios externos reconozcan el éxito de los servicios sanitarios online a través del uso de las TIC.

\section{LIMITACIONES Y LÍNEAS FUTURAS DE INVESTIGACIÓN}

En esta investigación se confirma la existencia de algunas limitaciones. La revisión bibliográfica que hemos realizado en el capítulo primero, nos indica que la 
mayoría de publicaciones realizadas se han centrado en la implantación de los servicios sanitarios desde la óptica de la "administración" y los estudios comparativos a nivel de usuario e institución carecen de resultados concluyentes. Además, los pocos estudios existentes de la implantación de los servicios sanitarios electrónicos, aportan una información incompleta, puesto que no contemplan estados avanzados de e-servicios, no miden la adopción de estos e-servicios por parte de los usuarios y no contemplan las herramientas tecnológicas.

A continuación se resaltan algunas de las limitaciones de este trabajo.

En primer lugar, la primera limitación surge ante la falta de generalización geográfica de los resultados, ya que el objeto de nuestra población se ha centrado únicamente en el sureste de España, concretamente en la Región de Murcia. Por tanto, hay que tener precaución a la hora de generalizar los resultados a otras áreas geográficas.

Una segunda limitación parte de la ausencia de análisis de otra serie de variables potenciales que de algún u otro modo podrían afectar a los resultados obtenidos en nuestro análisis empírico. En este estudio se han analizado variables tales como la capacidad innovativa, la autoeficacia, la accesibilidad y la seguridad como variables externas y como antecedentes al valor percibido. La variable de valor percibido se considera como una variable de respuesta cognitiva que refleja las creencias y percepciones de los usuarios externos del sector sanitario. Por otro lado se han considerado variables como la satisfacción, de carácter afectivo, ya que representa el grado en que una persona percibe el uso de los servicios online como necesario para el 
desarrollo de una serie de tareas específicas y la e-lealtad como variable conductual que implica el uso repetitivo de los servicios online.

Sin embargo, no se han considerado otras variables de carácter cognitivo, afectivo o de respuesta de comportamiento, que sí que se recogen en los modelos previos de aceptación de la tecnología. Por eso, a raíz del modelo presentado, nos planteamos como futuras líneas de trabajo, analizar diferentes formas de integración del conocimiento del usuario en la infraestructura de TIC sanitarias.

Esto nos lleva al planteamiento de nuevas líneas de investigación. En futuros estudios se podría proceder a la extensión de nuestro modelo incorporando otras variables que supondrían nuevas aportaciones prácticas al modelo que tendrían en cuenta variables externas como la influencia social o la resistencia al cambio, de carácter cognitivo, como la percepción de facilidad de uso o la percepción de la calidad de la información y de carácter afectivo (como la actitud), siguiendo la estructura del modelo propuesto en esta investigación y que se plantea en la figura 33.

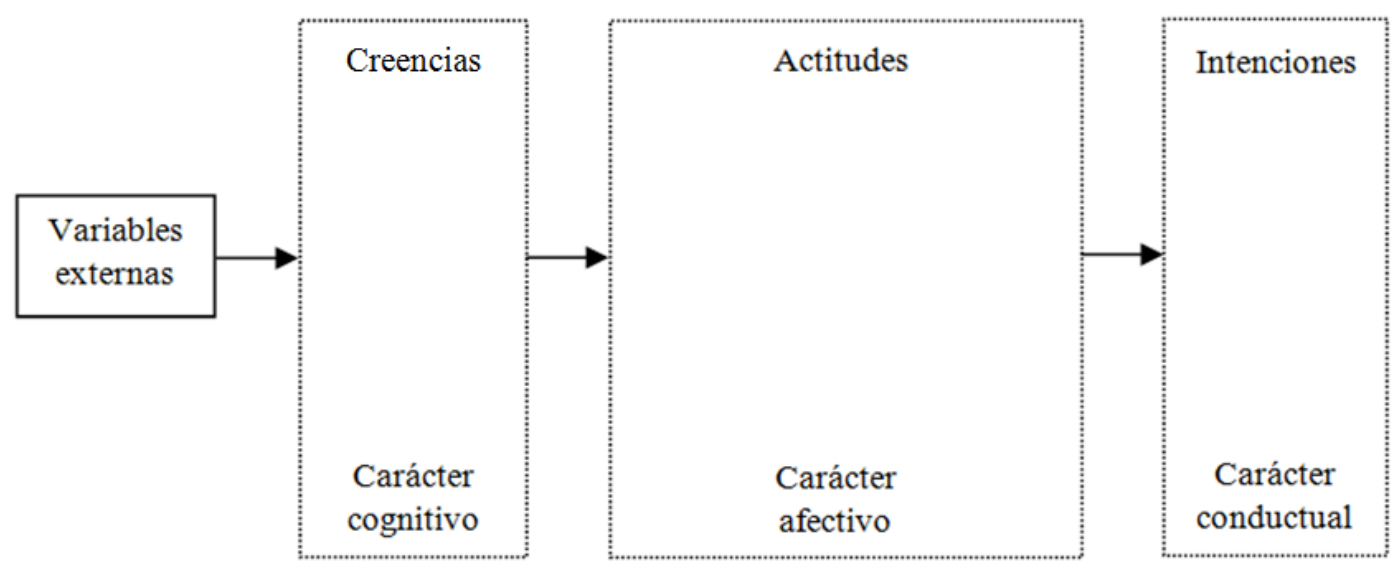

Figura 33. Esquema planteado para líneas futuras de investigación (Elaboración Propia) 
Finalmente, las futuras investigaciones podrían centrarse en otros sectores diferentes al sanitario, con otras características y otro tipo de usuarios. Estaríamos haciendo referencia a sectores como las telecomunicaciones o la banca cuyas actividades se desarrollan principalmente a través de un gran número de servicios electrónicos que son utilizados de forma más frecuente por los usuarios.

\section{APORTACIONES DE LA INVESTIGACIÓN}

\section{ARTÍCULOS PUBLICADOS}

Martinez-Caro, E.; Cegarra-Navarro, J.G.; Solano-Lorente, M. (en prensa): Understanding patient e-loyalty towards online health care services. Health Care Management Review (JCR: 1.721).

Solano-Lorente, M.; Martinez-Caro, E.; Cegarra-Navarro, J.G. (en prensa): The Role of eLoyalty in Online Healthcare Services Success. Electronic Journal of Knowledge Management (EBSCO database). 


\section{CAPÍTULOS DE LIBROS}

Solano-Lorente, M. (2010). El paciente y las Tecnologías de la Información y la Comunicación en el Sector Sanitario. En Apezetxea Celaya, A. et al. (coords.): "Dirección estratégica del conocimiento en unidades de hospitalización a domicilio: La escalera hacia el éxito". DM, Murcia.

Cegarra-Navarro, J.G.; Martínez Caro, E.; Solano-Lorente, M. (en prensa): An extension of the technology acceptance model in hospital-in-the-home units. En Miranda, I.M y Cruz-Cunha, M.M. (eds.): "Handbook of Research on ICTs for Healthcare and Social Services: Developments and Applications”. IGI Global, USA.

Martínez Caro, E.; Cegarra-Navarro, J.G.; Solano-Lorente, M. (2012): e-Loyalty towards ICT-based healthcare services: a patients' perspective. En Sethi, S.P. et al. (eds.): "Industrial Engineering: Innovative Networks". Springer, London.

\section{CONGRESOS}

Solano-Lorente, M.; Martinez-Caro, E.; Cegarra-Navarro, J.G. (2011): e-Loyalty Towards ICT-Based Healthcare Services. A Patients' Perspective. 5th International Conference of Industrial Engineering and Industrial Management, CIO 2011, Cartagena, September 7-9, 2011. 
Solano-Lorente, M.; Martinez-Caro, E.; Cegarra-Navarro, J.G. (2012): Assessing Online Health Care Services Success. International Conference on Organizational Learning, Knowledge and Capabilities, OLKC 2012, Valencia, April 25-27, 2012.

Solano-Lorente, M.; Martinez-Caro, E.; Cegarra-Navarro, J.G. (2012): The Role of eLoyalty in Online Health Care Services Success. 13th European Conference on Knowledge Management, ECKM 2012, Cartagena, September 6-7, 2012. 




\section{REFERENCIAS BIBLIOGRÁFICAS}

Ackerman, M. S., (2000). The Intellectual Challenge of CSCW: The Gap Between Social Requirements and Technical Feasibility. Human-Computer Interaction, 15, 179203.

Adams, D. A., Nelson, R. y Todd, A., (1992). Perceived usefulness, ease of use, and usage of information. MIS Q., 16, 227-47.

Adamson, I. y Shine, J., (2003). Extending the new technology acceptance model to measure the end user information systems satisfaction in a mandatory environment: A bank's treasury. Technol. Anal. Strat. Manage, 15(4), 441-55.

Agarwal, R., (2000). Individual Acceptance of Information Technologies. En: $R$. Zmud \& M. Price (eds.). Framing the Domains of IT Managment: Projecting the Future Through the Past, 464-76. Washington D. C.: Pinnaflex Educational Resources.

Agarwal, S.K., Kester, M.B., Debelenko, L.V., Heppner C., Emmert-Buck, M.R., Skarulis, M.C., Doppman, J.L., Kim, Y.S., Lubensky, I.A. y Zhuang, Z., (1997). Mutaciones de línea germinal del gen MEN1 en familiares neoplasia endocrina múltiple tipo 1 y los estados relacionados. Hum. Mol. Genet., 6, 1169-1175.

Agarwal, R. y Prasad, J., (1998). A conceptual and operational definition of personal innovativeness in the domain of information technology. Inf. Syst. Res., 9, $204-15$. 
Agarwal, R. y Prasad, J., (1999). Are individual differences germane to the acceptance of new information technologies? Decis Sci, 30, 361 -91.

Aggelidis, V. P. y Chatzoglou, P. D., (2009). Using a modified technology acceptance model in hospitals. International Journal of Medical Informatics, 78, 115126.

Aja, L., (2002). Gestión de información, gestión del conocimiento y gestión de la calidad en las organizaciones.

Disponible: http://bvs.sld.cu/revistas/aci/vol10_5_02/aci04502.htm.

Ajzen, I., (1985). From intentions to actions: A theory of planned behavior. In $J$. Kuhl, \& J. Beckmann (Eds.), Action control: From cognition to behavior. New York. Springer Verlag., $11-39$.

Ajzen, I., (1989). Attitude structure and behavior. In Attitudes Structure and Function (Edited by Pratkanis AR, Breckler SJ and Greenwald AG). Erlbaum, Hillsdale, N.J., 241-274.

Ajzen, I., (1991). The theory of planned behaviour. Organizational Behaviour and Human Decision Processes, 50, 179-211.

Ajzen, I. y Driver, B.L., (1992). Application of the Theory of Planned Behavior to Leisure Choice, Journal of Leisure Research, 24 (3), 207-224.

Ajzen, I. y Fishbein, M., (1975). Undestanding attitudes and predicting social behavior. New Jersey, Prentice-Hall. 
Ajzen, I. y Madden, T. J., (1986). Prediction of goal-directed behavior from attitudinal and normative variables. J. Experiment social psychology, 22, 453-474.

Alagheband, P., (2006). Adoption of electronic banking services by Iranian customers. Master Thesis, University of Technology, Sweden, Lulea.

Al-Gahtani, S. S. y King, M., (1999). Attitudes, satisfaction and usage: Factors contributing to each in the acceptance of information technology. Behaviour and Information Technology, 18 (4), 277-297.

Almogbil, A., (2005). Security, Perceptions, and Practices: challenges facing Adoption of Online Banking in Saudi. Unpublished Ph.D. Thesis, George Washington University, Washington.

Al-Somali, S.A., Gholami, R. y Clegg, B., (2009). An investigation into the acceptance of online banking in Saudi Arabia. Technovation, 29, 130-141.

Amador, L., (2004). Las tecnologías de la información y la comunicación y la formación en entornos virtuales. Revista Complutense de Educación, 15 (1), 51-74 ISSN: 1130-2496.

Amoako-Gyampah, K. y Salam, A.F., (2004). An extension of the technology acceptance model in an ERP implementation environment. Information \& Management, 41 (6), 731-745. 
Anderson, R. E. y Srinivasan, S. S., (2003). E-satisfaction and e-loyalty: a contingency framework. Psychology and marketing, 20 (2), 123-138. Publised online in Wiley InterScience (www.interscience.wiley.com).

Applegate, L. M., McFarlan, F. W. y McKenney, J. L., (1999). La información corporativa de texto y sistemas de gestión de casos, Irwin / McGraw-Hill,EE.UU., 5 Edn.

Arias, Y., (2007). Sistemas de gestión del conocimiento. Estado del arte. s. d.

Arjonilla, S.J. y Medina, J.A., (2002). La Gestión de los Sistemas de Información en la Empresa. Ed. Pirámide.

Arteche, G. y Rozas, W., (1999). Conocimiento Estratégico: Crear Valor con la Gestión del Conocimiento. Harvard Deusto Business Review, 91, 72-81.

Assasel, H., (1992). Consumer behavior and marketing action. Boston, MA: PWSKENT Publishing company.

Bagchi, S., Kanungo, S., y Dasgupta, S., (2003). Definición de modelos de sistemas de planificación de recursos empresariales: un estudio analítico camino. Revista Europea de Sistemas de Información, 12, 142-158.

Bahtt, G. D., (2000). Organizing Knowledge in the Knowledge Development Cycle. Journal of Knowledge Management, 4 (1), 15-26.

Bailey, J.E. y Pearson, S.W., (1983). Development of a tool for measuring and analyzing computer user satisfaction. Management Science, 29 (5), 530-545. 
Balas, E., Boren, A. y Boren, S., (2000). Managing clinical knowledge for health care improvement. Yearbook of Medical Informatics, National Library of Medicine, Bethesda, MD.

Balbón, M. A. y Fernández, N. M., (2006). Gestión del conocimiento. Parte II. Modelo de gestión por procesos. ACIMED, 14 (1). Disponible en: http://bvs.sld.cu/revistas/aci/ vol14_3_06/ aci05306.htm.

Baldwin, L.P., Clarke, M., Eldabi, T. y Jones, R.W., (2002). Telemedicine and its roles in improving communication in healthcare. Logistics Information Management, 15 (4), 309-319.

Bandura, A. (1977). Self-efficacy: toward a unifying theory of behavioural change. Psychological Review, 84 (2), 191-215.

Bandura, A., (1982). Self-efficacy mechanism in human agency. American Psychologist, 37 (2), 122-147.

Bandura, A., (1986). Social Foundations of Though and Action. Prentice-Hall, Englewood Cliffs, NJ.

Bañegil, T. y Sanguino, R., (2008). La estrategia basada en el conocimiento en el ámbito territorial. Revisión teórica. Pensamiento and Gestión, 25, 58-77. Universidad del Norte.

Bapuji, H. y Crossan, M., (2004). From questions to answers: Reviewing organizational learning research. Management Learning, 35 (4), 397-417. 
Beck, L., y Ajzen, I., (1991). Predicting dishonest actions using the theory of planned behavior. Journal of Research in personality, 25 (3), 285-301.

Bedard, A.C., Ickowicz, A., Logan, G.D., Hogg-Johnson, S., Schachar, R. y Tannock, R., (2003). Selective inhibition in children with attention-deficit hyperactivity disorder off and on stimulant medication. J Abnorm Child Psychol 31, 315-327.

Belsley, D., (1991). Conditional diagnostics: collinearity and weak data in regression. Wiley Series in Probability. John Wiley, New York.

Benamati, J.S. y Lederer, A., (2001). How IT Organizations Handle Rapid IT Change: Five Coping Mechanisms. Information Technology and Management, 2 (2), 95-112.

Benjamin, R. y Levinson, E., (1993). A Framework for Managing IT- Enabled Change. Sloan Management Review, 23-33.

Berenguer, J. y Ramos, J., (2003). Negocios digitales: competir utilizando Tecnologías de Información. Navarra, España: Universidad de Navarra (EDUNSA).

Berrocal, F. y Pereda, S., (2008). El Entorno Empresarial. Revista Computense de Educación, 25 (1), 15-35.

Berwick, D. M., (2003). Disseminating innovations in health care. Journal of the American Medical Association, 289 (15), 1969-1975

Bhatnagar, A., Misra, S., y Rao, H. R., (2000). On risk, convenience, and Internet shopping behavior. Communications of the ACM, 43 (11), 98-105. 
Bhatt, G., Gupta, J. N. D. y Kitchens, F., (2005). An exploratory study for groupware use in the knowledge management process. Journal of Enterprise Information Management, 18 (1), 28-46.

Bhattacherjee, A., (2001a). Understanding information systems continuance: An expectation-confirmation model. MIS Quarterly, 25 (3), 351-370.

Bhattacherjee, A., (2001b). An empirical analysis of the antecedents of electronic commerce service continuance. Decision Support Systems, 32 (2), 201-214.

Bhattacherjee, A., (2002). Individual trust in online firms: Scale development and initial test. Journal of Management Information Systems, 19 (1), 211-241.

Bitner, M. J., Ostrom, A. L. y Meuter, M. L., (2002). Implementing successful self-service technologies. Academy of Management Executive, 16 (4), 96-109.

Bobbitt, L. M., y Dabholkar, P. A., (2001). Integrating attitudinal theories to understand and predict use of technology-based self-service. International Journal of Service Industry Management, 12(5), 423-450.

Bontis, N. y Serenko, A., (2009). A Follow-up Ranking of Academic Journals. Journal of Knowledge Management, 13 (1), 16-26.

Brakensiek, J.C., (2002). Knowledge management for EHS professionals. Occupational Health and Safety, 71 (1), 72-74.

Bravo, R., (2002). La gestión del conocimiento en medicina: a la búsqueda de la información perdida. Anales. Sin San Navarra, 25 (3), 255-272. 
Brenix, S., (2003). En el Camino Hacia la Manufactura Guiada por la Demanda. Estrategia para Sobrevivir en el e-business. Contacto de Unión Empresarial, México.

Broadbent, M. y Lofgren, H., (1993). Information Delivery: Identifying Priorities, Performance, and Value. Information Processing and Management, 29 (6), 683-703.

Brown, G. H., (1952). Brand loyalty - fact o fiction? Advertising Age, 23 (June 9), $53-55$.

Bueno, E., (2002). Enfoques principales y tendencias en dirección del conocimiento. En: Gestión del conocimiento: desarrollos teóricos y aplicaciones. Ed. Ediciones La Coria, Cáceres,España. p. 23.

Buniyamin, N. y Barber, K. D., (2004). The Intranet: A Platform for Knowledge Management System Based on Knowledge Mapping. International Journal of Technology Management, 28 (7/8), 729- 746.

Burke, R.R., (2002). Technology and the customer interface: what consumers want in the physical and virtual store? Journal of the Academy of Marketing Science, 30 (4), 411-432.

Burkhardt, M. y Brass, D. J., (1990). Changing patterns or patterns of change: the effects of a change in technology on social network structure and power. Admin. Sei. $Q$. $35,104-127$. 
Byosiere, P., (1999). Fusión y difusión de las esferas de conocimiento en el ámbito regional, en las Sociedades del Conocimiento. Editado por Clúster del Conocimiento, Zamudio, 81-86.

Caballero, A., (2010). Propuestas de solución para los problemas educativos de hoy. Revista Electrónica Universitaria de Formación del Profesorado, 13 (4), 53-65.

Cagliani, R., Bresolin, N., Prelle, A., Gallanti, A., Fortunato, F., Sironi, M., Ciscato, P., Fagiolari, G., Bonato, S. y Galbiati, S., (2003). Una microdeleción CAV3 afecta diferencialmente el músculo esquelético y el miocardio. Neurología, 61, 1513 1519.

Cannon, L., (1984). Customer oriented technological future for library systems. Working Paper 8405, University of Stirling.

Caraballo, Y., Mesa, D. Y. y Herrera, J. A., (2009). Herramientas de gestión del conocimiento: convergencia hacia un aprendizaje organizacional. Revista cubana de ciencia agrícola, 43 (1).

Cea, M. A., (2001). Metodología Cuantitativa. Estrategia y Técnica de Investigación Social. Madrid: Síntesis de Sociología.

Cegarra, J. G., (2005). Linking Exploration with Exploitation Though Relationship Memory. Journal of Small Business Management, forthcoming. 
Cegarra, J. G. y Dewhurst, F. W., (2005). Linking e-business with Business Performance Through Knowledge Management. 5th European Conference Academy of Management, Munich (German), May 04-07.

Cegarra, J. G., Dewhurst, F. W. y Briones, A. J., (2007). Factors affecting the use of e-goverment in the telecommunications industry of Spain. Technovation, 27 (10), $595-604$.

Cegarra, J. G., Jiménez, D., Martínez, E., (2007). Implementing E-business through Organizational Learning: An empirical Investigation in SMEs. International Journal.

Cegarra, J. G. y Sabater, R., (2005a). E-learning: Organizational Requirements for Successful Feedback Learning. Journal of Workplace Learning, 17 (5/6), 276-290.

Cegarra, J. G. y Sabater, R., (2005b). Technological Strategies: Influences of Exploration and Exploitation on Relational Capital. International Journal of Management Concepts and Philosophy, 1 (2), 99-114.

Cegarra, J. G., Sánchez, M. M. y Díaz, L., (2006). Linking organizational learning with organizational unlearning by an ambidexterity context. XVI Congreso de la Asociación Científica de Economía y Dirección de la Empresa (ACEDE). Valencia. España.

Cepeda, G., Cegarra, J. G., Salmador, M. P. y Martínez, E., (2010). El desarrollo de programas de gestión del conocimiento. Las unidades de hospitalización a domicilio. Economía Industrial, N 378, 127-134. ISSN 0422-2784. 
Chau, P., y Hu, J.H., (2002). Investigating healthcare professionals’ decisions to accept telemedicine technology: An empirical test of competing theories. Information and Management, 39 (4), 297-311.

Chau, P. y Lai, V., (2003). An empirical investigation of the determinants of user acceptance of Internet Banking. Journal of organizational computing and electronic commerce, 13 (2), 123-145.

Chen, I., Yang, K., Tang, F., Huang, C. y Yu, S., (2008). Applying the technology acceptance model to explore public health nurses' intentions towards web-based learning: A cross-sectional questionnaire survey. International Journal of Nursing Studies, 45, 869-878.

Cheney, P, H. y Nelson, R. R., (1988). A Tool for Measuring and Analyzing Enduser Computing Abilities, Infonvation Processing and Management, 199-203.

Chiasson, M. y Lovato, C., (2001). Factores que influyen en la formación de las Percepciones del usuario y el uso de una innovación en el software DSS. En: Base de datos: Avances en Sistemas de Información, 32 (3), 16-35.

Chiavenato I., (1999). Administración de recursos humanos. México DF: Mc Graw-Hill Interamericana.

Chiu, C., Hsu, M., Sunb, S., Lin, T. y Sun, P., (2005). Usability, quality, value and e-learning continuance decisions. Computers and Education, 45 (4), 399-416. 
Choo, W., (1996). La organización inteligente: movilización de los conocimientos de la organización a través de la creación de alianzas de información. In The intelligent organizations: mobilizing organizacional knowledge through information partnerships. Toronto. University of Toronto, Faculty of Information Studies Disponible en http://128/.100.159.139/FIS/ResPub/IMIOart.html.

Clemmons, E. K. y McFarlan, F. W., (1986). Telecom: Hook up or lose out. Harvard Business Review, 64 (4) 91-97.

Colombo, M. y Delmastro, M., (2001). Technology-Based Entrepreneurs: Does Internet Make a Difference? Small Business Economics.

Compeau, D. R. y Higgins, C. A., (1991). A social cognitive theory perspective on individual reactions to computing technology. In Proceedings of the Twelfth International Conference on Information Systems (Edited by Gross JI, Benbasat I, DeSanctis G and Beath CM), New York, 187-198.

Compeau, D. R. y Higgins, C. A., (1995). Computer self-efficacy: development of a measure and initial test. MIS Quarterly, 19 (2), 189-211.

Compeau, D. R.y Higgins, C. A., (1996) Application of social cognitive theory to training for computer skills. Inform. Syst. Res. In press.

Compeau, D. R., Higgins, C. A., y Huff, S., (1999). Social Cognitive Theory and Individual Reactions to Computing Technology: A Longitudinal Study, MIS Quarteriy, $23(2), 145-158$ 
Conner R. y Rumelt P., (1991). Software privacy: an analysis of protection strategies. Manage Sci, 37, 125-139.

Córdoba, J. y Cegarra, J. G., (2010). Developing e-government services to small and médium enterpreises (SMEs): Beyond e-procurement. In Systems thinking and eparticipations. (editado por Dr. Córdoba Pachón). Idea Group Publising. Hershey (Pensilvania, Estados Unidos) ISBN: 978-1-60566-860-4. 154-172.

Correa J., (2009). Medición de las competencias investigativas en docentes de fisiología: una aproximación empírica. Revista Facultad Medicina Universidad Nacional Colombia, 57 (3), 205-217.

Cragg, P. B. y Zinatelli, N., (1995). La evolución de los sistemas de información en las empresas pequeñas. Información y Gestión, 29 (1), 1-8.

Culnan, M. J., (1984). The dimensions of accessibility to online information: Implications for implementing office information systems. ACM Transactions on Office Information Systems, 2, 141-150.

Cummings, J. N., (2004). Work Groups, Structural Diversity, and Knowledge Sharing in a Global Organization. Management Science, 50 (3), 352-264.

Damanpour, F., (1987). Adoption of technological, administrative and ancillary innovation: Impact of Organizational Factors. Journal of Management, 3 (4), 675-688.

Daniel, E., (1999). Provision of electronic banking in the UK and the Republic of Ireland. International Journal of Bank Marketing 17 (2), 72-82. 
Davenport, T. H. y Glaser, J., (2002). Just-in Time Delivery Comes to Knowledge management. Harv. Bus. Rev., 80, 107-111.

Davenport, T. H. y Grover, V., (2001). General perspectives on knowledge management: Fostering a research agenda. Journal of Management Information Systems, $18(1), 5$.

Davenport, T. y Prusak, L., (1998). Working Knowledge. How Organizations Manage what they Know. Harvard Business Scholl Press. Boston.

Davenport, T. H., y Short, J. E., (1990). La Ingeniería en la Industria: Tecnologías de la Información y Rediseño de Procesos de Negocio, Sloan. Management Review, 31.

Davis, F. D., (1986). A technology acceptance model for empirically testing new end-user information systems: Theory and results. Doctoral dissertation, Sloan School of Management, Massachusetts Institute of Technology, Cambridge, Massachusetts.

Davis, F. D., (1989). Perceived usefulness, perceived ease of use, and user acceptance of information technology. MIS Quarterly, 13 (3), 319-340.

Davis, F. D., (1993). User acceptance of information technology: system characteristics, user perceptions and behavioural impacts. International Journal of Man - Machine Studies, 38, 475-487.

Davis, F. D., Bagozzi, R. P. y Warshaw, P. R., (1989). User Acceptance of Computer Technology: a comparasion of two theoretical model. Management Science, 35, 982-1003. 
Davis, F. D., Bagozzi, R. P. y Warshaw, P. R., (1992). Extrinsic and intrinsic motivation to use computers in the workplace. Journal of Applied Social Psychology 22 (14), 1111-1132.

Day, G., (1969). A two-dimensional concept of brand loyalty. Journal of Marketing Research, 9, 29-36.

De León, G., (2009). Las empresas multinacionales y la economía mundial. Anuario Jurídico y Económico Escurialense, XLII. 339-352. ISSN: 1133-3677.

De Marco, M. A., Vessoni, A. L., Capelo, A. y Dias, C. C., (2010). Laboratório de comunicação: ampliando las habilidades do estudante de medicina para a prática da entrevista. Interface Comun Saúde Educ., 14 (32), 217-227.

Deci, E. L., (1975). Intrinsic Motivation. Plenum Press, New York.

Deci, E. L. y Ryan, R. M., (1985). Intrinsic motivation and self-determination in human behaviour. New York: Plenum Press.

DeLone, W. H. y McLean, E. R., (1992). Information systems success: the quest for dependent variable. Information Systems Research, 3 (1), 60-95.

Demsetz, H., (1991). The Theory of the Firm Revisited. Williamson y Winter (eds). The Nature of the Firm. Oxford University Press. Nueva York, 159-178.

Denning, S., (2000). The Springboard: How Storytelling Ignites Action in Knowledge Era Organizations. Butterworth Heinemann, Boston, London. 
Desouza, K. C., Awazu, Y., y Wan, Y., (2005). Factors governing the consumption of explicit knowledge. Journal of the American Society for Information Science and Technology, 57(1), 36-43.

Devaraj, S., Dasu, M. R. y Rockwood, J., (2008). Increased toll-like receptor (TLR) 2 and TLR4 expression in monocytes from patients with type 1 diabetes: further evidence of a proinflammatory state. J. Clin Endocrinol Metab, 93, 578-583.

Devaraj, S., Fan M. y Kohli, R., (2002). Antecedents of B2C channel satisfaction and preference: validating e-commerce metrics. Information Systems Research 13 (3), $316-333$.

Dillon, B., (2002). Las TIC, la formación por vía electrónica y el desarrollo local. Revista Europea de Formación Profesional, 27, 64-69. ISSN 0258-7483.

Ditzel, B., (2005). Desarrollo de un Modelo de Gestión del Conocimiento para un Departamento universitario. 158 [on line]. Biblioteca de Gestión del Conocimiento.

Dixon, J., Hellin, J., Erenstein, O. y Kosina, P., (2007). U-impact pathway for diagnosis and impact assessment of crop improvement. Journal of Agricultural Sci. 145 (3), 195-206.

Doll, W.J., y Torkzadeh, G., (1988). The measurement of end user computing satisfaction. MIS Quarterly, 12 (2), 259-274. 
Durán, P., (2008). Costes y beneficios de los sistemas informáticos de salud. Unidad de informática médica. Hospital Clínic. Barcelona. España. Artículo especial. JANO N 1689. www.jano.es.

Dwivedi, A., Bali, R. K., James, A. E., Naguib, R. N. G. y Johnston D., (2002). Merger of knowledge management and information technology in healthcare: opportunities and challenges. Proceedings of the 2002. IEEE Canadian Conference on Electrical and Computer Engineering.

Eagly, A. H. y Chaiken S., (1993). The Psychology of Attitudes. Harcourt, Brace Jovanovich, Fort Worth, TX.

Eastin, M., (2002). Diffusion of e-commerce: an analysis of the adoption of four e-commerce activities. Telematics and Informatics, 19 (3), 251-267.

Eastin, M. A. y LaRose, R. L., (2000). Internet self-efficacy and the psychology of the digital divide. Journal of Computer Mediated Communication, 6 (1) Available at http://www.ascusc.org/jemc/vol6/issue1/eastin.html.

Echebarría, A., (1991). Psicología Sociocognitiva. Bilbao: Desclee de Brower; 1991.

Echebarría, A. y Valencia, J. F., (1994). Private self-consciousness as moderator of the importance of attitude and subjective norm: The prediction of voting. Eur $J$ Soc Psychol, 24, 285-93. 
Edvinsson, L. y Malone, M. S., (1997). Intellectual Capital: Realizing your Company’s True Value by Finding its Hidden Brainpower. New York: Harper Collins.

Edvinsson, L. y Malone, M. S., (1999). El capital intelectual, Gestión 2000. Barcelona.

Ellen, P.S., Bearden, W.O. y Sharma, S., (1991). Resistance to technological innovations: an examination of the role of self-efficacy and performance satisfaction. J.Acad. Mktg Sci., 19, 297-307.

Faramarz, D., (2001). E-business e-commerce Evolution: Perspective and Strategy. Managerial Finance, Patrington, 27 (7), 16-18.

Fiddler, L., (2000). Facilitators and Impediments to the Internal Transfer of TeamEmbodied Competences in Firms Operating in Dynamic Environments. (Tesis Doctoral, Boston University). Proquest Dissertation Abstract.

Fishbein, M., y Ajzen, I., (1967). Behavioral theory approach to the relations between beliefs about an object and the attitude toward the object, in readings in attitude theory and measurement. Martin Fishbein, ed., John Wiley and Sons, New York. 1967, 389-400.

Fishbein, M. y Ajzen, I., (1975). Belief, attitude, intention and behaviour: an introduction to theory and resarch. Addison-Wesley, Reading, M.A.

Fishbein M. y Ajzen I., (1980). Understanding attitude and predicting social behavior. Nueva Jersey, Prentice Hall. 
Flynn, L. R., Goldsmith, R. E. A., (1993). Validation of the Goldsmith and Hofacker innovativeness scale. Educ Psychol Meas, 53, 1105-16.

García, F. J., (2003). La gestión del conocimiento: aplicación a la promoción de la salud. Scire. 9 (1), 151-170.

Gareca, M., Verdugo, R., Briones, J. y Vera, A., (2007). Salud ocupacional y teletrabajo. Ciencia and Trabajo, $\mathrm{N}^{\circ} 25,85-88$.

Gargallo, A. y Pérez, J., (2009). El papel de las tecnologías de la información y la comunicación en las empresas de economía social. Revesco $N^{o}$ 97. ISSN: 1885-8031. www.ucm.es/info/revesco.

Gefen, D., (2000). E-commerce: the role of familiarity and trust. The International Journal of Management Science. 28, 725-737.

Gefen D., (2004). What makes an ERP implementation relationship worthwhile: Linking trust mechanisms and ERP usefulness. J. Manage Inform. Syst., 21 (1), 263-88.

Gefen, D., y Straub, D. W., (2000). The Relative Importance of Perceived Ease of Use in IS Adoption: A Study of E-Commerce Adoption. Journal of the Association for Information Systems, 1 (8), 1-28.

George, J., (2004). The theory of planned behavior and Internet purchasing. Emerald Group Publishing Limited. Internet Research. 14 (3), 198-212. 
Gil, I., Ruiz, M. E. y Calderón, H., (2009). La influencia de las TIC en la satisfacción del cliente en el comercio minorista. Cuad. Adm. Bogotá (Colombia), 22 (39), 59-73.

Gist, M. E., (1989) The influence of training method on self-efficacy and idea generation among managers. Pets. Psychol. 42, 787-805.

Gist, M. E., (1992). Self-efficacy: a theoretical analysis of its determinants and malleability. Acad. Mgmt Rev. 17, 183-211.

Gist, M. E., Rosen, B. y Schwoerer, C., (1989). The influence of training method and trainee age on the acquisition of computer skills. Pers. Psychol. 41, 255-265.

Go, F. M., (1998). Turismo en el Contexto de la Globalización. Papers de turismo, 23, 6-47.

Gold, A., Malhotra y Segars, A., (2001). Knowledge Management: An Organizational Capabilities Perspective. Journal of Management Information System, $18(1), 185-214$.

Gómez, B., (2006). Internet, herramienta para la internalización de la pequeña y mediana empresa en el espacio iberoamericano. Universidad Europea Miguel de Cervantes de Valladolid, España. Grupo de trabajo: Publicidad y Marketing. IX Congreso IBERCOM. 
González, M. V., (2010). Algunas observaciones sobre los sistemas y herramientas para la gestión del conocimiento. Revista General de Información y Documentación, 20, 189-201. ISSN: 1132-1873.

González, R., Osuna, I., Zulueta, A., Faife, B., Peña, R. y Milhet, A. B., (2010). Propuesta de una guía de autoevaluación para programas de posgrado. Rev Cubana Cir [Internet], 49 (1). $\quad$ [aprox. $4 \quad$ p.]. Disponible en: http://scielo.sld.cu/scielo.php?script=sci_arttext\&pid=S003474932010000100013\&lng= es\&nrm=iso\&tlng=es.

Goodhue, D. L. y Straub, D. W., (1991). Security Concerns of System Users: A Study of Perceptions of the Adequacy of Security Measures, Information and Management, 20 (1), 13-27.

Goodman, P. S. y Darr, E., (1996). Exchanging best practices through computeraided systems. The Academy of Management Executive, 10 (2), 7-20.

Gould, J. D., Boies, S. J. y Lewis, C., (1991) Making usable, useful, productivityenhancing computer applications. Commun. ACM, 34, 74-85.

Grant, R., (2001). Knowledge and organization. In Managing industrial knowledge: Creation, transfer, and utilization. I. Nonaka and D. Teece (eds), 145-169. London: Sage.

Guerra, J., (2008). La gestión del conocimiento como nueva técnica de gestión empresaral. En U. P. d. M. Cepade (ed.). Diseño e implementación de sistemas de gestión del conocimiento (pp. 30). Madrid: Cepade, Universidad Politécnico de Madrid. 
Gummerus, J., Liljander, V., Pura, M. y Van Riel, A., (2004). Customer loyalty to content-based Web sites: the case of an online health-care service. Journal of Services Marketing 18(3):175-186.

Hamel, G. y Prahalad, C. K., (1994). Competing for the Future. Harvard Business School Press, Boston.

Harrigan, K. R., (1985). Strategy Flexibility. Lexington Books. Lexington, MA.

Harrison, D. A., Mykytyn, P. P. y Riemenschneider, C. K., (1997). Executive Decisions About Adoption of Information Technology in Small Business: Theory and Empirical Tests. Information System Research, 8 (2), 171-195.

Hartwick, J. y Barki, H., (1994). Explaining the role of user participation in information systems use. Management Science, 40 (4), 440-465.

Hayashi, A., Chen, C., Ryan, T. y Wu, J., (2004). The role of social presence and moderating role of computer self efficacy in predicting the continuance usage of elearning systems. Journal of Information Systems Education, 15 (2), 139-154.

Haynes, P. J., Becherer, R. C. y Helms, M. M., (1998). Small and Mid-sized Businesses and Internet Use: Unrealized Potential? Internet Research: Electronic Networking Applications and Policy, 8 (3), 229-235.

Henderson, J. C. y Venkatraman, N., (1993). Alineamiento estratégico: aprovechando la tecnología de información para las organizaciones de Transformación, IBM Systems Journal, 32, 1. 
Heo, J. y Han, I., (2003). Performance measure of information systems (IS) in evolving computing environments: an empirical investigation. Information and Management, 40, 243-256.

Hernández, F. y Martí, Y., (2006). Conocimiento organizacional: la gestión de los recursos y el capital humano. ACIMED, 14 (1). Disponible en: http://bvs.sld.cu/revistas/aci/vol14_1_06/aci03106.htm

Hernández, B., Jiménez, J., y Martín, M. J., (2007). Aceptación empresarial de las tecnnologías de la informaicón y la comunnicación: Un Análisis Del Sector Servicios. Business Acceptance Of Information And Commnication Technologyes: An Study Of The Service Sector. Journal Of Information Systems And Technology Management, 4 (1), 03-22.

Hernández, B., Jiménez, J. y Martin, M. J., (2008). Extending the technology acceptance model to include the IT decision-maker: a study of business management software. Technovation, 28 (3), 112-121.

Hill, T., Smith, N. D. y Mann, M. F., (1986). Communicating innovations: convincing computer phobics to adopt innovative technologies. In Advances in Consumer Research (Edited by Lutz R J), 3, 419-422. Association for Consumer Research, Provo, Utah.

Hill, T., Smith, N. D. y Mann, M. F., (1987). Role of efficacy expectations in predicting the decision to use advanced technologies: the case of computers. J. Appl. Psvchol. 72, 307-313. 
Hoffman, N. y Klepper, R., (2000). Assimilating New Technologies: The Role of Organizational Culture. Information Systems Management, 17 (3), 36-42

Horgan, J. (1996). The End of Science: Facing The Limits of Knowledge in the Twilight of the Scientific Age. Ed. Addison-Wesley, Reading, Massachusetts.

Howcroft, B., Hamilton, R. y Hewer, P., (2002). Consumer attitude and the usage and adoption of home-based banking in the United Kingdom. The International Journal of Bank Marketing 20 (3), 111-121.

Hu, P.J., Chau, P. Y. K., Sheng, O. R. L. y Tam, K.Y., (1999). Examining the technology acceptance model using physician acceptance of telemedicine technology. Journal of Management Information Systems 16 (2), 91-112.

Hubert, G. P., (1991). Organizational learning: the contributing processes and the literatures. Organization Science, 2 (1), 88-115.

Hsu, M. y Chiu, C., (2004a). Internet self-efficacy and electronic service acceptance. Decision Support Systems, 38, 369-381.

Hsu, C. y Pereira, A., (2008). Internationalization and Performance: The Moderating Effects of Organizational Learning, Omega, 36 (2), 188-205.

Igbaria, M., (1990). End-user computing effectiveness: A structural equation model. Omega, 18(6), 637-652.

Igbaria, M., (1993). User acceptance of microcomputer technology: an empirical test. OMEGA International Journal of Management Science, 21 (1), 73-90. 
Igbaria, M., Iivari, J. y Maragahh, H., (1995). Why do individuals use computer technology?: a Finnish case study. Information \& Management, 29 (5), 227-238.

Igbaria, M., Pavri, F. N. y Huff, S. L., (1989). Microcomputer applications: an empirical look at usaget. Information and Management, 16 (4), 187-196.

Igbaria, M. y Tan M., (1997). The consequences of information technology acceptance on subsequent individual performance. Information \& Management, 32, 113-121.

Ives, B., Olson, M. H. y Baroudi, J. J., (1983). The measurement of user information satisfaction. Communications of the ACM, 26 (10), 785-793.

Jacoby, J., (1971). Brand loyalty: a conceptual definition. In Proceedings of the American Psychological Association, 6, 655-656. Washington, DC: American Psychological Association.

Jacoby, J. y Chestnut, R., (1978). Brand loyalty: measurement and management. New York: John Wiley and Sons, Inc.

Jae-Nam, L. y Young-Gul, K., (2005). Understanding outsourcing partnership: a comparation of three theorical perspectives. Engineering Management, 52 (1), 43-58,

Jardines, J. B., (2005). Tele-educación y tele-salud en Cuba: mucho más que desarrollo tecnológico. Acimed, 13 (4). Disponible en: http://bvs.sld.cu/revistas/aci/vol13_4_05/aci07405.htm 
Jiang, J. J., Klein, G., y Carr, C. L., (2002). Measuring information system service quality: SERVQUAL from the other side. MIS Quarterly, 26 (2), 145-166.

Jiménez, D. y Cegarra, J. G., (2007). The performance effect of organizational learning and market orientation. Industrial Marketing Management, 36, 694-708.

Johansen, R. y Swigart, R., (1996). Upsizing the individual in the downsizing organization: managing in the wake of reengineering, globalization, and overwhelming technological change. Reading, MA: Addison-Wesley.

Johnson, M. (1997). Teleworking in Brief. Butterworth-Heinemann, Oxford.

Johnston, K. y White, K., (2003). Binge-drinking: A test of the role of group norms in the Theory of Planned Behaviour. Psychology and Health, 18, 63-77.

Jones, E., Sundaram, S. y Chin, W., (2002). Factors leading to sales force automation use: A longitudinal analysis. Journal of Personal Selling and Sales Management, 22 (3), 145- 156.

Judd, C. M. y Kenny, D. A., (1981). Process analysis: Estimating mediation in treatment evaluations. Evaluation Review, 5, 602-619.

Jurison, J., (1996). The temporal nature of IS benefits: a longitudinal study. Information and Management, 30, 75-79.

Kandemir, D. y Hult, G. T. M., (2005). A conceptualization of an organizational learning culture in international joint ventures. Industrial Marketing Management, 34 (5), 430-439. 
Kang, S., Morris, S. S. y Snell, S. A., (2007). Relational archetypes, organizational learning, and value creation: Extending the human resource architecture. Academy of Management Review, 32 (1), 236-256.

Karahanna, E. y Limayem, M., (2000). E-Mail and V-Mail Usage: Generalizing Across Technologies. Journal of Organizational Computing and Electronic Commerce, $10(1), 49-66$.

Karahanna, E. y Straub, D. W., (1999). The psychological origins of perceived usefulness and ease-ofuse."Information and Management, 35, 237-250.

Keil, M., Beranek, P. M. y Konsynski, B. R., (1995). Usefulness and ease of use: Field study evidence regarding task consideration. Decision Support Systems, 13 (1), $75-91$.

Keller, K., (1993). Conceptualizing, measuring and managing customer-based brand equity. Journal of Marketing, 57, 1-22

Khalfan, A., Yaqoub, S. Y., AlRefaei, Y. y Al-Hajery, M., (2006). Factors influencing the adoption of Internet banking in Oman: a descriptive case study analysis. International Journal of Financial Services Management, 1 (2), 155-172.

Khalifa, M. y Liu, V., (2002a). Satisfaction with internet-based services: the role of expectations and desires. International Journal of Electronic Commerce, 7 (2), 3149. 
Khalifa, M. y Liu, V., (2002b). Satisfaction with internet-based services. In: Proceedings of the 35th Hawaii International Conference on System Sciences.

Kim, D. y Chang, H., (2007). Key functional characteristics in designing and operating health information websites for user satisfaction: an application of extended technology acceptance model. International Journal of Medical Informatics, 76, 790800.

King, W., (2009). Gestión del conocimiento y aprendizaje organizacional. Anales de sistemas de información, 4 (part 1) 3-13. DOI: 10.1007/978-1-4419-0011-1_1.

Klein, R., (2007). Internet-Based Patient-Physician Electronic Communication Applications: Patient Acceptance and Trust. E-Service Journal, 5 (2), 27-51.

Kleinbaum, D. G., Kupper, L. L. y Muller, K. E., (1988). Applied Regression Analysis and Other Multivariable Methods. 2nd ed., Boston: PWS-Kent Publishing Co.

Kuehn, A., (1962). Consumer brand choice as a learning process. Journal of Advertising Research, 2, 10-17.

Lai, V.S. y Li, H., (2005). Technology acceptance model for internet banking: an invariance analysis. Information \& Management 42 (2), 373-386.

Lanseng, E. J. y Andreassen, T. W., (2007). Electronic healthcare: a study of people's readiness and attitude toward performing self-diagnosis. International Journal of Service Industry Management 18,(4):394-417. 
Lee, J. y Runge, J., (2001). Adoption of Information Techonology in Small Business: Testing Drivers of Adoptions for Entrepreneurs. Journal of Computer Information System, 42 (819), 44-58.

Leidner, D. E. y Mackay, J. M., (2007). How incoming CIOs transition into their new jobs. MIS Quarterly Executive 6 (1), 17-28.

Leonard-Barton, D. y Deschamps, I., (1988). Managerial influence in the implementation of new technology. Management Science, 34, 1252-1265.

Leonard-Barton, D. y Kraus, W. A., (1985). Implementing new technology. Harvard Bus. Rev. 63, November-December, 102-110.

Leventhal, H. y Cameron, L., (1987). Behavioral theories and the problem of compliance. Patient EducCouns, 10, 117-38.

Li, Y., Tan, C.H., Teo, H.H. y Tan, B., (2006). Innovative usage of information technology in Singapore organizations: do CIO characteristics make a difference? IEEE Transactions on Engineering Management, 53 (2), 177-190.

Liebowitz, J., (2000). Building organizational intelligence: A knowledge management primer. Boca Raton, FL: CRC Press.

Limayem, M., Khalifa, M. y Frini, A., (2000). What Makes Consumers Buy From Internet? A Longitudinal Study of Online Shopping. IEEE Transactions on Systems, Man, and Cybernetics--Part A: Systems and Humans, 30 (4), 421-432. 
Lin, C. S., Wu, S. y Tsai, R. J., (2005). Integrating perceived playfulness into expectation-confirmation model for web portal context. Information \& Management, 42 (5), 683-693.

Lind, P., Sepúlveda, E. y Núñez, J., (2000). On the Applicability of a Computer Model for Business Performance Analysis in SMEs: A Case Study from Chile. Information Technology for Development, $\mathrm{N}^{\circ}$ 9, 33-44.

Lipstein, B., (1959). The dynamics of brand loyalty and brand switching. In Proceedings of the Fifth Annual Conference of the Advertising Research Foundation, 101-108, New York: Advertising Research Foundation.

Liu, C. y Arnett, K. P., (2000). Exploring the factors associated with web site success in the context of electronic commerce. Information and management. 38, 23-33.

Loane, M. y Wootton, R., (2002). A review of guidelines and standards for telemedicine. J Telemed Telecare, 8, 63-71.

Luhmann, N., (1979). Trust and Power. New York: Wiley

Luque, T., (2000). Técnicas de Análisis de Datos de Investigación de Mercados. Madrid: Pirámide.

Lynn, G. S., Morone, J. G. y Paulson, A. S., (1996). Marketing and Discontinuous Innovation: the Probe and Learn Process. California Management Review, 38, 8-37.

Maestre, P., (2000). Diccionario de Gestión del Conocimiento e Informática. Fundación DINTEL, Madrid. 
Mahmood, M. A., Burn, J. M., Gemoets, L. A. y Jacquez, C., (2000). Variables affecting information technology end-user satisfaction: a meta-analysis of the empirical literatura. International Journal of Human-Computer Studies, 52 (4), 751-771.

Malhotra, Y., (2000). Knowledge Management for E-business Performance. Information Strategy: The Executives Journal, 16 (4), 5-16.

Malhotra, Y., (2002). Why Knowledge Management Systems Fail? Enablers and Constraints of Knowledge Management in Human Enterprises. Knowledge Management 1: Knowledge Matters. Springer-Verlag, Heidelberg, Germany, 577-599.

Martin, L. M. y Matlay, H., (2001). Blanket-Approaches to Promoting IT in Small Finns: Some Lessons from the DTI Ladder Adoption Model in the UK, Internet Research: Electronic networking Applications and Policy, 11 (5), 399-410.

Martínez, A. y Hermosilla, J. M., (2010). El blog como herramienta didáctica en el espacio europeo de educación superior. Revista de Medios y Educación. № 38, 165175. ISSS: 1133-8482. Pixel- Bit.

Martínez - Torres, M. R., Toral S. L., Barrero, F., Gallardo, S., Arias, M. y Torres, T., (2008). A technology acceptance of e-learning tolos used in practical and laboratory teaching according to the European higher education area. Behaviour and Information Technology, 27 (6), 495-505.

Martocchio, J. J. y Webster, J., (1992). Effects of feedback and cognitive playfulness on performance in microcomputer software training. Pers. Psychol. 45, 553578. 
Marwick, A. D., (2001). Knowledge Management Technology. IBM Systems Journal, 40(4), 814-830.

Marymalavi, T. R., y Leidner, D. E., (2006). An empirical examination of the influence of organizational culture on knowledge management practices. Journal of Management Information System, 22 (3), 191-224.

Mata, F. J., Fuerst, W. L. y Barney, J. B., (1995). Information technology and sustained competitive advantage: a resource-based analysis. MIS Quarterly, 19 (4), $206-487$.

Mathieson, K., (1991). Predicting user intentions: comparing the technology acceptance model with the theory of planned behavior. Inf Syst Res; 2 (3), 173 - 91.

McCarrol, T., (1991). What new age? Time, 138 (12), 44-46.

McCaughan, D., Thompson, C., Cullum, N., Sheldon, T. y Thompson, D. R., (2002). Acute care nurses' percepticons of barriers to using. Research information in clinical decision-making. Journal of Advanced Nursing, 39 (1), 46-60.

McFarlan , F. W., McKenney, J. L., y Pyburn, P., (1983). El Archipiélago de la Información, trazar un curso, Harvard Business Review, 61 (1).

McGowan, M. K. y Madey, G. R., (1998). The influence of organizational structure and organizational learning factors on the extent of EDI implementation in US Firms. Information Resource Management Journal, 11 (3), 17-27. 
McKinney V., Kanghyun Y. y Zahedi, M. F., (2002). The measurement of webcustomer satisfaction: an expectation and disconfirmation approach, Information Systems Research 13 (3), 296-315.

McKnight, D. H. y Chervany, N. L., (2001). What trust means in e-commerce customer relationships: an interdisciplinary conceptual typology. International Journal of Electronic Commerce, 6 (2), 35-60.

McNurlin, B.C., y Sprague, R., (2004). De Sistemas De Gestión en la práctica, Inc. Pearson Educación,Nueva Jersey, Sexto Edn .

Mehrtens, J., Cargg, P. B. y Mills, A. M., (2001). A Model of Internet Adoption by SMEs. Information and Management, 39 (3), 165-177.

Menachemi, N., Poderes, T. y Brooks, R., (2009). El papel del uso de tecnologías de la información en la satisfacción del médico de práctica. Health Care Management Review, 34 (4), 364-371.

Midgley, D. y Dowling, G. R., (1978). Innovativeness: the concept and its measurement. J Consum Res., 4, 229- 42.

Moffett, S. y McAdam, R., (2003). International Journal of Information Technology and Management, 2 (1-2), 31-49.

Molina, F. J. y Cuestas, P. J., (2008). Las ferias comerciales y el marketing electrónico: un análisis comparativo. Ferias comerciales, enero-febrero 2008. № 840. ICE. 
Monteagudo, J. L., Hernández, C. y García, F., (2004). Metodología de introducción de servicios de e-salud para el seguimiento y control de pacientes crónicos. Rev. Esp. Salud Pública, 78 (5), 571-581.

Monteagudo, J. L., Serrano, L. y Hernández, C., (2005). La telemedicina: ¿ciencia o ficción? An. Sist. Sanit. Navar, 28 (3).

Moore, G. C. y Benbasat, I., (1991). Development of an Instrument to Measure the Perceptions of Adopting an Information Technology Innovation. Information Systems Research, 2 (3), pp. 192-222.

Moorman, C., Zaltman, G. y Deshpande, R., (1992). Relationships between providers and users of market research: the dynamics of trust within and between organizations. J. Market Res, 29 (3), 314-328.

Moreno, S., (2001). El teletrabajo en España. Expansión 23/03/2001.

Moyano, J, Puig, F. y Bruque, S., (2008). Los determinantes de la competitividad en las cooperativas. CIRIEC-España, Revista de Economía Pública, Social y Cooperativa, número 61, 233-249.

Mukherjee, A. y Nath, P., (2003). A model of trust in online relationship banking. International Journal of Bank Marketing, 21 (1), 5-15.

Myers, I. B., McCaulley, M. H., Quenk, N. L. y Hammer, A. L., (1998). MBTI manual: A guide to the development and use of the Myers-Briggs Type Indicator (3 rd ed). Palo Alto: Consulting Psychologists Press. 
Nahar, N., (2001). Information Technology Supported Technology Transfer Process: A Multi-site Case Study of High-tech Enterprise. Univesity of Jyväskylä, Jyväskylä Studies in Computing 9, Jyväskylä University Printing House, Jyväskylä and ER-Paino Dy, Jyväskylä.

Nahar, N., Kakola, T. y Huda, N., (2002). Software Production in Developing and Emerging Countries through International Outsourcing. Proceedings of the Information and Communication Technologies and Development: New Opportunities, Perspectives y Challenges, $7^{\text {th }}$ International Working Conference of IFIP WG 9.4, S. Krishna y S. Madon (Eds), Indian Institute of Management Bangalore, Bangalore, India, May 29-31, 292-310.

Nath, R., Admanligil, M., Hejelm, K., Sakaguchi, T. y Schultz, M., (1998). Electronic Commerce and the internet: Issues, Problems, and Perspectives. International Journal of Information Management, 18 (2), 91-101.

Nerkar, A., (2003). Old is Gold? The Value of Temporal Exploration in the Creation of New Knowledge. Management Science, 49 (2), 211-229.

Nevis, E.C., Dibella, A, Gould, J. y Janet, M., (1995). Understanding Organizations As learning Systems. Sloan Management Review, 36 (29), 73-85.

Nickerson, R. S., (1981). Why Interactive Computer Systems Are Sometimes Not Used by People Who Might Benefit from Them." International Journal of ManMachine Studies, 15, 469-483.

Nielsen, J., (1992). The usability engineering life cycle. Computer, 25 (3), 12-22. 
Nonaka, I., (1991). The Knowledge-Creating Company. Harvard Business Review, 69, 96-104.

Nonaka, I. y Konno, N., (1998). The Concept of Ba: Building a Foundation for Knowledge Creation. California Management Review, 40 (3), 40-54.

Nonaka, I. y Takeuchi, H., (1995). The Knowledge-creating Company. How Japanese Companies Create the Dynamics of Innovation. Oxford University Press, New York.

Nunnally, J. C., (1978). Psychometric theory. 2nd ed. New York. McGraw-Hill.

Nunnally, J. C. y Bernstein, I. H., (1994). Psychometric Theory (3ª ed.), McGrawHill, New York.

Núñez, I., (2009). Is it possible to manage the knowledge without affecting the personal affective component? ACIMED, 20 (4), 55-66

Núñez, I. A., y Núñez, Y., (2005). Propuesta de clasificación de las herramientas software para la gestión del conocimiento. ACIMED, 13 (2).

O'Cass, A. y Fenech, T. (2003). Web retailing adoption: exploring the nature of Internet users web retailing behaviour. Journal of Retailing and Consumer Services, 10, 81-94.

O`Dell, C. y Grayson, C. J., (1998). If only we Knew what we Know: Identification and Transfer of Internal Best Practices. California Management Review. 40 (3), 154-170. 
Oliver, R.L., (1980). A cognitive model for the antecedents and consequences of satisfaction. Journal of Marketing Research, 17, 460-469.

Oliver, R. L., (1999). Whence customer loyalty. Journal of Marketing, 63, 33-44.

Orozco S. E., (1998). Enfoque conceptual de la inteligencia organizacional en algunas fuentes de información. Aplicación en la industria biofarmacéutica. Ciencias de la Información, 29 (4), 35-45.

Ortiz de Urbina, M., (2003). Medición y auditoría del capital intelectual. El profesional de la información, 12, 282.

Oteo, L. A. y Repullo, J. R., (2003). La innovación en los servicios sanitarios; consideraciones desde la perspectiva del Sistema Nacional de Salud Español. Rev, Adm. Sanit, (2), 307-32

Otero, M. J., (2003). Errores de medicación y gestión de riesgos. Rev Esp Salud Pública, 77 (5), 527-540.

Papoutsakis, H. y Vallés, R., (2006). Vinculación de la Gestión del Conocimiento y la Tecnología de la Información para el rendimiento empresarial: Una revisión bibliográfica y una propuesta de modelo. Diario de Prácticas de Gestión del Conocimiento, 7 (1).

Parthasarathy, M. y Hampton, D., (1993). The role of piracy in the diffusion of a software product: a propositional framework. AMA winter educators conference proceeding. Chicago (IL): American Marketing Association. 
Pavlou, P. A., (2003). Consumer acceptance of electronic commerce: integrating trust and risk with the technology acceptance model. Int J Electron Commer, 7 (3), 10134.

Pavlou, P. A. y Fygenson, M., (2006). Understanding and predicting electronic commerce adoption: An extensión of the Theory of Planned Behavior. MIS Quarterly, $30(1), 115-143$.

Pérez, S., Montes, J. M. y Vázquez, C., (2004). Managing Knowledge: The Link between Cultura and Organizacional Learning. Journal of Knowledge Management, 8 (6), 93-104.

Picas-Vidal, J. M., (2000). Gestión del conocimiento, Informe 2000. La profesión médica en la sociedad de la información. 4-6 de Octubre. Toledo.

Pikkarainen, T., Pijjarainen, K., Karjaluoto, H. y Pahnila, S., (2004). Consumer acceptance of online banking: an extension of the technology acceptance model. Internet Research 14 (3), 24-235.

Ponsa, P. y Aranda, J., (2002). Creación de un aplicativo multimedia en robótica. XXIII Jornadas de Automática, Universidad de La Laguna, Tenerife, septiembre 2002.

Poon, S. y Joseph, M., (2000). Product Characteristics and Internet Commerce Benefit among Small Business. Journal of Product \& Brand Management, 9 (1), 21-34.

Poon, S. y Swatman, P., (1997). Small Business use of the internet. International Marketing Review, 14 (5), 385-402. 
Porter, M. E., (2001). Strategy and the Internet. Harvard Business Review, 79 (3), $62-78$.

Prahalad , C. K. y Hamel, G., (1991). La competencia central de la Corporación. Harvard Business Review, 68 (3). Edición 1990.

Quaddus, M. y Xu, J., (2005). Adoption and diffusion of knowledge management systems: field studies of factors and variables. Knowledge-Based Systems, 18, 107-115.

Qureshi, Z., (1996). La Globalización: Nuevas Oportunidades. Grandes Desafíos. Finanzas y desarrollo. Estados Unidos, 30.

Rahimpour, M., Lovell, N. H., Celler, B. G., y McCormick, J., (2008). Patients' perceptions of a home telecare system. International Journal of Medical Informatics, 77, 486-489.

Rai, A., Lang, S. S. y Welker, R. B., (2002). Assessing the validity of IS success models: an empirical test and theoretical analysis. Information Systems Research 13 (1), $50-69$.

Ravichandran, T., (2005). La asimilación de tecnologías complejas de organización: un estudio empírico de desarrollo de software basado en componentes. IEEE Technology Management Council, 52 (2), 249-268.

Reichheld, F. y Schefter, P., (2000). E-loyalty: Your Secret Weapon on the Web. Harvard Business Review, 78 (4), 105-113. 
Rivero, S., (2002). Claves y pautas para comprender e implantar la gestión del conocimiento: un modelo de referencia. Las Arenas: SOCINTEC.

Roach, S. S., (1992). Technology imperatives. Unpublished speech on the restructuring imperative. Morgan Stanley and Co. Incorporated, January 21.

Robinson, L., Marshall, G. y Stamps, M., (2005). Sales force use of technology: antecedents to technology acceptance. Journal of Business Research, 58, 1623-1631.

Roca, J. C., Chiu, C. y Martínez, F. J., (2006). Understanding e-learning continuance intention: an extension of the Technology Acceptance Model. International Journal of Human-Computer Studies 64, 683-696.

Rodríguez, J. M., (1999). La gestión del conocimiento: Una gran oportunidad. El profesional de la Información, 8 (3).

Rodríguez, I., (2002). Marketing.com y comercio electrónico en la sociedad de la información. Pirámide.

Rodríguez, C., Minguela, B. y López, J. I., (2008). Transferencia de conocimiento en la creación y en el funcionamiento de los sistemas de franquicia: Un estudio empírico. Economía Industrial, 368, 227-237.

Rogers, E. M., (1962). Diffusion of Innovations. Free Press

Rogers, E. M. y Shoemaker, F., (1971). Communication of Innovations: A CrossCultural Approach (2 ed.). New York, NY: Free Press. 
Rubin, I., (1998). Personalizing the Internet. Banking Strategies, vol. (Sept/Oct), 6-10.

Rueda-Clausen, C. E., (2006). La historia clínica informatizada. Evaluación de los casos colombiano y español. Artículo recibido: 8 de febrero de 2006; aceptado: 21 de marzo de 2006, 9 (1) - Abril de 2006.

Sadowski, B. M., Maitland, C. y Van Dongen, J., (2002). Strategic Use of the Internet by Small- and Medium- sized companies: An Exploratory Study. Information Economics and Policy, 14 (1), 75-93.

Sainz, I., (2011). Estudio del impacto económico y social de la introducción de las TIC en el sector sanitario español: Perspectiva tecnológica. Universidad Carlos III de Madrid.

Sainz, B., Rodrigues, J. J., García, E., Burón, F. J., López, M. y Castro, C., (2011). M-Health y T-Health. La Evolución natural del E-Health. RevistaeSalud.com., 7 (25). ISSN. 1698-7969.

Salazar, C., (2007). El teletrabajo como aporte a la inserción laboral de personas con discapacidad en Chile: una gran carretera virtual por recorrer. Ciencia and Trabajo, $\mathrm{N}^{\circ} 25,89-98$.

Sánchez, M. y Sarabia, F. J., (1999).Validez y fiabilidad de escalas. In Sarabia, F.J.,Metodología para la investigación en marketing y dirección de empresas. Madrid: Ediciones Pirámides, p. 333-393. 
Sanguino, R., (2003). La gestión del conocimiento. Su importancia como recurso estratégico para la organización. (En línea). 5campus.org, Marketing http://www.5campus.org/leccion/km.

Santos, M., Dante, G. y Calvo, M., (2006). Procesos estratégicos de la gestión del conocimiento. ACIMED [Internet]. 2006 [citado 11 Ene 2012]; 14(2): [aprox. 5 p.]. Disponible en: http://bvs.sld.cu/revistas/aci/vol14_2_06/aci08206.htm.

Sathye, M., (1999). Adoption of internet banking by Australian consumer: an empirical investigation. International Journal of Bank Marketing, 17 (7), 324-334.

Seddon, P. B., (1997). A respecification and extension of the DeLone and McLean model of IS success. Information Systems Research, 8 (3), 240-253.

Seddon, P. B. y Kiew, M., (1994). A partial test and development of the DeLone and McLean Model of IS success. In: Proceedings of the International Conference on Information Systems. Vancouver, Canada (ICIS 94), 99-110.

Sejin, H. y Stoel, L., (2009). Consumer e-shopping acceptance: Antecedents in a technology acceptance model. Journal of Business Research 62, 565-571

Serenko, A. y Bontis, N., (2009). Global Ranking of Knowledge Management and Intellectual Capital Academic Journals. Journal of Knowledge Management, 13 (1), 415.

Serradel, E. y Pérez, A. A., (2006). La Gestión del Conocimiento en la Nueva Economía. Disponible en: http://www.uoc.edu/dt/20133/index.html. 
Shapiro, C. y Varian, H., (1999). El Dominio de la Información. Barcelona: Antoni Bosch Editor.

Sheppard, B. H., Hartwick, J. y Warshaw, P. R., (1988). The Theory of Reasoned Action: A Meta-Analysis of Past Research with Recommendations for Modifications and Future Research. Journal of Consumer Research, 15 (3), 325-343.

Shih, Y. y Fang, K., (2004). The use of a decomposed theory of planned behavior to study Internet banking in Taiwan. Emerald Group Publishing Limited. Internet Research, 14 (3), 213-223.

Skerlavaj, M., Indihar Stemberger, M., Skrinjar, R. y Dimovski, V., (2007). Organizational Learning Culture - The Missing Link between Business Process Change and Organizational Performance. International Journal of Production Economics (in press).

Smeral, E., (1998). The Impact of Globalization on Small and Medium Enterprises: New Challenges for Tourism Policies in European Countries. Tourism Management, 19 (4), 371-380.

Soo, C., Devinney, T., Midgley, D. y Deering, A., (2002). Knowledge management: Philosophy, Process and Pitfalls. California Management Review. Summer, 44 (4), 129-150.

Spender, J., (1996). Making Knowledge the Basis of a Dinamic Theory of the Firm. Strategic Management Journal, 17, Winter Special Issue, 45-62. 
Suh, B. y Han, I., (2002). Effect of trust on customer acceptance of Internet banking. 1(1), 247-263.

Sultan, F. y Mooraj, H. A., (2001). Designing a trust-based E-business strategy. Market Manage 2001. 10 (4):40-5.

Swee, C. G., (2002). Managing effective knowledge transfer:an integrative framework and some practice implications. Journal of Knowledge Management. 6 (1), 23-30.

Tan, M. y Teo, T., (2000). Factors influencing the adoption of Internet banking," Journal of the Association for Information Systems, 1 (5), 1-44.

Tanriverdi, H., (2005). Information Technology Related-ness, Knowledge Management Capability, and Performance of Multibusiness Firms. MIS Quarterly, 29 (2), 311-334.

Taylor, S. A. y Hunter, G.L., (2002). The impact of loyalty with e-CRM software and e-services. International Journal of Service Industry Management, 13, 452-474.

Taylor, S. y Todd, P. A., (1995). Understanting information technology usage: a test of competing models. Information Systems Research, 6 (2), pp. 144-176.

Tchokogue, A., Bareil, C. y Duguay, C.R., (2005). Key lessons from the implementation of an ERP at Pratt \& Whitney Canada. International Journal of Production Economics, 95 (2), 151-163. 
Temprano, A. y Gallego, D. J., (2009). Diseño, desarrollo e implantación de un software libre para la creación de Webquest. Revista de Medios y Educación. № 34, 165-177. Pixel-Bit.

Teo, T., Lim, V. K. G. y Lai, R. Y. C., (1999). Intrinsic and extrinsic motivation in Internet usage. Omega: International Journal of Management Science, 27 (1), 25-37.

Teo, H. H., Wei, K. K. y Benbasat, I., (2003). Predicting intention to adopt interorganizational linkages: An institutional perspective. MIS Quarterly 27(1) 19 49.Tetteh, E. y Burn, J. (2001). Global Strategies for SME Business: Applying the SMALL, Framework. Logistic Information Management, 14 (1/2), 171-180.

Terry, D. J., y O'Leary, J. E., (1995). The theory of planned behaviour: The effects of perceived behavioural control and self-efficacy. British Journal of Social Psychology, 34 (2), 199-220.

Thompson, R. L., (1991). Modificación del efecto y de los límites biológicos de la inferencia a partir de datos epidemiológicos. J. Clin. Epidemiol, 44 (3), 221-232.

Thompson, C. B., (1995). Apoptosis in the pathogenesis and treatment of disease. Science, 267, 1456-1462.

Thompson, R. L., Higgins, C. A. y Howell, J. M., (1991). Personal Computing Toward a Conceptual Model of Utilization. MIS Quarterly, 15 (1), 125-143.

Traynor, M., (1999). The problem of dissemination: Evidence and Ideology. Nursing Inquiry, 6, 187-97 
Triandis, H. C., (1971). Attitude and Attitude Change. Wiley, New York.

Triandis, H. C., (1977). Interpersonal Behavior. Brooke/Cole Publishing Company, Monterey, California, U.S.A.

Triandis, H. C., (1980). Values, attitudes, and interpersonal behavior. In: H. E. Howe (Ed.), Nebraska symposium on motivation, 1979: Beliefs, attitudes, and values, 27, 195-259. Lincoln, Nebraska7 University of Nebraska Press.

Trujillo, A., (2005). Nuevas tecnologías y Psicología. Una perspective actual. Colegio Oficial de Psicología de Andalucía Occidental y Universidad de Sevilla. Apuntes de Psicología, 23 (3), 331-335.

Tsai, W., (2001). Knowledge Transfer in Intraorganizational Network Position and Absorptive Capacity on Business Unit Innovation and Performance. Academy of Management Journal, 44 (15), 996-1004.

Tulu, B., Chatterjee, S. y Maheshwari, M., (2007). Telemedicine taxonomy: a classification tool. Telemedicine and e-Health, 13 (3), 349-358.

Turoff. M., Rao, U. y Hiltz, S. R., (1991). Collaborative Hypertext in Computer Mediated Communications, Proceedings of the Twenty-Fourth Annual Hawaii International Conference on System Sciences. CA: IEEE Press.

Vallerand, R. J., (1997). Toward hierarchical model of intrinsic and extrinsic motivation. Adv. Experiment Soc. Psych, 29, 271-360. 
Van Riel, A.C.R., Liljander, V. y Jurriens, P., (2001). Exploring consumer evaluations of e-services: a portal site. International Journal of Service Industry Management, 12 (4), 359-77

Vázquez, C. L. y Hermida, M., (2012). Las competencias profesionales en la gestión de la información y del conocimiento en salud. Mediciego, 18 (2).

Venkatesh, V., (2000). Determinants of perceived ease of use: Integrating control, intrinsic motivation, and emotion into the technology acceptance model. Information Systems Research, 11 (4), pp. 342-365.

Venkatesh, V. y Davis, F. D., (1994). Modelling the determinants of perceived ease of use. Proceedings of the International Conference on Information Systems, Vancouver, 213-227.

Venkatesh, V. y Davis, F. D., (1996). A model of the antecedents of perceived ease of use: development and test. Decision Science, 27 (3), 451-481.

Venkatesh, V. y Speier, C., (1999). Computer technology training in the workplace: a longitudinal investigation of the effect of the mood. Organ. Behavior and Human Decision Processes, 79 (1), 1-28.

Venkatesh, V., Morris, M. G., Davis, G. B. y Davis F. D., (2003). User acceptance of information technology: towards a unified view. MIS Quarterly, 27 (3), 425-478. 
Venkatraman, N., (1994). Habilitado para la transformación del negocio: desde la automatización a la redefinición de negocios Ámbito de aplicación, Sloan Management Review, 35.

Vera, G., (2006). La generación de conocimiento organizacional como factor clave en el desarrollo de la capacidad de innovación: el caso de una empresa textil poblana. I Congreso Iberoamericano de Ciencia, Tecnología, Sociedad e Innovación $C T S+I$.

Vroom, V., (1964). Work and Motivation, Wiley and Sons, Inc., New York. NY.

Wager, K. A., Lee, F. W. y Glaser, J. P., (2005). Managing Health Care Information Systems: A Practical Approach for Health Care Executive. Jossey-Bass, San Francisco.

Wallis Report, (1997). The Financial System Inquiry Final Report (Chairman: Mr. Stan Wallis), AGPS, Canberra.

Wang, Y., (2007). Assessing e-commerce systems success. Information Systems Journal, 18, 529-557.

Wang, Y., (2008). Assessing e-commerce systems success: a respecification and validation of the DeLone and McLean model of IS success. Info Systems J. 18 PP529557. Journal COMPILATION.

Wang, S. J., Middleton, B., Prosser, L. A., Bardon, C. G., Spurr, C. D., Carchidi, P. J., Kittler, A. F., Goldszer, R. C., Fairchild, D. G., Sussman, A. J., Kuperman, G. J. y 
Bates, D. W., (2003). A cost-benefit analysis of electronic medical records in primary care. Amer. J. Med., 114 (5), 347-403.

Watson, J., (1999). Enfermería postmoderna y más allá de Toronto, Canadá. Churchill Livingstone.

Webster, J. y Martocchio, J. J., (1992). Microcomputer playfulness: development of a measure with workplace implications. MIS Quarterly 16 (2), 201-226.

Webster, J. y Martocchio, J. J., (1993). Turning Work into Play: Implications for Microcomputer Software Training, Joumal of Management.

Weerawardena, J., O’Cass, A. y Julian, C., (2006). Does industry matter? Examining the role of industry structure and organisational learning in innovation and brand performance. Journal of Business Research, 59, 37 - 45.

Weiermair, K., (1997). Globalización and New Forms of Tourism Management. Foro internacional de turismo de Benidorm, 2007.

Weiner, L. R., (1993). Digital woes: why we should not depend on software. Reading, MA: Addison-Wesley.

Woodruff, R. B., (1997) Customer value: the next source for competitive advantage. Journal of the Academy of Marketing Science, 25, 139-153. 
Xu, J. y Quaddus, M., (2007). Exploring the Factors Influencing en User's Acceptance of Knowledge Management Systems: Development of a research model of adoption and continued use. Journal Organizational and End-Users Computing, 19 (4), $55-79$.

Yang, Z., y Peterson, R. T., (2004). Customer perceived value, satisfaction, and loyalty: The role of switching costs. Psychology \& Marketing, 21, 799-822.

Yang, H., Yang, H., Huang, F. F. y Yao, K., (2009). Structural Hole and Personal innovativeness in a Bureau of Health. Advances in Social Network Analysis and Mining. IEEE Computer Society.

Yang, H., Yu, J., y Yang, H., (2009). E-health service in Taiwan. The role of organizational innovativeness. Mastorakis et al. (eds.). Proceedings of the European Computing Conference. Chapter 71.

Yen, J. R. y Gwinner, K. P., (2003). Internet retail customer loyalty: the mediating role of relational benefits. International Journal of Service Industry Management, 14 (5), 483-500.

Yen, H. R., Sheu, C., (2004). Aligning ERP implementation with competitive priorities of manufacturing firms: an exploratory study. International Journal of Production Economics, 92 (3), 207-220.

Yong, L. A., Rivas, L. A. y Chaparro, J., (2010). Modelo de aceptación tecnológica (TAM): un estudio de la influencia de la cultura nacional y del perfil del usuario en el uso de las TIC. Revista innovar. 20 (36), 187-203. 
Yoon, S., (2002). The antecedents and consequences of trust in online-purchase decisions. Journal of interactive Marketing. 16 (2), 47-63

Yousafzai, S. Y., Pallister, J. G. y Foxall, G. R., (2003). A proposed model of etrust for electronic banking. Technovation 23 (11), 847-860.

Yu, S. y Yang, K-F., (2006). Attitudes toward web-based distance learning among public health nurses in Taiwan: A questionnaire survey. International Journal of Nursing Studies, 43, 767-774.

Zárate, E., (2010). Innovación en la investigación. Rev. Peru Med. Exp. Salud Pública, 27 (3), 432-37. 

ANEXO 



\title{
UNIVERSIDAD POLITÉCNICA DE CARTAGENA
}

\author{
ENCUESTA SOBRE LAS NUEVAS TECNOLOGÍAS APLICADAS A
}

\section{LA GESTIÓN DEL CONOCIMIENTO EN EL SECTOR SANITARIO}

\section{INSTRUCCIONES}

- Por favor, conteste todas las preguntas.

- No existen respuestas correctas, sólo queremos conocer su opinión sobre las cuestiones planteadas.

- Si de alguna de las preguntas no está totalmente seguro de la respuesta, no importa, nos interesa su estimación.

- La mayoría de las preguntas consiste en responder entre 1 (no se está de acuerdo con la afirmación) a 7 (se está totalmente de acuerdo con la afirmación). El resto de valores gradúan estos dos extremos. Marque con una cruz o con un círculo el valor más apropiado en cada caso. 
Indique su edad: Indique su nivel de estudios: Hombre Mujer
Indique su nivel de ingresos:

Alto Medio sanitarios:

Teniendo en cuenta los servicios sanitarios ofrecidos por el sector sanitario a través de las TIC, tales como: acceso a la página web del centro hospitalario, acceso a enlaces con otros centros hospitalarios, petición de citas por teléfono, petición de citas vía Internet, acceso al tablón de anuncios, búsqueda de información, realizar una consulta por teléfono, realizar una consulta por correo electrónico, dar sugerencias, hacer una queja o consultar las listas de espera.

Responda a las siguientes cuestiones relacionadas con el uso y aplicación de dichos servicios

\begin{tabular}{|c|c|c|c|c|c|c|c|}
\hline \multirow[b]{2}{*}{$\begin{array}{l}\text { P1. Si oigo hablar de los nuevos servicios online, buscaría la manera de } \\
\text { experimentar con ellos. }\end{array}$} & \multicolumn{4}{|c|}{\begin{tabular}{|l|} 
Total \\
Desacuerdo
\end{tabular}} & \multicolumn{3}{|c|}{$\begin{array}{r}\text { Tota } \\
\text { Acuerdo }\end{array}$} \\
\hline & 1 & 2 & 3 & 4 & 5 & 6 & 7 \\
\hline P2. Ante otros, usualmente soy el primero en probar, los nuevos servicios online. & 1 & 2 & 3 & 4 & 5 & 6 & 7 \\
\hline P3. Me gusta experimentar con los nuevos servicios online. & 1 & 2 & I & 4 & 5 & 6 & 7 \\
\hline $\begin{array}{l}\text { P4. Yo podría utilizar los nuevos servicios online si tuviera únicamente un manual } \\
\text { de usuario. }\end{array}$ & 1 & & 3 & 4 & & & 7 \\
\hline $\begin{array}{l}\text { P5. Yo podría utilizar los nuevos servicios online si veo a alguien más utilizarlos } \\
\text { antes de probar por mí mismo. }\end{array}$ & 1 & 2 & 3 & 4 & 5 & 6 & 7 \\
\hline $\begin{array}{l}\text { P6. Podría utilizar los nuevos servicios online si pudiera llamar a alguien para que } \\
\text { me ayudara si tengo problemas. }\end{array}$ & 1 & 2 & 3 & 4 & 5 & 6 & 7 \\
\hline P7. Los servicios online me proporcionan la información que necesito. & 1 & 2 & 3 & 4 & 5 & 6 & 7 \\
\hline P8. La información obtenida cubre mis necesidades. & 1 & 2 & 3 & 4 & 5 & 6 & 7 \\
\hline P9. Creo que los resultados obtenidos son fiables. & 1 & 2 & 3 & 4 & 5 & 6 & 7 \\
\hline $\begin{array}{l}\text { P10. Los servicios prestados a través de los servicios sanitarios online tienen la } \\
\text { información suficiente para responder a mis cuestiones. }\end{array}$ & 1 & 2 & 3 & 4 & & 6 & 7 \\
\hline P11. Siento que puedo confiar en los servicios online. & 1 & 2 & 3 & 4 & 5 & 6 & 7 \\
\hline P12. Los servicios online tienen características de seguridad : & 1 & 2 & 3 & 4 & 5 & 6 & 7 \\
\hline P13. Confío en la seguridad del sistema. & 1 & 2 & 3 & 4 & 5 & 6 & 7 \\
\hline P14. Los servicios online me permiten hacer cosas más fácilmente. & 1 & 2 & 3 & 4 & 5 & 6 & 7 \\
\hline P15. Los servicios online mejoran la efectividad a la hora de hacer las cosas. & 1 & 2 & 3 & 4 & 5 & 6 & 7 \\
\hline P16. El uso de los servicios online hace que sea más fácil hacer las cosas. & 1 & 2 & 3 & 4 & 5 & 6 & 7 \\
\hline $\begin{array}{l}\text { P17. El uso de los servicios online me permite lograr mis objetivos más } \\
\text { rápidamente. }\end{array}$ & 1 & 2 & 3 & 4 & & 6 & 7 \\
\hline P18. Estoy satisfecho con el rendimiento de los servicios online. & 1 & 2 & 3 & 4 & 5 & 6 & 7 \\
\hline P19. Los servicios online son de alta calidad. & 1 & 2 & 3 & 4 & 5 & 6 & 7 \\
\hline P20. Los servicios online cumplen mis expectativas. & 1 & 2 & 3 & 4 & 5 & 6 & 7 \\
\hline P21. Estoy contento con la experiencia sobre el uso de los servicios online. & 1 & 2 & 3 & 4 & 5 & 6 & 7 \\
\hline P22. Usaré los servicios online regularmente en el futuro. & 1 & 2 & 3 & 4 & 5 & 6 & 7 \\
\hline $\begin{array}{l}\text { P23. Asumiendo que tenga acceso al uso de los servicios online, intentaré } \\
\text { utilizarlos. }\end{array}$ & 1 & 2 & 3 & 4 & 5 & 6 & 7 \\
\hline P24. Utilizaré los servicios online con frecuencia en el futuro. & 1 & 2 & 3 & 4 & 5 & 6 & 7 \\
\hline P25. Recomendaré encarecidamente a otros su uso. & 1 & 2 & 3 & 4 & 5 & 6 & 7 \\
\hline
\end{tabular}

\section{MUCHAS GRACIAS POR SU COLABORACIÓN}


